Figura Capa: "Tomates Americanos"

Autoria: Leandro Quadrana 2012 


\section{Estudo de regiões genômicas envolvidas no metabolismo de aminoácidos e na determinação da estrutura da parede celular no tomateiro}

Tese apresentada ao Instituto de Biociências da Universidade de São Paulo para a obtenção de Titulo de Doutor em Ciências, na área de Botânica.

Fabiana de Godoy

Orientadora: Profa. Dra. Maria Magdalena Rossi

Co-Orientador: Prof. Dr. Fernando Carrari

Instituição: Laboratório Genética Molecular de Plantas, Departamento de Botânica

Instituto de Biociências, Universidade de São Paulo 


\section{FICHA CATALOGRÁFICA}

de Godoy, Fabiana

Titulo da tese: Estudo de regiões genômicas envolvidas no metabolismo de aminoácidos e na

determinação da estrutura da parede celular no tomateiro

Número de páginas: 151

Tese (Doutorado Direto) - Instituto de Biociências da Universidade de São Paulo. Departamento de Botânica.

1. tomate. 2. Solanum lycopersicum. 3. qualidade de fruto. 4. metabolismo. 5. parede celular. 6. poliaminas.

A comissão julgadora dos trabalhos de defesa da tese de doutorado, em sessão publica realizada a......................, considerou

Aprovado ( ) Reprovado( )

\section{COMISSÃO JULGADORA}

Prof (a). Dr (a).

Prof (a). Dr (a).
Prof (a). Dr (a).

Prof (a). Dr (a).

Profa. Dra. María Magdalena Rossi 


\section{AGRADECIMENTOS}

Ao Departamento de Botânica do Instituto de Biociências da Universidade de São Paulo pelo suporte acadêmico e estrutural.

A FAPESP pela bolsa concedida que possibilitou a realização desse trabalho.

A secretaria de pós graduação pelo suporte prestado

A Magda pela orientação tão dedicada. Não é comum, nem fácil encontrar um orientador que se dedique tanto aos seus alunos. Seus ensinamentos científicos me transformaram numa pesquisadora melhor, seus ensinamentos da vida me tornaram uma pessoa melhor. Obrigada por ter me retornado o prazer pela Biologia por ser orientadora, amiga, mãe. Obrigada por cada conselho, bronca e palavra de carinho. Obrigada por nesse novo momento me apoiar, insentivar e me aturar. Obrigada por me deixar voar....Você é e sempre será muito importante!

Ao Fernando que tanto me ensinou. Sua orientação foi da maior importância para meu crescimento científico. Mais ainda, obrigada por me receber de braços abertos em seu laboratório, me fazendo sentir parte do grupo. Obrigada pela amizade, carinho e apoio.

À Profa. Marie-Anne Van Sluys por ter sempre as portas abertas.

Ao Prof Marcos Bukeridge e Amanda Pereira de Souza obrigada por abrirem a porta do LAFIECO para mim e terem toda a paciência em me ensinar sobre esse mundo da parede celular.

À Profa. Eny Floh por ter sempre as portas de seu laboratório abertas para mim. À Amanda Macedo, obrigada pela enorme ajuda com a quantificação das poliaminas e aminoácidos.

Ao nosso grupo do GMP: Juliana, Junia, Silvia, Bruno, Gabi e Dani obrigada pelo apoio e por fazer com que esses anos tenham sido melhores. Ju, obrigada por ser minha companheira de viagem, por toda a troca de conhecimento e experiencias sejam elas científicas e muitas vezes educacionais. Sua ajuda, apoio e carinho foram imprecindiveis. Junia, obrigada pelas conversas, elas muito me ajudaram. Sil, muito obrigada por toda ajuda com experimentos, compras, plantas. Sem sua ajuda a vida teria sido muito mais difícil. Dani, sempre disposta a colaborar. Bruno, obrigada pela super ajuda com a GAUT.

Ao grupo do GaTE lab - Alessandro, Andrés, Bruno, Cushla, Dani Q, Douglas, Érika, Guilherme, Hana, Jonas, Juliana Nico, Juliane, Kleber, Leonor, Marcelo, Marisa, Mayra, Nathalia, Nilo, Robson, Tatiana. Obrigado por estarem sempre com as portas abertas, obrigada por toda ajuda, troca de conhecimento e por fazer os anos de convivencia muito divertidos.

Ao grupo da Argentina: Leandro, Guadalupe, Carla, Laura, Gabriel, Thomaz, Mariana Conte, Mariana Lopez e Marina Insani. Obrigada por me receberem como se fosse parte do grupo. Obrigada por todas as discussões científicas e bons momentos. Obrigada por sempre estarem dispostos a me ajudar nos momentos de correria de milhares de experimentos em pouco tempo. Lean, obrigada por todas as conversas científicas, por todos os momentos de diversão e por me permitir usar essa figura tão linda que você criou na capa da minha tese. Carla, obrigada por me receber na sua casa e fazer com que meus meses na Argentina fossem muito melhores e divertidos, a saudade de casa ficou muito mais 
suportável. Guada, obrigada por toda ajuda. Mari C, obrigada por ter me ajudado tanto, principalmente na minha primeira ida lá em 2008.

A Gabriela e Vanessa N que além de serem companheiras de trabalho na Argentina me fizeram tanta companhia em Peñas....Vocês foram primordiais em fazer minha primeira ida tão legal e fazer com que eu quisesse voltar tão rápido. Obrigada por tudo.

A Luisa, você é minha companheira, amiga, irmã...obrigada por ter feito parte dessa caminhada. Por ter crescido ao meu lado, por estar presente nos boms e nos maus momentos, por compartilhar... Comemoramos juntas nossos exitos profissionais, e também pessoais. Você é a melhor parceira científica que poderia ter. E foi essa parceria que foi primordial para que o meu trabalho resultasse no melhor possível, por isso essa tese também é sua, pois sem você tudo teria sido diferente. Te amo muito, mesmo que estejamos a distância.

A Natália, muito obrigada por tudo. Por ter paciencia de me ensinar tanto. Sua contribuição para essa tese é inestimável. Obrigada por discutir comigo não só sobre ciência, mas também sobre a vida, livros e filmes. Obrigada pela sua amizade, ela é muito importante para mim.

A Vivian, responsável por ter me levado ao laboratório da Magda. Você minha irmã, é tão importante para essa tese, se não fosse você ela não existira do jeito que é. Obrigada pelos 10 anos de amizade e carinho

Aos amigos da faculdade: Marie, Nati, Ric, Marcel, Ph, Thais, Ciça, Caio e tantos outros. Os anos de Biologia não teriam sido iguais sem vocês.

A minha família, meu centro o que me faz me manter no prumo. Em especial, obrigada mãe e pai, por terem sempre me apoiado, mesmo tomando decisões que os desagradasse. Obrigada por me darem todo o suporte mesmo durante todas as minhas ausencias, sem o apoio de vocês teria sido impossível. Obrigada por serem os responsáveis por eu ser quem eu sou hoje. A minha irmã e meus lindos sobrinhos que alegram a minha vida.

Aos meus avós que certamente contribuiram imensamente pra eu me tornar quem sou.

Ao Edu que tanto participou desse trabalho seja na forma discussão científica, revisão de texto, ou simplesmente me suportando nesses momentos de loucura. Um dos grandes presentes que esse doutorado me trouxe foi você. Obrigado por também ser meu porto seguro, por me apoiar e incentivar. Cada passo é pela nossa "família séria". Te amo. 


\section{ABREVIATURAS E NEOLOGISMOS}

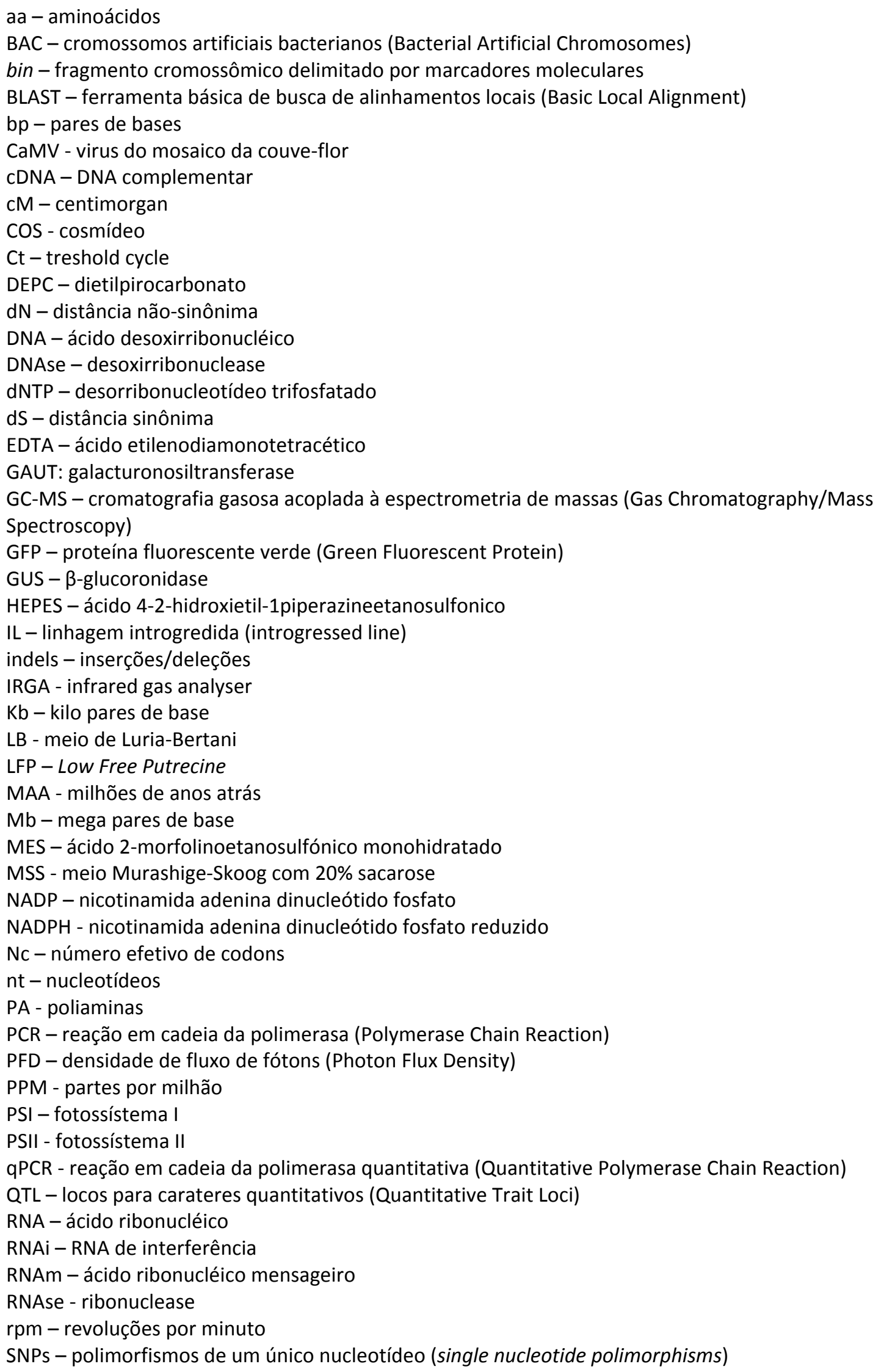


TAE - tampão tris-acetato-EDTA

Unigene - consenso de sequências de cDNA segundo a Solanaceae Genomics Network

5'UTR - região 5' não traduzida do RNAm

3'UTR - região 3' não traduzida do RNAm 


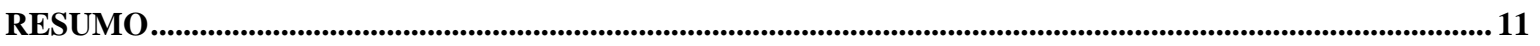

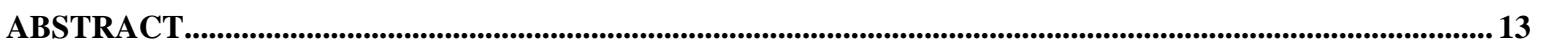

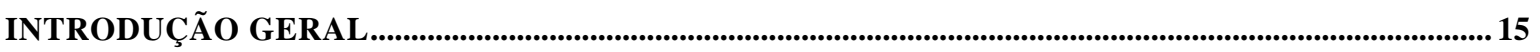

1. O TOMATEIRO: TAXONOMIA E RECURSOS GENÉTICOS ............................................................................ 17

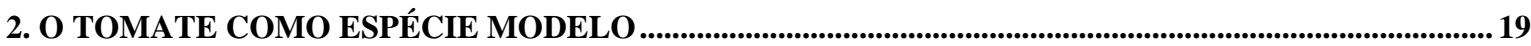

3. A CULTURA DE TOMATE E SUA IMPORTÂNCIA NA NUTRIÇÃO HUMANA........................................ 22

4. O MELHORAMENTO GENÉTICO E O USO DO GERMOPLASMA SELVAGEM..................................... 22

5. CONSTRUÇÃO DA HIPÓTESE DE TRABALHO ................................................................................ 24

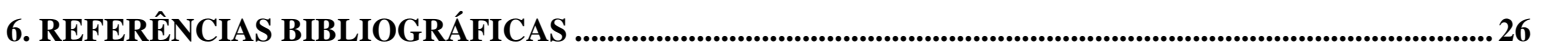

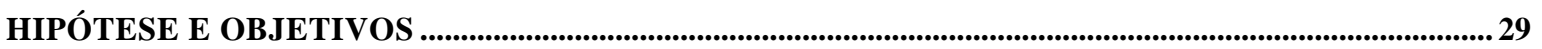

CAPÍTULO I: ANÁLISE DA DIVERSIDADE GENÔMICA ENTRE O TOMATEIRO CULTIVADO, SOLANUM LYCOPERSICUM, E A ESPÉCIE SELVAGEM SOLANUM PENNELLII ............................33

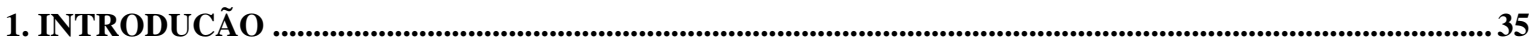

2. OBJETIVOS ……….................................................................................................................................................. 38

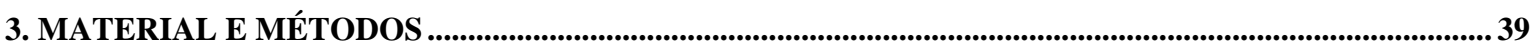

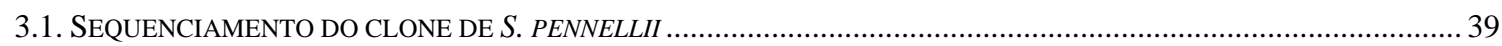

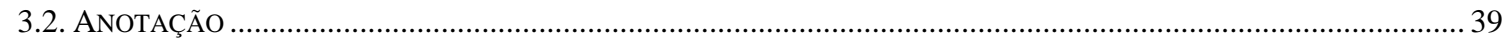

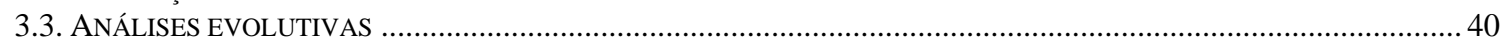

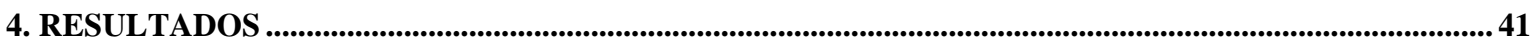

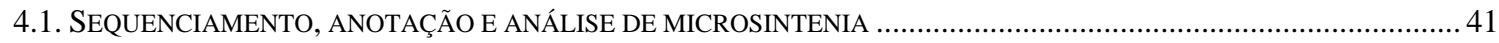

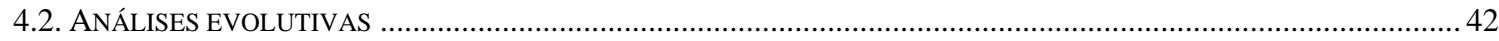

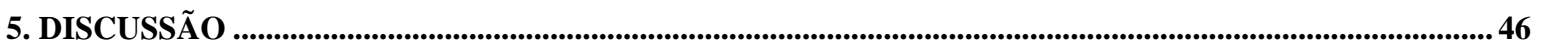

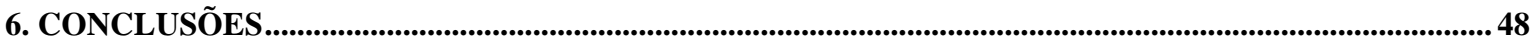

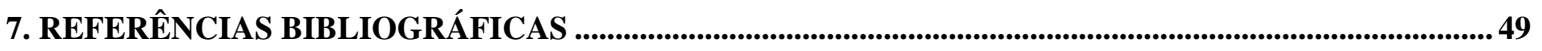

CAPÍTULO II: CARACTERIZAÇÃO E ESTUDO FUNCIONAL DO GENE LFP....................................51

1. INTRODUCÃO ........................................................................................................................................................53

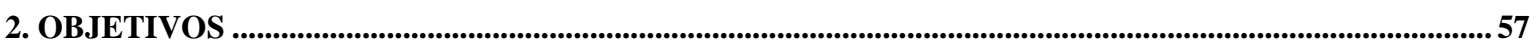

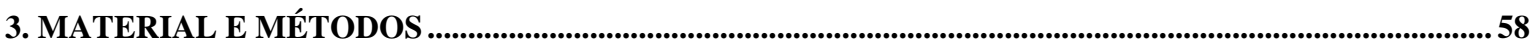

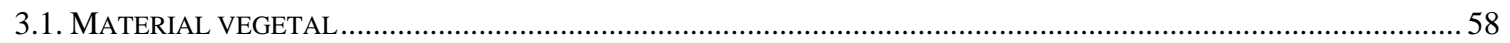

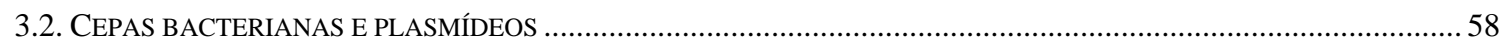

3.3. OBTENÇ̃̃o DAS SEQUÊNCIAS DOS ALELOS DO GENE $L F P$ E ANÁLISE DA ESTRUTURA GÊNICA ………………......59

3.4. PERFIL TRANSCRICIONAL DOS ALELOS DE S. PENNELLII E S. LYCOPERSICUM ……………................................ 60

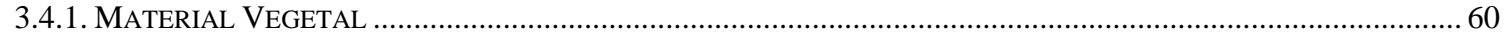

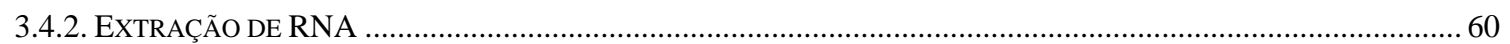

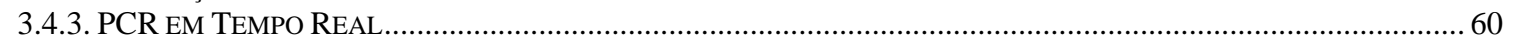

3.5. OBTENÇÃO DAS CONSTRUÇÕES PARA O ESTUDO DA ATIVIDADE DAS REGIÕES PROMOTORAS DOS ALELOS DE $S$.

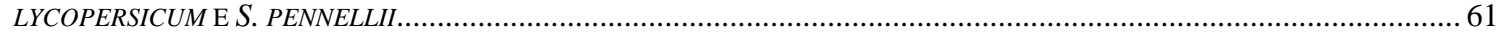

3.6. OBTENÇ̃̃O DA CONSTRUÇ̃̃O PARA ESTUDO DA LOCALIZAÇÃO SUBCELULAR DA PROTEÍNA LFP ....................... 62

3.7. OBTENÇÃO DA CONSTRUÇÃO PARA AVALIAÇÃO DO EFEITO DO SILENCIAMENTO GÊNICO POR RNA DE

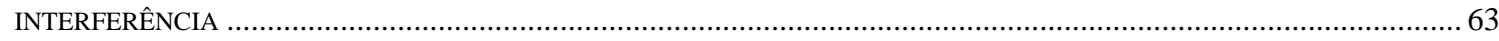

3.8. INFILTRAÇÃO E ENSAIO HISTOQUÍMICO DE FOLHAS DE $N$. BENTHAMIANA PARA O ESTUDO DA ATIVIDADE DAS

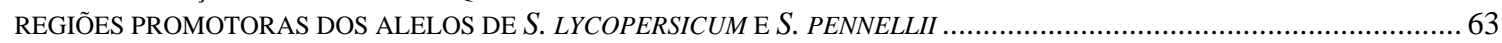

3.9. INFILTRAÇÃO DE FOLHAS DE $N$. BENTHAMIANA PARA O ESTUDO DA LOCALIZAÇÃO SUBCELULAR DA PROTEÍNA

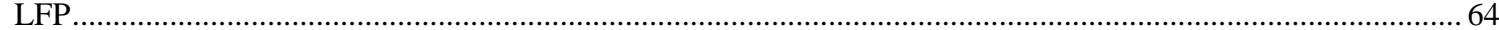

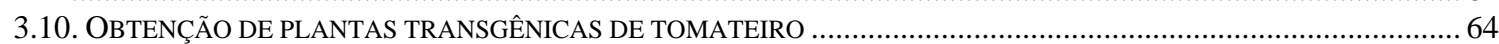

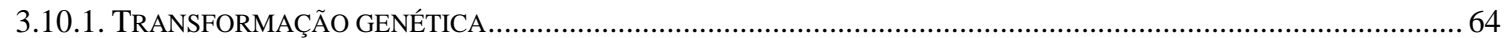

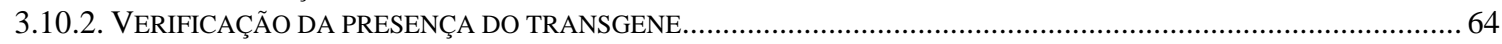

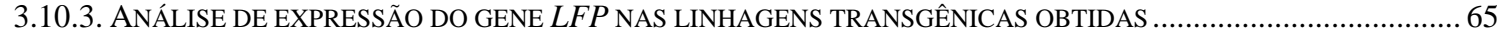

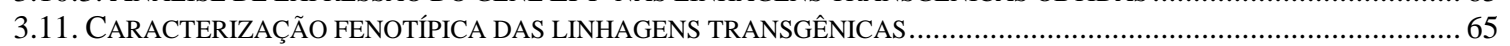


3.11.1. CULTIVO

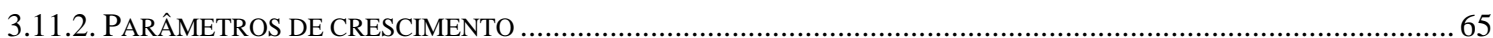

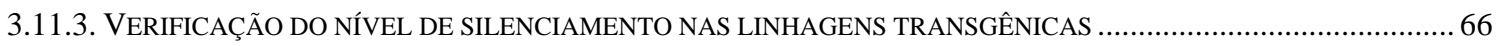

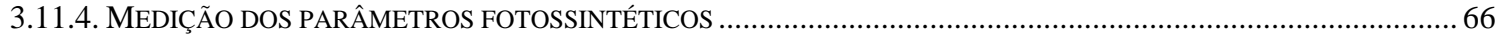

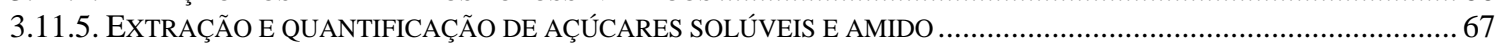

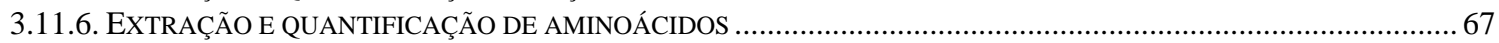

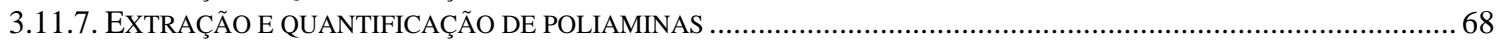

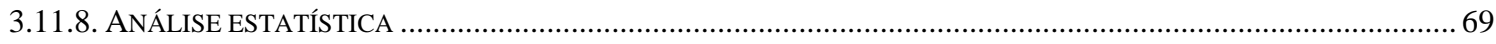

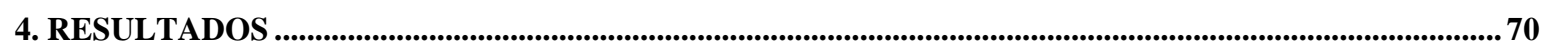

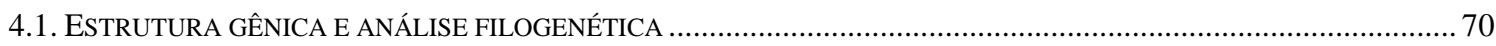

4.2. PERFIL TRANSCRICIONAL DOS ALELOS DE S. PENNELLII E S. LYCOPERSICUM ................................................. 72

4.3. ESTUDO DA ATIVIDADE TRANSCRICIONAL DOS PROMOTORES DOS ALELOS DE S. PENNELLII E S. LYCOPERSICUM

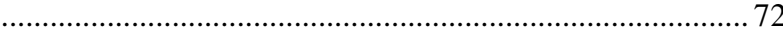

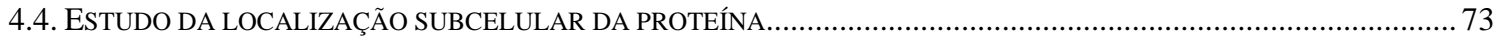

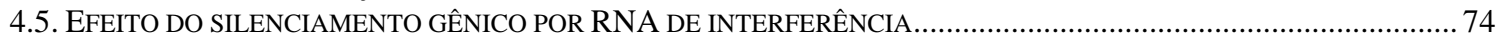

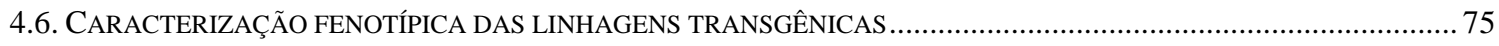

4.6.1. VERIFICAÇÃO DO NÍVEL DE SILENCIAMENTO NAS LINHAGENS TRANSGÊNICAS ...........................................75

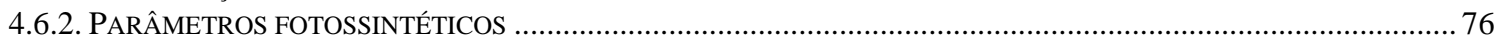

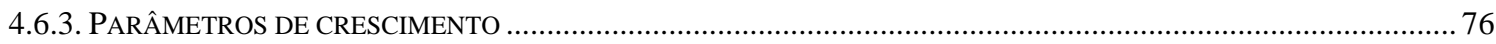

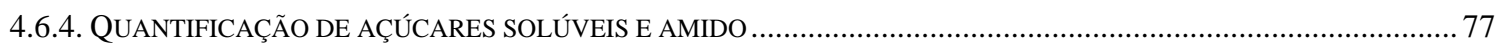

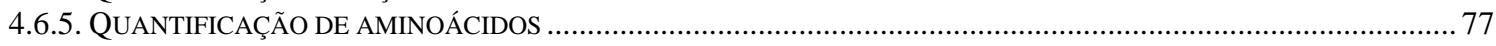

A CONCENTRAÇÃO DOS AMINOÁCIDOS ESTA EXPRESSA COMO MG/G MASSA SECA. …..................................... 80

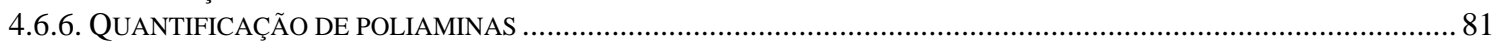

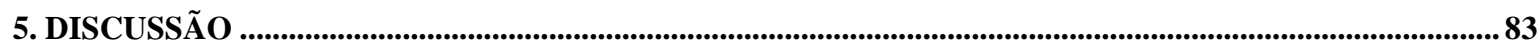

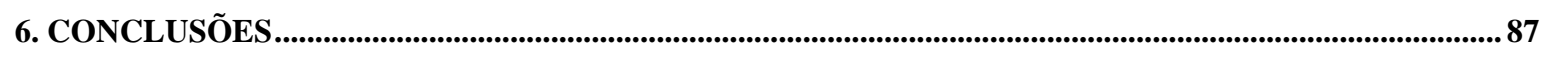

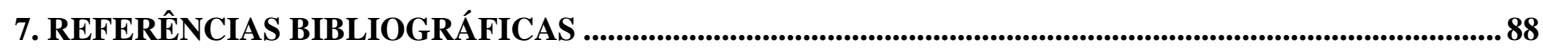

CAPÍTULO III: ESTUDO DA FAMÍLIA MULTIGÊNICA DAS

GALACTURONOSILTRANSFERASES E CARACTERIZAÇÃO ESTRUTURAL E FUNCIONAL DO

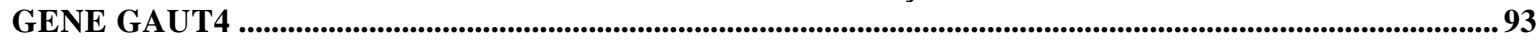

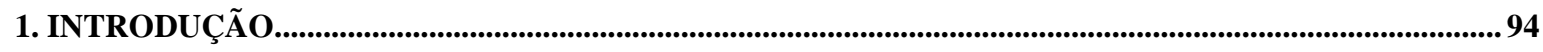

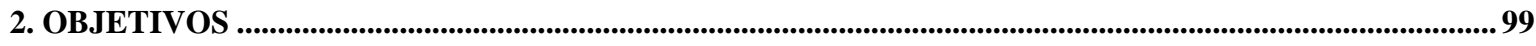

3. RESULTADOS, MATERIAL E MÉTODOS E DISCUSSÃO ............................................................................... 100

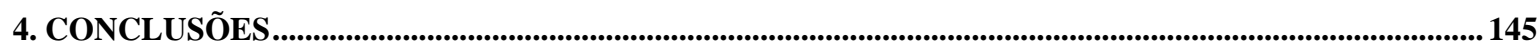

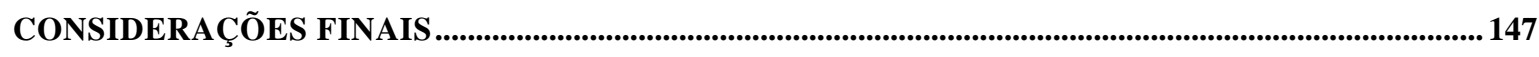

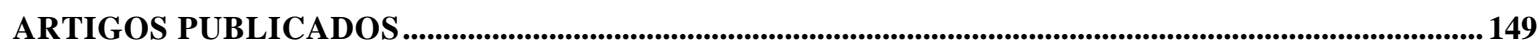

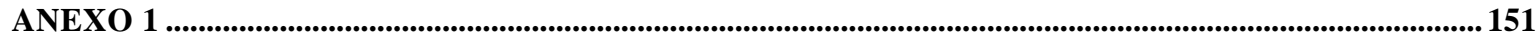




\section{Resumo}

Embora o cultivo de tomate seja muito antigo e amplamente distribuído, ainda enfrenta desafios para o melhoramento dos níveis de produção e, da qualidade para o processamento e consumo fresco. A grande maioria das características de interesse agronômico está determinada por loci de caracteres quantitativos (QTL), dificultando ainda mais a identificação e transferência gênica. Diversas características tornam o tomateiro um bom modelo para estudos de dissecação dos determinantes genéticos de QTL. Primeiro, a disponibilidade de fontes de germoplasma selvagens ainda inexploradas que podem aumentar a variabilidade genética, somada à possibilidade de cruzamento entre espécies não simpátricas e à autogamia. Segundo, a grande quantidade de informação genética como mapas, coleções de ESTs, QTL, e populações de mapeamento. Terceiro, o genoma de S. lycopersicum está completamente sequenciado. Por fim, devido a suas diferenças morfogenéticas em relação à espécie modelo Arabidopsis thaliana, o tomate se torna uma alternativa para estudos de eudicotiledonias, principalmente em estudos relacionadas a metabolismo de frutos carnosos.

A partir da abundante plataforma de dados disponível e por meio de ferramentas de genômica, e genética reversa, este trabalho aborda o estudo de duas regiões do genoma do tomateiro envolvidas no metabolismo de amino ácidos e na determinação da estrutura da parede celular. O estudo de genômica comparativa de uma região do cromossomo 7 permitiu revelar a perfeita sintenia existente entre S. lycopersicum e a espécies selvagem S. pennellii e estimar o tempo de divergência em 2,7 MAA. Complementarmente, foi possível determinar que as diferenças fenotípicas entre as espécies são maiormente devidas a mudanças nas regiões regulatórias e à presença de SNPs. O estudo funcional do gene LFP (Low Free Putrescine) permitiu caracterizar uma proteína plastidial, até o momento desconhecida em tomateiro, que participa do metabolismo de poliaminas. O silenciamento de LFP resultou na redução da disponibilidade de putrescina livre e no aumento da biomassa vegetativa. Por outro lado, os resultados obtidos do estudo do gene GAUT4 (galacturonosiltransferase 4) demonstraram que a enzima codificada se localiza em Golgi e participa do metabolismo das pectinas. Em frutos, a redução dos níveis de GAUT4 resultou na diminuição de pectina e na alteração da sua composição, porém estes se apresentaram mais firmes. Adicionalmente, o silenciamento do gene GAUT4 modificou o particionamento de açúcares provocando o aumento de massa vegetativa em detrimento do índice de colheita, revelando assim um mecanismo regulatório que comunica o metabolismo da parede celular ao controle da relação fonte-dreno. Desta forma, os resultados obtidos aportam dados fundamentais para a melhor compreensão de caracteres de interesse agronômico, assim como de processos fisiológicos complexos e pouco explorados até o momento no tomateiro. 


\section{ABSTRACT}

Although tomato is an old and widely distributed culture, it still faces challenges to improve production levels and quality for processing and consumption. The vast majority of agronomical important characteristics are determine by quantitative trait loci (QTL), further hindering the gene identification and transfer. Several features make tomato a good model for studying the genetic determinants underneath QTL. First, the availability of unexploited sources of wild germplasm that can increase genetic variability, coupled with the possibility of interbreeding between no sympatric species and autogamy. Second, the large amount of available genetic information as maps, EST collections, QTL, and an extensive collection of mapping populations. Third, the genome of S. lycopersicum is completely sequenced. Finally, due to their morphogenetic differences in relation to model species Arabidopsis thaliana, tomato becomes an alternative to eudicotyledons studies, especially in studies related to fleshy fruits metabolism.

From the abundant data platform available and by means of genomic tools, and reverse genetics, this work addresses the study of two tomato genomic regions involved in amino acids and cell wall metabolisms. The comparative genomic study in a region of chromosome 7 has revealed the perfect synteny between $S$. lycopersicum and the wild species $S$. pennellii, and estimated the time of divergence between both species in 2.7 MYA. Additionally, it was possible to determine that the phenotypic differences between species are mostly due to changes in regulatory regions and the presence of SNPS. The functional study of LFP gene (Low Free Putrescine) allowed us to characterize a plastid protein, yet unknown in tomato, which participates in the metabolism of polyamines. The LFP silencing resulted in reduced availability of free putrescine and increased vegetative biomass. Furthermore, the functional characterization of the GAUT4 (galacturonosyltransferase 4) gene demonstrated that the encoded enzyme is located in the Golgi apparatus and participates in the pectin metabolism. In fruits, the reduced levels of GAUT4 resulted in decreased pectin and in the change of its composition. Additionally, GAUT4 gene silencing modified sugars partitioning leading to an increased vegetative biomass together with a drastic reduction of the harvest index. Thus, revealing a regulatory mechanism that communicates the cell wall metabolism to source-sink relationship control. Concluding, the results obtained contribute to a better understanding of agronomical important traits, as well as of complex physiological processes little explored in tomato so far. 
INTRODUÇÃO GERAL 


\section{1. $O$ tomateiro: taxonomia e recursos genéticos}

Soalanaceae é uma família com grande importância agronômica e econômica, pois contém espécies que são amplamente utilizadas como alimento, ornamentais e fonte de medicamentos; dentre as quais se destacam a berinjela, batata, tomate, tabaco e pimenta. Essa família compreende aproximadamente 90 gêneros e 4000 espécies, das quais aproximadamente 2000 pertencem ao genero Solanum (Knapp et al. 2004). As espécies desta família possuem grande diversidade tanto em termos de habitat, estando distribuídas desde desertos a florestas tropicais, quanto de hábito, pudendo ser herbáceas ou arbóreas (Knapp 2002). Os genomas das solanáceas sofreram relativamente poucos rearranjos e duplicações apresentando um alto grau de sintenia entre as espécies, o que faz desta família um modelo para estudo da diversidade fenotípica (Mueller et al. 2005).

Dentre as espécies dessa família encontra-se o tomateiro (Solanum lycopersicum). Sua classificação taxonômica dentro da família foi, durante muito tempo, controversa. Em 1694, Tournefort foi o primeiro botânico a considerar as diferentes variedades de tomate cultivado como um gênero a parte dentro da família Solanaceae, agrupando-os sob o gênero Lycopersicon. Menos de cem anos depois, Linnaeus (1753) em seu livro Species Plantarum classificou o tomateiro como pertencente ao gênero Solanum agrupando as diferentes variedades dentro de Solanum lycopersicum. Por outro lado, Miller (1754) voltou a considerar a classificação de Tournefort e descreveu formalmente o gênero Lycopersicon. Durante muitos anos essa classificação foi seguida entre os botânicos. Recentemente, através de técnicas de taxonomia molecular uma nova classificação filiogenética colocou o tomate novamente no gênero Solanum (Peralta e Spoooner 2007, Spooner 2005, Costa e Heuvelink 2005). Apesar dos taxonomistas considerarem o tomate como pertencente ao gênero Solanum, muitos produtores continuam utilizando o nome Lycopersicum.

S. lycopersicum junto a outras 12 espécies de tomateiro selvagens pertencem à seção Lycopersicon. Todas as espécies desta seção são nativas da América do Sul distribuindo-se desde o Equador, ao longo do Perú, e até o norte do Chile, assim como nas Ilhas Galápagos (Peralta e Spooner 2000). A Figura 1 apresenta o fenótipo para seis dessas espécies. 


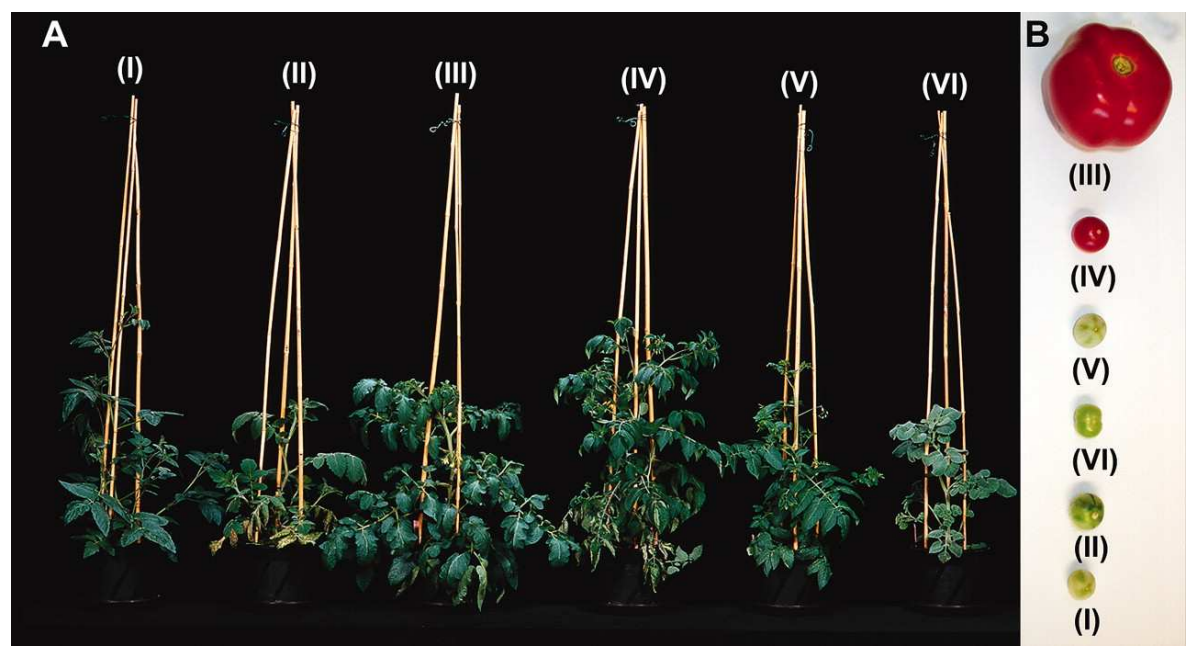

Figura 1. Algumas espécies da seção Lycopersicon.

Fenótipo de folhas (A) e frutos (B) de seis espécies da seção Lycopersicon. I: S. chmielewskii. II: S. habrochaites. III: S. Iycopersicum. IV: S. pimpinellifolium. V: S. neorickii. VI: S. pennellii. Adaptado de Schauer et al. (2005).

O provável ancestral a partir do qual o tomateiro cultivado foi domesticado é a espécie $S$. lycopersicum var. cerasiforme, essa espécie apresenta uma distribuição mais ampla, encontrando-se também no México, Colômbia e Bolívia (Rick e Holle 1990). A época e o local de domesticação do tomate não são claramente conhecidos. Existem duas hipóteses acerca do local de domesticação, a hipótese Mexicana e a Peruana (Peralta e Spooner 2007). Embora não tenham sido coletadas provas totalmente conclusivas, as evidências mais sólidas indicam que a área mais provável de domesticação tenha sido o México (Sims 1980).

Durante o processo de domesticação, foram selecionadas as características que melhor se adaptavam ao uso humano e ao cultivo como tamanho de fruto e cor homogênea. Esse processo, aliado às alterações incorporadas aos cultivares após a domesticação como a diversificação em cor e forma, levou a que a espécie domesticada seja bastante diferente ao ancestral selvagem com relação a caracteres morfológicos e fisiológicos (Frary e Doganlar 2003). Alguns estudos mostraram que essas características são controladas por poucos loci (Frary e Doganlar 2003). Acredita-se que o primeiro passo para a domesticação tenha sido uma mutação no locus fw2.2, que contém um gene que atua na divisão celular. A variação natural existente apenas para este locus pode alterar o tamanho do fruto em até $30 \%$. Todas as espécies selvagens possuem alelos para "fruto pequeno" neste locus, enquanto que todas as variedades cultivadas fixaram alelos para "fruto grande" nesta posição. Já a forma do fruto é controlada majoritariamente por três loci: ovate, sun e fs8.1 os quais modulam as primeiras fases do desenvolvimento dos carpelos (Tanksley 2004).

O processo de domesticação, sua história de melhoramento tanto na Europa quanto na América do Norte, aliado a uma tendência natural de redução de variabilidade, por ser uma espécie que se reproduz por autofecundação, levou a uma redução na variabilidade genética em S. lycopersicum (Rick e 
Yode 1988, Bai e Lindhout 2007). Em 1990, Miller e Tankslley encontraram que a espécie domesticada possuía muito pouco da variabilidade genética encontrada na seção Lycopersicon. A partir dos anos 40, o pesquisador Charlie Rick através de seus estudos com as espécies pertencentes a essa seção, observou que cruzamentos entre as espécies cultivadas e selvagens geravam uma grande variabilidade genética (Bai e Lindhout 2007). Mais tarde, ao longo dos anos 70 e 80, Rick examinou extensivamente a variabilidade genética entre as espécies da seção Lycopersicon, mostrando uma grande variabilidade em espécies encontradas próximas ao centro de distribuição e que se reproduzem por reprodução sexuada (Peralta e Spooner 2000). Devido ao fato de todas as espécies da seção Lycopersicon poder ser cruzadas (naturalmente ou artificialmente) com o tomateiro cultivado gerando descendentes férteis, o germoplasma selvagem passou a ser uma importante fonte de diversidade genética para a identificação de novos alelos de interesse (Miller e Tanksley 1990).

\section{0 tomate como espécie modelo}

Devido a suas diferenças morfogenéticas em relação à Arabidopsis thaliana, o tomate se tornou um modelo alternativo para estudos de eudicotiledônias, principalmente no que se refere ao desenvolvimento e metabolismo de frutos carnosos e climatéricos (Carrari et al. 2006). Este tipo de frutos possui um característico aumento na síntese de etileno no início do amadurecimento e foi precisamente em tomateiro onde foi desvendada a síntese e percepção deste hormônio (Klee e Giovannoni 2011).

Diversas características intrínsecas a essa espécie contribuem para esse papel. O tomateiro apresenta um genoma diplóide $(n=12)$ e relativamente pequeno, com aproximadamente $900 \mathrm{Mb}$ (Michaelson et al. 1991), que codifica para aproximadamente 35.000 genes (Van der Hoeven et al. 2002). O sequenciamento completo do genoma evidenciou que do montante de genes preditos, aproximadamente 31.000 foram suportados por sequencias de RNA (Tomato Genome Consortium 2012). Por ser uma espécie que se reproduz por autofecundação, a manutenção de linhagens é extremamente facilitada. Como discutido anteriormente, a existência de germoplasma selvagem, o qual constitue um banco de genes a ser explorado, também é uma das características que levaram ao tomateiro ser hoje uma planta modelo para o estudo da biologia vegetal (Rick e Yoder 1988). Dessa forma, diversos recursos genéticos e genômicos foram desenvolvidos para esta espécie: i) genoma de $S$. lycopersicum totalmente sequenciado (Tomato Genome Consortium 2012); ii) O genoma de S. pennellii (Usadel e Fernie, dados não publicados) e de S. pimpinellifolium (Ware, McCombie e Lippman, dados não publicados) em fase final de sequenciamento; iii) mais 100 espécies de Solanaceae sendo sequenciadas (Sol Genomics Network, http://solgenomics.net/organism/sol100); iv) bibliotecas genômicas; v) coleções de sequências de cDNA; vi) mapas genéticos de alta densidade; e vii) populações de mapeamento e mutantes (Rick e Yoder 1988, Eshed e Zamir 1995, Muller et al. 2005, Matsukura et 
al. 2008). Adicionalmente, diversas abordagens tecnológicas foram bem estabelecidas, e continuam sendo aplicadas com sucesso em tomateiro como, por exemplo, a transformação genética estável e o silenciamento gênico induzido por vírus (Barone et al. 2008, Quadrana et al. 2011).

O fruto do tomateiro é constituído de uma epiderme, um espesso pericarpo derivado da parede do ovário e de tecido placentário que envolve as sementes. Ao longo do desenvolvimento do fruto podem ser distinguidos quatro estágios (Figura 2): i) desenvolvimento da flor desde a iniciação floral até antese; ii) período de intensa divisão celular que começa após fertilização; iii) período de expansão celular que se extende desde o fim da fase de divisão até o início do amadurecimento no qual o fruto aumenta até 20 vezes de tamanho passando por sucessivos processos de endoreduplicação de maneira que as células de um fruto maduro são altamente polisomáticas (256C) ; iv) após o termino do crescimento o fruto passa por alteração bioquímicas e estruturais, o chamado amadurecimento, que interfere na aparência, textura, sabor e aroma de forma que os organismos dispersores de sementes sejam atraídos (Gillaspy et al. 1993, Tanksley 2004, Giovannoni 2004).

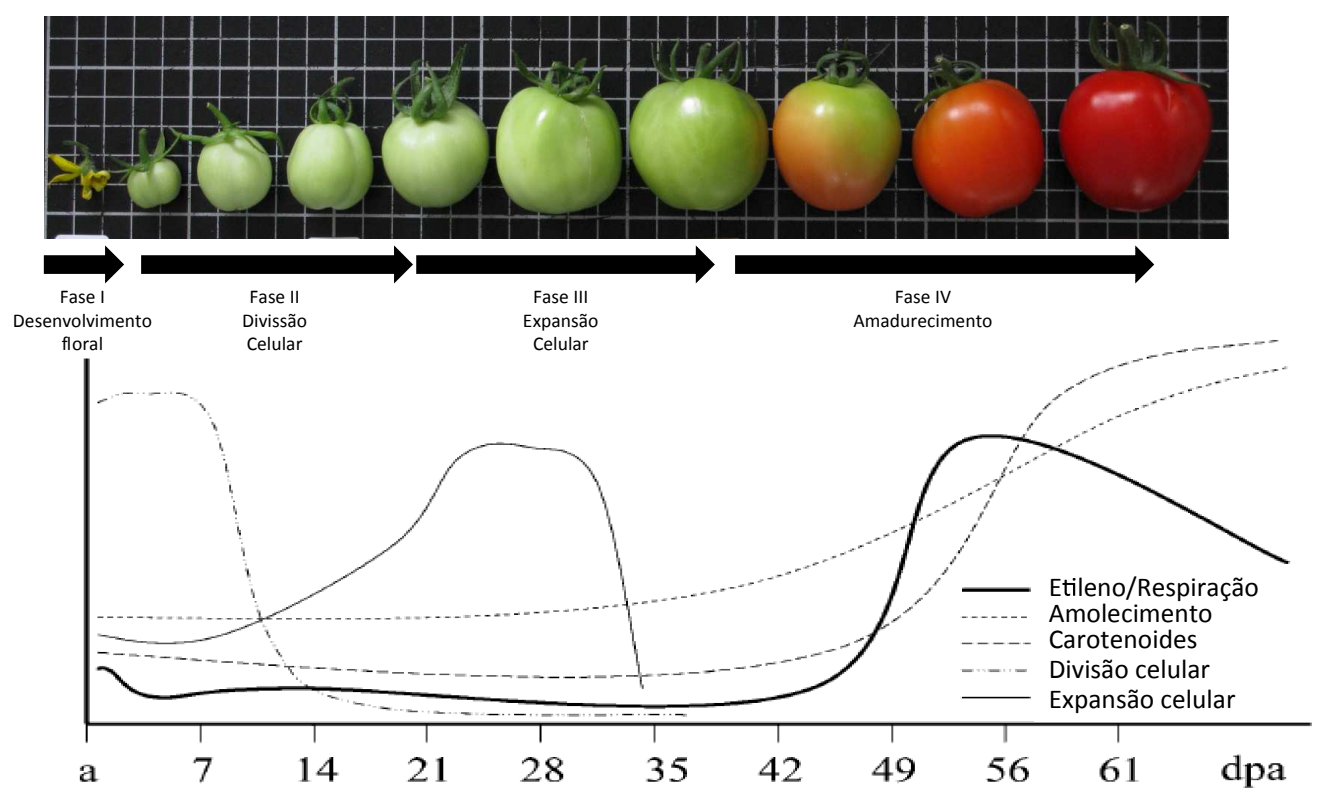

Figura 2. Desenvolvimento do fruto de tomateiro.

Aspecto do fruto desde antese até o amadurecimento e principais alterações bioquímicas e fisiológicas. a: antese. dpa: dias pós-antese. Adaptado de Giovannoni (2004).

O processo de amadurecimento coincide com o amadurecimento da semente e está intimamente relacionado com o aumento da respiração e da concentração de etileno, desencadeando uma complexa, coordenada e rápida alteração no perfil metabólico. Um dos passos mais importantes nesse processo é a conversão de cloroplastos a cromoplastos (Figura 3). Ao longo do amadurecimento, os tilacoides dos cloroplastos vão se desorganizando e se diferenciam estruturas globulares membranosas chamadas plastoglóbulos. Concomitantemente, enquanto a clorofila presente nos cloroplastos se degrada, começa a síntese de carotenoides, principalmente licopeno e $\beta$-caroteno, que 
são acumulados nos plastogóbulos determinando a característica mudança de cor (Klee e Giovannoni 2011, Giovannoni 2004).

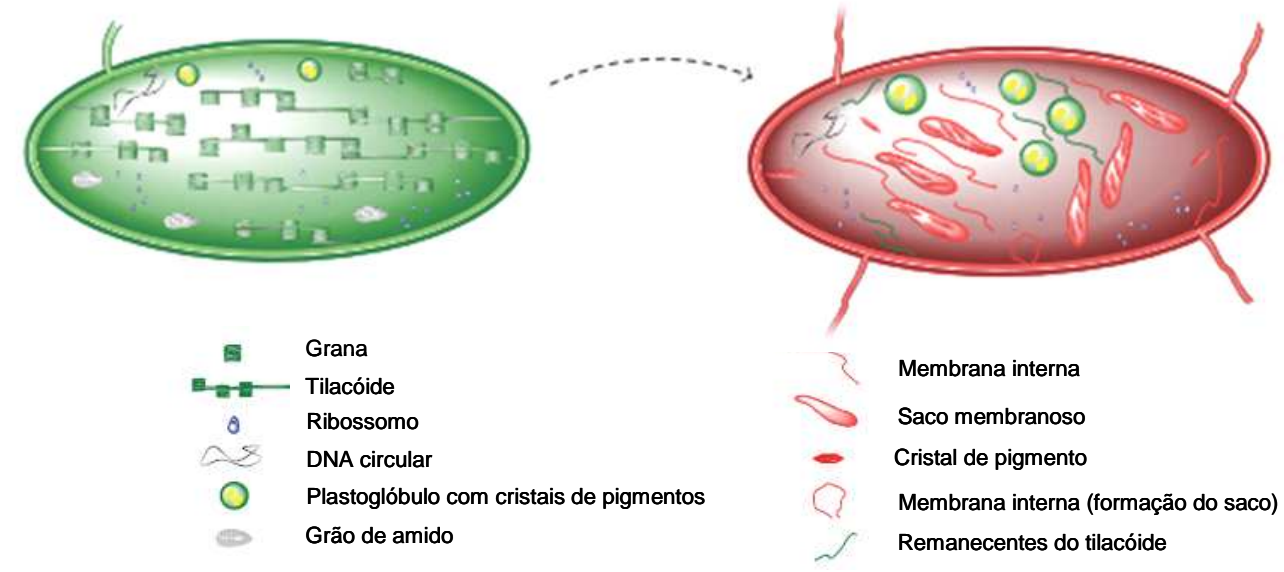

Figura 3. Representação esquemática das mudanças que ocorrem na diferenciação de cloroplastos em cromoplastos.

Adaptado de Bian et al. 2011.

Outro evento caracterísitico do amadurecimento é a alteração da estrutura da parede celular que resulta em mudanças no turgor e na textura. Essa alteração é mediada por enzimas relacionadas à degradação de pectinas como a poligactorunases e as pectina metilesterases, além de enzimas relacionadas com a degradação de hemicelulose como as endo- $\beta$-glucanases e a $\beta$-galactosidase (Giovannoni 2004).

Por fim, alterações no metabolismo de açucares, ácidos orgânicos e compostos voláteis tornam o fruto atrativo aos animais dispersores. $O$ amido acumulado ao longo do desenvolvimento é convertido em açúcares, principalmente glicose e frutose. O conteúdo de ácidos orgânicos - ácido cítrico e málico aumentam fazendo com que o $\mathrm{pH}$ de um fruto maduro seja próximo de quatro. Finalmente, desde o início do amadurecimento são produzidos compostos voláteis derivados de aminoácidos essenciais e de ácidos graxos que atingem o pico máximo de concentração quando o fruto está completamente maduro (Klee e Giovannoni 2011, Carrari e Fernie 2006).

Um aspecto muito interessante que ainda abre questionamentos é o papel da fotossíntese do fruto durante os três primeiros estágios de desenvolvimento descritos anteriormente. Sabe-se que nas células de frutos em desenvolvimento os cloroplastos são fotossinteticamente ativos. Os poucos dados publicados a respeito indicam que os frutos verdes possuem cadeia de transporte de elétrons e ciclo de Calvin ativos, mas embora fixem carbono, a taxa respiratória é muito alta mascarando a fixação líquida. Assim ao longo do desenvolvimento o fruto mudaria o seu metabolismo de parcialmente autótrofo para heterotrófico (Piechulla et al. 1987, Carrara et al. 2001, Carrari e Fernie 2006). Um estudo recente demonstrou que a fotossíntese do fruto não é determinante para o apropriado metabolimo energético do órgão reprodutivo, mas é essencial para o correto desenvolvimento das sementes (Lytovchenko et al. 2011), resultando assim fundamental desde o ponto de vista evolutivo. 


\section{A cultura de tomate e sua importância na nutrição humana}

Foram os espanhóis que introduziram no século 16 o tomate na Europa. Seu cultivo inicial foi como planta ornamental, pois se acreditava que era venenoso. Foi somente no século 17 que seu consumo passou a ser aceito (Peralta e Spooner 2007). Entre o fim do século 17 e o 18 os europeus espalharam a cultura do tomate pelo mundo. Primeiro para a China e Ásia e mais tarde para Japão e Estados Unidos.

O cultivo do tomateiro possui alta importância agronômica tanto no Brasil quanto no mundo. Nos últimos 40 anos a produção para consumo in natura e de derivados aumentou $300 \%$. 0 tomate ranqueia na posição décima primeira entre as comodities no mundo. Sua produção anual mundial atingiu 152 milhões de toneladas em 2010, e os principais produtores são China, Índia e Estados Unidos. Nesse contexto, o Brasil é o oitavo produtor mundial com uma produção de 4,5 milhões de toneladas em 2010 foi (FAO Base de dados estatísticos ultima atualização 2011, http://faostat.fao.org).

Além das suas qualidades nutracêuticas, devido a sua facilidade e versatilidade na utilização, o tomate é a hortaliça mais consumida no mundo, tanto em forma fresca como processada. $\mathrm{O}$ consumo médio mundial de tomate fresco per capita é de $12 \mathrm{~kg}$ por ano. Em média um americano adulto come 8 $\mathrm{kg}$ de tomate fresco e $31 \mathrm{~kg}$ de tomate na sua forma processada (Canene-Adams et al. 2005). Em países como Itália, Israel, Líbano e Grécia o consumo de tomate fresco pode chegar a um consumo per capita $100 \mathrm{~kg}$ por ano. Baseado nesses valores e nos valores nutricionais é possível inferir que o tomate fornece $50 \%, 26 \%$ e $19 \%$ das necessidades diárias de vitamina C, A e E respectivamente (Tabela 1). Apesar de não ser o alimento com o maior conteúdo de vitamina $C$, o tomate é a principal fonte alimentar desse composto devido ao seu alto consumo (Klee e Giovannoni 2011).

Tabela 1: Valor nutricional do tomate

\begin{tabular}{|c|c|c|c|c|c|}
\hline & \multicolumn{2}{|c|}{ TOMATE CRU } & \multicolumn{2}{|c|}{ TOMATE PROCESSADO } & \multirow{2}{*}{$\begin{array}{c}\text { Aporte do tomate à dieta } \\
\text { diária* }\end{array}$} \\
\hline Nutriente & $\begin{array}{l}\text { Quantidade } \\
\text { em 100g }\end{array}$ & $\begin{array}{l}\text { \% Valores } \\
\text { diários }\end{array}$ & $\begin{array}{c}\text { Quantidade em } \\
100 \mathrm{~g}\end{array}$ & $\begin{array}{l}\text { \% Valores } \\
\text { diários }\end{array}$ & \\
\hline Calorias & 18 (kcal) & $1 \%$ & 102 (kcal) & $5 \%$ & $4,5 \%$ \\
\hline Proteínas & $0,9 \mathrm{~g}$ & $2 \%$ & $3,2 \mathrm{~g}$ & $6 \%$ & $5,6 \%$ \\
\hline Carboidratos totais & $3,9 \mathrm{~g}$ & $1 \%$ & $21,3 \mathrm{~g}$ & $7 \%$ & $6,2 \%$ \\
\hline Vitamina A & $833 \mathrm{IU}$ & $17 \%$ & $1.298 \mathrm{IU}$ & $26 \%$ & $26 \%$ \\
\hline Vitamina C & $12,7 \mathrm{mg}$ & $21 \%$ & $32 \mathrm{mg}$ & $53 \%$ & $50 \%$ \\
\hline Vitmina $\mathrm{E}$ & $0,54 \mathrm{mg}$ & $3 \%$ & $4,2 \mathrm{mg}$ & $21 \%$ & $19 \%$ \\
\hline
\end{tabular}

*Baseado no consumo médio diário de tomate cru e processado por um americano adulto.

Fonte: Canene-Adams et al. 2005, Nutritive value of foods, USDA 2002

(http://www.nal.usda.gov/fnic/foodcomp/Data/HG72/hg72_2002.pdf).

\section{O melhoramento genético e o uso do germoplasma selvagem}

Embora o cultivo de tomate seja muito antigo e amplamente distribuído, ainda enfrenta desafios nos níveis de produção, processamento e consumo. Os produtores requerem mudanças na 
arquitetura da planta e a geração de variedades resistentes a fatores bióticos e abióticos, que diminuam os custos e possibilitem um manejo livre de agroquímicos. As cadeias de processamento desejam alterar o conteúdo de determinados metabólitos do fruto que melhorem características industriais (ex. conteúdo de sólidos solúveis, brix). E os consumidores, de maneira crescente, procuram o incremento na qualidade nutricional (Stiekema 2007).

Como mencionado anteriormente, devido à reduzida variabilidade genética existente nas variedades cultivadas de Solanum lycopersicum a incorporação de germoplasma proveniente de espécies selvagens relacionadas se apresenta como uma valiosa fonte para a identificação de novos genes (Tanksley et al. 1997). A partir dessa concepção, a existência de linhagens provenientes de cruzamentos interespecíficos onde fragmentos de genoma selvagem sejam incorporados ao de $S$. lycopersicum é de especial interesse (Barone et al. 2007).

Em 1995, Eshed e Zamir desenvolveram uma população pioneira de 76 linhagens introgredidas (ILS), nas quais segmentos definidos do genoma de Solanum pennellii (LA716) substituem regiões homólogas em um fundo genético de Solanum lycopersicum (cv. M82). Os fragmentos introgredidos de todas as linhagens estão bem delimitados através de marcadores moleculares (http://www.sgn.cornell.edu/maps/pe.pl) e, em conjunto, cobrem todo o genoma de tomate sendo que a sua sobreposição permite segmentar o genoma em 107 bins (Figura 4). Como as ILs são um recurso homozigoto e permanente, já que se propagam por autofecundação, elas constituem um excelente sistema genético para o mapeamento de caracteres quantitativos - QTL (Quantitative Trait Loci). Utilizando essas ILs, Rousseaux et al. (2005) identificaram 20 QTL para conteúdo de antioxidantes, ácido ascórbico e compostos fenólicos. Em outro estudo, Causse et al. $(2002,2004)$ identificaram 130 QTL para 38 caracteres relacionados à qualidade organoléptica do fruto. Posteriormente, Tieman et al. (2006) analisaram 23 compostos voláteis, relacionados ao sabor do fruto localizando 25 loci distribuídos nos 12 cromossomos. Desta maneira, até 2007 tinham sido mapeados 2.795 QTL para caracteres metabólicos e de rendimento na coleção de 76 ILs (Lippman et al.2007). 


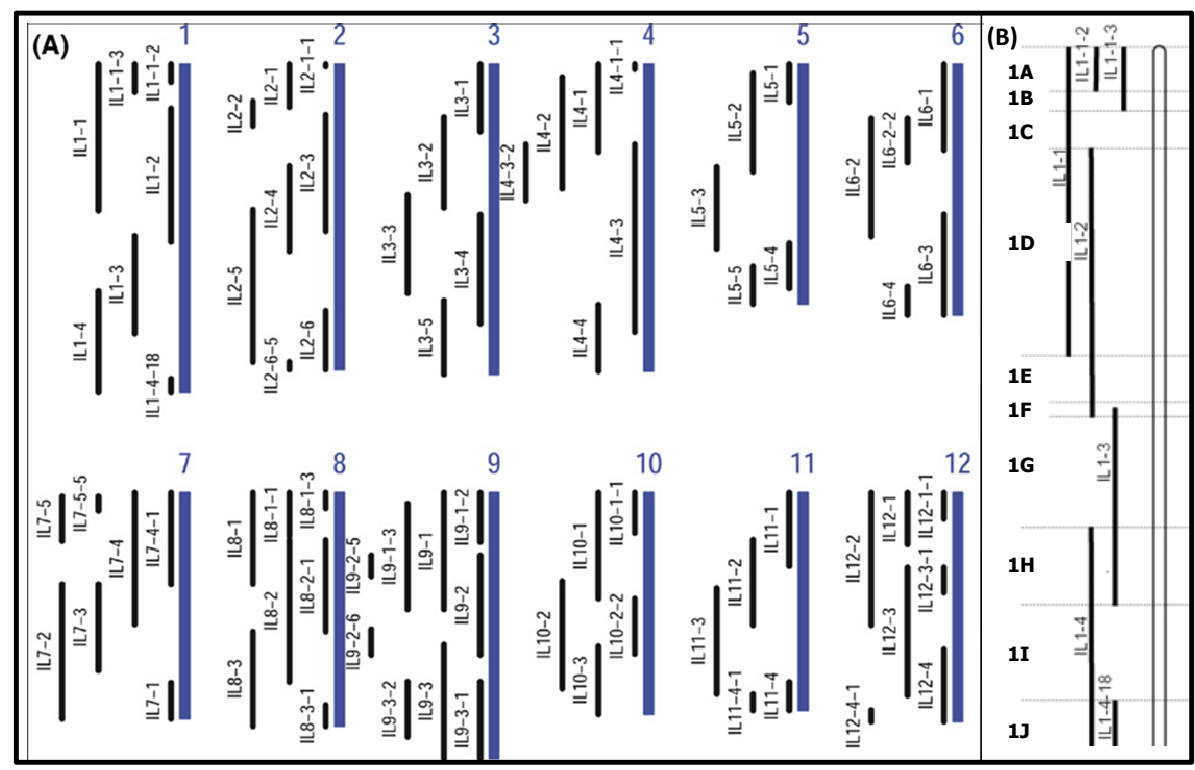

Figura 4: Representação esquemática das 76 linhagens introgredidas desenvolvidas por Eshed e Zamir (1995).

(A) esquema geral das ILs. As linhas pretas representam o fragmento de S. pennellii contido em cada linhagem. Junto aos fragmentos se indica o nome da linhagem. Fonte: Lippman et al. (2007). (B) ILs que abrangem o cromossomo 1 . As letras indicam os bins, nos quais é possível dividir o cromossomo 1 de acordo à sobreposição dos diferentes fragmentos introgredidos.

Historicamente, os genes de interesse agronômico têm sido identificados através de longos processos de mapeamento genético, seguidos de mapeamentos físicos para finalmente chegar à clonagem posicional. A integração dos dados de mapeamento com a crescente quantidade de informação sobre sequências genômicas e expressas, provindas do advento da genômica, resultou no surgimento da estratégia de "genes candidatos" como uma alternativa à demorada clonagem posicional. Esta abordagem consiste na identificação de genes que cosegregam com os caracteres de interesse e que, pela putativa função dos seus produtos, podem contribuir ou determinar as variações observadas. Um exemplo muito interessante da estratégia dos genes candidatos é o estudo realizado por Fridman et al. (2000, 2004). Neste estudo foi identificada uma região genômica no cromossomo 9 de S. pennellii responsável por um incremento de $25 \%$ no brix. Nessa região foi identificado um gene que codifica para uma invertase que foi chamada LIN5. Análises funcionais demonstraram que o aumento do brix observado estava determinado pela mudança de um único nucleotídeo no terceiro éxon do gene, que provocava uma substituição de aminoácido modificando as propriedades cinéticas da enzima. Esta invertase é determinante no descarregamento de sacarose do floema ao fruto, sendo este o maior fator envolvido no incremento do conteúdo de açúcar neste órgão (Baxter et al. 2005).

\section{Construção da hipótese de trabalho}

Em 2006, Schauer et al. identificaram e quantificaram 74 metabólitos e 9 caracteres morfológicos relacionados a rendimento nos frutos das 76 ILs previamente descritas. Os resultados 
permitiram identificar 889 QML (Quantitative Metabolic Loci) e 326 YAL (Yield Associated Loci) ao longo do genoma do tomate. Tendo como base esse estudo, e em colaboração com a equipe do Dr. Alisdair Fernie do Max-Planck-Institut (Golm, Alemanha) e do Dr. Fernando Carrari do INTA (Castelar, Argentina), nosso laboratório trabalha para identificar e caracterizar os determinantes genéticos responsáveis por essas mudanças. Em 2008, Bermúdez et al., combinando a análise de sequencias de marcadores moleculares, amplificação e sequenciamento, análise de variaçãoes alélicas e avaliação da coresposta entre expressão gênica e composição metabólica, disponibilizaram uma lista de genes que colocalizam com um subset de 106 QML e 20 YAL associados a importantes caracteres agronômicos e nutricionais. Essa estratégia permitiu a identificação de 127 genes candidatos, os quais estão localizados ao longo das 16 regiões genômicas (bins: 1J, 2F, 4E, 4I, 5D, 5E, 5F, 7B, 7F, 7H, 9B, 9D, 9E, 9J, 10B, 11C). A clonagem e sequenciamento parcial dos alelos de S. pennellii e $S$. lycopersicum para 85 desses genes revelou a existência de polimorfismos para $43 \%$ das proteínas codificadas.

Para três das regiões genômicas de interesse (bins 4I, $7 \mathrm{H}$ e 11C), além da estratégia de genes candidatos, foi construído um mapa físico de S. pennellii que permitiu avaliar a colinearidade entre os genomas da espécie selvagem e cultivada (Kamenetzky et al. 2010). O mapa físico foi complementado com o sequenciamento de fragmentos genômicos e análise da microsintenia sobre as regiões codificantes e regulatórias, assim como o estudo do padrão de inserção de elementos de transposição. Desta maneira, foram identificadas diferenças que provavelmente determinem alterações no padrão de expressão gênica, explicando assim, as mudanças observadas nos perfís metabólicos. Ainda, a obtenção de sequências genômicas de $S$. pennellii viabilizou também, a realização de análises evolutivas entre as duas espécies. Neste contexto, esta tese apresenta a análise da diversidade genômica entre $S$. lycopersicum e S. pennellii na região do bin $7 \mathrm{H}$ assim como a caracterização funcional de dois genes candidatos previamente identificados por Bermúdez et al. (2008) envolvidos no metabolismo de aminoácidos e na estrutura da parede celular. 


\section{Referências Bibliográficas}

Bai, Y. e Lindhout, P. (2007). Domestication and breeding of tomatoes: what have we gained and what can we gain in the future? Annals of botany, 100, 1085-94.

Barone, A., Chiusano, M.L., Ercolano, M.R., Giuliano, G., Grandillo, S., Frusciante, L. (2008). Structural and functional genomics of tomato. International journal of plant genomics, 2008, 820274.

Baxter, C.J., Carrari, F., Bauke, A., Overy, S., Hill, S.A, Quick, P.W. (2005). Fruit carbohydrate metabolism in an introgression line of tomato with increased fruit soluble solids. Plant \& cell physiology, 46, 425-37.

Bermúdez, L., Urias, U., Milstein, D., Kamenetzky, L., Asis, R., Fernie, A.R., Van Sluys, M.A., Carrari, F., Rossi, M. (2008). A candidate gene survey of quantitative trait loci affecting chemical composition in tomato fruit. Journal of Experimental Botany, 59, 2875-2890.

Bian, W., Barsan, C., Egea, I., Purgatto, E., Chervin, C., Zouine, M., Latché, A., Bouzayen, M., Pech, J.C. (2011). Metabolic and molecular events occurring during chromoplast biogenesis. Journal of Botany, 11, 13 pages

Canene-Adams, K., Campbell, J.K., Zaripheh, S., Jeffery, E.H., Erdman, J.W. (2005). The Tomato As a Functional Food. The Journal of Nutrition, 10, 1226-1230.

Carrara, S., Pardossi, A., Soldatini, G.F., Tognoni, F., Guidi, L. (2001). Photosynthetic Activity of Ripening Tomato Fruit. Photosynthetica, 39, 75-78.

Carrari, F. e Fernie, A.R. (2006). Metabolic regulation underlying tomato fruit development. Journal of experimental botany, 57, 1883-97.

Carrari, F. et al. (2006). Integrated analysis of metabolite and transcript levels reveals the metabolic shifts that underlie tomato fruit development and highlight regulatory aspects of metabolic network behavior. Plant physiology, 142, 1380-96.

Causse, M. (2002). QTL analysis of fruit quality in fresh market tomato: a few chromosome regions control the variation of sensory and instrumental traits. Journal of Experimental Botany, 53, 20892098

Causse, M., Duffe, P., Gómez, M., Buret, M., Damidaux, R., Zamir, D., Gur, A., Chevalier, C., LemaireChamley, M., Rothan, C. (2004). A genetic map of candidate genes and QTL involved in tomato fruit size and composition. Journal of Experimental Botany, 55, 1671-1685.

Costa, J.M. e Heuvelink, E. (2005). Introduction: The Tomato crop and industry. Em Tomatoes. Heuvelink, E. CABI publishing, Cambridge, EUA.

Eshed, Y., Zamir, D. (1995). An Introgression Line Population of Lycopersicon pennelli in the Cultivated Tomato Enables the Identification and Fine Mapping of Yield-Associated QTL. Genetics, 141, 11471162.

Frary, A. e Doganlar, S. (2003). Comparative Genetics of Crop Plant Domestication and Evolution. Turkish Journal of Agriculture \& Forestry, 27, 59-69.

Fridman, E., Carrari, F., Liu, Y.S., Fernie, A. R., Zamir, D. (2004). Zooming In on a Quantitative Interspecific Introgressions. Science, 305, 1786-1789.

Fridman, E., Pleban, T., Zamir, D. (2000). A recombination hotspot delimits a wild-species quantitative trait locus for tomato sugar content to $484 \mathrm{bp}$ within an invertase gene. Proceedings of the National Academy of Sciences of the United States of America, 97, 4718-23.

Gillaspy, G., Ben-David, H., Gruissem, W. (1993). Fruits: A Developmental Perspective. The Plant cell, 5, 1439-1451

Giovannoni, J.J. (2004). Genetic Regulation of Fruit Development and Ripening. The Palnt Cell, 16, 170181.

Kamenetzky, L. et al. (2010). Genomic analysis of wild tomato introgressions determining metabolismand yield-associated traits. Plant physiology, 152, 1772-86.

Klee, H.J. e Giovannoni, J.J. (2011). Genetics and control of tomato fruit ripening and quality attributes. Annual review of genetics, 45, 41-59.

Knapp, S. (2002). Tobacco to tomatoes: a phylogenetic perspective on fruit diversity in the Solanaceae. Journal of Experimental Botany, 53, 2001-2022. 
Knapp, S., Bohs, L., Nee, M., Spooner, D.M. (2004). Solanaceae-a model for linking genomics with biodiversity. Comparative and functional genomics, 5, 285-91.

Lippman, Z.B., Semel, Y., Zamir, D. (2007). An integrated view of quantitative trait variation using tomato interspecific introgression lines. Current opinion in genetics \& development, 17, 545-52.

Lytovchenko, A., Eickmeier, I., Pons, C., Osorio, S., et al. (2011). Tomato fruit photosynthesis is seemingly unimportant in primary metabolism and ripening but plays a considerable role in seed development. Plant physiology, 157, 1650-63.

Matsukura, C., Aoki, K., Fukuda, N., Mizoguchi, T., Asamizu, E., Saito, T., Shibata, D., Ezura, H. (2008). Comprehensive resources for tomato functional genomics based on the miniature model tomato micro-tom. Current genomics, 9, 436-43.

Michaelson, M.J., Price, H.J., Ellison, J.R., Johnston, J.S. (1991). Comparison of plant dna contents determined by feulgen microspectrophotometry and laser flow cytometry. American Journal of Botany, 78, 183-188.

Miller, J.C. e Tanksley, S.D. (1990). RFLP analysis of phylogenetic relationships and genetic variation in the genus Lycopersicon. Theoretical and Applied Genetics, 80, 437-448.

Mueller, L.A. et al. (2005). The SOL Genomics Network . A Comparative Resource for Solanaceae Biology and Beyond 1. Bioinformatics, 138, 1310-1317.

Peralta, I.E. e Spooner, D.M. (2000). Classification of wild tomatoes: a review. Tomo, 28, 45-54.

Peralta, I.E. e Spooner, D.M. (2007). History, origin and early cultivation of tomato (Solanaceae). Em Genetic improvement of Solanaceaus crops. Razdan MK e Mattoo AK. Science publishers Enfield, New Hampshire, EUA.

Piechulla, B., Glick, R., Bahl, H., Gruissem, W. (1987). Changes in Photosynthetic Capacity and Photosynthetic Protein Pattern during Tomato Fruit Ripening. Plant Physiology, 84, 911-917.

Quadrana, L., Rodriguez, M.C., López, M., Bermúdez, L., Nunes-Nesi, A., Fernie, A.R., Descalzo, A., Asis, R., Rossi, M., Asurmendi, S., Carrari, F. (2011). Coupling virus-induced gene silencing to exogenous green fluorescence protein expression provides a highly efficient system for functional genomics in Arabidopsis and across all stages of tomato fruit development. Plant Physiology, 156, 1278-91.

Rick, C.M. e Holle, M. (1990). Andean lycopersicon esculentum var. cerasiforme: genetic variation and its evolutionary significance. Economic Botany, 44, 69-78.

Rick, C.M. e Yoder, J.I. (1988). CLASSICAL AND MOLECULAR GENETICS OF TOMATO : Highlights and Perspectives. Annual Reviw of Genetics, 22, 281-300.

Rousseaux, M.C., Jones, C.M., Adams, D., Chetelat, R., Bennett, A., Powell, A. (2005). QTL analysis of fruit antioxidants in tomato using Lycopersicon pennellii introgression lines. TAG. Theoretical and applied genetics, 111, 1396-408.

Schauer, N., Semel, Y., Roessner, U., Gur, A., Balbo, I., Carrari, F. (2006). Comprehensive metabolic profiling and phenotyping of interspecific introgression lines for tomato improvement. Nature biotechnology, 24, 447-54.

Schauer, N., Zamir, D., Fernie, A.R. (2005). Metabolic profiling of leaves and fruit of wild species tomato: a survey of the Solanum lycopersicum complex. Journal of experimental botany, 56, 297307.

Spooner, D.M., Peralta, I.E., Knapp, S. (2005). Comparison of AFLPs with other markers for phylogenetic inference in wild tomatoes [ Solanum L . section Lycopersicon ( Mill .) Wettst .]. Taxon, 54:43-61.

Stiekma, W. (2007). Introduction to EU-Sol em EU-SOL High Quality Solanaceous Crops for consumers, Processors and Producers by Exploration of Natural Biodiversity Newsletter

Tanksley, S.D. (1997). Seed Banks and Molecular Maps: Unlocking Genetic Potential from the Wild. Science, 277, 1063-1066.

Tanksley, S.D. (2004). The Genetic, Developmental, and Molecular Bases of Fruit Size and Shape Variation in Tomato. The Palnt Cell, 16, 181-190.

The Tomato Genome Consortium (2012). The tomato genome sequence provides insights into fleshy fruit evolution. Nature, 485, 635-41.

Tieman, D.M., Zeigler, M., Schmelz, E.A, Taylor, M.G., Bliss, P., Kirst, M. (2006). Identification of loci affecting flavour volatile emissions in tomato fruits. Journal of experimental botany, 57, 887-896.

Van Der Hoeven, R., Ronning, C., Giovannoni, J., Martin, G., Tanksley, S. (2002). Deductions about the Number, Organization, and Evolution of Genes in the Tomato Genome Based on Analysis of a 
Large Expressed Sequence Tag Collection and Selective Genomic Sequencing. The Plant Cell, 14, 1441-1456. 


\section{Hipótese e Objetivos}


Tendo como ponto de partida os genes candidatos identificados por Bermúdez et al. (2008) associados aos QTL que afetam a composição química de tomate, o objetivo geral desta tese foi aprofundar o conhecimento sobre os genes envolvidos na qualidade industrial e nutricional, em particular no conteúdo de aminoácidos e estrutura da parede celular. As abordagens experimentais propostas se sustentam na hipótese das variantes alélicas introduzidas pelo genitor selvagem da população (Solanum pennellii) e, as interações destas com o fundo genético do genitor recorrente (Solanum lycopersicum) serem os principais fatores causadores das diferenças fenotípicas observadas. Assim, foram propostos os seguintes objetivos:

- Analisar a diversidade genômica entre o tomateiro cultivado, S. lycopersicum, e a espécie selvagem, S. pennellii (Capítulo I).

- Caracterizar estrutural e funcionalmente o gene LFP (Low Free Putrescine) (Capítulo II).

- Estudar a família multigênica das galacturonosiltransferases (GAUT) e caracterizar estrutural e funcionalmente o gene GAUT4 (Capítulo III). 
CAPÍtulo I: ANÁlISE dA DIVERSIDADE GENÔMICA ENTRE O TOMATEIRO CULTIVAdo, Solanum LYCOPERSICUM, E A ESPÉCIE SELVAGEM SOLANUM PENNELLII 


\section{INTRODUCÃO}

Com o surgimento das tecnologias de sequenciamento de segunda e terceira geração, o aumento de informação sobre as sequencias genômicas e expressas dos organismos é cada vez maior criando a necessidade de desenvolver estratégias que permitam a análise dessa imensa quantidade de dados (Brautigam and Gowik 2010). Particularmente, o grande desafio é o entendimento da função gênica, uma vez que a determinação da sequencia de nucleotídeos não implica no conhecimento dos mecanismos pelos quais esta determina o fenótipo. Nesse sentido, a genômica comparativa se tornou uma ferramenta importante para desvendar a função e estrutura dos genomas, além de entender os mecanismos evolutivos que os moldaram. Desta forma, tanto a comparação de regiões cromossômicas homólogas, quanto à análise das relações de ortologia e da diversidade alélica, permitem identificar a origem da variação estrutural e funcional dos sistemas biológicos (Salse et al. 2009). Ainda mais, essa metodologia tem facilitado a predição de exons terminais ou pequenos, precursores de microRNAs e marcos abertos de leitura correspondentes a pequenos peptídeos cuja identificação seria impossível sem a utilização de dados experimentais em outras espécies (Windsor and Mitchell-Olds 2006).

Há inúmeros exemplos da utilização de genômica comparativa, o que tem demonstrado a eficácia desta abordagem. Por meio do estudo comparativo da região genômica do locus da aldeído desidrogenasse de milho, arroz e sorgo foi possível reconstruir a natureza, o momento e a linhagem dos rearranjos que diferenciaram esse segmento cromossômico ao longo dos últimos 60 milhões de anos (Ilic et al. 2003). Da mesma forma, recentemente a história evolutiva dos genes Mustang também foi revelada em gramíneas (Kajihara et al. 2012).

É interessante ressaltar que os estudos comparativos tem permitido a aplicação de dados de uma espécie em outras taxonomicamente distantes. Por exemplo, utilizando o genoma de Arabidopsis thaliana, foram identificados genes relacionados à replicação e reparo de DNA potencialmente relacionados à proliferação celular de tumores humanos (Quimbaya et al. 2012). Finalmente, para a anotação e entendimento da dinâmica evolutiva do genoma de trigo diversos genomas como os de Escherichia coli, humano, A. thaliana e Oryza sativa foram utilizados (Heslop-Harrison 2000).

Até o momento os genomas de duas espécies de Solanaceae foram totalmente sequenciados e disponibilizados: o de Solanum tuberosum (Potato Genome Sequencing Consortium 2011) e mais recentemente, o de Solanum lycopersicum (The Tomato Genome Consortium 2012). Neste último trabalho foram comparados pela primeira vez os genomas de três espécies:, Solanum tuberosum, Solanum lycopersicum e o tomate selvagem, Solanum pimpinelifolium (parcialmente sequenciado). 0 resultado dessa comparação permitiu concluir que as espécies do gênero Solanum sofreram duas triplicações consecutivas do genoma, uma ancestral, compartilhada com Rosidae, e uma mais recente. Essas triplicações permitiram o aumento no número de genes de famílias multigênicas que resultaram na determinação de importantes caracteres dos frutos. 
Valendo-se da disponibilidade de sequencias parciais, estudos pioneiros, nos últimos vinte anos realizaram análises de genômica comparativa em Solanaceae. Em 1988, Zamir and Tanksley mostraram a conservação do conteúdo gênico entre tomate, batata, tabaco, petúnia e berinjela. Outro estudo posterior mostrou que o alto grau de colinearidade gênica entre tomate e batata estava interrompido apenas por inversões paracêntricas (Tanksley et al. 1992). Mapas físico-genéticos comparativos entre espécies de Solanaceae revelam que a posição relativa de QTL é, em muitos casos, conservada (Muller et al. 2005). Mais recentemente, alguns trabalhos de genômica comparativa em grande escala foram realizados em Solanaceae (Rensink et al. 2005, Song e Wang 2010,). Em particular, um deles desenvolvido pelo nosso grupo (Kamentezky et al. 2010, vide anexo 1), comparou os genomas da espécie de tomate selvagem, $S$. pennellii, e da cultivada, S. lycopersicum, ao longo de cinco regiões genômicas que compreendem 104 QTL associados ao metabolismo primário, rendimento e compostos voláteis (Schauer et al. 2006, Tieman et al. 2006). Para isso, foram integrados os mapas genético e físico das duas espécies, onde foram ancorados 374 clones de BACs e cosmídeos, provenientes de bibliotecas genômicas de S. pennellii, ao mapa genético de S. lycopersicum. A topologia do mapa demonstra que os genomas das espécies selvagem e domesticada podem ser considerados colineares. Isto é claramente evidenciado pela densidade de conexões entre os clones de S. pennellii e S. lycopersicum e suas posições no mapa genético (Figura 1A). Entretanto, foram identificadas algumas regiões que apresentam rearranjos como inversões e duplicações (Figura 1B). Finalmente, foi possível sugerir a expansão de regiões do genoma de $S$. pennellii, evidenciado pelas maiores distâncias genéticas entre clones de $S$. pennellii quando comparadas às distâncias entre os clones ortólogos de S. lycopersicum (Figura 1A). Esses resultados estão de acordo com as estimativas do tamanho de ambos os genomas de $1.200 \mathrm{Mb}$ e $950 \mathrm{Mb}$ para as espécies selvagem e cultivada, respectivamente (Kamentzky et al. 2010). De forma complementar ao mapa físico, outra abordagem utilizada pelo nosso grupo para avaliar a diversidade genômica dentro da seção Lycopersicon foi a realização de uma análise de microsintenia. Esta análise revelou uma quase perfeita colinearidade, apresentando alto grau de conservação na ordem, orientação e estrutura dos genes. A colinearidade foi interrompida apenas pelo tamanho variável das regiões intergênicas e alterações no padrão de inserção de elementos de transposição. Os resultados descritos do mapa físico e da análise de microsintenia formam parte do mesmo artigo publicado pelo grupo em 2010 (Kamenetzky et al. 2010). Em particular, os estudos realizados sobre o cromossomo 7, onde tinham sido mapeados QTL para 12 aminoácidos e glicose-6-P (Schauer et al. 2006) e identificados 7 genes candidatos (Bermúdez et al. 2008), foram desenvolvidos no contexto da presente tese de doutorado. 


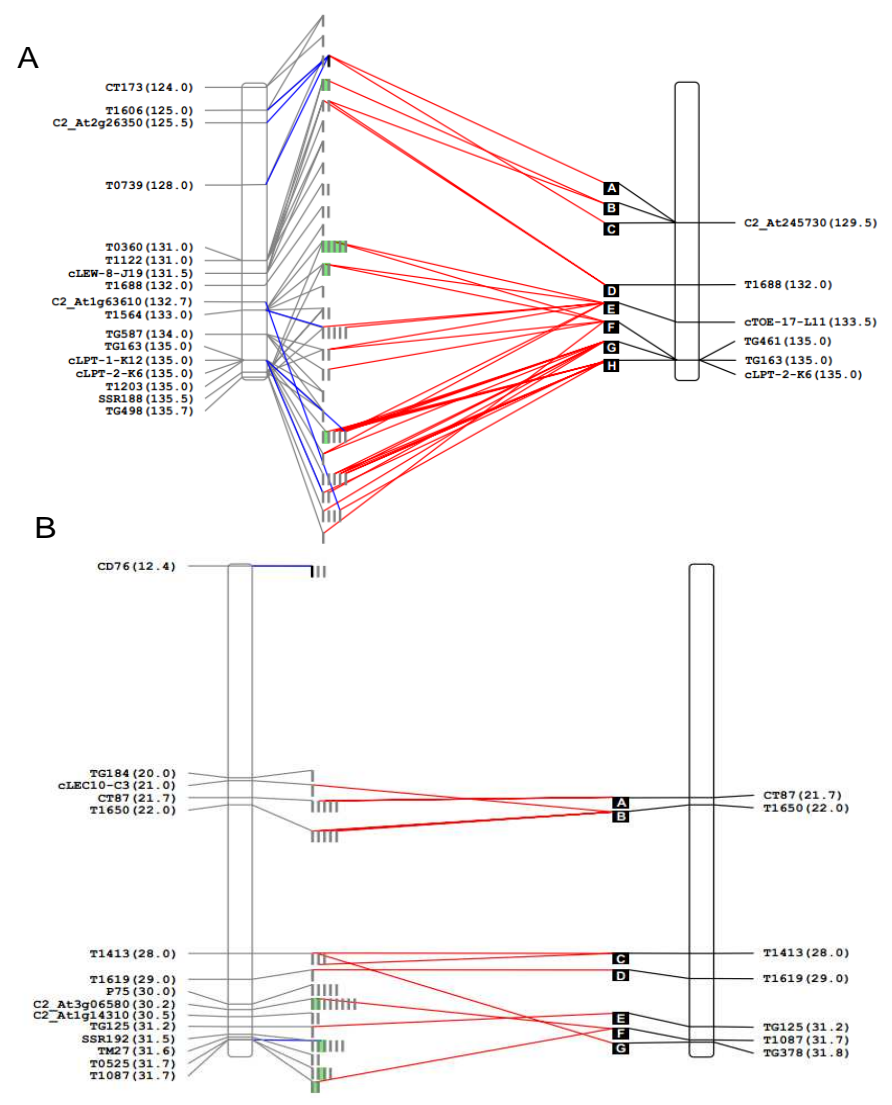

Figura 1: Mapas físicos e genéticos integrados de S. pennellii e S. lycopersicum. Os marcadores genéticos e suas posições em cM de acordo ao mapa Tomato EXPEN 2000 estão indicados à esquerda e à direita dos fragmentos cromossômicos de $S$. pennellii e S. lycopersicum, respectivamente. Os clones ancorados de $S$. pennellii estão indicados com barras cinza. Os clones pertencentes ao mesmo contig estão agrupados em verde. Os clones de BAC de S. lycopersicum estão indicados com quadrados pretos. As linhas cinza unem clones de $S$. pennellii com os marcadores com os quais hibridam. As linhas azuis indicam os clones de $S$. pennellii que possuem a sequência do markers na sua sequência terminal. As linhas vermelhas unem os clones de ambas as espécies que possuem sequencias ortólogas. As linhas pretas unem os clones de $S$. lycopersicum com seus correspondentes marcadores. (A) Fragmento do cromossomo 4. (B) Fragmento do cromossomo 1. Adaptado de Kamenetzky et al. (2010). 


\section{OBJETIVOS}

O objetivo geral deste capítulo é analisar comparativamente uma região genômica do cromossomo 7 de S. lycopersicum e S. pennellii associada a variações nos níveis de aminoácidos e glicose-6P em frutos de tomateiro, com o intuito de identificar os determinantes genéticos das mesmas. Assim, foram propostos os seguintes objetivos específicos:

- Sequenciar e anotar um cosmídeo do cromossomo 7, (Bin 7H do mapa genético publicado por Eshed and Zamir, 1995), da espécie selvagem S. pennellii contendo um dos genes candidatos previamente descritos por Bermúdez et al. (2008) possivelmente envolvidos nas variações metabólicas observadas;

- Analisar a microsintenia com a região ortóloga da espécie cultivada S. lycopersicum e;

- Analisar o padrão de evolução dos genes identificados e estimar o tempo de divergência entre as duas espécies. 


\section{MATERIAL E MÉTODOS}

\subsection{Sequenciamento do clone de S. pennellii}

O cosmídeo de S. pennellii C07SpCP066B007.P5C4 foi identificado a partir da triagem de uma biblioteca genômica de Solanum pennellii (Chen et al. 2007) utilizando o marcador T1255 (Kamenetzky et al. 2010). O DNA foi purificado usando o kit R.E.A.L Prep 96 Plasmid Kit (Qiagen) segundo recomendações do fabricante e sequenciado, por piro sequenciamento, por meio de uma colaboração realizada com a empresa Roche com a Plataforma 454. O processo de montagem foi realizado usando o programa Phred+Phrap+Consed (Ewing e Green 1998; Gordon et al. 1998).

\subsection{Anotação}

A sequência obtida do clone de S. pennellii, assim como a correspondente do clone ortólogo de S. Iycopersicum (C07HBa0061J13) obtido da base de dados da Solanaceae Genomics Network (SGN, http://solgenomics.net/) que apresentou a maior cobertura do clone de S. pennellii, foi anotada usando dois programas de predição gênica FGENESH (Salamov e Solovyev 2000) e Augustus (Stanke et al. 2004). Cada clone foi comparado independentemente contra a base de dados de unigenes da SGN (versão de Setembro 2009, com 123.550 sequências e 92.327 .235 bp) usando o programa de alinhamento global cross-match (www.phrap.org). As sequências dos genes preditos foram verificadas manualmente por comparação por BLAST (Altschul et al. 1997) com o unigene correspondente identificado. Quando não foi possível identificar um unigene associado na SGN, foi usada a base de dados do TIGR (Plant Transcript Assemblies) (http://plantta.tigr.org/). Apenas os genes preditos pelos dois programas e que apresentaram homologia com uma sequência de RNAm de S. lycopersicum e/ou A. thaliana foram anotados. Quando os RNAm homólogos eram provenientes de S. lycopersicum, foram utilizados parâmetros de corte de $95 \%$ de identidade e $90 \%$ de cobertura. Quando os RNAm eram provenientes de A. thaliana, os critérios considerados foram menos estringentes, com $70 \%$ de identidade e $85 \%$ de cobertura do RNAm. A identificação das sequências repetitivas foi realizada usando o software RepeatMasker (http://www.repeatmasker.org), e só foram considerados elementos que cobriram no mínimo $70 \%$ da sequência do elemento de referência. Os genes encontrados no cosmídeo de S. pennellii foram nomeados com a seguinte nomenclatura: Sp07gCP5C04.\# onde Sp pertence a S. pennellii, os dois dígitos (07) indicam o número do cromossomo, g representa a sequência genômica, $\mathrm{C}$ que identifica o clone de cosmídeo, os cinco dígitos (P5C04) indicam as coordenadas do clone na biblioteca, e o \# corresponde a números consecutivos que indicam a ordem dos genes dentro do clone. A identificação 
de indels e SNPs foi calculada usando o algoritmo Needleman-Wunsch global alignment disponível em http://www.ebi.ac.uk/Tools/emboss/align.

\subsection{Análises evolutivas}

As sequências codificantes dos genes foram alinhadas usando o software ClustalW multiple alignment (versão 1.5; Thompson et al. 1994). O alinhamento foi manualmente ajustado usando como referência o alinhamento da sequência proteica. As distâncias sinônimas $\left(d_{s}\right)$ e não sinônimas $\left(d_{N}\right)$ foram estimadas usando o programa MEGA 3.1 (Kumar et al. 2004) usando o método Nei-Gojobori (JukesCantor). O desvio no uso de códons foi determinado pelo índice Nc (número efetivo de códons) usando o software DNAsp versão 4.10 .99 (Rozas et al. 2003). O teste de seleção foi realizado com o programa MEGA 3.1 (Kumar et al. 2004) usando o método Nei-Gojobori (Jukes-Cantor). Para rejeitar a hipótese nula de evolução neutra $\left(d_{S}=d_{N}\right)$ foi considerado um $P<0,05$ no teste $Z$. O teste da taxa relativa foi realizado usando o programa HYPHY e o modelo de códons proposto por Muse e Gaut (1994). Para rejeitar a hipótese nula de homogeneidade foi considerado um $P<0,05$ no teste de $\chi^{2}$. As taxas de substituição específicas da região genômica $(r)$ e os tempos de divergência entre as espécies foram estimados usando a equação $r=d_{S} / 2 \mathrm{~T}$, onde: $d_{S}$ é o número estimado das substituições sinônimas por sítio entre as sequências homólogas (distância sinônima) e T é o tempo de divergência. $r$ foi estimado usando o dado de tempo de divergência entre arabidopsis/Solanaceae baseado em dados fósseis de 120 MAA (milhões de anos atrás) (Bell et al. 2005, Magallon e Sanderson 2005). Para o cálculo de $d_{s}$ foram utilizadas as regiões codificantes concatenadas dos genes. 


\section{RESULTADOS}

\subsection{Sequenciamento, anotação e análise de microsintenia}

Na região do bin $\mathrm{H}$ do cromossomo 7 de tomateiro foram identificados 13 QTL, para diversos aminoácidos e glicose 6P, por meio do mapeamento numa população de linhagens introgredidas de $S$. pennellii com fundo genético de S. Iycopersicum (Schauer et al. 2006). Com o intuito de identificar diferenças genômicas que possam estar envolvidas nas altercações fenotípicas observadas, foi sequenciado um fragmento da região de interesse do genoma da espécie selvagem para realizar a comparação com a região ortóloga da espécie cultivada.

Desta forma, foi selecionado e sequenciado o clone de S. pennellii C07SpCP066B007.P5C4 que contém o gene da poligalacturonase. Este gene foi identificado como candidato envolvido na determinação dos QTL mapeados no bin 7H por Bermúdez et al. (2008). A sequência apresentou 146.349 pb a partir da qual, por meio de programas de predição gênica e posterior validação manual, foram anotados 22 genes resultando em uma densidade de 0,15 genes/Kb. Também foram identificados elementos de transposição de diversos tipos incluindo retrotransposons com e sem longas repetições terminais (LTRs), retroelementos sem LTRs, transposons e elementos de transposição miniatura (MITEs). A densidade de elementos de transposição resultou em 0,05 elementos/Kb (Kamenetzky et al. 2010). Para realizar a análise de microsintenia foi selecionado, da base de dados da Solanaceae Genomics Network, o clone ortólogo de S. lycopersicum C07HBa0061J13. Esse clone possui 97.158 pb e foram anotados 15 genes o que representa a mesma densidade gênica encontrada na espécie selvagem. A análise de microsintenia revelou que a ordem, orientação e estrutura dos genes nessa região são conservadas entre as duas espécies e que elas apresentam alterações apenas no tamanho das regiões intergênicas. Como esperado, estas regiões apresentaram menor identidade entre as espécies do que as regiões portadoras de genes (Figura 2).

S. pennellii clone C07SpCP066B007.P5C04

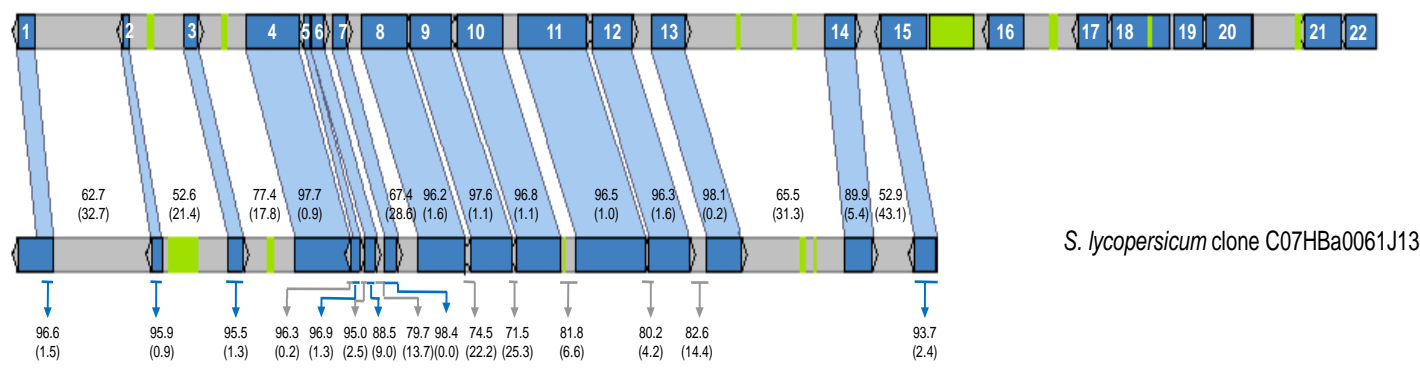

Figura 2: Análise comparativa de uma região do cromossomo 7 ortóloga entre S. lycopersicum e S. pennellii.

Os genes estão indicados como setas azuis e a percentagem de identidade e InDels (em parêntesis) entre as espécies nas regiões gênicas e intergênicas também se encontra indicada. Os quadrados verdes representam elementos de transposição.

Analisando os genes identificados, como esperado observou-se uma maior identidade nas regiões codificantes do que nos introns (Tabela 1). A anotação desse fragmento genômico permitiu a 
identificação de um novo gene candidato que poderia também, estar envolvido na alteração do conteúdo de aminoácidos e glicose-6-P. O gene Sp07gCP5C04.14 codifica para uma S-adenosil-Lmetionina carboxil metiltransferase, este gene em tomate se encontra expresso em folhas em desenvolvimento (Kamentsky et al. 2010) e apresenta 4 polimorfismos de aminoácidos entre $S$. lycopersicum e S. pennellii (Tabela 1).

\subsection{Análises evolutivas}

O grau de conservação de cada gene entre as duas espécies de tomateiro e $A$. thaliana foi avaliado através do calculo das distâncias de substituição sinônimas e não sinônimas $\left(d_{S} / d_{N}\right)$. Essa analise foi feita para todos os genes que preenchiam os seguintes critérios: a) sequencia codificante completa (exclusão de genes localizados no fim do clone); b) não possuir código de parada (exclusão do gene Sp07gCP5C04.8); c) possuir ortólogo de Arabdopsis e d) taxas de substituição relativas homogêneas. Desta forma, dos 15 genes compartilhados entre os clones sequenciados de S. pennelli e S. lycopersicum, para 10 foi possível calcular os parâmetros evolutivos. Todos os genes analisados apresentaram relação $d_{S} / d_{N}$ maior que 1 , evidenciando a ausência de seleção positiva. A fim de obter um indicio sobre o tipo de seleção à qual estão submetidos os genes, foi realizado um teste para determinar a existência de seleção neutra $\left(d_{S}=d_{N}\right)$ ou purificadora $\left(d_{S}>d_{N}\right)$. Apenas dois genes Sp07gCP5C04.3 e Sp07gCP5C04.8 demonstraram estar sob seleção purificadora.

A informação gerada neste capítulo com o sequenciamento e anotação de 15 genes de $S$. pennellii e sua subsequente comparação com os ortólogos de S. lycopersicum representam uma fonte única para investigar a data de divergência entre essas duas espécies. Baseado em dados fósseis, foi estimado que A. thaliana e Solanaceae divergiram a 120 MAA (Bell et al. 2005, Magallon and Sanderson 2005). Usando esse dado, foram estimadas as taxas de substituição especifica para a região genômica analisada e o tempo de divergência entre as espécies. A região do cromossomo 7 estudada apresenta uma taxa de substituição de $4.44 \times 10^{-9}$ substituições por ano por sítio e uma taxa de divergência entre S. Iycopersicum e S. pennellii de $2,700,421( \pm 6661,591)$ MAA (Figura 3). 


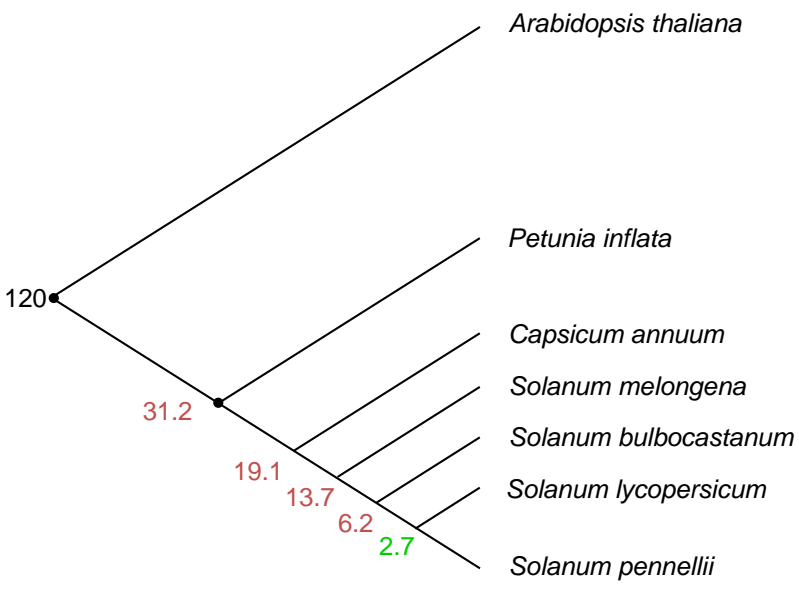

Figura 3: Estimativa do tempo de divergência das espécies.

As datas estimadas por Bell et al. (2005) e Magallon e Anderson (2005) estão em preto. As datas estimadas por Wang et al. (2008) estão em vermelho. A data de divergência entre S. pennellii e S. lycopersicum, estimada segundo o relógio molecular, está indicada em verde. 
Tabela 1. Anotação e análise comparativa entre S. lycopersicum e S. pennellii.

\begin{tabular}{|c|c|c|c|c|c|c|c|c|c|c|c|c|c|}
\hline \multirow[t]{2}{*}{ Gene $^{a}$} & \multirow[t]{2}{*}{$+/^{b}$} & \multirow[t]{2}{*}{ Nome $^{c}$} & \multirow[t]{2}{*}{$\begin{array}{c}\text { cDNA }^{\mathrm{d}} \\
\text { referência }^{\mathrm{d}}\end{array}$} & \multirow[t]{2}{*}{ Biblioteca cDNA ${ }^{e}$} & \multirow[t]{2}{*}{$\begin{array}{l}\text { Ortólogo em } \\
\text { arabdopsis }^{f}\end{array}$} & \multicolumn{2}{|c|}{$\begin{array}{l}\text { \% identidade } \\
(\% \operatorname{lnDel})^{\mathrm{g}}\end{array}$} & \multirow[t]{2}{*}{ Exon $^{h}$} & \multirow[t]{2}{*}{$\begin{array}{l}\text { Tamanho } \\
(\mathrm{aa})^{\mathrm{i}}\end{array}$} & \multirow[t]{2}{*}{ Polimorfismo aa } & \multicolumn{3}{|c|}{$d_{S} / d_{N}{ }^{k}$} \\
\hline & & & & & & Exon & Intron & & & & SI-Sp & SI-Att & Sp-At \\
\hline Sp07gCP5C04.1 & - & $\begin{array}{l}\text { Glicerofosforil diester } \\
\text { fosfodiesterase }\end{array}$ & U564028 & $\begin{array}{c}\text { FR, L, RT, DFBF, } \\
\text { CG, WSD,L, LT, FL, } \\
\text { RC, RTND, CL, FP }\end{array}$ & At5g55480 & $\begin{array}{l}98.8 \\
(0.0)\end{array}$ & $\begin{array}{l}95.9 \\
(1.9)\end{array}$ & 2 & 54 & 2 & & & \\
\hline Sp07gCP5C04.2 & - & $\begin{array}{l}\text { Inibidor da protease/reserva } \\
\text { de semente/proteína de } \\
\text { transferência de lipídeos } \\
\text { (LTP) }\end{array}$ & U577838 & $\begin{array}{c}\mathrm{SD}, \mathrm{FR}, \mathrm{RT}, \mathrm{DFBF} \\
\mathrm{SH}, \mathrm{CL}\end{array}$ & At5g55450 & $\begin{array}{l}97.8 \\
(0.0)\end{array}$ & & 1 & 104 & 5 & 1.04 & $1.9^{*}$ & $1.95^{*}$ \\
\hline Sp07gCP5C04.3 & + & $\begin{array}{l}\text { Inibidor da Poligalacturonase } \\
\text { 1(PGIP1) }\end{array}$ & U579059 & $\begin{array}{l}\text { FR, DFBF, LT, SH, } \\
L, F L, W S D, F P, C G \text {, } \\
\text { WSD }\end{array}$ & At5g06860 & $\begin{array}{l}97.7 \\
(0.0)\end{array}$ & & 1 & 327 & 6 & $5.8^{*}$ & $4.1^{*}$ & $3.6^{*}$ \\
\hline Sp07gCP5C04.4 & + & Proteína similar a fimbrina & U585714 & L, DFBF, RT, FR & At4g26700 & $\begin{array}{l}98.8 \\
(0.0)\end{array}$ & $\begin{array}{l}97.0 \\
(1.5)\end{array}$ & 12 & 856 & 0 & NC & $7.3^{*}$ & $7.4^{*}$ \\
\hline Sp07gCP5C04.5 & - & Gene expresso 1 & U577161 & $\mathrm{RT}, \mathrm{RC}$ & - & $\begin{array}{l}96.9 \\
(1.3)\end{array}$ & & 1 & ND & ND & & & \\
\hline Sp07gCP5C04.6 & + & Wax sintase isoforma 3 & 11564974 & BC EI I DERE $C$ & $A+5 \sigma 55340$ & $\begin{array}{l}86.8 \\
(11.1)\end{array}$ & & 1 & 350 & 53 & 2 & $2.0^{*}$ & $\begin{array}{c}2.06 \\
*\end{array}$ \\
\hline Sp07gCP5C04.7 & + & wax sintase isororma 3 & $05649 / 4$ & $\mathrm{KC}, \mathrm{FL}, \mathrm{L}, \mathrm{DFBF}, \mathrm{CL}$ & Atsg53340 & $\begin{array}{l}98.4 \\
(0.0)\end{array}$ & & 1 & 344 & 10 & 1.9 & $2.1^{*}$ & $2.0^{*}$ \\
\hline Sp07gCP5C04.8 & + & $\begin{array}{l}\text { Proteína de divisão celular } \\
\qquad \text { FtsZ }\end{array}$ & U566680 & $F P, F R, D F B F, L, S H$ & At5g55280 & $\begin{array}{l}99.0 \\
(0.0)\end{array}$ & $\begin{array}{l}95.1 \\
(2.2)\end{array}$ & 6 & 417 & 1 & $15.5^{*}$ & $6.0^{*}$ & $6.3^{*}$ \\
\hline Sp07gCP5C04.9 & - & $\begin{array}{l}\text { Fator associado à proteína } \\
\text { de ligação ao TATA }\end{array}$ & U567340 & DFBF, L, SH, RC & At1g04950 & $\begin{array}{l}99.3 \\
(0.0)\end{array}$ & $\begin{array}{l}96.5 \\
(1.8)\end{array}$ & 12 & 577 & 9 & 0.87 & $2.9^{*}$ & $2.9 *$ \\
\hline Sp07gCP5C04.10 & - & Similar a sintaxina 52 (SYP52) & U584786 & $\begin{array}{l}\text { FR, DFBF, L, RT, } \\
\text { FL,WSD, RTND, LT }\end{array}$ & At1g16240 & $\begin{array}{l}94.8 \\
(4.8)\end{array}$ & $\begin{array}{l}94.9 \\
(2.8)\end{array}$ & 5 & 243 & 11 & & & \\
\hline Sp07gCP5C04.11 & + & Serina/treonina fosfatase & U569502 & $\begin{array}{c}\text { DFBF, CG, SD, LT, } \\
F R, O V, R T, C L, R C, \\
F P\end{array}$ & At5g55260 & $\begin{array}{l}99.5 \\
(0.0)\end{array}$ & $\begin{array}{l}96.1 \\
(1.1)\end{array}$ & 8 & 305 & 1 & 8.0 & $29 . *$ & $\begin{array}{c}32.6 \\
*\end{array}$ \\
\hline Sp07gCP5C04.12 & + & $\begin{array}{l}\text { Lipid-binding serum } \\
\text { glicoproteína }\end{array}$ & U578267 & $\begin{array}{l}\text { L, RC, SD, DFBF, } \\
\text { FP; FR, LT,CL, RT, } \\
\quad O V, C L\end{array}$ & At1g04970 & $\begin{array}{l}98.8 \\
(0.0)\end{array}$ & $\begin{array}{l}95.1 \\
(2.3)\end{array}$ & 5 & 433 & 8 & 1.9 & $2.1^{*}$ & $2.2 *$ \\
\hline Sp07gCP5C04.13 & + & PHD finger & U572301 & $L, F P, L T, F L$ & At1g50620 & $\begin{array}{l}98.1 \\
(0.1)\end{array}$ & $\begin{array}{l}98.2 \\
(0.3)\end{array}$ & 3 & 727 & 24 & & & \\
\hline Sp07gCP5C04.14 & + & $\begin{array}{l}\text { S-adenosil-L-metionina- } \\
\text { carboxil metiltransferase }\end{array}$ & U567938 & CG,DFBF & At5g55250 & $\begin{array}{l}99.1 \\
(0.0)\end{array}$ & $\begin{array}{c}80.1 \\
(11.7)\end{array}$ & 4 & 384 & 3 & 5.5 & $7.0^{*}$ & $6.6^{*}$ \\
\hline Sp07gCP5C04.15 & - & $\begin{array}{l}\text { Glicoproteína rica em } \\
\text { hidroxiprolina }\end{array}$ & U569149 & $\begin{array}{c}\mathrm{FR}, \mathrm{FL}, \mathrm{WSD}, \mathrm{CL} \\
\text { FP }\end{array}$ & At4g26750 & $\begin{array}{l}96.5 \\
(1.2)\end{array}$ & $\begin{array}{l}91.8 \\
(3.1)\end{array}$ & 3 & 295 & 23 & & & \\
\hline Sp07gCP5C04.16 & - & $\begin{array}{l}\text { Proteína associada à } \\
\text { microtúbulo MAP65-1a } \\
\text { Fosfatase citidililitransferase }\end{array}$ & U564865 & $\begin{array}{l}\text { FR, L, DFBF, FL, } \\
\text { SH, OV, CG, RT }\end{array}$ & At5g55230 & & & & & & & & \\
\hline Sp07gCP5C04.17 & + & CDP-diglicerideo sintase & U562959 & $S F, F R, L, D F B F, F P$ & At4g22340 & & & & & & & & \\
\hline
\end{tabular}




\begin{tabular}{|c|c|c|c|c|c|}
\hline Sp07gCP5C04.18 & - & $\begin{array}{l}\text { Trigger factor type } \\
\text { chaperone }\end{array}$ & U586360 & $\begin{array}{c}\text { L, DFBF, FR, SH, } \\
\text { LT, RC, WS, RTND, } \\
\text { FP }\end{array}$ & At5g55220 \\
\hline Sp07gCP5C04.19 & + & $\begin{array}{l}\text { Proteína da família } \\
\text { tioredoxina }\end{array}$ & U563721 & $\begin{array}{c}\mathrm{LT}, \mathrm{FR}, \mathrm{RC}, \mathrm{CG}, \mathrm{RT}, \\
\mathrm{L}, \mathrm{FR}\end{array}$ & At4g37200 \\
\hline Sp07gCP5C04.20 & - & Chaperona GrpE tipo 1 & U567827 & $\begin{array}{c}\text { DFBF, } F R, R C, R T, L \text {, } \\
F P\end{array}$ & At4g26780 \\
\hline Sp07gCP5C04.21 & - & Proteína de ligação Cálcio- EF & U569620 & $\mathrm{SH}, \mathrm{CG}, \mathrm{DFBF}, \mathrm{FR}$ & At3g20290 \\
\hline Sp07gCP5C04.22 & - & Gene expresso 2 & U276317 & & At $3 g 20300$ \\
\hline
\end{tabular}

a. Identificação do gene.

b. Orientação do gene na sequência genômica.

c. Identidade funcional do gene.

d. cDNA de referência de acordo com Sol Genomics Network (SGN) ou TIGR Transcript Assemblies.

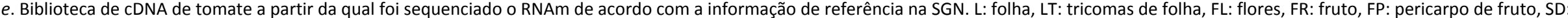

sementes, RT: raiz, SH: caule, CG: galha de coroa, DFBF: gemas florais e flores em desenvolvimento, OV: ovário, CL: calos diferenciados e não diferenciados, RTND: raízes crescidas em diferentes

condições de deficiências nutricionais e minerais, RC: coleção rearranjada de CDNAs de S. lycopersicum, WSD: sementes completas.

f. Categoria funcional de acordo ao programa MapMan (Urbanczyk-Wochniak et al. 2006). 2: carboidratos principais, 17: hormônios, 26: diversas famílias enzimáticas, 27: regulação de RNA, 29:

modificadores de proteínas, 31: célula, 35: função desconhecida.

g. Porcentagem de identidade e indels entre $S$. lycopersicum e S. pennellii da região analisada. BC: bases comparadas totais.

h. Número de exons comparados entre os dois genótipos.

i. Número de aminoácidos comparados entre os dois genótipos.

j. Aminoácidos polimórficos na sequência proteica predita. ND: não determinado.

k. Distância sinônima/Distância não sinônima. Sl: S. lycopersicum, Sp: S. pennellii, At: A. thaliana

*. Seleção purificadora estatisticamente significativa $(P<0.05)$. NC: Não calculável porque $d_{N}=0$. 


\section{DISCUSSÃO}

Tem sido conjeturado que as mudanças evolutivas ocorreram predominantemente por meio de alterações na regulação da expressão gênica e não por mudanças em funções proteicas específicas (ex. atividade enzimática) (Wang et al. 1999, Cong et al. 2002). Isto pode ser atingido por meio da alteração de proteínas que participam da regulação da expressão gênica em qualquer dos seus níveis; ou da intensidade de expressão de um fator de transcrição. Desta forma, diversas funções proteicas são afetadas simultaneamente. Particularmente estudando o processo de domesticação, Doebley et al. (1997) demonstrou que a maioria das alterações anatômicas selecionadas durante a domesticação do milho é determinada pela modificação do padrão de expressão gênica de apenas alguns loci regulatórios. Em tomate é possível reconstruir uma história semelhante. S. lycopersicum foi domesticado provavelmente no México pelas civilizações pré-colombianas (Jenkins 1948, Rick 1995) onde foram selecionadas e acumuladas mutações em diversos loci associados com "frutos grandes", dando origem às variedades atuais (MacArthur e Butler 1938, Banerjee e Kalloo 1989). Neste sentido, um exemplo deste processo é o gene fw2.2 que codifica para um repressor da divisão celular durante o desenvolvimento do fruto. Os alelos associados a "frutos grandes" são menos transcritos, devido a diferenças na região promotora, promovendo o maior crescimento (Frary et al. 2000, Cong et al. 2002).

Neste trabalho, dos $146.349 \mathrm{pb}$ sequenciados de S. pennellii, $97.158 \mathrm{pb}$ puderam ser comparados com S. lycopersicum. Ao longo dessa região, 15 genes foram anotados e para 10 deles foi possível realizar análises evolutivas. Todos os genes apresentam seleção purificadora entre as espécies de tomateiro e $A$. thaliana, indicando uma função conservada evolutivamente. Pelo contrario, ao comparar ambas as espécies de tomate, sete genes não estão sob seleção purificadora. Interessantemente, de acordo aos argumentos acima expostos, cinco deles possuem funções relacionadas à regulação da expressão gênica segundo a categorização do MapMan ontology (Urbanczyk-Wochniak et al. 2006). Aos outros dois genes não foi possível outorga-lhes nenhuma função conhecida. $\mathrm{O}$ acúmulo de polimorfismos nas regiões codificantes destes genes reforça a hipótese de que mudanças nos padrões de regulação gênica são as principais responsáveis pelas inovações evolutivas entre S. lycopersicum e S. pennellii (Nesbitt e Tanksley 2002).

Analisando quatro loci e utilizando uma taxa de substituição de $6,03 \times 10^{-9}$, um trabalho determinou que S. lycopersicum e S. pennellii divergiram a 7,0 MYA (Nesbitt e Tanksley 2002). Recentemente, Wang et al. (2008) analisaram um fragmento conservado e não duplicado no genoma de cinco espécies de Solanaceae (petúnia, pimenta, berinjela, batata e tomate). O resultado deste trabalho indica que o ancestral dessas espécies viveu a aproximadamente 31,2 MYA, e que a divergência entre tomate e batata ocorreu a 6,2 MYA. No presente estudo, um cálculo mais exato, utilizando taxas de substituições específicas e distâncias genéticas permitiu estimar que S. lycopersicum e S. pennellii divergiram a 2,7 MYA. Uma vez que $S$. pennellii é uma das espécies selvagens mais distantes de $S$. lycopersicum, os resultados aqui apresentados indicam que as espécies da seção Lycopersicon 46 
divergiram antes do que havia sido estimado. É interessante mencionar que a presença de elementos de transposição diferenciais ao longo da região genômica ortóloga sugere que a inserção desses elementos foi posterior à divergência entre as espécies.

Além da análise evolutiva, este trabalho permitiu identificar um novo possível gene candidato para as alterações no conteúdo de aminoácido observadas. A S-adenosil-L-metionina-carboxil metiltransferase atua transferindo grupos metil, a partir da S-adenosilmetionina (SAM), a diversas moléculas biológicas como ácido salicílico, ácido jasmônico e ácido indolacético (Seo et al. 2001, Zhao et al. 2008). Assim, estudos funcionais deverão ser desenvolvidos com o intuito de verificar o envolvimento dessa enzima no metabolismo de aminoácidos. Não foram encontrados rearranjos na região estudada, no entanto a existência de polimorfismos, tanto nas regiões codificantes como nas não-codificantes, permitem postular que sejam essas as responsáveis pelas mudanças fenotípicas observadas.

É oportuno mencionar que além da importância per se da informação gerada, as sequencias produzidas auxiliaram a montagem tanto do genoma de S. lycopersicum recentemente publicado (The Tomato Genome Consortium 2012), assim com para o de S. pennellii que se encontra em andamento (Usadel, Fernie e Carrari, dados não publicados). 


\section{CONCLUSÕES}

Foi sequenciada uma região genômica do cromossomo 7 de S. pennellii correspondente a 146 $\mathrm{Kb}$, das quais $97 \mathrm{~Kb}$ puderam ser comparados com S. lycopersicum. Essa análise nos permitiu concluir que na região analisada existe um alto grau de sintenia entre as duas espécies, uma vez que a ordem e orientação dos genes estão conservadas. Ainda, foi possível identificar nessa região polimorfismos nas putativas regiões regulatórias dos genes, polimorfismos de aminoácidos nas proteínas codificadas e a presença de elementos de transposição diferenciais, além de um novo gene candidato que não havia sido descrito anteriormente por Bermúdez et al. (2008). Por fim, os dados permitiram a datação da divergência entre $S$. pennellii e $S$. lycopersicum em 2,7 milhões de anos. Pela abordagem adotada se trata da estimativa mais exata calculada até o momento.

Todos os resultados deste capítulo formam parte do artigo Kamenetzky et al. (2010) (Anexo I). 


\section{REFERÊNCIAS BIBLIOGRÁFICAS}

Altschul, S.F., Madden, T.L., Schaffer, A.A., Zhang, J., Zhang, Z., Miller, W., Lipman, D. J. (1997). Gapped BLAST and PSLBLAST: a new generation of protein database search programs. Nucleic acids research, 25, 3389-3402.

Bell, C.D., Soltis, D.E., Soltis, P. S. (2005). The age of the angiosperms: a molecular timescale without a clock. Evolution, 59, 1245-1258.

Banerjee, M.K., Kalloo, G. (1989). Role of phenols in resistance to tomato leaf curl virus, Fusarium wilt and fruit borer in Lycopersicon. Current Science, 58, 575-576

Bermúdez, L., Urias, U., Milstein, D., Kamenetzky, L., Asis, R., Fernie, A.R., Van Sluys, M.A., Carrari, F., Rossi, M. (2008). A candidate gene survey of quantitative trait loci affecting chemical composition in tomato fruit. Journal of Experimental Botany, 59, 2875-2890.

Brautigam, A. e Gowik, U. (2010). What can next generation sequencing do for you? Next generation sequencing as a valuable tool in plant research. Plant Biology 12, 831-841.

Chen, K.Y., Cong, B., Wing, R., Vrebalov, J., Tanksley, S. D. (2007). Changes in regulation of a transcription factor lead to autogamy in cultivated tomatoes. Science (New York, N.Y.), 318, 643-5.

Cong, B., Liu, J., Tanksley, S. D. (2002). Natural alleles at a tomato fruit size quantitative trait locus differ by heterochronic regulatory mutations. Proceedings of the National Academy of Sciences , 99, 13606-13611.

Doebley, J., Stec, A., Hubbard, L. (1997). The evolution of apical dominance in maize. Nature, 386, 485488.

Ewing, B. e Green, P. (1998). Base-calling of automated sequencer traces using Phred . II . error probabilities. Genome Research, 8, 186-194.

Frary, A., Nesbitt, C.T., Frary, A., Grandillo, S., van der Knaap, E., Cong, B., Liu, J., Meller, J., Elber, R., Alpert, K.B., et al. (2000). fw2.2: A quantitative trait locus key to the evolution of tomato fruit size. Science, 289, 85-88.

Gordon, D., Abajian, C., Green, P. (1998). Consed: a graphical tool for sequence finishing. Genome research, 8, 195-202.

Heslop-Harrison, J.S. (2000). Comparative genome organization in plants: from sequence and markers to chromatin and chromosomes. The Plant cell, 12, 617-36.

Ilic, K., SanMiguel, P.J., Bennetzen, J.L. (2003). A complex history of rearrangement in an orthologous region of the maize, sorghum, and rice genomes. Proceedings of the National Academy of Sciences of the United States of America, 100, 12265-70.

Jenkins, J. (1948). The origin of the cultivated tomato. Economic Botany, 2, 379-392.

Kajihara, D., de Godoy, F., Hamaji, T.A., Blanco, S.R., Van Sluys, M.A., Rossi, M. (2012). Functional characterization of sugarcane Mustang domesticated transposases and comparative diversity in sugarcane, rice, maize and sorghum. Genetics and Molecular Biology. in press.

Kamenetzky, L., Asís, R., Bassi, S., de Godoy, F., Bermúdez, L., Fernie, A.R., Van Sluys, M.A., Vrebalov, J., Giovannoni, J.J., Rossi, M., et al. (2010). Genomic analysis of wild tomato introgressions determining metabolism- and yield-associated traits. Plant physiology, 152, 1772-86.

Kumar, S., Tamura, K., Nei, M. (2004). MEGA3: integrated software for molecular evolutionary genetics analysis and sequence alignment. Briefings in bioinformatics, 5, 150-63.

Magallóon, S. A. e Sanderson, M. J. (2005). Angiosperm divergence times: the effect of genes, codon positions, and time constraints. Evolution, 59, 1653-1670.

Macarthur, J.W. e Butler, L. (1938). Size inheritance and geometric growth processes in the tomato fruit. Genetics, 23, 253-268.

Mueller, L.A., Solow, T.H., Taylor, N., Skwarecki, B., Buels, R., Binns, J., Lin, C., Wright, M.H., Ahrens, R., Wang, Y., et al. (2005). The SOL Genomics Network . A comparative resource for Solanaceae biology and beyond 1. Bioinformatics, 138, 1310-1317.

Muse, S.V. e Gaut, B.S. (1994). A likelihood approach for comparing synonymous and nonsynonymous nucleotide substitution rates, with application to the chloroplast genome. Molecular biology and evolution, 11, 715-24. 
Nesbitt, T.C. e Tanksley, S.D. (2002). Comparative sequencing in the genus Lycopersicon. Implications for the evolution of fruit size in the domestication of cultivated tomatoes. Genetics, 162, 365-79.

The Potato Genome Sequencing Consortium. (2011) Genome sequence and analysis of the tuber crop potato. Nature, 475, 189-95.

Quimbaya, M., Vandepoele, K., Raspé, E., Matthijs, M., Dhondt, S., Beemster, G., Berx, G., and De Veylder, L. (2012). Identification of putative cancer genes through data integration and comparative genomics between plants and humans. Cellular and Molecular Life Sciences, 69, 1-15.

Rensink, W.A., Lee, Y., Liu, J., lobst, S., Ouyang, S., Buell, C.R. (2005). Comparative analyses of six solanaceous transcriptomes reveal a high degree of sequence conservation and species-specific transcripts. BMC genomics, 6 .

Rick, C.M. (1995). Tomato (Lycopersicon esculentum), p. 452-457. In: J. Smartt and N.W. Simmonds (eds.). Evolution of Crop Plants, 2nd Edition, Longman, London.

Rozas, J., Sanchez-DelBarrio, J.C., Messeguer, X., Rozas, R. (2003). DnaSP, DNA polymorphism analyses by the coalescent and other methods. Bioinformatics, 19, 2496-2497.

Salamov, A.A. e Solovyev, V.V. (2000). Ab initio gene finding in drosophila genomic DNA. Genome Research, 10, 516-522.

Salse, J., Abrouk, M., Murat, F. (2009). Improved criteria and comparative genomics tool provide new insights into grass paleogenomics. Briefings in Bioinformatics, 10, 619-630.

Schauer, N., Semel, Y., Roessner, U., Gur, A., Balbo, I., Carrari, F., Pleban, T., Perez-Melis, A., Bruedigam, C., Kopka, J., et al. (2006). Comprehensive metabolic profiling and phenotyping of interspecific introgression lines for tomato improvement. Nature biotechnology, 24, 447-54.

Seo, H.S., Song, J. T., Cheong, J.J., Lee, Y.H, Lee, Y.W, Hwang, I., Lee, J. S., and Choi, Y. D. (2001). Jasmonic acid carboxyl methyltransferase : A key enzyme for jasmonate-regulated plant responses. PNAS, 98, 4788-4793.

Song, C., Wang, Y. (2010). Microsynteny analysis of tomato and peach genome. Yi Chuan, 32, 966-73.

Stanke, M., Steinkamp, R., Waack, S., Morgenstern, B. (2004). AUGUSTUS: a web server for gene finding in eukaryotes. Nucleic acids research, 32, 309-312.

Tanksley, S.D., Ganal, M.W., Prince, J.P., de Vicente, M.C., Bonierbale, M.W., Broun, P., Fulton, T.M., Giovannoni, J.J., Grandillo, S., Martin, G.B. (1992). High density molecular linkage maps of the tomato and potato genomes. Genetics, 132, 1141-60.

The Tomato Genome Consortium (2012). The tomato genome sequence provides insights into fleshy fruit evolution. Nature, 485, 635-641.

Thompson, J.D., Higgins, D.G., Gibson, T.J. (1994). CLUSTAL W: improving the sensitivity of progressive multiple sequence alignment through sequence weighting, position-specific gap penalties and weight matrix choice. Nucleic acids research, 22, 4673-80.

Tieman, D.M., Zeigler, M., Schmelz, E.A., Taylor, M.G., Bliss, P., Kirst, M., Klee, H.J. (2006). Identification of loci affecting flavour volatile emissions in tomato fruits. Journal of experimental botany, 57, 887-96.

Urbanczyk-Wochniak, E., Usadel, B., Thimm, O., Nunes-Nesi, A., Carrari, F., Davy, M., Bläsing, O., Kowalczyk, M., Weicht, D., Polinceusz, A., et al. (2006). Conversion of MapMan to allow the analysis of transcript data from Solanaceous species: effects of genetic and environmental alterations in energy metabolism in the leaf. Plant molecular biology, 60, 773-92.

Wang, R.L., Stec, A., Hey, J., Lukens, L., Doebley, J. (1999). The limits of selection during maize domestication. Nature, 398, 236-239.

Wang, Y., Diehl, A., Wu, F., Vrebalov, J., Giovannoni, J., Siepel, A., Tanksley, S. D. (2008). Sequencing and comparative analysis of a conserved syntenic segment in the Solanaceae. Genetics, 180, 391408.

Windsor, A.J. e Mitchell-Olds, T. (2006). Comparative genomics as a tool for gene discovery. Current opinion in biotechnology, 17, 161-7.

Zamir, D. e Tanksley, S.D. (1988). Tomato genome is comprised largely of fast-evolving, low copynumber sequences. Molecular and General Genetics MGG, 213, 254-261.

Zhao, N., Ferrer, J.L., Ross, J., Guan, J., Yang, Y., Pichersky, E., Noel, J. P., Chen, F. (2008). Structural , biochemical, and phylogenetic analyses suggest that indole-3-acetic acid methyltransferase is an evolutionarily ancient member of the SABATH family. Society, 146, 455-467. 


\section{CAPÍtulo II: CARACTERIZAÇÃo E ESTUdo FUNCIONAL DO GENE LFP}




\section{INTRODUCÃO}

Em 2006, Schauer et al. utilizando GC-MS realizaram uma extensa caracterização metabólica de frutos das 76 linhagens introgredidas de S. pennellii desenvolvidas por Eshed e Zamir (1995). Esse estudo resultou na identificação de 889 QTL para metabólitos em frutos de tomateiro. Em particular, na região do bin $\mathrm{H}$ do cromossomo 7 foram descritas alterações para o conteúdo de alanina, $\beta$-alanina, GABA, lisina, metionina, treonina, homoserina, leucina, isoleucina, glicina, serina, valina e glicose-6-P.

Por meio da abordagem de genes candidatos, Bermúdez et al. (2008) identificaram 7 genes candidatos colocalizados com os QTL descritos. Entre eles foi identificado o lócus Solyc07g065180 (Unigene U580355, SOL Genomics Network) cuja proteína predita apresentou 70 \% de identidade com a proteína codificada pelo gene At1g50575 de A. thaliana, o qual está anotado na base de dados TAIR (The Arabidopsis Information Resource) como uma putativa lisina descarboxilase (LDC). As LDC são enzimas que atuam na biossíntese de poliaminas (PAs) na conversão de lisina em cadaverina. Pela estreita relação entre a biossíntese de PAs e o metabolismo de aminoácidos o lócus Solyc07g065180 se apresentou como um forte candidato responsável pelos QTL para o conteúdo de aminoácidos mapeados na região 7H do genoma do tomateiro (Mattoo e Handa 2008).

As PAs são aminas alifáticas encontradas em todos os organismos vivos com exceção de duas ordens de Archaea, Methanobacteriales e Halobacteriales. Este alto grau de conservação reforça a importância destes compostos para a supervivência celular, mas, por outro lado, sugere a ausência de uma função específica (Wallace et al. 2003). As PAs mais comuns são a tetramina espermina (Spm), a triamina espermidina (Spd) e as diaminas putrescina (Put) e cadaverina (Cad) (Figura 1).

Em plantas, as PAs estão localizadas no vacúolo, mitocôndria e em cloroplastos, em particular nos tilacóides (Kummar 1997). Diferentes estudos demonstraram a participação das PAs em diversos processos fisiológicos como: organogênese, embriogênese, senescência folhar, desenvolvimento e amadurecimento de frutos e, respostas a estresses bióticos e abióticos (Galston 1983, Galston e KaurSawhney, 1990; Kumar et al. 1997; Walden et al. 1997; Marco et al. 2011, Alcázar et al. 2010). De acordo com Drolet et al. (1986), as PAs podem também atuar na estabilização molecular da membrana plasmática.

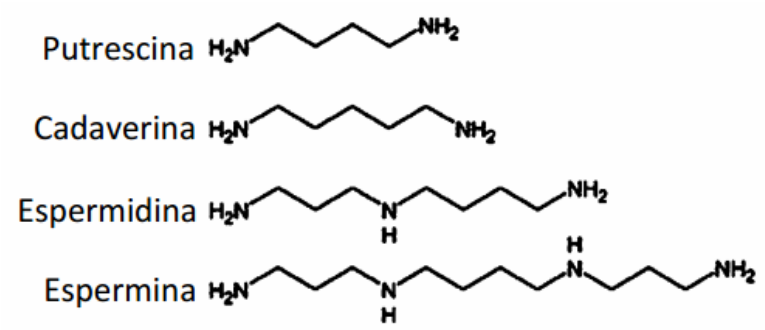

Figura 1: Estrutura das poliaminas. 
Embora a Spm tenha sido descrita por Antonie van Leeuwenhoek em 1674 em amostras de sêmen humano (Bachrach 2010), a rota biossintética das PAs começou a ser dilucidada apenas a partir da década de 1970. Em 1972, Ono et al. fizeram os primeiros estudos de purificação de ornitina descarboxilase (ODC) em ratos, mas foi somente em 1984 que o gene de camundongo foi clonado (McConlogue et al.1984).

Entretanto, as bases moleculares das funções da PAs in vivo continuam obscuras (Cohen 1988). Foi proposto que o mecanismo de ação seja por meio da interação com componentes celulares como a cromatina, a maquinaria transcricional e traducional, e macromoléculas (proteínas, RNA e DNA) (Handa e Matoo 2010, Liquori et al.1967, Cohen et al. 1969). Neste sentido, existem evidencias de que alterações no metabolismo de PAs resultam em alterações no padrão de expressão gênica. Por exemplo, tomates transgênicos que sobre-expressam a espermidina sintase apresentam elevado conteúdo de Spd, assim como maiores níveis de licopeno como consequência da ativação transcricional dos genes de biossíntese de carotenoides (Neily et al. 2011).

Algumas evidências indicam que as poliaminas atuam de forma conjunta com outros grupos de fitohormônios, particularmente com as citocininas; no entanto pouco se conhece sobre a existência de um crosstalk entre ambas as rotas de sinalização. Já foi reportado que as citocininas afetam a biossíntese e conteúdo das PAs (Galston 1983, Sergiev et al. 1995). Neste sentido, Galston (1983) sugeriu que as poliaminas poderiam funcionar como mensageiros secundários das citocininas. Em 2009, experimentos com Dendrobium huoshanense mostraram que a aplicação exógena de Spm ou Put levava a um incremento da relação citocinina/auxina. Adicionalmente, foi verificado que as PAs inibem a atividade da citocinina oxidase ao mesmo tempo em que aumentam a atividade da acido índole acético oxidase, enzimas responsáveis pela degradação de citocinina e auxinas, respectivamente, alterando assim a taxa citocinina/auxina (Wang et al. 2009).

A respeito da biossíntese, estudos sugerem que as plantas adquiriram a rota biossintética de PAs da cianobactéria ancestral precursora dos cloroplastos (Illingworth et al. 2003). Nas plantas, a produção destes compostos se inicia com a formação de Put, que em animais e fungos é formada a partir da ornitina pela ornitina descarboxilase (ODC). Nas plantas e bactérias existe uma segunda via de formação de Put, usando como precursor a arginina, em uma reação promovida pela arginina descarboxilase (ADC). A formação dessa diamina serve como precursor para a formação da triamina (Spd) e tetramina (Spm). Esses compostos são formados pela sucessiva adição de grupos aminopropil, derivados da descarboxilação da S-adenosilmetionina (SAM), pela espermidina sintase e espermina sintase. Por sua vez, como mencionado anteriormente, a cadaverina se origina a partir da descarboxilação da lisina, reação catalisada pela LDC (Figura 2) (Alcázar et al. 2010). Nas leguminosas, foi descrita uma rota alternativa de síntese desta poliamina a partir da homoarginina via homoagmatina, metabólitos que estão presentes durante a germinação das sementes (Smith 1977). Devido à utilização de SAM como substrato para biossíntese de algumas PAs, essa via adquiriu uma importância diferencial 
em plantas com frutos climatéricos como tomate, uma vez que a via de síntese de etileno compartilha esse substrato. Diversos estudos mostram que o aumento na produção destes fitohormônios resulta também em um incremento de etileno (Mehta et al. 2002). Por sua vez, quando a produção de etileno esta reduzida, a SAM seria direcionada para a produção de PAs, mas quando a produção de etileno aumenta, a síntese de SAM é estimulada sugerindo que as duas vias não necessariamente competem pelo substrato (Van de Poel et al. 2012).

As PAs são catabolizadas oxidativamente por aminas oxidases, grupo de enzimas que inclui a poliamina sintase e a diamina sintase. Essa via de degradação é crucial para a regulação do nível intracelular desses compostos (Wimalasekera et al. 2011). Entretanto, especula-se que no caso das Solanaceae o nível desses compostos seja regulado principalmente pela biossíntese e por meio de sua associação a outras moléculas (Rastogi e Davis 1990).

Na célula, as PAs podem estar em sua forma livre ou conjugada. Quando conjugadas, esses compostos podem estar ligados a macromoléculas como proteínas ou até ao próprio DNA (KaurSawhney et al. 2003). Também, foi verificada a conjugação de PAs a ácidos fenólicos (ex. p-cumárico, ferúlico ou caféico) por meio da ligação covalente entre o grupo amina e o grupo carboxílico dos ácidos. Os produtos derivados desta reação são chamados de amidas de ácidos hidroxicinâmicos (HCAAs) (Martin-Tanguy 1997, Fontaniella et al. 2001, 2003). Diversas enzimas responsáveis por essas ligações já foram descritas, por exemplo, a enzima putrescina hidroxicinamoil transferase (PHT) a qual foi isolada de células de tabaco em suspensão, atua na síntese de cafeoilputrescina (Negrel 1989). As enzimas espermina e espermidina hidroxicinamoil transferases que conjugam ácido hidroxicinâmicos a Spm e Spd, respectivamente, também já foram isoladas (Hedberg et al. 1996). As HCAAs têm sido associadas a processos de crescimento e desenvolvimento de plantas, como iniciação da floração (Martin-Tanguy 1997), além de participarem em respostas de defesa a patógenos (Walters 2003).

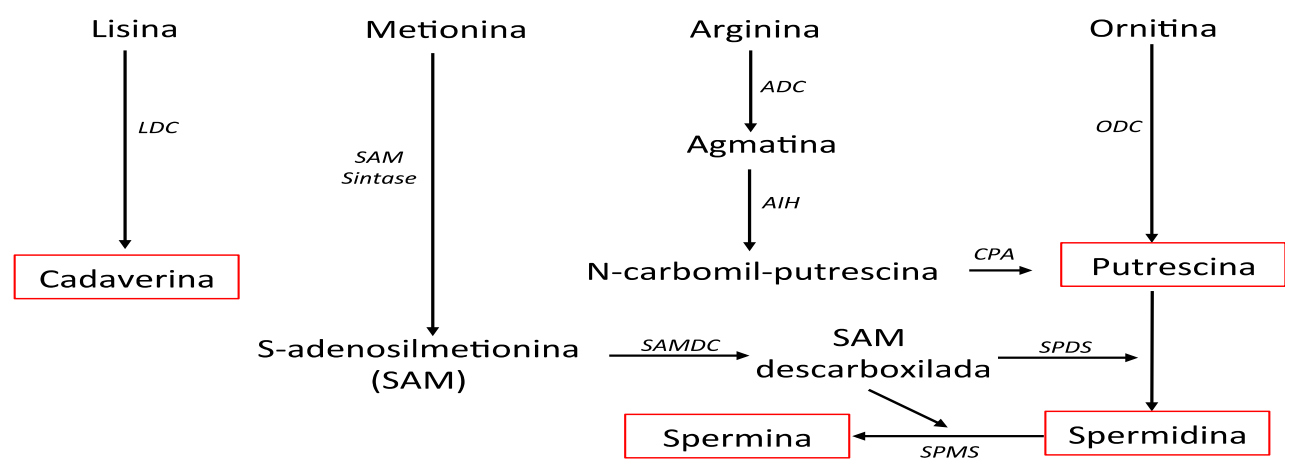

Figura 2: Rota biossintética das poliaminas.

As poliaminas estão assinaladas com um quadrado vermelho. As enzimas que participam da rota biossintética estão em itálico e suas abreviações são: LDC - lisina descarboxilase, ADC - arginina descarboxilase, AIH - agmatina imunohidrolase, ODC - ornitina descarboxilase, CPA - N-carbomil-putrescina aminohidrolase, SAMDC - SAM descarboxilase, SPDS - espermidina sintase, SPMS - espermina sintase. Adaptado de Wimalasekera et al. (2011).

A cadaverina é a PA menos estudada e sua atividade foi associada à indução da divisão celular em explantes de parênquima de tubérculos dormentes de Helianthus tuberosus (Bagni et al. 1993). A 
partir de estudos funcionais em Lupinus polyphyllus, tremoceiro, foi verificado que a enzima responsável pela síntese de cadaverina, a LDC, atua no cloroplasto, junto à síntese de aminoácidos e dos alcaloides derivados dela (Hartamann et al.1980).

Em bactérias, é proposto que existam dois genes para a LDC, enquanto que para Arabdopsis thaliana foram identificados três putativos genes parálogos (Ohe et al. 2008). No entanto, recentemente, foi descoberto que em A. thaliana não existe atividade de LDC. Consequentemente, esses três genes, e por analogia o lócus de tomate Solyc07g065180 que colocaliza com os QTL para aminoácidos, não codificariam LDCs (Bunsupa et al. 2012). Em contra partida, em tomate já foi identificada a presença de cadaverina em algumas variedades (Villanueva e Adlakha 1978, Saftner e Baldi 1990).

Desta forma, após o estudo funcional realizado neste trabalho sobre o gene Solyc07g065180, o mesmo foi nomeado como LFP (Low Free Putrecine). Os resultados sugerem que LFP está envolvido no metabolismo de PAs, mais precisamente no de putrescina desempenhando uma função ainda não caracterizada em plantas. 


\section{OBJETIVOS}

O objetivo geral deste capítulo foi realizar a caracterização estrutural e funcional do gene LFP (Low Free Putrecine). Assim, foram propostos os seguintes objetivos específicos:

- Analisar da estrutura gênica e realizar um estudo filogenético;

- Estudar o perfil transcricional dos alelos de S. pennellii e S. lycopersicum;

- Estudar a atividade transcricional dos promotores dos alelos de S. pennellii e S. lycopersicum;

- Estudar a localização subcelular da proteína e;

- Avaliar o efeito do silenciamento gênico por RNA de interferência. 


\section{MATERIAL E MÉTODOS}

\subsection{Material vegetal}

As sementes da espécie Solanum lycopersicum (cv. M82 e Moneymaker) e da linhagem introgredida IL 7-1 foram gentilmente cedidas pelo Tomato Genetic Resource Center (http://tgrc.ucdavis.edu). As sementes de Nicotiana benthamiana foram obtidas do Instituto de Biotecnologia do INTA - Argentina. As plantas de tomateiro e N. benthamiana foram crescidas em casa de vegetação, em potes de 20 e 1 I, respectivamente, contendo terra vegetal e vermiculita (1:1). As condições da casa vegetação foram: fotoperíodo de $16 / 8 \mathrm{~h}$, temperatura de $24 \pm 3{ }^{\circ} \mathrm{C}, 60 \%$ umidade e fotoirradiância de $140 \pm 40 \mu \mathrm{mol} m-2 \mathrm{~s}-1$.

\subsection{Cepas bacterianas e plasmídeos}

Escherichia coli: Foram utilizadas as cepas DH5 $\alpha$, DH10â e DB3.1. Todos os cultivos foram realizados em meio LB (meio de Luria-Delbrück). A temperatura de crescimento foi de $37^{\circ} \mathrm{C}$ e nos casos de cultivo líquido a agitação foi de 200 rpm. Para a transformação das cepas com o vetor plasmidial, foi adicionado o antibiótico de seleção adequado ao meio de cultivo.

Agrobacterium tumefaciens: Foram utilizadas as cepas GV3101 e GV2260. GV3101 possui resistência a rifampicina $(25 \mathrm{mg} / \mathrm{l})$ e gentamicina $(50 \mathrm{mg} / \mathrm{l})$ e foi utilizada para experimentos de expressão transitória. GV2260 é resistente a rifampicina (25 mg/l) (Hoeckema et al. 1983) e foi utilizada para a transformação estável. As bactérias foram cultivadas em meio LB com antibiótico a uma temperatura de $28{ }^{\circ} \mathrm{C}$ e nos casos de cultivo líquido a agitação foi de $200 \mathrm{rpm}$.

Plasmídeos: Os vetores utilizados para os diferentes métodos experimentais estão listados na Tabela 1. 
Tabela 1. Vetores utilizados.

\begin{tabular}{|c|c|c|c|c|}
\hline Vetores & $\begin{array}{c}\text { Resistência em } \\
\text { bactéria }\end{array}$ & $\begin{array}{l}\text { Resistência } \\
\text { em plantas }\end{array}$ & Características & Origem \\
\hline pENTR/D-TOPO & canamicina & & $\begin{array}{l}\text { Vetor linearizado com sítio de clonagem } \\
\text { direcional para produtos de PCR. Possui } \\
\text { os sítios attL1 e attL2 para recombinação } \\
\text { sítio-específica do clone de entrada com } \\
\text { um vetor destino no sistema Gateway }{ }^{\circledR} \text {. }\end{array}$ & Invitrogen \\
\hline pK7FWG2 & $\begin{array}{l}\text { espectinomicina } \\
\text { estreptomicina }\end{array}$ & canamicina & $\begin{array}{l}\text { Vetor binário que possui o promotor } 35 S \text {, } \\
\text { sítios attR1 e attR2, para recombinação } \\
\text { sítio-específica no sistema Gateway }{ }^{\circledR} \text {, } \\
\text { para fusão da proteína de interesse a } \\
\text { GFP (Green Fluorescent Protein) e } \\
\text { terminador 35S. }\end{array}$ & $\begin{array}{c}\text { Karimi et al. } \\
\text { (2002) }\end{array}$ \\
\hline pHGWFS7 & $\begin{array}{l}\text { espectinomicina } \\
\text { estreptomicina }\end{array}$ & higromicina & $\begin{array}{l}\text { Vetor binário que possui sítios attR1 e } \\
\text { attR2 para recombinação sitio-especifica } \\
\text { no sistema Gateway }{ }^{\circledR} \text { para região } \\
\text { promotora putativa seguida pelos genes } \\
\text { repórteres gfp (green fluorescent } \\
\text { protein) e gus ( } \beta \text {-glucuronidase) e } \\
\text { terminador 35S. }\end{array}$ & $\begin{array}{c}\text { Karimi et al. } \\
\text { (2002) }\end{array}$ \\
\hline p7GWIWG2(I) & $\begin{array}{l}\text { espectinomicina } \\
\text { estreptomicina }\end{array}$ & canamicina & $\begin{array}{l}\text { Vetor binário que possui o promotor } 35 \mathrm{~s} \text {, } \\
\text { um íntron flanqueado por sítios attR1 e } \\
\text { attR2, para recombinação sítio-específica } \\
\text { no sistema Gateway }{ }^{\circledR} \text {, e terminador } 35 S \text {. } \\
\text { Viabiliza a inserção do mesmo fragmento } \\
\text { gênico em ambas as orientações } \\
\text { permitindo a formação de uma estrutura } \\
\text { de alça. }\end{array}$ & $\begin{array}{c}\text { Karimi et al. } \\
\text { (2002) }\end{array}$ \\
\hline pHGWFS735S & $\begin{array}{l}\text { espectinomicina } \\
\text { estreptomicina }\end{array}$ & canamicina & pHGWFS7 contendo o promotor 35S. & $\begin{array}{l}\text { Karimi et al. } \\
\quad(2002)\end{array}$ \\
\hline
\end{tabular}

\subsection{Obtenção das sequências dos alelos do gene LFP e análise da estrutura gênica}

A sequência completa do alelo de S. lycopersicum foi obtida do clone de BAC CO7HBa0184E04 (Projeto de Sequenciamento Internacional de Tomate) disponível na página da SGN (Sol Genomics Network, http://solgenomics.net/, Mueller et al. 2005). O alelo de S. pennellii foi clonado e sequenciado pelo nosso grupo, clone C07SpCP101P015.P5F03 (Capítulo I, Kamenetzky et al. 2010). As UTRs foram determinadas de acordo com o unigene de referência (U580355) disponível na página da SGN. A comparação das sequencias foi realizada com o auxílio do programa MULTALIN (http://www-archbac.upsud.fr/genomics/multalin.html, Corpet 1988). Foi realizada uma busca para identificar as sequências ortólogas por meio de uma análise usando o algoritmo BLASTP (Altschul et al. 1990) no banco de dados do NCBI. Os genes identificados foram utilizados para a construção de uma árvore filogenética com as sequências de aminoácidos utilizando o método Neighbor Joining e o modelo de análise JTT (JonesTaylor-Thorton) com o programa MEGA 5 (Tamura et al. 2011). A análise estatística foi realizada pelo método de bootstrap utilizando 1000 réplicas. Para todas as sequências proteicas foi predita a 
localização subcelular utilizando os programas TargetP 1.1 (http://www.cbs.dtu.dk/services/TargetP/) e ChloroP 1.1 (http://www.cbs.dtu.dk/services/ChloroP/).

\subsection{Perfil transcricional dos alelos de S. pennellii e S. lycopersicum}

\subsubsection{Material Vegetal}

Foram cultivados quatro indivíduos de S. lycopersicum (cv. M82) e da IL 7-1 dos quais foram coletadas amostras de folha fonte (segundo e terceiro folíolos da terceira folha totalmente expandida), folha dreno (folhas ainda em expansão), flor, caule, raiz, fruto verde (37 dias após antese) e fruto maduro (52 dias após antese). Os tecidos foram coletados sempre entre as 10 e 11 horas da manhã, e imediatamente congelados em nitrogênio liquido. Foram realizados dois experimentos independentes em anos diferentes (2008 e 2009).

\subsubsection{Extração de RNA}

O RNA foi purificado, a partir de $200 \mathrm{mg}$ de tecido moído em nitrogênio liquido, utilizando $1 \mathrm{ml}$ do reagente TRIZOL (Invitrogen). Após extração utilizando clorofórmio (0,2 V/V de TRIZOL), o acido nucleico foi precipitado utilizando isopropanol $(0,6 \mathrm{~V} / \mathrm{V}$ de solução). Finalmente, o RNA foi ressuspendido em $20 \mu \mathrm{l}$ de água 0,1 \% DEPC (livre da ação de RNase) e as amostras foram estocadas a $80^{\circ} \mathrm{C}$. A quantificação das amostras foi feita utilizando espectrofotômetro e a pureza da preparação foi estimada através razão entre as absorbâncias obtidas a 260nm e $280 \mathrm{~nm}$, amostras com razões acima de 1,8 foram consideradas puras.

\subsubsection{PCR em Tempo Real}

Aproximadamente $1 \mu \mathrm{g}$ de RNA foi tratado com $1 \mu$ de DNase (Invitrogen), e posteriormente foi realizada a síntese de cDNA utilizando a enzima SuperScript III Reverse Transcriptase (Invitrogen), segundo instruções do fabricante. Cada reação conteve $11 \mu \mathrm{l}$ do RNA tratado com DNase (aproximadamente $1 \mu \mathrm{g}$ ), 150ng de iniciadores OligoDT (Invitrogen) e 0,2 mM dNTPs. Após incubação a $65{ }^{\circ} \mathrm{C}$ por 5 minutos foi adicionado $1 \mathrm{X}$ tampão da enzima, $5 \mathrm{mM} \mathrm{DTT}$, 40 unidades de inibidor de RNase, RNaseOUT (Invitrogen) e 200 unidades da enzima SuperScript III RT. Essa reação foi incubada por 5 minutos a $25{ }^{\circ} \mathrm{C}, 50^{\circ} \mathrm{C}$ por 1 hora e, finalmente, $70^{\circ} \mathrm{C}$ por $15 \mathrm{~min}$. Para testar a pureza do cDNA (livre de DNA genômico), foi realizada uma PCR usando 0,2 mM de cada dNTPs, 0,2 mM de cada iniciador [ActinaUp (5'- TGGCATCATACCTTTTACAA -3') e ActinaLow (5'- TCCGGGCATCTGAACCTCT -3')], 1,5 mM de $\mathrm{MgCl}_{2}$ e 2,5 unidades de enzima TAQ polimerase ${ }^{\circledR}$ (Invitrogen,). O programa de amplificação utilizado foi de $94{ }^{\circ} \mathrm{C}$ por $3 \mathrm{~min} ; 35$ ciclos de $94{ }^{\circ} \mathrm{C}$ por $30 \mathrm{seg}, 55^{\circ} \mathrm{C}$ por $1 \mathrm{~min}, 72{ }^{\circ} \mathrm{C}$ por $1 \mathrm{~min}$; e uma extensão final 
a $72{ }^{\circ} \mathrm{C}$ por $10 \mathrm{~min}$. Os produtos da amplificação foram visualizados por eletroforese em gel de agarose 0,8\% em TBE 1/2X. Devido aos iniciadores ActinaUp e ActinaLow estarem flanqueando um íntron o produto de PCR obtido permite avaliar claramente a eventual contaminação da amostra com DNA. A reação de qPCR foi realizada com $1 \mu \mathrm{l}$ de uma diluição de cDNA 1:5, 0,2 mM de cada iniciador [LFP-FN (5'- CTATTAGATTGTACGACATGGTCCG -3') e LFP-RN (5'- CATGTAAGGTAACTCTCTGATGGTAAG - $3^{\prime}$ ) para o gene alvo, e EF-1 $\alpha$-up (5'- ATTGGAAACGGATATGCTCCA-3') e EF-1 $\alpha$-Low (5' - TCCTTACCTGAACGCCTGTCA $\left.-3^{\prime}\right)$ para o gene de referência] e 2x SYBR Green Master Mix (Applied Biosystems). Foi utilizado um termociclador 7500 PCR Real Time (Applied Biosystems) e o programa de amplificação foi de $95^{\circ} \mathrm{C}$ por 10 min e 40 ciclos de: $95^{\circ} \mathrm{C}$ por $15 \mathrm{seg}, 55^{\circ} \mathrm{C}$ por $1 \mathrm{~min}$ e $72{ }^{\circ} \mathrm{C}$ por $30 \mathrm{seg}$ (momento no qual ocorre a leitura do sinal emitido pelo SYBR Green). Os dados obtidos foram analisados com o software LinRegPCR (Ruijter et al., 2009) para calcular os valores de Ct (cycle threshold) e a eficiência da reação. A expressão relativa foi calculada segundo fórmula abaixo (Pfaffl et al., 2002) com o software fgStatistics (Di Rienzo, 2009). Para a análise estatística foi utilizado o mesmo software e aplicado o teste de Wilcoxon ( $<<0.05)$.

$$
\mathrm{ER}=\frac{\mathrm{Ef}_{\text {alvo }} \wedge \text { (média de } \mathrm{Ct} \text { do controle }- \text { média de } \mathrm{Ct} \text { da linhagem) }}{\mathrm{Ef}_{\text {ref }} \wedge \text { (média de } \mathrm{Ct} \text { do controle - média de } \mathrm{Ct} \text { da linhagem) }}
$$

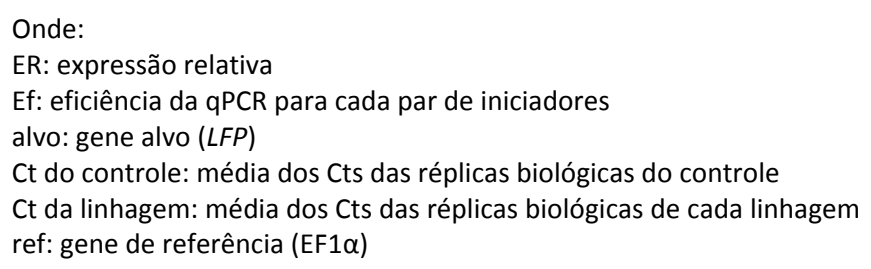

\subsection{Obtenção das construções para o estudo da atividade das regiões promotoras dos alelos de $S$. lycopersicum e S. pennellii}

Para a amplificação da região promotora dos alelos de S. pennellii e S. lycopersicum foi utilizado DNA genômico da IL 7-1 e da variedade M82, respectivamente, extraído segundo o protocolo do CIMMYT (2005). A reação de PCR foi realizada utilizando 100 ng de DNA molde, 0,2 mM de cada dNTPs, 0,2 mM de cada iniciador [PROM-LFP-F (5'- CACCGACGGCTCTGCAAGAGTTG -3') e PROM-LFP -R (5'GGAACAAAGCTCTCAACTTGG -3')], 1,5 mM de $\mathrm{MgCl}_{2}$, e 2,5 unidades de enzima TAQ polimerase ${ }^{\circledR}$ (Invitrogen). O programa de amplificação utilizado foi de $94{ }^{\circ} \mathrm{C}$ por $3 \mathrm{~min} ; 35$ ciclos de $94{ }^{\circ} \mathrm{C}$ por 30 seg, $50{ }^{\circ} \mathrm{C}$ por $30 \mathrm{seg}, 72{ }^{\circ} \mathrm{C}$ por $1 \mathrm{~min}$; e uma extensão final a $72{ }^{\circ} \mathrm{C}$ por $5 \mathrm{~min}$. Os fragmentos amplificados foram purificados utilizando o Kit GFX (Amersham Biosciences), de acordo com especificações do fabricante. Os fragmentos foram clonados no vetor de entrada pENTR/D-TOPO (Invitrogen) e posteriormente recombinados utilizando a enzima LR clonase (Invitrogen) no vetor binário de pHGWFS7 (Tabela 1). Os clones obtidos pHGWFS7LFPPromLyc e pKGWFS7LFPPromPen foram analisados por 
restrição com endonucleases e confirmados por sequenciamento. Após confirmação da identidade dos clones, os mesmos foram incorporados em A. tumefaciens cepa GV3101 segundo protocolo de Wen-Jun e Forde (1989).

\subsection{Obtenção da construção para estudo da localização subcelular da proteína LFP}

Tecido de folha fonte (segundo e terceiro folíolos da terceira folha totalmente expandida) de $S$. lycopersicum (cv. M82), foi processado em nitrogênio líquido e uma alíquota de $200 \mathrm{mg}$ foi submetida à extração de RNA total empregando-se o reagente Trizol (Invitrogen), segundo o protocolo recomendado pelo fabricante. Após extração com clorofórmio (0,2 V/V de TRIZOL), o ácido nucleico foi precipitado com isopropanol (0,6 V/V de solução). O RNA foi ressuspendido em $20 \mu \mathrm{l}$ de água 0,1\% DEPC (livre de RNase) e a amostra estocada a $-80{ }^{\circ} \mathrm{C}$. A quantificação das amostras foi feita utilizando espectrofotômetro e a pureza da preparação foi estimada através da razão entre as absorbâncias obtidas a $260 \mathrm{~nm}$ e $280 \mathrm{~nm}$, amostras com razões acima de 1,8 foram consideradas puras. Aproximadamente $1 \mu \mathrm{g}$ de RNA foi tratado com $1 \mu \mathrm{l}$ de DNase (Invitrogen), e posteriormente foi realizada a síntese de cDNA utilizando a enzima SuperScript III Reverse Transcriptase (Invitrogen), segundo instruções do fabricante. Cada reação conteve $11 \mu l$ do RNA tratado com DNase (aproximadamente $1 \mu \mathrm{g}$ ), 150ng de iniciadores OligoDT (Invitrogen) e 0,2 mM dNTPs. Após incubação a $65{ }^{\circ} \mathrm{C}$ por 5 minutos foi adicionado $1 \mathrm{X}$ tampão da enzima, $5 \mathrm{mM}$ DTT, 40 unidades de inibidor de RNase, RNaseOUT (Invitrogen) e 200 unidades da enzima SuperScript III RT. Essa reação foi incubada por 5 minutos a $25^{\circ} \mathrm{C}, 50^{\circ} \mathrm{C}$ por 1 hora e, finalmente, $70^{\circ} \mathrm{C}$ por $15 \mathrm{~min}$. Para testar a pureza do cDNA (livre de DNA genômico), foi realizada uma PCR usando 0,2 $\mathrm{mM}$ de cada dNTPs, 0,2 $\mathrm{mM}$ de cada iniciador ActinaUp (5'- TGGCATCATACCTTTTACAA -3') e ActinaLow (5'- TCCGGGCATCTGAACCTCT -3'), 1,5 mM de $\mathrm{MgCl} 2$ e 2,5 unidades de enzima TAQ polimerase ${ }^{\circledR}$ (Invitrogen). 0 programa de amplificação utilizado foi de $94{ }^{\circ} \mathrm{C}$ por $3 \mathrm{~min}$; 35 ciclos de $94{ }^{\circ} \mathrm{C}$ por $30 \mathrm{seg}, 55^{\circ} \mathrm{C}$ por $1 \mathrm{~min}, 72^{\circ} \mathrm{C}$ por $1 \mathrm{~min}$; e uma extensão final a $72{ }^{\circ} \mathrm{C}$ por $10 \mathrm{~min}$. Os produtos da amplificação foram visualizados por eletroforese em gel de agarose $0,8 \%$ em TBE $1 / 2 X$.

A amplificação do cDNA completo do gene foi realizada por PCR utilizando 50 ng de cDNA, 0,2 mM de cada dNTPs, 0,2 mM de cada iniciador [FUS-LFP-F (5'- CACCATGGGGTTTGCTGCAGATAG -3') e FUS-LFP-R (5'- ACCATGGTTAATTTTTAAATGTGC -3')], 1,5 mM de Mg2SO4 e 2 unidades de enzima Elongase ${ }^{\circledR}$ DNA polimerase (Invitrogen). O programa de amplificação utilizado foi de $94{ }^{\circ} \mathrm{C}$ por $3 \mathrm{~min} ; 35$ ciclos de $94{ }^{\circ} \mathrm{C}$ por $30 \mathrm{seg}, 53^{\circ} \mathrm{C}$ por $30 \mathrm{seg}, 68^{\circ} \mathrm{C}$ por $3 \mathrm{~min}$, e; uma extensão final a $68^{\circ} \mathrm{C}$ por $10 \mathrm{~min}$. $\mathrm{O}$ fragmento amplificado foi purificado utilizando o Kit GFX (Amersham Biosciences), de acordo com especificações do fabricante e clonado no vetor de entrada pENTR/D-TOPO (Invitrogen). Posteriormente, foi recombinado utilizando a enzima LR clonase (Invitrogen) no vetor binário de pK7FWG2 (Tabela 1). O clone obtido pK7FWG2LFPLyc foi analisado por restrição com endonucleases e 
confirmado por sequenciamento. Após confirmação da identidade, o clone foi inserido em $A$. tumefaciens cepa GV3101 segundo protocolo de Wen-Jun e Forde (1989).

\subsection{Obtenção da construção para avaliação do efeito do silenciamento gênico por RNA de interferência}

DNA plasmidial do clone contendo o alelo de S. lycopersicum do gene LFP (Bermúdez et al. 2008) foi purificado segundo Sambrook et al. (1989). Para a amplificação do fragmento para RNAi, foram usados $10 \mathrm{ng}$ de DNA molde, 0,2 mM de cada dNTPs, 0,2 mM de cada iniciador [LFPRNAi-F (5'CACCCTATTAGATTGTACGACATGGTCCG -3') e LFPRNAi-R (5'- CATGTAAGGTAACTCTCTGATGGTAAG -3')], 1,5 mM de $\mathrm{MgCl} 2$ e 2,5 unidades de enzima TAQ polimerase ${ }^{\circledR}$ (Invitrogen). O programa de amplificação utilizado foi de $94{ }^{\circ} \mathrm{C}$ por $3 \mathrm{~min}$; 35 ciclos de $94{ }^{\circ} \mathrm{C}$ por $30 \mathrm{seg}, 52{ }^{\circ} \mathrm{C}$ por $30 \mathrm{seg}, 72{ }^{\circ} \mathrm{C}$ por $1 \mathrm{~min}$; e uma extensão final a $72{ }^{\circ} \mathrm{C}$ por 10 min. O fragmento amplificado correspondente a 173 pb do éxon 4 foi purificado utilizando o Kit GFX (Amersham Biosciences), de acordo com especificações do fabricante. O fragmento foi clonado no vetor de entrada pENTR/D-TOPO (Invitrogen) e posteriormente recombinado utilizando a enzima LR clonase (Invitrogen) no vetor binário de p7GWIWG2(I) (Tabela 1). O clone obtido pK7GWIWG2(I)LFP foi analisado por restrição com endonucleases e confirmado por sequenciamento. Após confirmação da identidade, o clone foi inserido em A. tumefaciens cepa GV2260 segundo protocolo de Wen-Jun e Forde (1989).

3.8. Infiltração e ensaio histoquímico de folhas de $\boldsymbol{N}$. benthamiana para o estudo da atividade das regiões promotoras dos alelos de S. lycopersicum e S. pennellii

As células de $A$. tumefaciens cepa GV3101 contendo os plasmídeos pHGWFS7LFPPromPen e pHGWFS7LFPPromLyc foram cultivadas a $28^{\circ} \mathrm{C}$ durante 16 horas em $20 \mathrm{ml}$ de meio LB com rifampicina (25 $\mathrm{\mu g} / \mathrm{ml})$, espectinomicina $(50 \mu \mathrm{g} / \mathrm{ml})$ e gentamicina $(50 \mu \mathrm{g} / \mathrm{ml})$, até se obter uma densidade óptica (OD) a $600 \mathrm{~nm}$ de 0,5. Posteriormente, as células foram coletadas a $4000 \mathrm{rpm}$ por $10 \mathrm{~min}$ a temperatura ambiente e ressuspendidas em MES 10 mM com acetosiringona (100 mM). A suspensão foi incubada por quatro horas a temperatura ambiente e a infiltração foi realizada em plantas de seis semanas na superfície abaxial de folhas intermediárias com uma seringa de $1 \mathrm{ml}$ sem agulha. Três dias após a infiltração, as folhas foram retiradas e a atividade de $\beta$-glucuronidase foi identificada por meio de um ensaio histoquímico utilizando X-Glu (5-bromo-4-chloro-3-indolyl-ß-D-glucurónido) como substrato (McCabe et al. 1988). As folhas infiltradas foram incubadas em placas de Petri com um volume suficiente para cobrir o tecido com tampão de reação GUS [X-Glu (0,5 mg/ml), Na2PO4H2 (100 mM), EDTA (10 mM), K4Fe(CN)6.3H2O (5 mM), Triton X-100 (0,1\%), pH 7]. Posteriormente, foram incubadas a $37^{\circ} \mathrm{C}$ por 
$18 \mathrm{~h}$, tempo no qual foi detectada a presença de um precipitado azul no tecido. Para a melhor visualização e fixação do tecido, foram realizadas várias lavagens com etanol $70 \%$.

\subsection{Infiltração de folhas de $\boldsymbol{N}$. benthamiana para o estudo da localização subcelular da proteína LFP}

As células de $A$. tumefaciens cepa GV3101 contendo o plasmídeo pK7FWG2-LFPLyc foram cultivadas a $28{ }^{\circ} \mathrm{C}$ durante 16 horas em $20 \mathrm{ml}$ de meio LB com rifampicina $(25 \mu \mathrm{g} / \mathrm{ml}$ ), espectinomicina $(50 \mu \mathrm{g} / \mathrm{ml})$ e gentamicina $(50 \mu \mathrm{g} / \mathrm{ml})$, até se obter uma densidade óptica (OD) de 0,5 a $600 \mathrm{~nm}$. Posteriormente, as células foram coletadas a $4.000 \mathrm{rpm}$ por $10 \mathrm{~min}$ a temperatura ambiente e ressuspendidas em MES $10 \mathrm{mM}$ com acetosiringona (100 mM). A suspensão foi incubada por 4 horas a temperatura ambiente e a infiltração realizada em plantas de aproximadamente seis semanas na superfície abaxial de folhas intermediárias com uma seringa de $1 \mathrm{ml}$ sem agulha. Após $48 \mathrm{~h}$, as folhas infiltradas foram analisadas e fotografadas no microscópio de laser confocal Zeiss LSM 400, usando a objetiva de 63x. A linha de $488 \mathrm{~nm}$ do laser de Argon foi usada para excitar as partículas de GFP e a de $543 \mathrm{~nm}$ para clorofila. A emissão da fluorescência foi detectada a 505-550 nm para GFP e a acima de 590 $\mathrm{nm}$ para a clorofila. As imagens de cada plano foram tomadas em modo sequencial para evitar o cruzamento de espectros de ambos os fluoróforos. A configuração geral do microscópio foi ajustada para otimizar o contraste e a resolução de cada imagem individualmente.

\subsection{Obtenção de plantas transgênicas de tomateiro}

\subsubsection{Transformação genética}

A obtenção de linhagens transgênicas de S. lycopersicum (cv. Moneymaker), via Agrobacterium, foi realizada segundo o protocolo utilizado pelo Instituto de Biotecnologia do INTA Castelar, Argentina (http://www.inta.gov.ar/biotec/actividad/transformaciondeplantas.htm). As linhagens regeneradas foram micropropagadas em fluxo laminar horizontal (Nuaire, EUA) e mantidas em tubos de vidro de 2,5 $\mathrm{cm}$ de diâmetro e $10 \mathrm{~cm}$ de altura com meio de cultura MSS (sais Murashige-Skoog com 20\% sacarose), em câmaras de cultura a $22^{\circ} \mathrm{C}$, e fotoperíodo de $16 \mathrm{~h}$ claro (5000 lux) - $8 \mathrm{~h}$ escuro.

\subsubsection{Verificação da presença do transgene}

Para conferir a presença do transgene, DNA genômico das linhagens foi extraído segundo CIMMYT (2005) e foi realizada uma PCR usando $50 \mathrm{ng}$ de DNA molde, 0,2 mM de cada dNTPs, 0,2 mM de cada iniciador [35S-right (5'-CCCACTATCCTTCGCAAG-3') e 35S-left (5'- GCAGGTCACTGGATTTTGG-3')], 1,5 mM de $\mathrm{MgCl} 2$ e 2,5 unidades de enzima TAQ polimerase ${ }^{\circledR}$ (Invitrogen). O programa de amplificação 
utilizado foi de $94{ }^{\circ} \mathrm{C}$ por $3 \mathrm{~min}$; 35 ciclos de $94{ }^{\circ} \mathrm{C}$ por $30 \mathrm{seg}, 55^{\circ} \mathrm{C}$ por $1 \mathrm{~min}, 72{ }^{\circ} \mathrm{C}$ por $2 \mathrm{~min}$, e; uma extensão final a $72{ }^{\circ} \mathrm{C}$ por $10 \mathrm{~min}$. Os produtos amplificados foram verificados por eletroforese em gel de agarose $0,8 \%$ TBE $1 / 2 X$.

\subsubsection{Análise de expressão do gene $L F P$ nas linhagens transgênicas obtidas}

As linhagens crescidas in vitro em meio seletivo com antibiótico, para as quais foi confirmada a presença do transgene por PCR, foram levadas a casa de vegetação. Após quatro semanas, foram retiradas gemas vegetativas para sincronização das plantas com o respectivo controle. Uma vez que as plantas apresentavam oito folhas completamente expandidas, foram coletados o segundo e terceiro folíolos da terceira folha totalmente expandida para a análise do silenciamento por qPCR. A extração de RNA e posterior síntese de cDNA foram realizadas como descrito no item 3.4. A reação de qPCR foi realizada com $1 \mu \mathrm{l}$ de uma diluição de cDNA 1:5, 0,2 mM de cada iniciador [RNAitrans-LFP-F (5'GGTGGATGCTGTTGTGAGATG -3') e RNAitrans-LFP-R (5'- GCAAAGGAACAGGAAGTTGAG -3') para o gene alvo, e EF-1 $\alpha$-up (5'- ATTGGAAACGGATATGCTCCA-3') e EF-1 $\alpha$-Low (5'- TCCTTACCTGAACGCCTGTCA -3'), para o gene de referência] e 2X SYBR Green Máster Mix (Applied Biosystems). Foi utilizado um termociclador 7500 PCR Real Time (Applied Biosystems) e o programa de amplificação foi de $95{ }^{\circ} \mathrm{C}$ por 10 min e 40 ciclos de: $95^{\circ} \mathrm{C}$ por $15 \mathrm{seg}, 55^{\circ} \mathrm{C}$ por $1 \mathrm{~min}$ e $72{ }^{\circ} \mathrm{C}$ por $30 \mathrm{seg}$ (momento no qual ocorre a leitura do sinal emitido pelo SYBR Green). Os dados obtidos foram analisados como descrito no item 3.4.3.

\subsection{Caracterização fenotípica das linhagens transgênicas}

\subsubsection{Cultivo}

Três das linhagens que apresentaram a maior redução dos níveis de RNAm do gene LFP foram selecionadas para caracterização fenotípica: RNAi:LFP-11, RNAi:LFP-12, RNAi:LFP-14. Assim, foram estabelecidas seis réplicas de cada linhagem por meio de propagação por estaquia, em fevereiro de 2011. Após 12 semanas, foi realizada uma coleta no período das $10 \mathrm{~h}$ às $14 \mathrm{~h}$ onde foi coletado o segundo e terceiro folíolo da terceira folha totalmente expandida e amostras de pericarpo de frutos verdes e maduros.

\subsubsection{Parâmetros de crescimento}

Após seis meses as plantas foram coletadas destrutivamente. Foram tomados os pesos frescos e secos de caule e folha. Esses parâmetros foram usados para o calculo de biomassa (parte aérea da 
planta), da porcentagem de água e do índice de colheita, que foram calculados segundo as seguintes fórmulas:

Índice de colheita $=$ (peso fresco total de frutos verdes e maduros $) * 100 /$ biomassa.

Porcentagem de água $=($ massa fresca-massa seca $) /$ massa fresca*100

\subsubsection{Verificação do nível de silenciamento nas linhagens transgênicas}

Uma nova verificação do nível de silenciamento do gene $L F P$ foi realizada para as seis réplicas de cada linhagem selecionada. Foram testadas por qPCR amostras de folhas fonte e fruto maduro segundo descrito no item 3.10.3.

\subsubsection{Medição dos parâmetros fotossintéticos}

As medidas de trocas gasosas e fluorescência da clorofila foram realizadas com o sistema portátil Licor-6400 (Li-Cor; www.licor.com) que consiste em um sistema aberto contendo um analisador de gases por infravermelho (IRGA) e uma câmara fluorimétrica acoplada (Modelo 6400-40, Li-Cor).

As medidas foram realizadas no segundo folíolo da primeira folha totalmente expandida de plantas em estado vegetativo, no período das $10 \mathrm{~h}$ às $14 \mathrm{~h}$. Antes de realizar as medições, as folhas a serem analisadas passaram por um processo de adaptação a escuridão durante no mínimo 30 min. Foram realizadas curvas de resposta à luz com uma câmara que possui uma área de exposição foliar de 2 $\mathrm{cm}^{2}$, as condições padrão para as medições foram de 400 PPM de $\mathrm{CO} 2$ e temperatura foliar de $25^{\circ} \mathrm{C}$.

Os parâmetros fotossintéticos foram determinados segundo Maxwell e Johnson (2000). Foram calculadas as fluorescências mínimas de folhas adaptadas à escuridão (F0) e adaptadas à luz (FO'). Após um pulso de luz saturante branca (3.000 $\mu$ moles E m-2 s-1) foi determinada a fluorescência máxima da clorofila nas folhas adaptadas ao escuro $(\mathrm{Fm})$ e à luz $\left(\mathrm{Fm}^{\prime}\right)$. A fluorescência variável foi determinada pelo cálculo de $\mathrm{Fv}=\mathrm{Fm}-\mathrm{FO}$ em folhas adaptadas à escuridão, ou $\mathrm{Fv}^{\prime}=\mathrm{Fm}^{\prime}-\mathrm{FO}^{\prime}$ em folhas adaptadas à luz variando a densidade de fluxo de fótons (PFD) entre 200 e 1200 moles E m-2 s-1. A relação entre a eficiência variável e a eficiência máxima Fv/Fm, a eficiência do fotossistema II (Fm'-Fs) /Fm', o quenching fotoquímico $\mathrm{qP}=\left(\mathrm{Fm}^{\prime}-\mathrm{Fs}\right) /\left(\mathrm{Fm}^{\prime}-\mathrm{FO} \mathbf{O}^{\prime}\right)$, o quenching não fotoquímico $\mathrm{NPQ}=\left(\mathrm{Fm}-\mathrm{Fm} \mathrm{m}^{\prime}\right) / \mathrm{Fm}^{\prime}$ e a acumulação de quinonas reduzidas $1-\mathrm{pQ}=\left(\mathrm{Fs}^{-}-\mathrm{FO}^{\prime}\right) /\left(\mathrm{Fm}^{\prime}-\mathrm{FO}^{\prime}\right)$ também foram calculados. Finalmente, foi avaliada a taxa de transferência de elétrons:

$\mathrm{ETR}=\left[\left(\mathrm{Fm} \mathrm{m}^{\prime}-\mathrm{Fs}\right) / \mathrm{Fm}^{\prime}\right] * \mathrm{fl} \alpha \mathrm{\alpha olha}$

Onde Fs é o estado estável de fluorescência, f é a fração de quanta absorvido que é usado pelo fotossistema II o qual se assume ser de 0,5 para plantas C3, I é a densidade de fluxo de fótons incidente e $\alpha$ folha é a absorbância da folha que se assume ser 0,85 (Sienkiewicz-Porzucek et al. 2010). 
3.11.5. Extração e quantificação de açúcares solúveis e amido

As extrações de açúcares solúveis e amido para folhas fonte foram realizadas usando protocolos estabelecidos pelo nosso grupo (Fernie et al. 2001).

Extração

Foram adicionados $250 \mu \mathrm{l}$ de etanol $80 \%$ a $10 \mathrm{mg}$ de tecido triturado, seguido de agitação por 20 min a $80^{\circ} \mathrm{C}$. Após centrifugação por $5 \mathrm{~min}$ a $14.000 \mathrm{rpm}$, o sobrenadante foi recuperado e o pellet submetido a duas novas extrações, com $150 \mu$ l de etanol $80 \%$ e $250 \mu$ l de etanol 50\%, respectivamente. Os três sobrenadantes foram reunidos para posterior quantificação de açúcares e aminoácidos.

Ao pellet obtido foram adicionados $500 \mu \mathrm{l}$ de etanol $40 \%$ e centrifugado por $10 \mathrm{~min}$ a 14.000 rpm. O sobrenadante foi descartado e o pellet ressuspendido em $400 \mu \mathrm{l}$ de $\mathrm{KOH} 0,2 \mathrm{M}$. A suspensão foi incubada durante $1 \mathrm{~h}$ a $95^{\circ} \mathrm{C}$ e, posteriormente, foram adicionados $70 \mu \mathrm{l}$ de ácido acético $1 \mathrm{M}$ seguido de uma centrifugação por $10 \mathrm{~min}$ a $14.000 \mathrm{rpm}$. O sobrenadante foi recuperado, e as amostras diluídas $1: 3$.

Determinação de açúcares

Para uma placa de 96 poços foi preparada uma mistura com 15,5 ml de tampão (HEPES/KOH 1

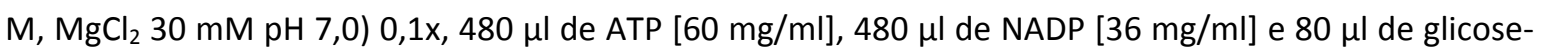
6-fosfato desidrogenase (G6PDH) [5 mg/ml]. Em cada poço, foram adicionados $50 \mu$ do extrato etanoico e $160 \mu \mathrm{l}$ da mistura descrita anteriormente. A leitura foi feita em espectrofotômetro a $340 \mathrm{~nm}$ com medições a cada minuto. Uma vez que a OD se estabilizou foram adicionadas sucessivamente $1 \mu \mathrm{l}$ de hexoquinase $[1500 \mathrm{U} / \mathrm{ml}], 1 \mu \mathrm{l}$ de fosfoglicose isomerase $[2 \mathrm{mg} / \mathrm{ml}$ ] e finalmente $1 \mu \mathrm{l}$ de invertase 0,1 M. Para fazer os cálculos da concentração dos respectivos açúcares, foi usada a seguinte equação:

$$
\mu \mathrm{mol} \text { NADPH }=\Delta \mathrm{OD} /(2.85 * 6.22)
$$

Os valores foram normalizados pelo volume utilizado na medição e a massa de tecido.

Determinação de amido

A determinação enzimática foi realizada com o kit Starch (GO/P) Assay da empresa SIGMA (STA20), segundo instruções do fabricante. A produção de NADH foi medida em espectrofotômetro a $340 \mathrm{~nm}$. Foi realizada uma curva padrão com glicose e o cálculo do conteúdo de amido foi realizado segundo a seguinte fórmula:

$\mu \mathrm{g} / \mathrm{g}$ peso fresco de amido $=\mu \mathrm{mol}$ de glicose*162 (massa da anidroglicose)

Os valores foram normalizados pelo volume utilizado na medição e a massa de tecido.

\subsubsection{Extração e quantificação de aminoácidos}

A metodologia para a determinação de aminoácidos baseou-se naquela descrita por Astarita et al. (2003). Amostras liofilizadas (20 mg) passaram por extração com etanol $80 \%$ e foram concentradas até eliminação do etanol. Os volumes das amostras foram ajustados para $2 \mathrm{ml}$ com água e centrifugadas 
a $20.000 \mathrm{~g}$, por $10 \mathrm{~min}$. O sobrenadante foi filtrado em membrana de $20 \mu \mathrm{m}$ e utilizado para determinação dos aminoácidos. Alíquotas de $550 \mu \mathrm{l}$ do filtrado e $700 \mu \mathrm{l}$ da solução OPA-borato (oftalaldeído-borato) foram utilizadas para a derivatização dos aminoácidos à temperatura ambiente. A identificação e quantificação dos aminoácidos por HPLC foram realizadas utilizando-se uma coluna C18 de fase reversa (Shimadzu Shim-pack CLC ODS ${ }^{\circledR}$ ). Foram utilizados como solventes metanol 65\% e uma solução de acetato de sódio $50 \mathrm{mM}$, fosfato de sódio $50 \mathrm{mM}$, metanol $\left(20 \mathrm{ml}^{-1} \mathrm{I}^{-1}\right.$ ) e tetrahidrofurano (20 ml. ${ }^{-1}$ ) com fluxo de $1 \mathrm{ml} \cdot \mathrm{min}^{-1}$, a $40{ }^{\circ} \mathrm{C}$. O detector de fluorescência foi ajustado para excitação em 250 $\mathrm{nm}$ e emissão em $480 \mathrm{~nm}$. As áreas e tempos de retenção de cada aminoácido foram avaliados por comparação com aminoácidos padrão em concentrações conhecidas: ácido aspártico (Asp), ácido glutâmico (Glu), asparagina (Asn), serina (Ser), glutamina (Gln), histidina (His), glicina (Gly), arginina (Arg), treonina (Tre), alanina (Ala), ácido $\gamma$-aminobutírico (Gaba), tirosina (Tir), metionina (Met), triptofano (Trp), valina (Val), fenilalanina (Phe), isoleucina (Ile), leucina (Leu), ornitina (Orn), lisina (Lis) e citrulina.

\subsubsection{Extração e quantificação de poliaminas}

Para a extração de foram utilizados $20 \mathrm{mg}$ de tecido liofilizado ao qual foram adicionados 1,4 ml de ácido perclórico (PCA) 5\%. Após homogeneização com vórtex por $1 \mathrm{~min}$, as amostras foram centrifugadas a $4.000 \mathrm{~g}$ por $20 \mathrm{~min}$ a $4{ }^{\circ} \mathrm{C}$. Esse passo foi repetido utilizando $0,2 \mathrm{ml}$ de PCA $5 \%$. As PAs conjugadas foram extraídas por hidrólise ácida, utilizando-se $200 \mu \mathrm{l}$ do sobrenadante em volume igual de $\mathrm{HCl} 12 \mathrm{~N}$, por $18 \mathrm{~h}$ a $110{ }^{\circ} \mathrm{C}$ no escuro. Posteriormente, as amostras foram secas a $40{ }^{\circ} \mathrm{C}$ sob jato de $\mathrm{N}_{2}$ e ressuspendidas em $180 \mu \mathrm{l}$ de PCA 5\%. As PAs livres e conjugadas foram em seguida derivatizadas. Para isso, a $40 \mu \mathrm{l}$ de amostra foram adicionados $20 \mu \mathrm{l}$ de diaminoheptano (DAH) 0,05 mM, $50 \mu \mathrm{l}$ de solução saturada de carbonato de sódio e $100 \mu \mathrm{l}$ de cloreto de dansil 1,8 mM. As amostras foram incubadas por $50 \mathrm{~min}$ a $70{ }^{\circ} \mathrm{C}$. Posteriormente, foram adicionados $25 \mu \mathrm{l}$ de prolina $100 \mathrm{mg} / \mathrm{ml}$ e as amostras foram incubadas no escuro a temperatura ambiente por $30 \mathrm{~min}$. Após esse período foram adicionados $200 \mu \mathrm{l}$ de tolueno e coletados $175 \mu \mathrm{l}$ da fase orgânica que foram secos em jato de $N_{2}$. As amostras foram ressuspendidas em $175 \mu \mathrm{l}$ de acetonitrila, e alíquotas de $20 \mu \mathrm{l}$ foram utilizadas para cromatografia liquida. A identificação e quantificação das PAs foram realizadas utilizando-se HPLC, com coluna C18 de fase reversa (Shimadzu Shim-pack CLC ODS). Acetonitrila absoluta e acetonitrila 10\% em água $\left(\mathrm{pH} \mathrm{3,5}\right.$ ajustado com $\mathrm{HCl} 1 \mathrm{~N}$ ) foram utilizadas como solventes com fluxo de $1 \mathrm{ml}^{\mathrm{min}} \mathrm{min}^{-1}$, a $40{ }^{\circ} \mathrm{C}$. $\mathrm{O}$ detector de fluorescência foi ajustado para excitação em 340 nm e emissão em $510 \mathrm{~nm}$. As áreas e tempos de retenção de cada PA foram avaliados por comparação com os padrões de putrescina (Put), espermidina (Spd), espermina (Spm) e DAH. 


\subsubsection{Análise estatística}

Os diferentes parâmetros analisados nas linhagens transgênicas foram avaliados estatisticamente de acordo com Sokal e Rohlf (1981). Quando o conjunto de dados obedeceu ao critério de homoscedasticidade, os dados foram analisados por ANOVA seguido pelo teste de Tukey $(P<0,05)$. Na falta de homoscedasticidade, uma comparação não paramétrica foi feita por meio do teste Kruskal Wallis $(P<0,05)$. Os testes estatísticos foram realizados utilizando o programa InfoStat v. 2009 (www.infostat.com, Grupo InfoStat, FCA, Universidad Nacional de Córdoba, Argentina). 


\section{RESULTADOS}

\subsection{Estrutura gênica e análise filogenética}

Tendo disponíveis as sequencias genômicas de LFP do alelo de S. pennellii (Sp-LFP), obtida pelo nosso grupo (Kamenetzky et al. 2010), e de S. lycopersicum (SI-LFP) (Sol Genomics Network, SGN, http://solgenomics.net/) foi realizada uma comparação entre o alelo selvagem e cultivado. As regiões intergênicas a montante do sítio de inicio da transcrição, até o começo do cDNA do gene vizinho, foram consideradas como os putativos promotores. A estrutura gênica foi determinada comparando as sequencias genômicas com a informação do cDNA (Unigene SGN-U580355). O gene apresenta quatro éxons com uma 5'UTR de 46 bases (Figura 3A) e a proteína predita possui 302 aa. A estrutura gênica dos alelos foi similar variando apenas no tamanho dos íntrons e pela presença de polimorfismos na região codificante, nesta última resultando na mudança de quatro aminoácidos (Figura 3B). Além disso, foi identificada na proteína uma região conservada, a qual esta anotada como domínio de lisina descarboxilase (LDC) segundo os bancos de InterPro (IPR005269) e PFAM (PF03641) (Punta et al. 2012), que possui o motivo PGGXGXXE (Figura 3B). No entanto, um trabalho recente demonstrou que em $A$. thaliana não se detecta cadaverina nem atividade de LDC (Bunsupa et al. 2012). Por outro lado, a partir de sequencias previamente clonadas de arginina descarboxilase (ADC) de tomate, arabidopsis, ervilha e aveia, assim como de ornitina descarboxilase (ODC) de Datura stramonium, Pérez-Amador et al. (1995) identificaram a sequencia xx[D/N] xGGGx [G/T] como domínio descarboxilase.

A

B
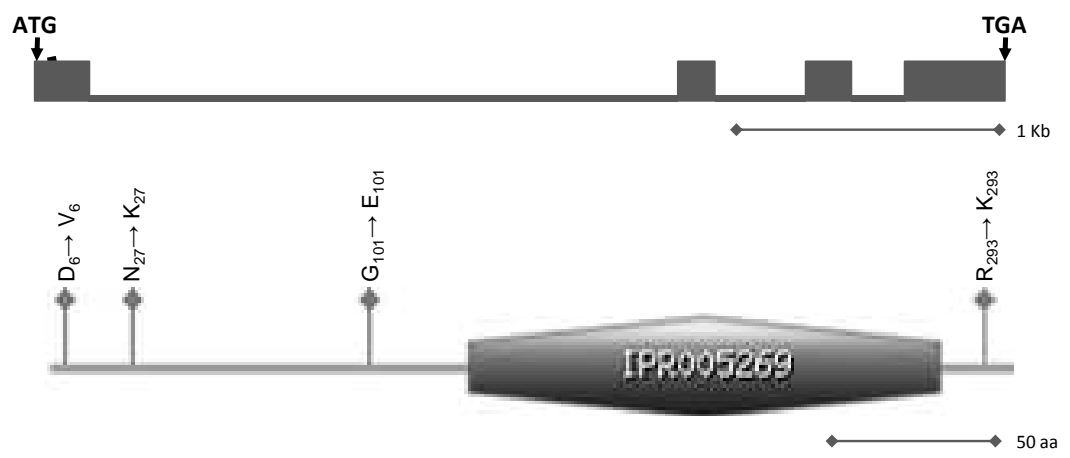

Figura 3: Comparação genômica e proteica entre os alelos de $S$. pennellii e S. lycopersicum do gene LFP.

(A) Estrutura da região codificante do gene LFP. Os éxons encontram-se indicados como caixas e os introns como linhas. $O$ início e o fim da tradução também se encontram indicados. (B) Representação esquemática da estrutura proteica de LFP. Os polimorfismos de aminoácidos entre ambos os alelos encontram-se indicados assim como as suas posições. O hexágono cinza representa o domínio conservado lisina descarboxilase segundo InterPro. 
Frente a estas evidências contraditórias, e para compreender qual seria a função do gene $L F P$ de acordo a sua estrutura, foram comparadas as sequencias proteicas de: L/ODC funcionalmente caracterizada de Lupinus angustifolius (Bunsupa et al. 2012) e a sua ortóloga de S. lycopersicum; a proteína LOG1 de A. thaliana (Kuroha et al. 2009) e a sua ortóloga de tomate, as quais compartilham o domínio PGGXGXXE com LFP; e finalmente, a LFP descrita neste trabalho e a sua ortóloga de Nicotiana tabacum, proteína funcionalmente caracterizada por Hakkinen et al. (2007). O domínio descarboxilase foi encontrado nas sequencias correspondentes a L/ODCs, já nas LFPs e LOGs foi identificado o domínio comum PGGXGXXE. Essa evidencia, aliada ao fato que Hakkinen et al. (2007) não identificaram atividade de LDC na LFP de N. tabacum nos permite propor que esta proteína não é de fato uma LDC e teria uma função ainda não descrita em plantas (Figura 4A).

Para avaliar a diversidade das proteínas LFP foi realizada uma análise filogenética contendo as sequências ortólogas a Sp-LFP e SI-LFP de A. thaliana, Ricinus communis, Oryza sativa, Zea mays, Sorghum bicolor, Vitis vinifera e N. tabacum. A topologia da árvore permitiu identificar dois clados, os quais respondem às espécies de eudicotiledôneas e monocotiledôneas, respectivamente (Figura 4B). Dentro de cada clado, a relação filogenética entre as espécies é mantida. Todas as sequencias possuem o domínio conservado PGGXGXXE. Assim, a árvore sugere que LFP tem uma função evolutivamente conservada ainda não descrita.

A

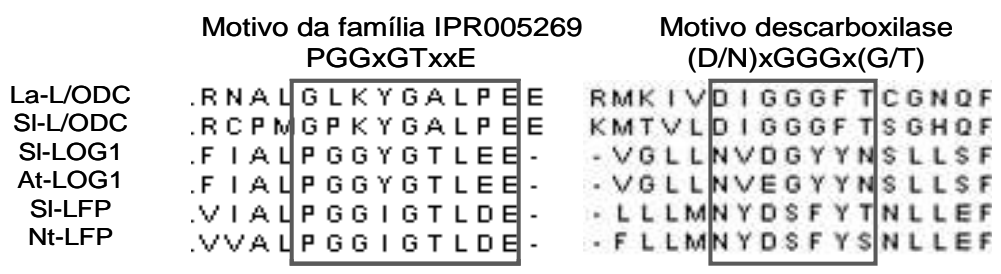

B
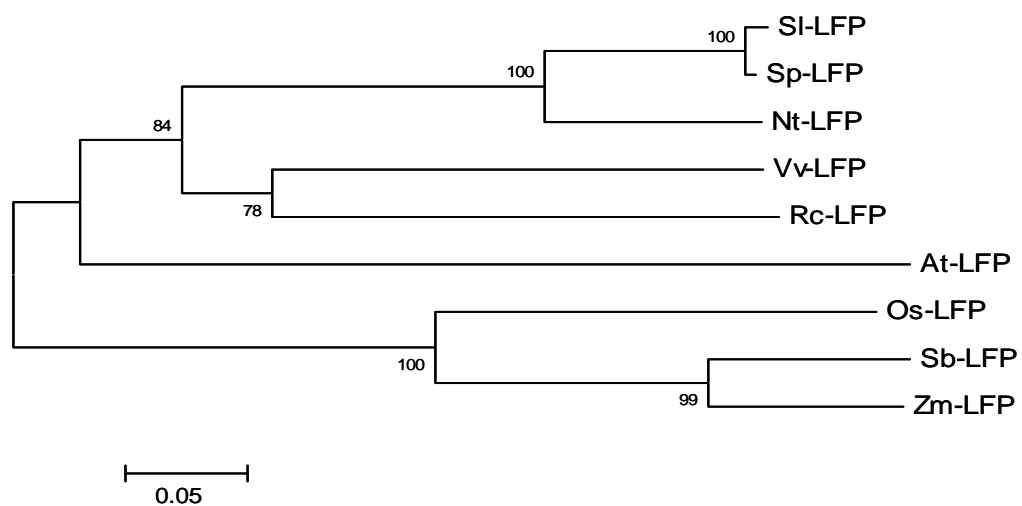

Figura 4: Comparação entre as sequencias proteicas e análise filogenética de L/ODCs, LFPs, e LOGs

(A) Comparação dos domínios conservados das proteínas: SI-L/ODC (S. lycopersicum, AAB82301.2), La-L/ODC (Lupinus angustifolius, BAK32797.1), SI-LFP (SGN-U580355, S. lycopersicum), Nt-LFP (N. tabacum, CAO91858), SI-LOG1 (S. lycopersicum, SGN-U585768), At-LOG1 (A. thaliana, AEC08102). Ressaltado em cinza se indica o domínio conservado PGGXGXXE, e o domínio descarboxilase descrito por Perez-Amador et al. (1995). (B) Análise filogenética das proteínas ortólogas a LFP: At-LFP (A. thaliana, At1g50575), Os-LFP (O. sativa, AAT76324), SI-LFP (S. lycopersicum), Sp-LFP (S. pennellii, Capítulo I), Nt-LFP (N. tabacum, CAO91858), Vv-LFP (V. vinifera, XP_002276560), Rc-LFP (R. communis, XP_002529033), Sb-LFP (S. bicolor, XP_002466870) e Zm-LFP (Z. mays, NP_001150828). Nos ramos estão indicados os valores de bootstrap maiores que $50 \%$. 


\subsection{Perfil transcricional dos alelos de S. pennellii e S. Iycopersicum}

Motivado pela identificação de polimorfismos nas regiões promotoras dos alelos, foi avaliado o perfil transcricional de LFP em diferentes tecidos através da técnica de qPCR. Em folha fonte, caule, raiz e frutos os níveis de expressão do alelo cultivado, S. lycopersicum, foram significativamente maiores aos níveis do alelo selvagem, S. pennellii (Figura 5).

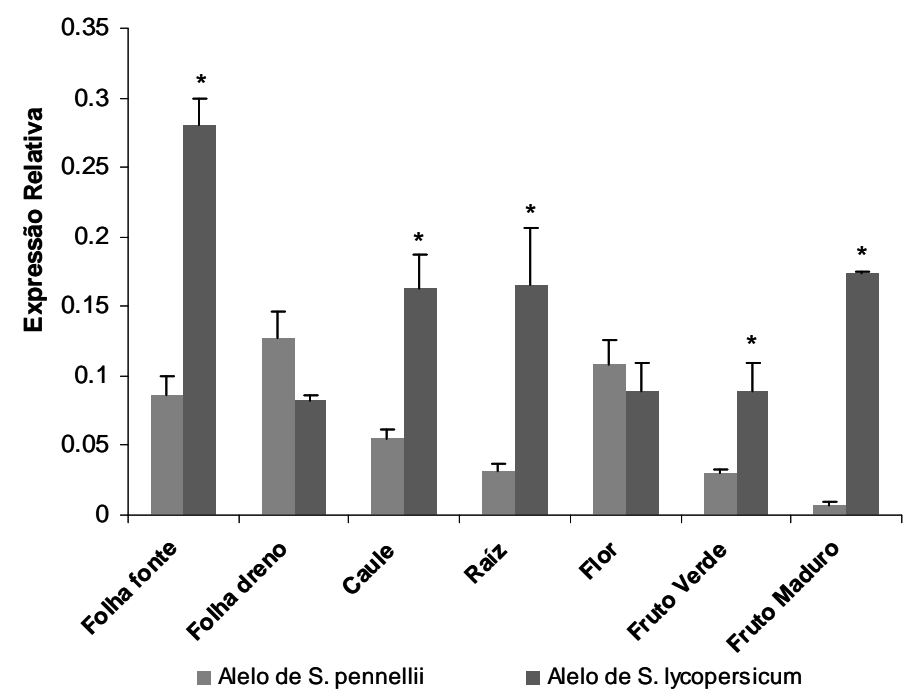

Figura 5: Perfil de expressão do gene LFP por qPCR.

A expressão relativa está calculada como quantidade de RNAm do gene $L F P / q u a n t i d a d e ~ d e ~ R N A m$ do gene de referência EF1 $\alpha .{ }^{*}$ Diferença estatística pelo teste de Wilcoxon $\mathrm{P}<0,05$.

\subsection{Estudo da atividade transcricional dos promotores dos alelos de S. pennellii e S. lycopersicum}

Para verificar se a diferença nos níveis de expressão de ambos os alelos é devida, ao menos em parte, às regiões promotoras, foram obtidas construções fusionando as respectivas sequencias à região codificante do gene repórter gus. Folhas de $N$. benthamiana foram infiltradas com cultivos de $A$. tumefaciens contendo as construções pHGWFS7LFPPromLyc (promotor de S. lycopersicum::gus), pHGWFS7LFPPromPen (promotor de S. pennellii::gus) e pHGWFS735s (controle positivo com promotor 35S:gus) e, após três dias foi realizado o ensaio histoquímico. A Figura 6 mostra o resultado do experimento, no qual foi verificado que os fragmentos clonados de S. lycopersicum e S. pennellii correspondem aos respectivos promotores dos genes. Quando comparada a atividade transcricional de ambos, o experimento de expressão transitória revelou que o promotor de do alelo cultivado apresenta maior nível de atividade. 


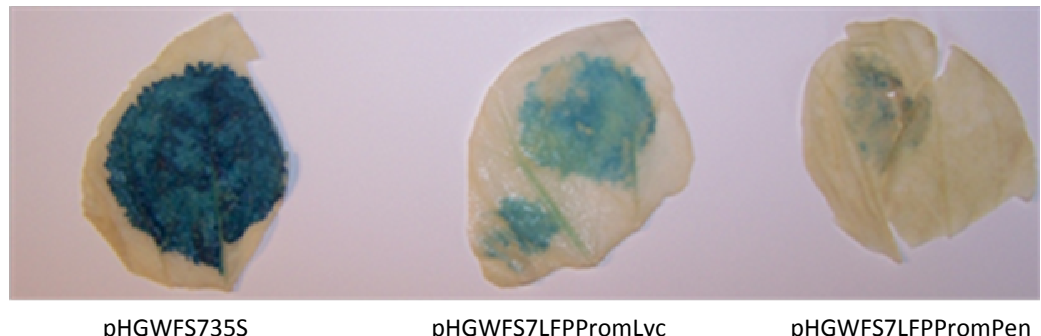

Figura 6: Estudo da atividade dos promotores por meio de ensaios de expressão transitória em folhas de $N$. benthamiana.

O precipitado azul revela a presença de atividade da proteína GUS. pHGWFS7LFPPromLyc: promotor de $S$. lycopersicum fusionado a gus. pHGWFS7LFPPromPen: promotor de S. pennellii fusionado a gus. pHGWFS735S: controle positivo com promotor 35 S fusionado a gus.

\subsection{Estudo da localização subcelular da proteína}

Embora nas sequências proteicas de ambos os alelos, S. lycopersicum e S. pennellii, a análise in silico de LFP não tenha revelado a presença de peptídeo sinal, nas proteínas ortólogas Nt-LFP, Vv-LFP, At-LFP e Os-LFP foi predita a presença de um peptídeo para direcionamento para cloroplasto. Assim, para avaliar in vivo a localização subcelular da LFP de tomate foi desenhado um experimento com o intuito de identificar o compartimento celular onde essa proteína atua. Para isso, foi obtida a construção pK7FWG2LFPLyc contendo a região codificante do gene de 906 pb, de S. lycopersicum, abrangendo desde o ATG até o códon anterior ao de fim da tradução, fusionado à sequência codificante da proteína GFP. Um cultivo de A. tumefaciens contendo a construção supramencionada foi infiltrado em folhas de N. benthamiana. Após $48 \mathrm{~h}$, foram montadas lâminas com discos de folhas infiltradas e visualizadas ao microscópio confocal. Na Figura 7 podem ser observadas células do mesófilo das folhas de $N$. benthamiana onde a autofluorescência da clorofila co-localiza com a proteína de fusão LFP:: GFP fluorescente demonstrando que LFP é direcionada para o cloroplasto.

LFP::GFP

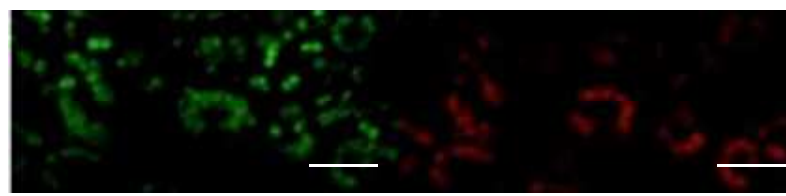

sobreposição

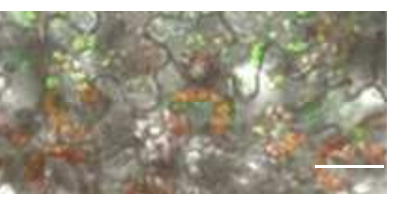

Figura 7: Localização subcelular da proteína de fusão LFP::GFP em células de mesófilo de folhas de N. benthamiana.

Imagem de microscopia confocal de células do mesófilo de folhas de $N$. benthamiana expressando de forma transiente a proteína de fusão LFP::GFP onde é observada fluorescência de GFP (LFP::GFP), a auto-fluorescência da clorofila (clorofila) e a sobreposição entre as imagens anteriores (sobreposição). A barra branca representa $25 \mu \mathrm{m}$. 


\subsection{Efeito do silenciamento gênico por RNA de interferência}

Para demonstrar o envolvimento do gene LFP na determinação das diferenças observadas nos níveis de aminoácidos em frutos entre S. lycopersicum (cv. M82) e a IL 7-1 foi adotada a estratégia de silenciamento gênico por RNA de interferência. Desta forma, foi obtida a construção pK7GWIWG2(I)LFP contendo um fragmento de $173 \mathrm{pb}$ do quarto éxon do gene (Figura 8). Para garantir que o silenciamento fosse específico para o gene de interesse, evitando interferir na expressão de outros genes, foi realizado uma análise por BLAST no banco da SGN. Por meio da transformação genética mediada por $A$. tumefaciens, foram obtidas 26 linhagens independentes de tomate que enraizaram em presença do agente seletivo.

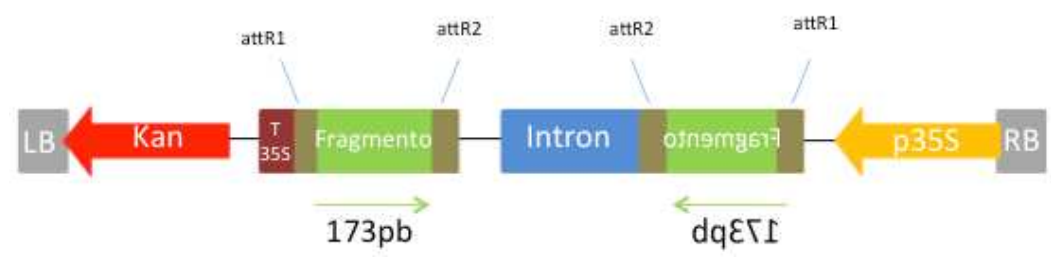

Figura 8: Representação esquemática do vetor pK7GWIWG2(I)LFP.

Construção utilizada para a obtenção das plantas transgênicas de tomateiro $S$. lycopersicum (cv. Moneymaker). LB: borda esquerda. Kan: cassete de resistência a canamicina. T: terminador 3Ss do CaMV. 173b: fragmento da sequência codificante do gene LFP. p35S: promotor 35Ss do CaMV. RB: borda direita.

A presença do transgene nas linhagens obtidas foi verificada por meio de PCR utilizando iniciadores específicos para o promotor 35S. Dessa forma, foram identificados nove escapes e determinada uma eficiência de transformação de 65 \% (Tabela 2). Posteriormente, 10 das linhagens positivas foram sincronizadas por meio de estaquia junto aos respectivos controles, e foi avaliado o silenciamento do gene alvo utilizando qPCR. A Figura 11 apresenta os dados de expressão relativa do gene LFP demonstrando que oito das linhagens transgênicas testadas possuem níveis de RNAm mais baixos que o controle selvagem.

Tabela 2. Eficiência da transformação de tomateiro com a construção para silenciamento do gene LFP.

\begin{tabular}{ccccc}
$\begin{array}{c}\text { Linhagens } \\
\text { regeneradas }\end{array}$ & $\begin{array}{c}\text { Linhagens positivas } \\
\text { por PCR }\end{array}$ & $\begin{array}{c}\text { Eiciência de } \\
\text { transformaçồ } \\
(\%)\end{array}$ & $\begin{array}{c}\text { Linhagens } \\
\text { avaliadas por } \\
\text { qPCR }\end{array}$ & $\begin{array}{c}\text { Linhagens } \\
\text { silenciadas }\end{array}$ \\
\hline 26 & 17 & 65 & 10 & 8 \\
\hline
\end{tabular}




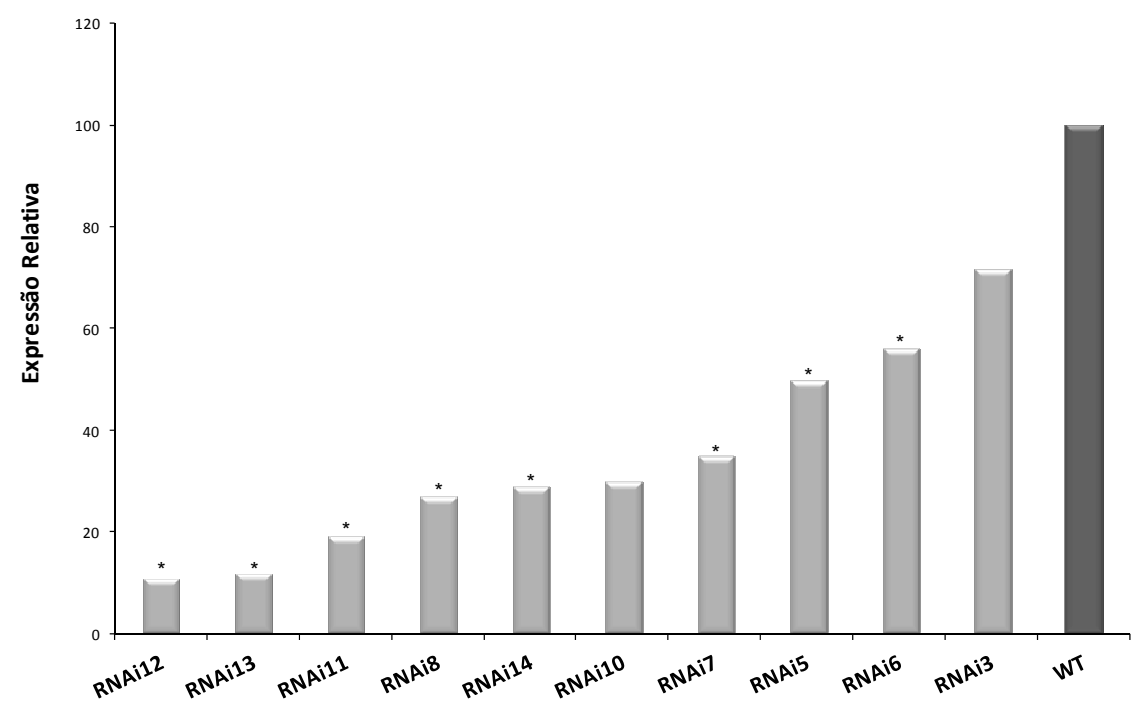

Figura 9: Análise de expressão do gene LFP nas linhagens transgênicas.

Os resultados representam a média de três réplicas técnicas. Os valores estão expressos como a abundância relativa do RNAm comparado ao controle (WT) S. lycopersicum (cv. Moneymaker). *Diferenças estatisticamente significativa pelo teste de Kruskal-Wallis $(P<0,005)$.

\subsection{Caracterização fenotípica das linhagens transgênicas}

Para a avaliação fenotípica, foram selecionadas três das linhagens (RNAi11, RNAi12, RNAi14) que apresentaram baixos níveis de RNAm do gene LFP (Figura 9). As plantas escolhidas foram propagadas vegetativamente por meio de estaquia gerando seis réplicas para cada linhagem para posterior caracterização fenotípica.

4.6.1. Verificação do nível de silenciamento nas linhagens transgênicas

Com o intuito de confirmar o silenciamento nas réplicas biológicas, os níveis de RNAm do gene LFP foram novamente verificados em folhas e frutos maduros por qPCR. Os dados de expressão relativa confirmaram que o silenciamento previamente observado é estável (Figura 10). 

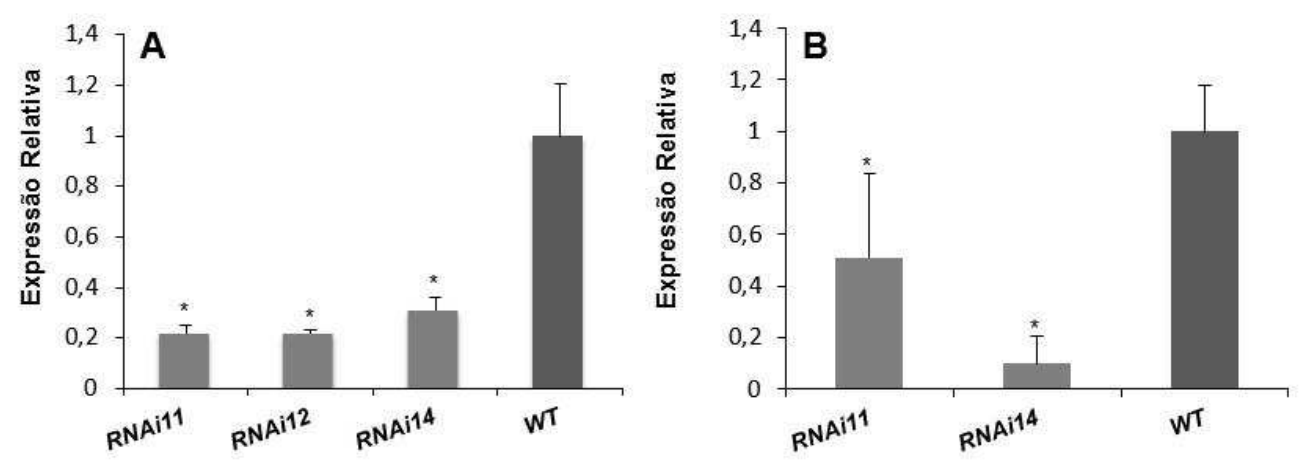

Figura 10: Análise de expressão do gene LFP nas linhagens transgênicas selecionadas.

(A) Níveis de expressão de LFP em folha. (B) Níveis de expressão da LFP em fruto maduro. Os resultados representam a média de seis réplicas biológicas com três réplicas técnicas cada. Os valores estão expressos como a abundância relativa do RNAm comparado ao controle WT, S. lycopersicum (cv. Moneymaker). *Diferenças estatisticamente significativa $(P<0,005)$. Devido à escassa massa de fruto maduro obtida da linhagem RNAi12 se decidiu priorizar as avaliações bioquímicas não restando material para extração de RNA.

\subsubsection{Parâmetros fotossintéticos}

Para avaliar o possível efeito do silenciamento do gene LFP na atividade fotossintética foram realizadas medições de intercâmbio gasoso e fluorescência da clorofila a diferentes densidades de fluxo de fótons. Não foram registradas alterações na taxa de assimilação de $\mathrm{CO}_{2}$ para as linhagens silenciadas. A respeito dos parâmetros de fluorescência de clorofila, excetuando à linhagem RNAi14 que apresentou aumento significativo no quenching fotoquímico e redução nos níveis de quinonas reduzidas acumuladas não se registraram mudanças produzidas pelo silenciamento de LFP (Tabela 3).

Tabela 3: Parâmetros fotossintéticos.

\begin{tabular}{|c|c|c|c|c|c|c|c|c|c|}
\hline \multirow[t]{3}{*}{ Linhas } & \multicolumn{4}{|c|}{ Taxa de Assimilação } & ETR $^{(b)}$ & $\begin{array}{c}\text { Quenching } \\
\text { fotoquímico }\end{array}$ & $\begin{array}{l}\text { Quenching } \\
\text { não } \\
\text { fotoquímico }\end{array}$ & $1-p Q^{(c)}$ & $\begin{array}{c}\text { Eficiência } \\
\text { de PSII }\end{array}$ \\
\hline & \multicolumn{4}{|c|}{$\operatorname{PFD}\left(\mu \mathrm{mol} \mathrm{m} \mathrm{m}^{-2} \mathrm{~s}^{-2}\right)^{(\mathrm{a})}$} & & & & & \\
\hline & 200 & 400 & 800 & 1200 & & & & & \\
\hline RNAi11 & $\begin{array}{c}5.12 \\
( \pm 0.9)\end{array}$ & $\begin{array}{c}7.89 \\
( \pm 1.4)\end{array}$ & $\begin{array}{c}9.97 \\
( \pm 2.9)\end{array}$ & $\begin{array}{l}11.43 \\
( \pm 4.1)\end{array}$ & $128.27 \pm 28.34$ & $0.45 \pm 0.09$ & $1.54 \pm 0.24$ & $0,55 \pm 0,09$ & $0,25 \pm 0,06$ \\
\hline RNAi12 & $\begin{array}{l}3.61 \\
( \pm 1.3)\end{array}$ & $\begin{array}{r}7.13 \\
( \pm 0.6)\end{array}$ & $\begin{array}{l}10.53 \\
( \pm 2.9)\end{array}$ & $\begin{array}{l}12.54 \\
( \pm 4.0)\end{array}$ & $149.81 \pm 27.03$ & $0.51 \pm 0.04$ & $1.43 \pm 0.38$ & $0,49 \pm 0,04$ & $0,29 \pm 0,05$ \\
\hline RNAi14 & $\begin{array}{c}4.29 \\
( \pm 1.8)\end{array}$ & $\begin{array}{c}8.27 \\
( \pm 2.1)\end{array}$ & $\begin{array}{c}9.85 \\
( \pm 1.7)\end{array}$ & $\begin{array}{c}10.9 \\
( \pm 1.8)\end{array}$ & $148.36 \pm 11.10$ & $0.52 \pm 0.02$ & $1.62 \pm 0.12$ & $0,48 \pm 0,02$ & $0,28 \pm 0,01$ \\
\hline & $\begin{array}{c}4.55 \\
( \pm 2.5)\end{array}$ & $\begin{array}{c}7.52 \\
( \pm 2.0)\end{array}$ & $\begin{array}{r}9.72 \\
( \pm 2.2)\end{array}$ & $\begin{array}{r}12.68 \\
( \pm 2.0)\end{array}$ & $113.38 \pm 20.33$ & $0.4 \pm 0.07$ & $1.49 \pm 0.30$ & $0,61 \pm 0,07$ & $0,22 \pm 0,04$ \\
\hline
\end{tabular}

\subsubsection{Parâmetros de crescimento}

Apesar de não ter sido verificada nenhuma alteração significativa nos níveis de assimilação de carbono, as plantas transgênicas silenciadas para a LFP apresentaram um aumento significativo de massa fresca e seca da parte aérea (Figura 11A e B) sem alteração no conteúdo de água (Figura 11C). Ao 
avaliar separadamente a biomassa, tanto a massa folhar quanto caulinar foi maior nas plantas transgênicas, no entanto o incremento da massa caulinar foi mais evidente como revelado pelo aumento no calibre (Figura 11D). Levando em consideração que a porcentagem de água na parte aérea não mostra diferenças entre os genótipos a maior grossura do caule das linhagens transgênicas estaria determinada por um aumento no número de células. A linhagem RNAi12 também apresenta menor massa de frutos, que junto ao aumento da biomassa, fazem com que apresente drástica redução do índice de colheita (Figura 11E e F).

\subsubsection{Quantificação de açúcares solúveis e amido}

A determinação do conteúdo de açúcares solúveis e amido em folhas das plantas transgênicas demonstrou que o silenciamento de LFP não altera o metabolismo de carboidratos majoritários, pois não foi verificada nenhuma diferença significativa entre as linhagens e o controle (Tabela 4).

\begin{tabular}{ccccc}
\multicolumn{6}{l}{ Tabela 4. Determinação de açúcares solúveis e amido. } \\
& $\begin{array}{c}\text { Glicose } \\
\left(\mu \mathrm{mol} / \mathrm{gPF}^{(\mathrm{a})}\right)\end{array}$ & $\begin{array}{c}\text { Frutose } \\
\left(\mu \mathrm{mol} / \mathrm{gPF}^{(\mathrm{a})}\right)\end{array}$ & $\begin{array}{c}\text { Sacarose } \\
\left(\mu \mathrm{mol} / \mathrm{gPF}^{(\mathrm{a})}\right)\end{array}$ & $\begin{array}{c}\text { Amido } \\
\left(\mu \mathrm{gg} / \mathbf{g P F}^{(\mathrm{a})}\right)\end{array}$ \\
\hline RNAi11 & $1,63( \pm 0,88)$ & $4,20( \pm 1,40)$ & $6,26( \pm 1,72)$ & $73,73( \pm 71,45)$ \\
RNAi12 & $4,00( \pm 0,37)$ & $8,08( \pm 1,08)$ & $8,66( \pm 1,32)$ & $89,06( \pm 40,21)$ \\
RNAi14 & $1,92( \pm 0,70)$ & $5,04( \pm 1,70)$ & $7,77( \pm 1,72)$ & $87,26( \pm 85,31)$ \\
WT & $2,80( \pm 1,08)$ & $5,81( \pm 1,54)$ & $7,03( \pm 1,45)$ & $77,85( \pm 57,13)$ \\
\hline
\end{tabular}

(a) PF: peso fresco de folha.

\subsubsection{Quantificação de aminoácidos}

A quantificação de aminoácidos em folhas e frutos das linhagens silenciadas não revelou nenhuma alteração generalizada desses compostos, nem em particular aqueles aminoácidos para os quais tinham sido descritos QTL co-localizados com LFP. Em frutos, foram identificadas apenas alterações pontuais. Já em folhas, vale ressaltar a clara queda do conteúdo de asparagina (Tabela 5). Esses resultados sugerem alterações na percepção no nitrogênio orgânico, função que tem sido associada às PAs (Mattoo et al. 2006). 

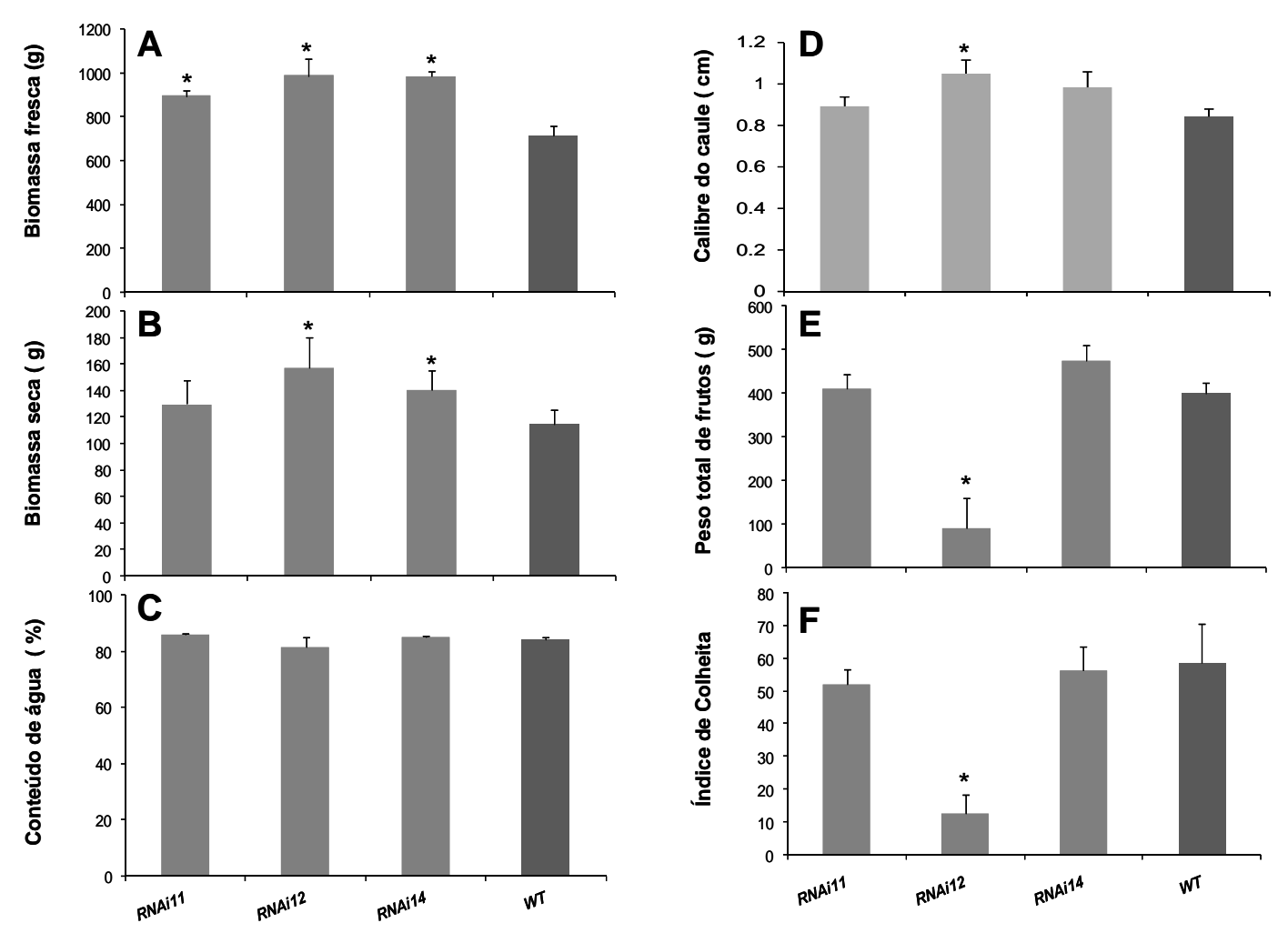

Figura 11: Parâmetros de crescimento das linhagens silenciadas para LFP.

(A) Peso fresco da parte aérea. (B) Peso seco da parte aérea. (C) Porcentagem de água da parte aérea (D) Calibre do caule medido a $50 \mathrm{~cm}$ da base da planta. (E) Peso total dos frutos. (F) Índice de colheita. Os dados foram obtidos a partir de plantas com seis meses de idade e representam a média de pelo menos três réplicas biológicas. *Diferenças estatisticamente significativa $(P<0,05)$. 


\begin{tabular}{|c|c|c|c|c|c|c|c|c|c|c|c|c|c|}
\hline & \multirow[b]{2}{*}{ Aspartato } & \multicolumn{3}{|c|}{ RNAi11 } & \multicolumn{3}{|c|}{ RNAi12 } & \multicolumn{3}{|c|}{ RNAi14 } & \multicolumn{3}{|c|}{ WT } \\
\hline \multirow{20}{*}{ Fruto Maduro } & & 1933.8 & \pm & 260.8 & 2092.3 & \pm & 191.1 & 1980.9 & \pm & 83.6 & 2151.7 & \pm & 162.7 \\
\hline & Glutamato & 7918.2 & \pm & 458.3 & 8347.4 & \pm & 481.4 & 8682.2 & \pm & 555.3 & 9653.4 & \pm & 462.9 \\
\hline & Asparagina & 1777.7 & \pm & 163.0 & 1357.3 & \pm & 123.2 & 1841.8 & \pm & 79.2 & 1928.7 & \pm & 144.4 \\
\hline & Serina & 679.8 & \pm & 110.3 & 530.2 & \pm & 66.5 & 628.7 & \pm & 70.0 & 624.5 & \pm & 44.3 \\
\hline & Glutamina & 298860.0 & \pm & 29275.0 & 246834.1 & \pm & 19317.7 & 299502.8 & \pm & 12887.5 & 351762.2 & \pm & 18530.3 \\
\hline & Glicina & 33.9 & \pm & 4.8 & 25.8 & \pm & 6.1 & 28.3 & \pm & 5.7 & 43.3 & \pm & 1.5 \\
\hline & Arginina & 173.2 & \pm & 23.3 & 109.0 & \pm & 7.6 & 160.6 & \pm & 11.4 & 201.7 & \pm & 26.1 \\
\hline & Treonina & 333.5 & \pm & 29.3 & 314.2 & \pm & 37.0 & 322.2 & \pm & 24.7 & 386.1 & \pm & 33.4 \\
\hline & Alanina & 166.7 & \pm & 34.2 & 131.9 & \pm & 20.4 & 123.3 & \pm & 9.5 & 249.0 & \pm & 49.8 \\
\hline & GABA & 1731.0 & \pm & 144.8 & 2287.1 & \pm & 669.2 & 2353.9 & \pm & 194.4 & 1775.8 & \pm & 112.6 \\
\hline & Tirosina & 197.2 & \pm & 27.5 & 156.0 & \pm & 9.4 & 175.9 & \pm & 18.7 & 197.8 & \pm & 19.0 \\
\hline & Triptofano & 121.1 & \pm & 13.1 & 99.9 & \pm & 12.0 & 112.0 & \pm & 6.4 & 125.0 & \pm & 16.2 \\
\hline & Metionina & 54.0 & \pm & 7.2 & 41.6 & \pm & 5.1 & 50.3 & \pm & 3.9 & 47.4 & \pm & 3.4 \\
\hline & Valina & 120.6 & \pm & 9.2 & 98.7 & \pm & 13.4 & 117.3 & \pm & 16.8 & 138.5 & \pm & 9.5 \\
\hline & Fenilalanina & 531.5 & \pm & 58.3 & 841.7 & \pm & 154.0 & 842.4 & \pm & 77.6 & 753.0 & \pm & 71.0 \\
\hline & Isoleucina & 225.0 & \pm & 26.3 & 230.0 & \pm & 26.5 & 195.9 & \pm & 9.8 & 280.9 & \pm & 26.2 \\
\hline & Leucina & 183.2 & \pm & 28.4 & 159.9 & \pm & 13.3 & 142.6 & \pm & 6.6 & 201.5 & \pm & 21.7 \\
\hline & Ornitina & 95.2 & \pm & 2.8 & 99.3 & \pm & 7.9 & 88.4 & \pm & 5.6 & 96.3 & \pm & 9.0 \\
\hline & Lisina & 182.9 & \pm & 13.4 & 174.7 & \pm & 20.8 & 174.8 & \pm & 11.8 & 198.2 & \pm & 20.4 \\
\hline & Citrullina & 27.8 & \pm & 4.1 & 13.6 & \pm & 1.0 & 21.7 & \pm & 1.6 & 29.5 & \pm & 5.6 \\
\hline \multirow{12}{*}{ Folha Fonte } & Aspartato & 921.5 & \pm & 142.1 & 1211.0 & \pm & 290.7 & 814.4 & \pm & 50.0 & 810.1 & \pm & 66.0 \\
\hline & Glutamato & 728.4 & \pm & 101.0 & 1014.2 & \pm & 230.3 & 603.6 & \pm & 88.6 & 774.8 & \pm & 70.7 \\
\hline & Asparagina & 69.2 & \pm & 12.2 & 60.1 & \pm & 13.6 & 54.6 & \pm & 8.7 & 136.8 & \pm & 24.4 \\
\hline & Serina & 209.0 & \pm & 36.9 & 338.5 & \pm & 102.9 & 197.8 & \pm & 34.7 & 406.9 & \pm & 68.2 \\
\hline & Glutamina & 43614.6 & \pm & 9284.2 & 42991.2 & \pm & 11300.8 & 28095.2 & \pm & 3795.8 & 37321.1 & \pm & 1794.6 \\
\hline & Glicina & 29.1 & \pm & 5.3 & 22.6 & \pm & 0.3 & 32.0 & \pm & 4.9 & 34.6 & \pm & 2.0 \\
\hline & Arginina & 189.1 & \pm & 40.0 & 148.9 & \pm & 16.5 & 167.2 & \pm & 32.3 & 146.8 & \pm & 10.2 \\
\hline & Treonina & 152.7 & \pm & 28.7 & 163.1 & \pm & 31.5 & 126.9 & \pm & 20.3 & 213.0 & \pm & 45.9 \\
\hline & Alanina & 182.2 & \pm & 30.6 & 208.8 & \pm & 44.7 & 149.4 & \pm & 23.5 & 162.6 & \pm & 3.0 \\
\hline & GABA & 67.5 & \pm & 8.2 & 86.1 & \pm & 22.5 & 80.5 & \pm & 12.3 & 97.7 & \pm & 10.7 \\
\hline & Tirosina & 20.9 & \pm & 3.0 & 24.4 & \pm & 3.2 & 18.3 & \pm & 1.8 & 27.1 & \pm & 3.4 \\
\hline & Triptofano & 37.8 & \pm & 5.2 & 42.8 & \pm & 7.4 & 31.0 & \pm & 3.8 & 40.9 & \pm & 4.0 \\
\hline
\end{tabular}




\begin{tabular}{|c|c|c|c|c|c|c|c|c|c|c|c|c|}
\hline Metionina & 14.8 & \pm & 0.9 & 19.0 & \pm & 2.3 & 17.5 & \pm & 2.3 & 22.1 & \pm & 2.0 \\
\hline Valina & 46.1 & \pm & 7.4 & 51.9 & \pm & 11.1 & 38.2 & \pm & 4.6 & 50.9 & \pm & 6.9 \\
\hline Fenilalanina & 71.7 & \pm & 12.8 & 91.4 & \pm & 13.5 & 55.7 & \pm & 2.8 & 76.6 & \pm & 7.7 \\
\hline Isoleucina & 33.5 & \pm & 4.0 & 32.6 & \pm & 5.2 & 29.4 & \pm & 3.0 & 42.6 & \pm & 5.2 \\
\hline Leucina & 32.5 & \pm & 2.9 & 31.2 & \pm & 4.6 & 35.1 & \pm & 4.7 & 39.5 & \pm & 4.6 \\
\hline Ornitina & 127.0 & \pm & 10.4 & 123.3 & \pm & 8.2 & 139.5 & \pm & 13.4 & 142.0 & \pm & 12.2 \\
\hline Lisina & 165.7 & \pm & 8.7 & 184.9 & \pm & 4.0 & 187.1 & \pm & 12.0 & 184.6 & \pm & 18.4 \\
\hline Citrullina & 72.6 & \pm & 15.6 & 118.9 & \pm & 29.8 & 67.4 & \pm & 9.1 & 93.4 & \pm & 7.3 \\
\hline
\end{tabular}

A concentração dos aminoácidos esta expressa como $\mu \mathrm{g} / \mathrm{g}$ massa seca.

Valores em negrito representam diferenças significativas $(p<0,05)$ com relação ao controle. 
4.6.6. Quantificação de poliaminas

Embora as evidências coletadas indicarem que LFP não é uma LDC, para avaliar a eventual relação de LFP com o metabolismo de PAs, foi quantificado o conteúdo de Put, Spm, Spd e Cad em folhas e frutos maduros. As folhas das plantas silenciadas apresentaram redução significativa do conteúdo de Put livre quando comparadas ao controle selvagem (Figura 12A). Por tanto, o gene objeto de estudo foi nomeado como LFP (Low Free Putrecine). Em particular, a linhagem RNAi12 apresentou uma alteração massiva dos níveis de PAs livres, com redução dos níveis de Put, Cad, Spd e poliaminas totais (Figura12A). De forma contrária, os frutos maduros dessas linhagens não apresentaram alterações no perfil destes compostos (Figura 12B). É interessante notar que em folhas a relação putrescina/espermina+espermidina é menor que um, enquanto que em fruto essa relação se inverte, pois a putrescina é a PA prevalente (Figura 12A e B). Para avaliar se a queda na Put revelada em folhas era por causa da menor síntese ou maior degradação, ou pela alteração no padrão de conjugação, foi quantificada a Put conjugada. A figura $12 \mathrm{C}$ mostra que as linhagens transgênicas apresentaram um aumento da Put conjugada, levantando, desta forma a hipótese de que LFP participaria da liberação de Put conjugada ou na própria conjugação. 

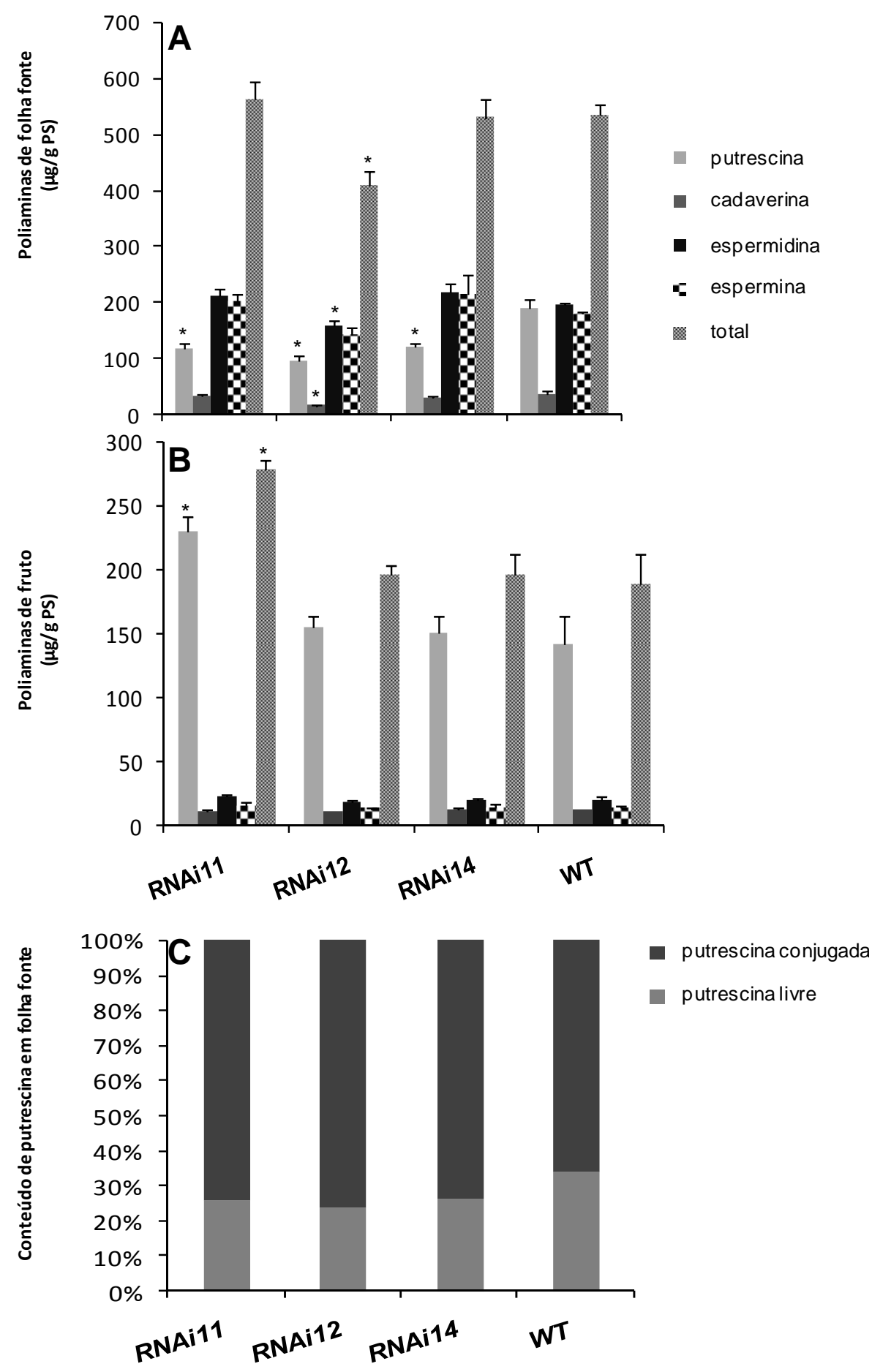

Figura 12: Conteúdo de poliaminas em linhagens silenciadas para LFP.

(A) Quantificação de poliaminas livres em folhas das linhagens transgênicas. (B) Quantificação de poliaminas livres em frutos maduros das linhagens transgênicas. (C) proporção entre putrescina livre e conjugada em folhas das linhagens transgênicas. PS: peso seco. * Diferenças estatisticamente significativa $(\mathrm{P}<0,05)$. 


\section{DISCUSSÃO}

O gene LFP foi identificado por Bermúdez et al. (2008) como um possível responsável na determinação de QTL para aminoácidos, os quais formam descritos no cromossomo 7 por Schauer et al. (2006) a partir da avaliação metabólica de frutos de uma população de linhagens introgredidas de $S$. pennellii em fundo genético de S. lycopersicum. A sua candidatura foi proposta devido à sua homologia com o lócus At1g50575 de A. thaliana, o qual está descrito como LDC por possuir o motivo PGGxxGxxE (InterPro - IPR005269, PFAM - PF03641). Entretanto, as análises comparativa e filogenética realizadas neste trabalho demonstraram que o domínio compartilhado pelas descarboxilases, descrito por PérezAmador et al. (1995), é diferente do apresentado pela LFP. Por outro lado, o gene ortólogo a LFP de N. tabacum, único funcionalmente descrito, não possui atividade de L/ODC, embora também esteja anotado como lisina descarboxilase pela sua homologia com o gene de $A$. thaliana (Hakkinen et al. 2007). Ainda mais, recentemente, Bunsupa et al. (2012) reportaram a ausência Cad em A. thaliana o que levaria a suposição de que não há função de descarboxilação de lisina nessa espécie. Desta forma, as evidências constataram que, além das anotações dos genes de $A$. thaliana e $N$. tabacum estarem equivocadas, o gene sob estudo não deveria ser considerado uma putativa LDC. No entanto, o fato de ter sido detectada Cad tanto em folha como em fruto de tomateiro indica que: i) $S$. lycopersicum possui atividade de LDC e, portanto deve existir uma LDC codificada por outro gene que provavelmente seja o SI-L/ODC identificado neste trabalho; ou ii) no tomateiro a Cad é produzida por outra via como descrito para leguminosas (Smith 1977). Desta forma, os argumentos expostos acima levaram à incerteza a respeito da função de $L F P$ no tomateiro.

Em tomate, LFP possui quatro éxons e codifica uma proteína de 302 aa que, possivelmente, desempenha uma função conservada em plantas superiores como sugerido pela análise filogenética. A análise comparativa entre S. lycopersicum e S. pennellii permitiu identificar quatro polimorfismos de aminoácidos e diversos polimorfismos de nucleotídeos na região promotora entre os alelos. Estes últimos resultaram, pelo menos em parte, responsáveis pela diferença no padrão de expressão entre as duas espécies como demonstrado pela análise funcional dos promotores. Não podendo descartar, de qualquer maneira, a participação de algum outro mecanismo de regulação transcricional ou póstranscricional.

A fim de ganhar evidencias do papel de LFP em tomateiro, foram desenvolvidas linhagens transgênicas silenciadas por meio da expressão de um RNAm dupla fita para desencadear o mecanismo de RNAi. Essa técnica tem se tornado muito eficiente para estudos de genética reversa, através da avaliação de fenótipos por perda de função (Mello e Conte Jr 2004, Waterhouse e Helliwell 2003). Foram selecionadas três linhagens transgênicas que apresentaram entre 60 e $80 \%$ de redução dos níveis de transcritos de LFP. 
A caracterização fenotípica das plantas silenciadas revelou que a redução nos níveis e transcritos de LFP levou ao aumento de biomassa, mais evidente em caules que em folhas, e menor conteúdo de asparagina nas folhas. A respeito das PAs, como esperado a partir dos resultados obtidos do estudo da estrutura e diversidade de LFP, não houve mudanças nos níveis de Cad. Pelo contrário, a Put livre se mostrou diminuída.

O aumento de biomassa observada nas plantas transgênicas é resultado do incremento na massa seca, uma vez que a porcentagem de água se manteve constante, sugerindo assim uma maior taxa de divisão celular nesse órgão. Já foi descrito que as PAs possuem um papel importante no ciclo celular. Paschalidis e Roubelakis-Angelakis (2005) fizeram um mapeamento espaço-temporal do conteúdo destes compostos ao longo do corpo da planta de tabaco e demonstraram que existe um gradiente de concentração que decresce em sentido basípeto. Desta forma, no meristema apical, onde se encontram células em divisão, estão as maiores concentrações de PAs, sendo que Spm e Spd possuem um papel fundamental nesse processo. Em regiões onde há predominantemente expansão celular, os níveis destes metabólitos são menores. Trabalhando com cenoura, Schons e Brasil (1995) obtiveram resultados similares, mostrando a importância dessas duas PAs no processo de divisão celular. Uma vez que já foi proposto que Put tenha efeito antagônico ao de Spm e Spd (Matoo et al.2010), a relação Put/Spm+Spd se torna um indicativo da progressão do ciclo. Seguindo essa linha de pensamento, as plantas silenciadas para LFP apresentariam uma menor relação Put/Spm+Spd resultando no aumento da resposta a Spm e Spd explicando assim a maior taxa de divisão celular proposta.

Em tomate, a Put pode ser sintetizada tanto a partir da descarboxilação da ornitina, quanto da arginina. Evidencias sugerem que há uma preferência pela via da ODC em células que estão em divisão e uma preferência pela via da ADC em células em elongação, sendo que em folha a síntese de putrescina é feita quase que exclusivamente através da via de ADC (Acosta et al. 2005). Estudos de imunolocalização realizados em Avena sativa e $N$. tabacum demonstraram que em tecidos fotossintéticos a ADC se localiza no cloroplasto enquanto que em tecidos heterótrofos a enzima se encontra no núcleo (Borrell et al. 1995, Bortolotti et al. 2004). É interessante mencionar que esse fato possui grande significância a respeito da evolução metabólica relacionada à endossimbiose já que explica a presença de duas vias de síntese de Put em plantas, assim como a ausência de ADC em animais (Borrell et al. 1995). Embora para as proteínas ortólogas de tabaco, uva, arabidopsis e arroz a análise in silico tenha indicado localização plastidial, a caracterização de LFP não revelou a presença de peptídeo sinal. Não entanto os experimentos de expressão transiente in vivo demonstraram que a proteína LFP é direcionada para o cloroplasto. Desta forma, e como proposto originariamente, os resultados sugerem a participação de LFP no metabolismo de PAs (em particular de Put) e, consequentemente de aminoácidos. Este estreito vínculo já foi reportado em diversas oportunidades. Por exemplo, células de álamo (Populos nigra) expressando a ODC de camundongo apresentaram altos níveis de Put e aumento massivo nos níveis de 
aminoácidos devido ao desvio do fluxo metabólico para a produção de poliaminas (Bhatnagar et al. 2001, Mohapatra et al. 2010). As poliaminas, pelo seu alto teor de N, são indicativas do nível deste elemento nas plantas e consequentemente seu conteúdo afeta a homeostase de N. Neste sentido, em tomate, a superexpressão da s-adenosilmetionina descarboxilase (SAMDC) de levedura, levou ao incremento de espermina e espermidina nos frutos. Este incremento foi acompanhado pelo aumento nos níveis de diversos metabólitos entre os quais se encontraram a glutamina e a asparagina. Estes dois os aminoácidos são considerados moléculas chave na comunicação entre o metabolismo de C e N (Lam et al. 1996). Assim, foi proposto que o aumento dos níveis de PAs sinalizaria um estado nutricional favorável da planta ativando o metabolismo dos frutos inclusive em estágios avançados do amadurecimento (Matoo et al. 2006). De forma oposta, é possível propor que nas plantas silenciadas para LFP, a queda na Put seja percebida como déficit de $\mathrm{N}$ explicando a redução de asparagina, aminoácido marcador da alta disponibilidade deste elemento pela sua alta proporção N/C (Lam et al. 1996). Se a alteração no conteúdo de aminoácidos observada nas plantas transgênicas fosse devido a alterações na síntese ou degradação de Put decorrentes do silenciamento de $L F P$, seria esperada uma queda massiva destes compostos ou aumento/diminuição dos aminoácidos diretamente envolvidos nas respectivas rotas (Mohapatra et al. 2010). No entanto, é observada uma redução nos níveis de asparagina exclusivamente, sugerindo que LFP não participa das rotas de biossíntese nem degradação de Put.

Em razão das PAs estarem envolvidas num amplo leque de processos, sua concentração intracelular deve ser estritamente regulada. Além do controle da síntese, a compartimentalização subcelular e a conjugação são mecanismos que contribuem à determinação da funcionalidade das PAs (Moschou et al. 2008). Quando as formas conjugadas foram quantificadas nas plantas silenciadas para $L F P$, foi revelado um incremento da Put conjugada, demonstrado que o gene LFP participa no controle da conjugação/desconjugação desta PA no tomateiro. Dois tipos de enzimas que atuam na conjugação de Put têm sido descritas. As transglutaminases (TGase) catabolizam pós-traducionalmente a união covalente entre proteínas e poliaminas (ex. mono-y-glutamyl-Put). Em Brassica pekinensis essa conjugação resulta na "fixação" das poliaminas nos cloroplastos como reportado por Cohen et al. (1982). Por outro lado, as hidroxicinamoil transferases conjugam PAs com ácidos fenólicos por meio da ligação covalente entre o grupo amina e o grupo carboxílico resultando em amidas de ácidos hidroxicinâmicos (HCAAs) (Martin-Tanguy 1997, Fontaniella et al. 2001, 2003). Diversas enzimas responsáveis por essas ligações já foram descritas, por exemplo, a enzima putrescina hidroxicinamoil transferase (PHT) a qual foi isolada de células de tabaco em suspensão e atua na síntese de cafeoilputrescina (Negrel 1989). Em folhas de tomateiro foi descrito que o tratamento com metil jasmonato (MeJA) induz o acúmulo de PAs conjugadas como cafeoilputrescina, assim como os níveis de RNAm dos genes que codificam as enzimas da rota biossintética, como ODC e ADC (Chen et al. 2006). É interessante notar que o ortólogo de LFP de tabaco, MC126, o qual foi estudado no contexto da 
biossíntese de alcaloides em células BY-2, também é induzido por MeJA novamente junto ao aumento de expressão dos genes $O D C$ e $A D C$, e o conteúdo de Put livre e conjugada (Goossens et al. 2003, Hakkinen et al. 2007), reforçando ainda mais o eventual papel de LFP na regulação da disponibilidade de Put.

Além de LFP de N. tabacum, o único gene funcionalmente descrito e que compartilha o domínio conservado PGGXGXXD, é o gene $L O G$, clonado a partir de um mutante de arroz que apresentava defeitos na manutenção do meristema apical. A proteína codificada por este gene possui atividade de fosforibohidrolase, convertendo citocinina ribosídeo $5^{\prime}$ monofosfato inativa em citocinina livre ativa como, por exemplo, iP (isopentenil adenina) e tZ (zeatina trans) (Kurakawa et al. 2007). As LOGs também foram estudadas em arabidopsis, onde também foi demonstrada a sua atuação na ativação de citocininas (Kuroha et al. 2009). A conjugação com açúcares, já foi identificada, como uma forma de regulação de diversos fitohormônios. Estudos indicam que as giberelinas podem conjugar-se com açúcares (Gibson 2004), e que tanto as auxinas como as citocininas podem ser também glicosiladas (Jackson et al. 2000). Da mesma forma, foi reportada também a associação das PAs com açúcares (Mateos et al. 2000). Adicionalmente, experimentos de ressonância magnética nuclear verificaram que as PAs podem também estar conjugadas a nucleotídeos tanto por meio de ligações com o fosfato quanto com a base nitrogenada (Song et al. 2010). No entanto, até o momento, nenhuma enzima foi proposta como possível candidata para estabelecer a interação entre PAs e açúcares ou nucleotídeos.

A análise integrada dos dados obtidos neste trabalho expõe claramente a semelhança estrutural e funcional de LFP com os genes MC126 e LOG permitindo propor a hipótese que a proteína LFP participe da regulação da associação das poliaminas com nucleotídeos ou açúcares abrindo assim, um campo inexplorado da bioquímica vegetal. 


\section{CONCLUSÕES}

LFP foi identificado como possível candidato associado à QTL para o conteúdo de $\beta$-alanina, GABA, lisina, metionina, treonina, homoserina, leucina, isoleucina, glicina, serina e valina Bermúdez et al. (2008). Não obstante, os resultados deste trabalho indicam que LFP não participa da determinação desses QTL, função que pode ser adjudicada a algum dos outros seis genes descritos por Bermúdez et al. (2008) ou ao novo candidato identificado no Capítulo I desta tese, a s-adenosil-L-metioninacarboxil metiltransferase. No entanto, a caracterização funcional de LFP de S. lycopersium revelou um gene de função inédita em plantas cujo silenciamento resultou no aumento da biomassaprovavelmente determinado pelo um aumento da divisão celular. Este fenótipo somado à diminuição nos níveis de putrescina livre e o aumento de putrescina conjugada nas plantas transgênicas permite propor que LFP atua no metabolismo de poliaminas, mas particularmente no controle da relação putrescina livre/conjugada. 


\section{REFERÊNCIAS BIBLIOGRÁFICAS}

Acosta, C., Pérez-Amador, M.A, Carbonell, J., Granell, A. (2005). The two ways to produce putrescine in tomato are cell-specific during normal development. Plant science, 168, 1053-1057.

Alcázar, R., Altabella, T., Marco, F., Bortolotti, C., Reymond, M., Koncz, C., Carrasco, P., Tiburcio, A. F. (2010). Polyamines: molecules with regulatory functions in plant abiotic stress tolerance. Planta, 231, 1237-49.

Altschul, S.F., Gish, W., Miller, W., Myers, E.W., Lipman, D. J. (1990). Basic local alignment search tool. Journal of Molecular Biology, 215, 403-410.

Astarita, L.V., Floh, E.I.S., Handro, W. (2003). Free amino acids, protein and water content changes associated with seed development in Araucaria angustifolia. Biologia plantarum, 47, 53-59.

Bachrach, U. (2010). The early history of polyamine research. Plant physiology and biochemistry : PPB / Société française de physiologie végétale. 48, 490-5.

Bagni, N., Altamura, M.M., Biondi, S., Mengoli, M., Torrigiani, P. (1993) Polyamines and morphogenesis in normal and transgenic plant cultures. In: Roubelakis-Angelakis KA, Van Tran Than K (eds) Morphogenesis in plants, molecular approaches, Plenum Press, New York, 89-111.

Bermúdez, L., Urias, U., Milstein, D., Kamenetzky, L., Asis, R., Fernie, A.R., Van Sluys, M.A., Carrari, F., Rossi, M. (2008). A candidate gene survey of quantitative trait loci affecting chemical composition in tomato fruit. Journal of Experimental Botany, 59, 2875-2890.

Bhatnagar, P., Glasheen, B.M., Bains, S.K., Long, S. L., Minocha, R., Walter, C., Minocha, S.C. (2001). Transgenic manipulation of the metabolism of polyamines in poplar cells. Plant physiology, 125, 2139-53.

Borrell, A., Culianez-Macia, F.A., Altabella, T., Besford, R.T., Flores, D., Tiburcio A. F. (1995). Arginine decarboxylase is localized in chloroplasts. Plant physiology, 109, 771-776.

Bortolotti, C., Cordeiro, A., Alcazar, R., Borrell, A., Culiañez-Macià, F.A., Tiburcio, A.F., Altabella, T. (2004). Localization of arginine decarboxylase in tobacco plants. Physiologia plantarum, 120, 8492.

Bunsupa, S., Katayama, K., Ikeura, E., Oikawa, A., Toyooka, K., Saito, K., Yamazaki, M. (2012). Lysine decarboxylase catalyzes the first step of quinolizidine alkaloid biosynthesis and coevolved with alkaloid production in Leguminosae. The Plant cell, 1-16.

Chen, H., Jones, A.D., Howe, G.A (2006). Constitutive activation of the jasmonate signaling pathway enhances the production of secondary metabolites in tomato. FEBS letters, 580, 2540-6.

Cohen, S.S. (1988). A guide to the polyamines, Oxford University Press, NY.

Cohen, S.S., Marcu, D.E., Balint, R. F. (1982) FEBS Lett. 141, 93-97.

Cohen, S.S., Morgan, S., Streibel, E. (1969). THE POLYAMINE CONTENT OF THE tRNA OF E. COLI. PNAS. 669-676.

Corpet, F. (1988). Multiple sequence alignment with hierarchical clustering. Nucleic Acids Research, 16, 10881-10890.

Di Rienzo, J.A. (2009). Statistical software for the analysis of experiments of functional genomics. RDNDA. Argentina. 756587.http://sites.google.com/site/fgStatistics/.

Drolet, G., Dumbroff, E.B., Legge, R., Thompson, J.E. (1986). Radical scavenging properties of polyamines. Phytochemistry, 25, 367-371.

Eshed, Y. e Zamir, D. (1995). An introgression line population of Lycopersicon pennellii in the cultivated tomato enables the identification and fine mapping of yield-associated QTL. Genetics, 141, 11471162.

Fernie, A.R., Roscher, A., Ratcliffe, G., Kruger, N.J. (2001). Fructose 2,6-biphosphate activates pyrophosphate: fructose-6-phosphate 1-phosphotransferase and increases triose phosphate to hexose phosphate cycling in heterotrophic cells. Plantta, 212, 250-263.

Fontaniella, B., Mateos, J.L., Vicente, C., Legaz, M.E. (2001). Improvement of the analysis of dansylated derivatives of polyamines and their conjugates by highperformance liquid chromatography. Journal of Chromatography, 919, 283-288. 
Fontaniella, B., Vicente, C., Legaz, M.E., Armas, R., Rodriguez, C.W., Martinez, M., Pinon, D., Acevedo, R., Solas, M.T. (2003).Yellow leaf syndrome modifies the composition of sugarcane juices in polysaccharides, phenols and polyamines. Plant Physiology and. Biochemestry, 41, 1027-1036.

Galston, A.W., Sawhney, R.K. (1990). Polyamines in plant physiology. Plant physiology, 94, 406-10.

Galston, A.W. (1983). Polyamines as modulators of plant development. BioScience, 33, 382-388.

Gibson, S.I. (2004). Sugar and phytohormone response pathways: navigating a signaling network. Journal of Experimental Bothany,55, 253-64.

Goossens, A., Häkkinen, S.T., Laakso, I., Seppänen-Laakso, T., Biondi, S., De Sutter, V., Lammertyn, F., Nuutila, A.M., Söderlund, H., Zabeau, M., Inzé, D., Oksman-Caldentey, K.M. (2003). A functional genomics approach toward the understanding of secondary metabolism in plant cells. Proc Natl Acad Sci, 100, 8595-600.

Häkkinen, S.T., Tilleman, S., Swiatek, A., De Sutter, V., Rischer, H., Vanhoutte, I., Van Onckelen, H., Hilson, P., Inzé, D., Oksman-Caldentey, K.M., et al. (2007). Functional characterisation of genes involved in pyridine alkaloid biosynthesis in tobacco. Phytochemistry, 68, 2773-85.

Handa, A.K. e Mattoo, A.K. (2010). Differential and functional interactions emphasize the multiple roles of polyamines in plants. Plant physiology and biochemistry : PPB / Société française de physiologie végétale, 48, 540-6.

Hartmann, T., Schoofs, G., Wink, M. (1980). A chloroplast localized lysine descarboxylase of LUPINUS POLYPHYLLUS - The first enzyme in the biosynthetic pathway of quinolizidine alkaloids. FEBS Letters, 115, 35-38.

Hedberg, C., Hesse, M., Werner, C. (1996). Spermine and spermidine hydroxycinnamoyl transferases in Aphelandra tetragona. Plant Science. 113, 149-156.

Hoeckema, A., Hirsch, P.R., Hooykas, P.J., Schilperoot, R.A. (1983). A binay plant vector strategy based on separation of vir and T-region of the Agrobacterium tumefaciens Ti-plasmid. Nature, 303, 179180.

Illingworth, C., Mayer, M.J., Elliott, K., Hanfrey, C., Walton, N.J., Michael, A.J. (2003). The diverse bacterial origins of the Arabidopsis polyamine biosynthetic pathway. FEBS Letters, 549, 26-30.

Jackson, R.G., Lim, E.K., Li, Y., Kowalczyk, M., Sandberg, G., Hoggett, J., Ashford, D.A., Bowles, D.J. (2001). Identification and biochemical characterization of an Arabidopsis indole-3-acetic acid glucosyltransferase. J Biol Chem, 276, 4350-6.

Kamenetzky, L., Asís, R., Bassi, S., de Godoy, F., Bermúdez, L., Fernie, A.R., Van Sluys, M.A., Vrebalov, J., Giovannoni, J.J., Rossi, M., et al. (2010). Genomic analysis of wild tomato introgressions determining metabolism- and yield-associated traits. Plant physiology, 152, 1772-86.

Karimi, M., Inzé, D., Depicker, A. (2002). GATEWAY vectors for Agrobacterium - mediated plant transformation. Trends in Plant Science, 7, 193-195.

Kaur-Sawhney, R., Tiburcio, A.F., Altabella, T., Galston, A.W. (2003). Polyamines in plants: An overview. Journal of Cell and Molecular Biology, 2, 1-12.

Kumar, A., Altabella, T., Taylor, M.A., Tiburcio, A.F. (1997). Recent advances in polyamine research. Science, 2, 124-130.

Kurakawa, T., Ueda, N., Maekawa, M., Kobayashi, K., Kojima, M., Nagato, Y., Sakakibara, H., Kyozuka, J. (2007). Direct control of shoot meristem activity by a cytokinin-activating enzyme. Nature, 445, 652-5.

Kuroha, T., Tokunaga, H., Kojima, M., Ueda, N., Ishida, T., Nagawa, S., Fukuda, H., Sugimoto, K., Sakakibara, H. (2009). Functional analyses of LONELY GUY cytokinin-activating enzymes reveal the importance of the direct activation pathway in Arabidopsis. The Plant cell, 21, 3152-69.

Lam, H.M., Coschigano, K.T., Oliveira, I.C., Melo-Oliveira, R., Coruzzi, G.M. (1996) The molecular genetics of nitrogen assimilation into aminoacids in higher plants. Annual Review on plant physiology, 47, 569-59 3

Liquori, A.M., Costantino, L., Crescenzi, V., Elia, V., Giglio, E., Puliti, R., Savino, M.S., Vitagliano, V. (1967). Complexes between DNA and Polyamines: a Molecular Model. Journal of Molecular Biology. 24, 113-122. 
Marco, F., Alcázar, R., Tiburcio, A.F., Carrasco, P. (2011). Interactions between polyamines and abiotic stress pathway responses unraveled by transcriptome analysis of polyamine overproducers. OMICS: A Journal of Integrative Biology, 15, 775-781.

Martin-Tanguy, J. (1997). Conjugated polyamines and reproductive development: Biochemical, molecular and physiological approaches. Physiologia Plantarum, 100, 675-688.

Mateos, J.L., Reyes, A., Vicente, C., Legaz, M.E. (2000). Separation of polyamines, conjugated to DNA, by reversed-phase high-performance liquid chromatography. Journal of Chromatography, 870, 425-31.

Mattoo, A.K. e Handa, A.K. (2008). Higher polyamines restore and enhance metabolic memory in ripening fruit. Plant Science, 174, 386-393.

Mattoo, A.K., Minocha, S.C., Minocha, R., Handa, A.K. (2010). Polyamines and cellular metabolism in plants: transgenic approaches reveal different responses to diamine putrescine versus higher polyamines spermidine and spermine. Amino acids, 38, 405-13.

Mattoo, A.K., Sobolev, A.P., Neelam, A., Goyal, R. K., Handa, A.K., Segre, A.L. (2006). Nuclear Magnetic Resonance Spectroscopy-Based Metabolite Profiling of Transgenic Tomato Fruit Engineered to Accumulate Spermidine and Spermine Reveals Enhanced Anabolic and. Plant physiology, 142, 1759-1770.

Maxwell, K. e Johnson, G.N. (2000). Chlorophyll fluorescence - a practical guide. Journal of experimental botany, 51, 659-68.

McCabe, D.E., Swain, W.F., Martinell, B.J., Christou, P. (1988). Stable transformation of soybean (Glycine max) by particle acceleration. Biotechnology, 6, 923-926.

McConlogue, L., Gupta, M., Wu, L., Coffino, P. (1984). Molecular cloning and expression of the mouse ornithine decarboxylase gene. Proceedings of the National Academy of Sciences of the United States of America. 81, 540-4.

Mehta, R.A, Cassol, T., Li, N., Ali, N., Handa, A.K. e Mattoo, A.K. (2002). Engineered polyamine accumulation in tomato enhances phytonutrient content, juice quality, and vine life. Nature biotechnology. 20, 613-8.

Mello, C.C. e Conte-Jr, D. (2004). Revealing the world of RNA interference. Nature, 431, 338-342.

Mohapatra, S., Minocha, R., Long, S., Minocha, S.C. (2010). Transgenic manipulation of a single polyamine in poplar cells affects the accumulation of all amino acids. Amino acids, 38, 1117-29.

Moschou, P.N., Paschalidis, K.A., Roubelakis-Angelakis, K.A (2008). Plant polyamine catabolism: The state of the art. Plant signaling \& behavior, 3, 1061-6.

Mueller, L.A., Solow, T.H., Taylor, N., Skwarecki, B., Buels, R., Binns, J., Lin, C., Wright, M.H., Ahrens, R., Wang, Y., et al. (2005). The SOL Genomics Network . A comparative resource for Solanaceae biology and beyond . Bioinformatics, 138, 1310-1317.

Negrel, J. (1989). The biosynthesis of cinnamoylputrescines in callus tissue cultures of Nicotiana tabacum. Phytochemistry, 28, 477-481.

Neily, M.H., Matsukura, C., Maucourt, M., Bernillon, S., Deborde, C., Moing, A., Yin, Y.G., Saito, T., Mori, K., Asamizu, E., et al. (2011). Enhanced polyamine accumulation alters carotenoid metabolism at the transcriptional level in tomato fruit over-expressing spermidine synthase. Journal of Plant Physiology, 168, 242-252.

Ohe, M., Scoccianti, V., Bagni, N., Tassoni, A., Matsuzaki, S. (2009). Putative occurrence of lysine decarboxylase isoforms in soybean (Glycine max) seedlings. Amino acids, 36, 65-70.

Ono, M., Inoue, H., Suzuki, F., Takeda, Y.(1972). Studies on ornithine decarboxylase from the liver of thioacetamide-treated rats. Purification and some properties. Biochim Biophys Acta, 284, 285-97.

Paschalidis, K.A. e Roubelakis-Angelakis, K.A. (2005). Spatial and temporal distribution of polyamine levels and polyamine anabolism in different organs / tissues of the tobacco plant. Correlations with age , cell, division/expansion, and differentiation. Plant physiology, 138, 142-152.

Pérez-Amador, M.A., Carbonell, J., Granel, A. (1995). Expression of arginine decarboxylase is induced during early fruit develop- ment and in young tissues of Pisum sativum (L.). Plant molecular biology, 28, 997-1009. 
Pfaffl, M.W., Horgan, G.W., Dempfle, L. (2002). Relative expression software tool (REST) for group-wise comparison and statistical analysis of relative expression results in real-time PCR. Nucleic acids research, 30, e36.

Punta, M., Coggill, P.C., Eberhardt, R.Y., Mistry, J., Tate, J., Boursnell, C., Pang, N., Forslund, K., Ceric, G., Clements, J., et al. (2012). The Pfam protein families database. Nucleic acids research, 40, D290-301.

Rastogi, R. e Davies, P.J. (1990). Polyamine Metabolism in Ripening Tomato Fruit. 1. Identification of Metabolites of Putrescine and Spermidine. Plant Physiology. 94, 1449-1455.

Ruijter, J. M., Ramakers, C., Hoogaars, W.M.H., Karlen, Y., Bakker, O., van den Hoff, M.J.B., Moorman, F.M. (2009). Amplification efficiency: linking baseline and bias in the analysis of quantitative PCR data. Nucleic acids research, 37, e45.

Saftner, R. e Baldi, B. G. (1990). Polyamine levels and tomato fruit development: possible interaction with ethylene. Plant physiology, 92, 547-50.

Sambrook, J., Fritsch, T., Maniatis, T. (1989) Molecular cloning: A laboratory manual. Cold Spring Harbor Laboratory Press, Cold Spring Harbor, NY.

Schauer, N., Semel, Y., Roessner, U., Gur, A., Balbo, I., Carrari, F., Pleban, T., Perez-Melis, A., Bruedigam, C., Kopka, J., et al. (2006). Comprehensive metabolic profiling and phenotyping of interspecific introgression lines for tomato improvement. Nature biotechnology, 24, 447-54.

Schons, J. e Brasil, G. (1995). Poliaminas na embriogênese somática em cenoura (Daucus carota L.). Scientia Agricola Journal, 52, 534-536.

Sergiev, I.G., Alexieva, V.S., Karanov, E.N. (1995). Cytokinin and anticytokinin effects on growth and free polyamine content in etiolated and green radish cotyledons. Journal of Plant Physiology, 145, 266-270.

Sienkiewicz-Porzucek, A., Sulpice, R., Osorio, S., Krahnert, I., Leisse, A., Urbanczyk-Wochniak, E., Hodges, M., Fernie, A.R., Nunes-Nesi, A. (2010). Mild reductions in mitochondrial NAD-dependent isocitrate dehydrogenase activity result in altered nitrate assimilation and pigmentation but do not impact growth. Molecular plant, 3, 156-73.

Smith, T. A. (1977). Homospermidine in Rhizobium and legume root nodules. Phytochemistry, 16, 278279.

Sokal, R.R. e Rohlf, F.J. (1981). Biometry. Second Edition. Freeman, New York.

Tamura, K., Peterson, D., Peterson, N., Stecher, G., Nei, M., Kumar, S. (2011). MEGA5: molecular evolutionary genetics analysis using maximum likelihood, evolutionary distance, and maximum parsimony methods. Molecular biology and evolution, 28, 2731-9.

Van de Poel, B., Bulens, I., Oppermann, Y., Hertog, M.L.A.T.M., Nicolai, B.M., Sauter, M., Geeraerd, A.H. (2012). S-adenosyl-I-methionine usage during climacteric ripening of tomato in relation to ethylene and polyamine biosynthesis and transmethylation capacity. Physiologia plantarum.

Villanueva, V.R. e Adlakha, R. C. (1978). Automated analysis of common basic amino acids, mono-, di-, and polyamines, phenolicamines and indoleamines in crude biological samples. Analytical Biochemistry, 91, 264-275.

Walden, R., Cordeiro, A., Tiburcio, A.F. (1997). Polyamines: small molecules triggering pathways in plant growth and development. Plant physiology, 113, 1009-13.

Wallace, H.M., Fraser, A.V., Hughes, A. (2003). A perspective of polyamine metabolism. Biochemical Journal, 376, 1-14.

Walters, D.R. (2003). Polyamines and plant disease. Phytochemistry, 64, 97-107.

Wang, Y., Luo, J.-P., Wu, H.Q., Jin, H. (2009). Conversion of protocorm-like bodies of Dendrobium huoshanense to shoots: The role of polyamines in relation to the ratio of total cytokinins and indole-3-acetic acidindole-3-acetic acid. Journal of Plant Physiology, 166, 2013-2022.

Waterhouse, P.M. e Helliwell, C.A. (2003). Exploring plant genomes by RNA-induced gene silencing. Nature Reviews, 4, 29-38.

Wen-Jun, S. e Forde, B. (1989). Efficient transformation of Agrobacterium spp. by high electroporation. Nucleic acids research, 17, 8385.

Wimalasekera, R., Tebartz, F. e Scherer, G.F.E. (2011). Polyamines, polyamine oxidases and nitric oxide in development, abiotic and biotic stresses. Plant science, 181, 593-603. 
Song, Z., Parker, K.J., Enoh, I., Zhao, H., Olubajo, O.L. (2010). Elucidation of spermidine interaction with nucleotide ATP by m ultiple NMR techniques. Magn.Reson.Chem. 48, 123-128. 
CAPÍTULO III: ESTUdO dA FAMÍLIA MULTIGÊNICA DAS GALACTURONOSILTRANSFERASES E CARACTERIZAÇÃO ESTRUTURAL E FUNCIONAL DO GENE GAUT4 


\section{INTRODUÇÃO}

A parede celular é uma estrutura macromolecular complexa que rodeia todas as células vegetais. Além de sustentar o corpo da planta e de ser uma barreira física que a protege de organismos invasores, a parede restringe a taxa e direção do crescimento celular influenciando o desenvolvimento e a morfologia do organismo. Determinando a forma das células vegetais, esta estrutura contribui à especialização funcional das mesmas (Buchanan et al. 2000). Adicionalmente, a parede representa uma importante reserva de energia, principalmente para as sementes de algumas espécies. Grãos de gramíneas, como milho, arroz e trigo, além do amido armazenado no endosperma utilizam material de parede como fonte de energia (Burton et al. 2010). Nas leguminosas a principal função da parede das células do endosperma é atuar como reserva (Buckeridge 2010). Por exemplo, $40 \%$ do peso seco dos cotilédones da semente de jatobá, Hymenaea courbaril, é composto por xiloglucano, um polissacarídeo da parede celular que é mobilizado para gerar energia durante as primeiras fases do desenvolvimento da plântula (Santos e Buckeridge 2004). Por sua vez, fragmentos não celulósicos derivados da degradação da parede são importantes sinalizadores para diversos estímulos internos e ambientais. Por exemplo, em tomate foi demonstrado que fragmentos de oligogalacturonidios derivados de pectina têm ação regulatória na produção de etileno durante o processo de amadurecimento (Campbell e Lebavitch 1991). Esse mesmo tipo de fragmentos pode desencadear ainda mecanismos de defesa como a indução da síntese de fitolexinas, lignina e inibidores de proteinases como resposta ao ataque de patógenos (Cotê e Hann 1994, Hammond-Kosack e Jones 1996).

A estrutura da parede é dinâmica, mudando ao longo da vida da célula. Durante o crescimento inicial e a fase de expansão, a célula é envolvida apenas pela parede celular primária. Em algumas células a parede é engrossada e fortalecida pela adição de uma parede secundária, depositada entre a membrana plasmática e a parede primária (Figura 1A) (Caffall e Mohnen 2009). A parede celular das eudicotiledôneas consiste em polissacarídeos - micro fibrilas de celulose, hemicelulose, e a matriz de pectina- compostos fenólicos, íons e glicoproteínas estruturais (Carpita e Gibeaut, 1993) (Figura 1B). A celulose é o componente comum a todas as paredes celulares vegetais e é constituída por cadeias não ramificadas de $\beta$-(1,4)-D-glicose que se associam entre si por ligações de hidrogênio e forças de Van der Waals (Burton et al. 2010). As hemiceluloses são polímeros de parede que assumem uma conformação parecida a da celulose e que através de ligações de hidrogênio podem se ligar a ela. Existem quatro tipos de hemicelulose: xilanos, xiloglucanos, mananos e arabinogalactanos. Os xilanos são polímeros lineares de $\beta$-(1,4)-D-xilose que podem ser modificados pela adição de arabinose (arabinoxilanos) ou ácido glucurônico (glucuronoxilano) ou ainda pela adição dos dois açúcares (glucuronoarabinoxilano). Já os xiloglucanos tem uma estrutura como a de celulose, sendo um polímero de $\beta$-(1,4)-D-glicose modificado pela adição de xilose (Caffall e Mohnen 2009). Menos abundantes, os mananos são polímeros de $\beta$ - $(1,4)$ D-manose que podem ser modificados pela adição de galactose dando origem aos galactomananos. 
Finalmente, os arabinogalactanos são polímeros de $\beta$-(1,6)-D-galactose ramificados por cadeias de $\alpha$ (1,2)-L-arabinose (Buckeridge 2010).
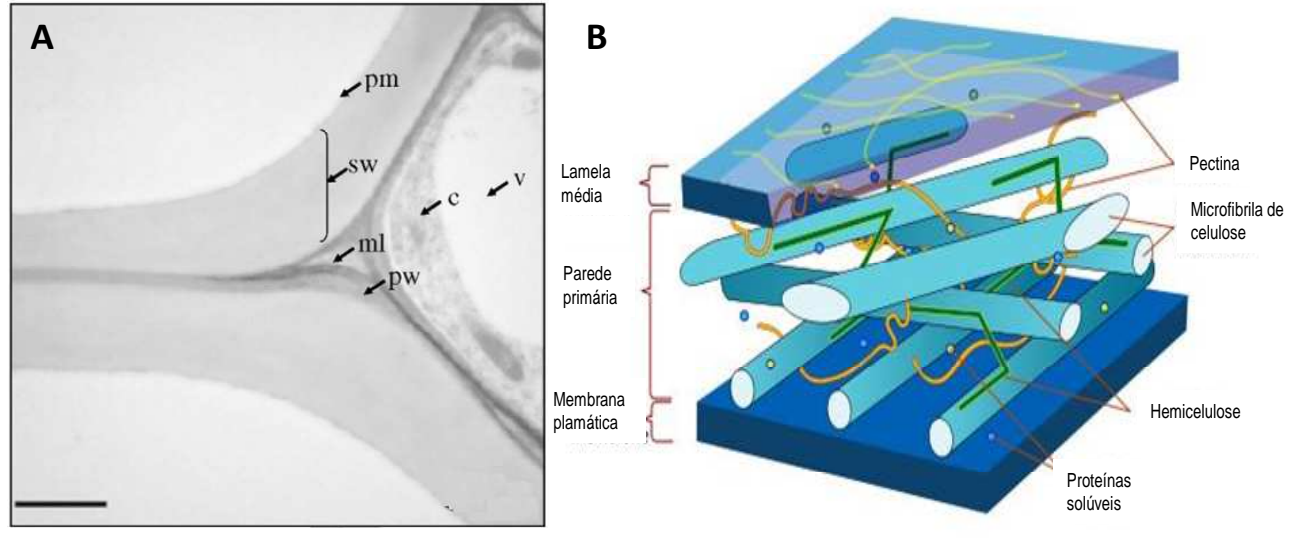

Figura 1: A parede celular.

(A) Microfotografia apresentando a membrana plasmática (pm), parede secundária (sw), parede primária (pw), lamela média ( $\mathrm{ml}$ ), citoplasma (c) e vacúolo (v). A barra representa $2 \mu \mathrm{m}$. Adaptado de Caffall e Mohnen (2009). (B) Esquema da parede celular.

Em plantas a parede celular primária pode estar organizada de duas formas distintas, parede do TIPO I e TIPO II. A maioria das eudicotiledônias e as monocotiledôneas não comelinóides apresentam parede do TIPO I, onde as microfibrilas de celulose são interligadas e estabilizadas por xiloglucanos. Essa estrutura celulose:xiloglucano esta embebida em uma matriz que contém grande quantidade de pectina. A parede do TIPO II esta presente nas monocotiledôneas comelinóides e se caracteriza por ter glucuronoarabinoxilano como polissacarídeo que interliga e estabiliza a estrutura das microfibrilas e por ser pobre em pectinas (Carpita e Gibeaut 1993, Buchanan et al. 2000).

As pectinas são uma família de polissacarídeos complexos ricos em D-ácido galacturônico (GalA) o qual perfaz $70 \%$ da pectina (Mohnem 2008). Existem dois tipos de polímeros que compõem a estrutura básica da pectina: o homogalacturano (HG) e o raminogalacturano I (RG I) (Figura 2).

O HG é um polímero de $\alpha$-(1,4)-D-GalA sem ramificações. Acredita-se que o HG seja secretado na parede altamente metilado sendo que as metilas são acrescentadas no carbono 6 dos resíduos de GalA (Ridley et al. 2001). Os resíduos não metilados são carregados negativamente e, por isso, podem interagir com $\mathrm{Ca}^{2+}$ formando um gel estável. Essa interação com cálcio gera uma estrutura compacta que é chamada de "caixa de ovo" (Caffall e Mohnen 2009). O HG pode ainda ser modificado pela adição de xilose ou apiofuranose, dando origem ao xilogalacturano (XGA) e apiogalacturano, respectivamente. Além dessas simples substituições o HG pode estar ramificado com complexas cadeias laterais formando raminogalacturano II (RG II). Geralmente, cada domínio de RG-II possui quatro longas cadeias laterais complexas nomeadas de A a D, que juntas, possuem 11 tipos diferentes de açúcares (Harholt et al. 2010) (Figura 2). O domínio RG-II é encontrado como dímero, sendo que a ligação entre as duas 
unidades se estabelece entre cadeias A e é intermediada por um íon borato (O'Neill et al. 2001). O RG-II é ubíquo e perfaz $8 \%$ da parede de folhas de $A$. thaliana (Caffall e Mohnen 2009).

Já o RG I é composto por um esqueleto formado por GalA e raminose (Rha) formando unidades do dissacarídeo $\alpha-1,4-D-G a l A-\alpha-1,2-L-R h a$ (Figura 2). Os resíduos de raminose da base podem ser ramificados com estruturas $\alpha-(1,5)$-arabinanos, $\beta-(1,4)$ galactanos e vários arabinogalactanos (Carpita e Gibeaut 1993). Ao contrario do que acontece em RG-II, as ramificações de RG I são muito variáveis nas diferentes espécies. É importante ressaltar que as diferentes estruturas descritas acima não ocorrem de forma isolada, mas compondo diferentes domínios da mesma matriz péctica (Harholt et al. 2010).

Em fruto de tomateiro, $1 / 4$ da massa da parede é composta por pectina, Interessantemente, as pectinas são menos ramificadas e com menos quantidade de RG, quando comparada a outras espécies. Além disso, de 60 a 70 \% dos resíduos de GalA estão metilados. A hemicelulose desempenha um papel adicional em tomate, por estar presente nas junções celulares, participando da adesão celular. Diferente do que acontece em outras espécies, a hemicelulose de tomate é abundante em mananos (Houben et al. 2011, Christiaens et al. 2012).

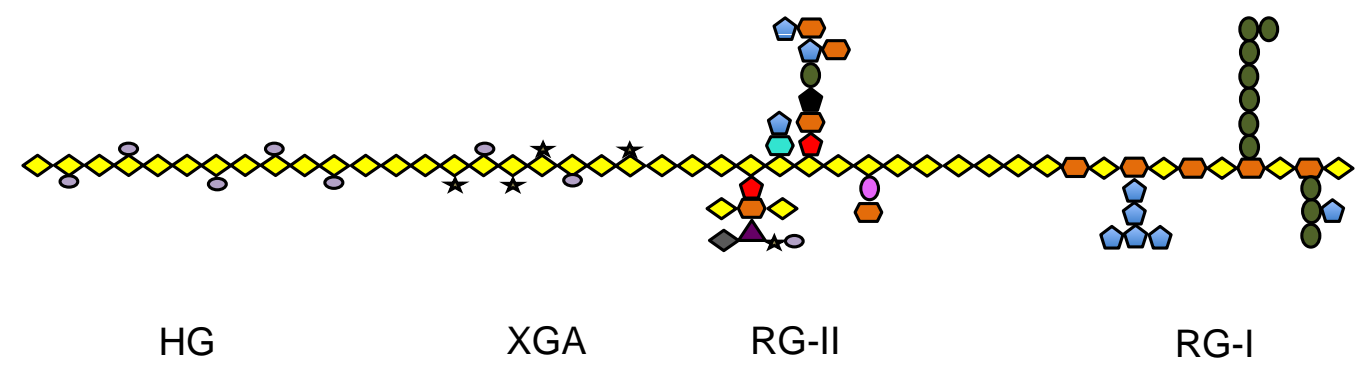

$\begin{array}{lll}\text { Legenda: } & & \\ \diamond \text { Ácido galacturonico } & \triangle \text { Apiose } & \star \text { Xilose } \\ \square \text { Raminose } & \diamond \text { Ácido glucuronico } & \text { O KDO } \\ \checkmark \text { Arabinose } & \triangle \text { Fucose } & \bigcirc \text { Grupo metila } \\ 0 \text { Galactose } & \square \text { Ácido acérico } & \square \text { Dha }\end{array}$

Figura 2: Representação esquemática da estrutura da pectina.

Esta representada a estrutura e composição dos quatro diferentes domínios que compõem a pectina. KDO (ácido 3-desoxi-D-mano-2-octulosônico) e Dha (ácido desoxi-lixo-heptalosárico). Adaptado de Mohnen 2008.

De acordo com os dados de localização das poucas enzimas que foram caracterizadas até o momento (Harholt et al. 2010), a biossíntese dos polissacarídeos da matriz de pectinas ocorre nas membranas do complexo de Golgi (Keegstra 2010). É proposto que a biossíntese aconteça simultaneamente em diversas vesículas do Golgi de uma maneira compartimentalizada e sequencial, onde cada vesícula contém uma enzima específica do processo (Mohnen et al. 2008). Por se tratar de um polímero tão complexo, foi estimado que mais de 67 enzimas sejam necessárias para a síntese dos polissacarídeos pécticos (Mohnen et al. 2008), entre essas enzimas se encontram as 
galacturonosiltransferases (GAUT) que estão associadas à síntese de pectina transferindo unidades de ácido galacturônico à extremidade não redutora de HG (Sterling et al. 2006).

As GAUTs pertencem ao grupo das glicosiltransferases (GT), enzimas que estão catalogadas no banco de dados CAZy juntamente com outras enzimas do metabolismo de carboidratos (www.cazy.org, Cantarel et al. 2009). Mais especificamente, fazem parte da família 8 das GTs (Harholt et al. 2010, Yin et al. 2010) que pode ser dividida em três classes de proteínas. As Classes I e II consistem de proteínas eucarióticas, enquanto que a classe III de proteínas de origem bacteriana. O grupo das proteínas relacionadas à parede celular de plantas, o qual inclui as GAUTs e as galacturonosiltransferases-like (GATLs), fazem parte da Classe I. Uma extensiva análise filogenética mostrou que a família GT8 foi adquirida de um progenitor ancestral de cianobactéria, e posteriormente dividida nas três classes que passaram a ter especialização funcional. Mais ainda, o número de genes GAUT e GATL aumentou nas plantas superiores o que sugeriria que esses genes possuem um papel importante na adaptação das plantas ao ambiente terrestre (Yin et al. 2010).

Até o momento, a atividade de galacturonosiltransferase (GAUT) foi demonstrada apenas para o produto de um único gene identificado em $A$. thaliana que foi denominado GAUT1. A caracterização bioquímica de GAUT1 comprovou seu papel na elongação dos oligogalactoronídeos (OGAs) (Sterling et al. 2001, 2006). Recentemente, foi demonstrado que GAUT1 atua no lúmen do Golgi formando um complexo juntamente com a GAUT7, que ancora o complexo proteico na membrana (Atmodjo et al. 2011).

Tanto as GAUTs quanto as GATLs pertencem a famílias multigênicas. A. thaliana contém 15 GAUTs e 10 GATLs (Caffall et al. 2009). Devido à redundância entre os membros dessa família e aos efeitos pleiotrópicos, a assinação de uma função específica para cada membro da família se torna uma tarefa muito difícil. Adicionalmente a GAUT1 e GAUT7, foram estudados funcionalmente outros três genes dessa família e o fenótipo encontrado sugere que as proteínas GAUT possuem diversas atividades específicas na síntese de pectinas. Em 2002, Bouton et al. descreveram o mutante de $A$. thaliana quasimodo 1 (qua 1), que possui uma inserção de T-DNA no gene GAUT8 e apresenta reduzida adesão celular e fenótipo anão. Análises bioquímicas da parede celular dessa mutante revelaram redução no conteúdo de ácido galacturônico e xilose, assim como um aumento significativo no conteúdo de arabinose, raminose e fucose (Leboeuf et al. 2005, Orfila et al. 2005). Desta forma, foi proposto que a alteração na adesão celular fosse resultado da diminuição nos níveis de $\mathrm{HG}$ interagindo com $\mathrm{Ca}^{2+}$, enquanto que a alteração na composição das pectinas indicam mudanças ou deficiências na ramificação das mesmas (Orfila et al. 2005). Por sua vez, a caracterização do mutante irx8, permitiu propor que o alelo selvagem da GAUT12 esteja envolvido na biossíntese de glucuranoxilano (GX) (Peña et al. 2007). A mutação desse gene levou a uma redução de 57 \% no conteúdo de xilose (Xyl), levando a hipótese de que GAUT12 seja responsável pela adição de um resido de $\alpha$-D-GalA ao resíduo de xilose da sequencia $\alpha$-D-Xyl-(1,4)- $\beta$-D-Xyl-(1,3)- $\alpha$-L-Rha-(1,2)- $\alpha$-D-GalA-(1,4)-D-Xyl presente na extremidade redutora dos 
GXs (Peña et al. 2007). Finalmente, estudos recentes com a mutante para o gene da GATL1 (parvus), demonstraram que o fenótipo dessas plantas é muito similar ao das mutantes irx8. Assim foi proposto que os dois genes estejam envolvidos na mesma via biossintética. (Brown et al. 2007, Lee et al. 2007).

Por meio da abordagem de genes candidatos, Bermúdez et al. (2008) descreveu uma lista de genes candidatos que mapeiam junto a QTLs para caracteres agronômicos de grande importância no tomateiro. Entre os genes identificados encontra-se um gene que codifica para uma putativa GAUT e que colocaliza com um QTL para ácido galacturônico livre em frutos maduros. Embora o metabolismo da parede celular tenha grande importância para a qualidade agronômica e industrial deste cultivo, já que determina caracteres como tempo de amadurecimento e conteúdo de ácidos solúveis (brix), até o momento nenhum gene da família das GAUTs foi descrito em tomateiro. Assim, esse estudo propôs a caracterização funcional do gene identificado por Bermúdez et al. (2008) visando compreender a sua participação no metabolismo de pectina assim como seu efeito sobre a fisiologia da planta como um todo. 


\section{OBJETIVOS}

O objetivo geral deste capítulo foi realizar o estudo da família multigênica das galacturonosiltransferases e a caracterização estrutural e funcional do gene GAUT4. Assim, foram propostos os seguintes objetivos específicos:

- Identificar todos os genes que codificam galacturonosiltransferases em tomateiro;

- Realizar um estudo filogenético da família multigênica;

- Estudar o perfil transcricional dos membros da família multigênica;

- Analisar da estrutura do gene GAUT4 e a localização subcelular da proteína codificada e;

- Avaliar o efeito do silenciamento gênico por RNA de interferência. 


\section{RESULTADOS, MATERIAL E MÉTODOS E DISCUSSÃO}

Os resultados, material e métodos e discussão deste capítulo são apresentados na forma de artigo científico aceito para publicação no periódico Journal of Experiemental Botany. 


\section{Galacturonosyltransferase 4 silencing alters pectin composition and carbon partitioning in tomato}

de Godoy Fabiana ${ }^{\ddagger \#}$, Bermúdez Luisa ${ }^{\ddagger \#}$, Silvestre Bruno Lira ${ }^{\ddagger}$, de Souza Amanda Pereira ${ }^{\ddagger}$, Elbl Paula ${ }^{\ddagger}$, Demarco Diego ${ }^{\ddagger}$, Alseekh Saleh ${ }^{\S}$, Insani Marina ${ }^{*}$, Buckeridge Marcos$^{\ddagger}$, Almeida Juliana ${ }^{\ddagger}$, Grigioni Gabriela $^{\ddagger}$, Fernie Alisdair Robert ${ }^{\S}$, Carrari Fernando ${ }^{*}$ and Rossi Magdalena ${ }^{\ddagger 1}$.

‡ Departamento de Botânica-IB-USP, 277, 05508-900, São Paulo, SP, Brazil.

$\S$ Max Planck Institute for Molecular Plant Physiology, Wissenschaftspark Golm, Am Mühlenberg 1, Potsdam-Golm, D-14 476, Germany.

* Instituto de Tecnología de Alimentos, Instituto Nacional de Tecnología Agropecuaría, PO Box 25, B1712WAA Castelar, Argentina.

*Instituto de Biotecnología, Instituto Nacional de Tecnología Agropecuaría, PO Box 25, B1712WAA Castelar, Argentina.

\# These authors contributed equally to this work

${ }^{1}$ Corresponding Author:

Magdalena Rossi, Departamento de Botânica, Instituto de Biociências, Universidade de São Paulo, Rua do Matão, 277, 05508-900, São Paulo, Brasil. Phone: 55-11-3091-8063, FAX: 55-11-3091-7547. e-mail: mmrossi@usp.br

Running title: Characterization of the tomato GAUT4

de Godoy Fabiana: fabidegodoy@gmail.com

Bermúdez Luisa: lubhe0@gmail.com

Lira Bruno Silvestre: bslira.bsl@gmail.com

de Souza Amanda Pereira: amanda_psouza@yahoo.com.br

Elbl Paula: paulaelbl@gmail.com

Demarco Diego: diegodemarco@usp.br

Alseekh Saleh: Alseekh@mpimp-golm.mpg.de

Marina Insani: minsani@cnia.inta.gov.ar

Buckeridge Marcos: msbuck@usp.br

Almeida Juliana: juliana_abs@yahoo.com.br

Grigioni Gabriela: ggrigioni@cnia.inta.gov.ar 
Fernie Alisdair Robert: Fernie@mpimp-golm.mpg.de

Carrari Fernando: fcarrari@cnia.inta.gov.ar

Date of submission: March $12^{\text {th }}, 2013$.

Number of tables: 3

Number of figures: 8 (1, 2, 3 coloured in print and online versions; 4, 5, 6, 7 and 8 black and white).

Total word count (without title, authors and affiliation): 11,098

Supplementary tables: 3

Supplementary figures: 2 
ABSTRACT

Pectin is a main component of cell wall and the most complex family of polysaccharides in nature. Its composition is essential for the normal growth and morphology pattern, as demonstrated by pectindefective mutant phenotypes. Besides this basic role in plant physiology, in tomato, pectin structure contributes to very important quality traits such as fruit firmness. Sixty seven different enzymatic activities have been sugested to be required for pectin biosynthesis but only a few genes have been identified and studied so far. In this work we characterized the tomato galacturonosyltransferase family and performed a detailed functional study of the GAUT4 gene. The tomato genome harbors all orthologous genes to those previously described in $A$. thaliana and a transcriptional profile revealed that the GAUT4 gene is expressed at higher levels in developing organs. GAUT4 silenced tomato plants exhibited an increment in vegetative biomass associated with the palisade parenchyma enlargement. Silenced fruits showed an altered pectin composition, accumulated less starch along with a reduced amount of pectin which coincided with an increase in firmness. Moreover, harvest index was dramatically reduced as a consequence of reduction in the fruit weight and number. Altogether, these results suggest that, beyond its role in pectin biosynthesis, GAUT4 interferes with carbon metabolism, partitioning and allocation. Hence, this cell wall-related gene seems to be key in determining plant growth and fruit production in tomato.

Key words: fruit metabolism, galacturonic acid, galacturonosyltransferase, pectin, Solanum pennellii, tomato. 


\section{INTRODUCTION}

The main role of cell walls is to confer physical strength and provide a barrier against the external environment. Pectins constitute the $\sim 35 \%$ of the primary cell wall in eudicot and nongraminaceous monocots, and $2-10 \%$ in grasses (Mohnen, 2008). Thus, as a main component of cell wall, pectins contribute to these two functions together with cellulose and hemicellulose. Pectins include a family of polysaccharides, whose major constituent is galacturonic acid (GalA) ( 70 \%). Four pectin polysaccharides have been described: homogalacturonan (HG), xylogalacturonan (XGA), rhamnogalacturonan II (RG-II), and rhamnogalacturonan I (RG-I). HG is a linear polymer made of $\alpha-1,4-$ linked GalA and is the most abundant component of pectin ( $65 \%)$. XGA is a modified HG with lateral ramifications of xylose attached to the 0-3 position of some GalA residues. RG-II is a much more complex structure and makes up $\sim 10 \%$ of the pectin. In RG-II the HG backbone is complemented by lateral chains composed of 12 different sugars attached by 22 distinct linkages. Finally, RG-I is the only pectin polysaccharide whose backbone is not exclusively made of GalA but composed of a disaccharide ( $\alpha-1,4-D-G a l A-\alpha-1,2-L-R h a)$ repeating unit where the L-rhamnose (Rha) residues may be branched with arabinan, galactan, and/or arabinogalactan (Harholt et al., 2010). Different models have been proposed to explain how these structural elements are combined into a macromolecular structure. The model most consistent with the recent results suggests the existance of a RGI-I backbone decorated with side chains composed by the other pectic constituents (Vincken et al., 2003).

Galacturonosyltransferases (GAUTs) are amongst the enzymes responsible for pectin biosynthesis and belong to a vast group of glycosyltransferases that, together with other carbohydrate active enzymes, are cataloged in the CAZy database (www.cazy.org, Cantarel et al., 2009). More specifically they can be assigned to the glycosyltransferase family 8 (GT8) (Harholt et al., 2010; Yin et al., 2010) consisting of three separate protein classes. Class I and class II contain mostly eukaryotic proteins, while class III consists almost entirely of bacterial proteins. The plant cell wall-related proteins are all located in class I which includes the galacturonosyltransferase (GAUT) genes and the galacturonosyltransferase-like (GATL) genes (Sterling et al., 2006). An extensive phylogenetic analysis revealed that GT8 family was acquired from an ancient cyanobacterium progenitor and further separated into sub-clades which have undergone functional specialization. Moreover, the increase in the numbers of GAUTs and GATLs from lower to higher plants suggests that these genes have an important role in the plant adaptation to living on land and adopting upright growth habit (Yin et al., 2010).

In Arabidopsis thaliana, 15 GAUT and 10 GATL coding genes have been described and cumulative evidence indicates that they are involved in cell wall pectin and hemicellulose biosynthesis (Orfila et al., 2005; Sterling et al., 2006; Caffall et al., 2009; Kong et al., 2011). However, redundancy between the individual GAUTs and pleiotropic effects complicate the assignation of specific functional 
activities to each protein. Given these problems, only four of them have been functionally characterized to date. In 2002, Bouton et al. reported the A. thaliana mutant quasimodo1, which harbors a T-DNA insertion in GAUT8 gene, displays dwarfism and reduced cell adhesion. Qua1 cell walls contained significantly higher proportions of arabinose (Ara), Rha, and fucose (Fuc), and a lower proportion of uronic acid and xylose (Leboeuf et al., 2005, Orfila et al., 2005). The reduction of cell adhesion in qua1 was explained by the low content in calcium dimerized HG, while the alterations of pectin composition indicate modifications of other pectic domains like RG-I side chains (Leboeuf et al. 2005). Moreover, Sterling et al. (2006) biochemically characterized the homogalacturonan galacturonosyltranferase activity in A. thaliana, and identified GAUT1 protein as well as its encoding gene, demonstrating its role in oligogalacturonides (OGAs) elongation. Recently, it has been demonstrated that GAUT1 acts in the Golgi lumen in a complex manner together with GAUT7, which anchors the protein complex to the Golgi membrane (Atmodjo et al., 2011). Finally, the characterization of irregular xylem8 (irx8) dwarf mutant allowed to propose that the wild type locus product, GAUT12, is involved in glucuronoxylan (GX) biosynthesis, a hemicellulosic component of the secondary cell wall in dicot plants. The mutation led to a $57 \%$ reduction in the xylose (XYl) content of GX polysaccharide and it was proposed the GAUT12

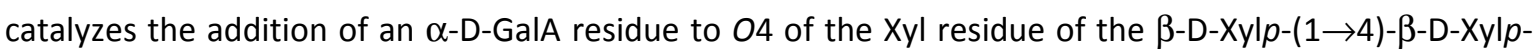
$(1 \rightarrow 3)-\alpha-L-R h a p-(1 \rightarrow 2)-\alpha-D-G a l p A-(1 \rightarrow 4)-D-X y l$ sequence present at the reducing end of GXs (Peña et al., 2007).

As demonstrated by the characterization of the mutant phenotypes, galacturonosyltranferase activity, and consequently pectin composition, is essential for normal growth and morphology (Caffall et al., 2009). Besides this crucial role, in tomato, the amount and composition of pectin and hemicellulose affect fruit firmness (Giovannoni et al., 1989; Tieman et al., 1992; Brummell, 1997, 1999a, 1999b; Saladié et al., 2007; Lahaye et al., 2012; Chapman et al., 2012, Lunn et al., 2013). However, no GAUT genes have, as yet, been functionally described in this species. To gain further insight into the function of pectin composition in the whole plant physiology, in this work we characterized the GAUT gene family in tomato focusing on a functional study of a putative GAUT encoding gene associated with the content of free galacturonate in ripe fruits (Bermúdez et al., 2008). The results demonstrated that this gene affects pectin content and solubility suggesting that disturbance of cell wall metabolism causes pleiotropic effects leading to significant changes in growth and carbon partitioning in tomato. 


\section{MATERIALS AND METHODS}

Plant material, growth conditions and sampling

Tomato seeds from Solanum lycopersicum L. (cv M82 and Moneymaker) were obtained from the Tomato Genetic Resource Center (http://tgrc.ucdavis.edu). Nicotiana benthamiana seeds were obtained from Meyer Beck (Berlin). Tomato and tobacco plants were grown in $20 \mathrm{I}$ and $1 \mathrm{I}$ pots, respectively. The greenhouse conditions were $16 / 8 \mathrm{~h}$ photoperiod, $24 \pm 3{ }^{\circ} \mathrm{C}, 60 \%$ humidity, and $140 \pm 40 \mu \mathrm{mol} \mathrm{m} \mathrm{m}^{-1}$ incident irradiance.

For expression profile analysis, source (the first totally expanded leaf which for our cultivar and growing conditions, corresponds to the third leaf from the top of the plant) and sink (the first apical leaf not fully expanded) leaves were collected from eight-week-old plants (cv M82). Fruit pericarps (without placenta and locule walls) at green, mature green, breaker and ripe stage were harvested 30, 45, 50 and 60 days after anthesis, respectively. All samples were obtained from six independent plants, immediately frozen into liquid $\mathrm{N}_{2}$, and stored at $-80 \stackrel{\circ}{ }$ C until use. Samples were pooled in three replicates (two independent plants per pool) for further analyses.

For transgenic plants phenotyping, at least three replicates of the selected T0 lines were established. After sixteen weeks, source leaves and ripe fruit pericarps were collected as described above. Fruit biochemical phenotyping was performed exclusively at ripe stage due to the extremly low fruit production of GAUT4 silenced plants. Six-month-old plants were harvested and fresh and dry aerial biomass were determined. These parameters were used to determine water content and harvest index according to the following formula:

Harvest index $=\underline{\text { fruit fresh mass } x 100}$

total aerial biomass

For heritability assays, fifteen T1 plants for each T0 transgenic line were evaluated for the presence of the transgene by PCR reactions. As expected, the transgene segregated 3:1 according to $\chi^{2}$ test $(P<0$, 05). GAUT4 expression was reduced by at least $60 \%$ for all three transgenic lines (Supplementary Figure S1A). In agreement with the T0 phenotype, T1 silenced plants displayed higher biomass and were taller (Supplementary Figure S1B and Figure 5A). All measurements in T1 generation were performed in triplicate in eight-week-old plants.

\section{Light microscopy}

Completely expanded leaves were fixed in neutral buffered formalin in phosphate buffer $\mathrm{pH} 7.0$ for $48 \mathrm{~h}$ (Lillie, 1965), dehydrated in a graded ethanol series and embedded in plastic resin (Historesin Leica; Gerrits, 1991). Cross-sections (10 $\mu \mathrm{m})$ were cut on a rotating microtome (Autocut 2040-Reichert Jung), 
stained with $0.05 \%(\mathrm{v} / \mathrm{v})$ toluidine blue in $0.1 \mathrm{M}$ sodium acetate $\mathrm{pH} 4.7$ (OBrien et al., 1964) and analyzed with an Olympus BX41 light microscope with a coupled digital camera. Total, palisade and sponge parenchyma areas were measured using ImageJ software (Rasband, http://imagej.nih.gov/ij/).

Identification and analyses of GAUT sequences

The complete sequence of the S. Iycopersicum GAUT4 gene, Solyc04g015270, was obtained from Solanaceae Genomics Network (SGN) database (Bombarely et al., 2011). Untranslated regions were determined based on comparison with reference unigene (U320717) using MULTALIN software (http://www-archbac.u-psud.fr/genomics/multalin.html; Corpet, 1988).

Gene family protein sequences were identified in SGN database by BLAST search, using the Arabidopsis thaliana and Oryza sativa orthologs described by Caffall et al. (2009). GAUT protein sequences were aligned using ClustalX (Thompson et al., 1997) and phylogenetic analysis was performed by MEGA5 (Tamura et al., 2011). Evolutionary distances were computed using the JTT matrix-based method (Jones et al., 1992) and are expressed as number of amino acid substitutions per site. The bootstrap values were determined from 1,000 trials. As out-groups an A. thaliana (At1g19300, Kong et al., 2011) and a S. lycopersicum (Solyc02g065530) galacturonosyltransferase-like (GATL) sequence were included in this analysis. The identified tomato genes were mapped onto the Tomato-EXPEN 2000 genetic map available at the SGN database. The genetic positions were obtained by BLASTN (Altschul et al., 1990) against the entire Tomato-EXPEN 2000 map marker sequence database. Map Chart software 2.2 (Voorrips, 2002) was used to construct the graphical representation of the genetic map. Protein subcellular localization prediction was performed by using TargetP software (Emanuelsson et al., 2007), SherLoc (Shatkay et al., 2007), MultiLoc (Hoeglund et al., 2006), Plant-mPLoc (Chou and Shen, 2010) and iPSORT (Bannai et al., 2002) softwares. Transmembrane domains were predicted using TMpred (http:// www.ch.embnet.org/software/TMPRED_form.html).

RNA isolation and $\mathrm{QPCR}$ analyses

Total RNA from $100 \mathrm{mg}$ of samples was extracted with TRIZOL reagent (Invitrogen) according to the manufacturer's instructions. DNA was removed with $1 \mu \mathrm{l}$ of amplification-grade DNase (Invitrogen) following the recommended protocol. cDNA was synthesized from $1 \mu \mathrm{g}$ of RNA using random primers and the SuperScript III kit (Invitrogen) and quality was confirmed by PCR using actin intron-flanking specific primers (ActinaUp 5'- TGGCATCATACCTTTTACAA -3' and ActinaLow 5'- TCCGGGCATCTGAACCTCT $\left.-3^{\prime}\right)$. Elongation factor 1- $\alpha$ (EF1- $\left.\alpha\right)$, TIP4 and EXPRESSED were used as housekeeping genes. mRNA levels were quantified by quantitative real-time PCR using a 7500 Real-Time PCR system (Applied Biosystem), SYBR Green Master Mix (Applied Biosystem) and specific primers (Supplementary Table S1) at final concentrations of $200 \mathrm{nM}$. PCR conditions were: 95 으 for $10 \mathrm{~min}, 40$ cycles of 95 으 for $15 \mathrm{~s}$, primer 
annealing temperature for $1 \mathrm{~min}$, and $72 \stackrel{\circ}{\circ} \mathrm{C}$ for $30 \mathrm{~s}$. All reactions were performed with two technical replicates and at least three biological replicates.

Data were analyzed with LinRegPCR software (Ruijter et al., 2009) to obtain Ct values and primer efficiency. Relative expression and statistics analysis were calculated using fgStatistics software (Di Rienzo, 2009).

\section{Cloning procedures}

Primers were designed using the software Oligo Analyzer 3.1 (http://www.idtdna.com) on the basis of unigene sequences. For GAUT4 subcellular localization experiment, a 699 bp fragment spanning the first 233 amino acids of the protein was amplified by PCR using Taq Platinum Pfx DNA polymerase (Invitrogen) and the following set of primers FUS-GAUT-F (5'-CACCATGAAGATGAAACTGAGGAAGCC - $3^{\prime}$ ) and FUS-GAUT-R (5'- TGAACCACCCAATTTGTTG $\left.-3^{\prime}\right)$. PCR reactions were conducted in a total volume of $50 \mu$ containing $0.2 \mathrm{mM}$ of each dNTPs, $0.2 \mathrm{mM}$ of each primer, $1 \mathrm{X}$ reaction buffer, $1.5 \mathrm{mM} \mathrm{MgClO}_{4}, 50$ ng of cDNA, and $2.0 \mathrm{IU}$ of enzyme. The amplification conditions were: $94{ }^{\circ} \mathrm{C}$ for $3 \mathrm{~min}$; 35 cycles of $94{ }^{\circ} \mathrm{C}$ for $30 \mathrm{~s}, 53^{\circ} \mathrm{C}$ for $30 \mathrm{~s}$, and then $68^{\circ} \mathrm{C}$ for $3 \mathrm{~min}$. Amplification product was cloned into a pENTR/d-TOPO vector (Invitrogen) and then, the expression cassette was transferred to the binary vector pK7FWG2 by recombination using LR clonase (Invitrogen) resulting in C-terminal GFP fusion protein (pK7FWG2GAUTLyc).

For RNAi silencing, a $161 \mathrm{bp}$ fragment of GAUT4 gene was used to generate a hairpin construct. The fragment was amplified with the primers GAUTRNAi-F (5'- CACCCGAGCAGCAGTCATACACTAC $-3^{\prime}$ ) and GAUTRNAi-R (5'- GTGCAGAGAACACTTCATGAACCAC -3'), and Taq DNA polymerase (Invitrogen). The amplicon was cloned into pENTR/d-TOPO vector (Invitrogen) and then, transferred into the pK7GWIWG2(I) binary vector using LR clonase, to generate a hairpin construct (pK7GWIWG2(I)GAUTLyc).

Binary vectors (Karimi et al., 2002) were introduced in Agrobacterium tumefaciens strains GV3101 and GV2260 for subcellular localization and plant stable transformation, respectively.

\section{$N$. benthamiana transient transformation and confocal microscopy}

The Agrobacterium strains containing pK7FWG2-GAUTLyc, a cytosolic control pK7FWG2-HPPDLyc (fulllength cDNA fragment of the hydroxyphenylpyruvate dioxygenase fused to GFP, Almeida et al. unpulblished results), and a Golgi complex control (based on the cytoplasmic tail and transmembrane domain of GmMan1, soybean $\alpha$-1,2-mannosidase I fused to YFP, Nelson et al. 2007) were grown at 28 ㄷ in LB medium with appropriate antibiotics until optical density of 0.6 at $600 \mathrm{~nm}$. Cells were harvested, resuspended in $10 \mathrm{mM}$ MES with $100 \mathrm{mM}$ acetosyringone (Sigma), incubated for $4 \mathrm{~h}$ in the dark at room temperature, and then infiltrated into leaves of six-week-old Nicotiana benthamiana plants. After $48 \mathrm{~h}$, the infiltrated tissues were observed with a confocal laser microscope Zeiss LSM 400 under a 63X water 
objective. Chlorophyll images were captured over $590 \mathrm{~nm}$ after excitation at $543 \mathrm{~nm}$, while GAUT:GFP fusion, HPPD:GFP and Golgi:YFP control were captured over 505 to $550 \mathrm{~nm}$ range after excitation at 488 $\mathrm{nm}$ with an argon laser beam.

Plant transformation

Seedling cotyledons of S. lycopersicum (cv. Moneymaker) were used as explants to generate transgenic tomato plants with the hairpin construct pK7GWIWG2(I)-GAUTLyc. Agrobacterium-mediated transformation was carried out as described previously (Nunes-Nesi et al., 2005). The presence of the transgene was confirmed by PCR with $35 \mathrm{~S}$ promoter specific primers (35S-right 5'CCCACTATCCTTCGCAAG-3' and 35S-left 5'- GCAGGTCACTGGATTTTGG-3'). Thirteen independent T0 transgenic lines were checked for GAUT4 expression level by qPCR. Three lines were chosen for further detailed phenotypic characterization. GAUT4 transcript levels were checked in ripe fruits and leaves in at least six biological replicates for each line.

Photosynthetic parameters

Photosynthetic parameters, including gas-exchange and chlorophyll fluorescence emission, were evaluated in four to five-week-old plants maintained at fixed irradiance of $140 \pm 40 \mu \mathrm{mol} \mathrm{m}^{-2} \mathrm{~s}^{-1}$ using a Li-cor-6400 system (Li-Cor; www.licor.com/) under different light intensities (200, 400, 800 and 1,200 $\left.\mu \mathrm{mol} \mathrm{m} \mathrm{s}^{-1}\right), 400 \mathrm{ppm} \mathrm{CO}_{2}$, and a leaf temperature of $25 \stackrel{\circ}{\circ} \mathrm{C}$. All measurements were performed in darkadapted plants on the second or third leaflet of the third fully expanded leaf. Photosynthetic parameters were estimated according to Maxwell and Johnson (2000). The NPQ (non-photochemical quenching), qP (photochemical quenching), ETR (electron transport rate), and 1-pQ (reduced plastoquinone accumulation) were estimated as:

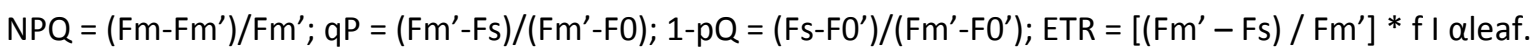
$\mathrm{Fm}$ and $\mathrm{Fm}^{\prime}$ are the maximal chlorophyll fluorescence after dark and light adaptation, respectively. Fs is steady-state fluorescence. FO and FO' are the minimal chlorophyll fluorescence after dark and light adaptation, respectively. $f$ is the fraction of absorbed quanta that is used by PSII, which is assumed to be 0.5 for C3 plants, I is the incident photon flux density, and aleaf is leaf absorbance that is assumed to be 0.85 (Sienkiewicz-Porzucek et al., 2010).

\section{Fruit firmness measurements}

Firmness was measured on similar-sized intact ripe fruits (60 days after anthesis). Measurments were performed twice on at least one fruit per plant and three plants per line, totaling 44 assessments, according to Smith et al. (2002). Each fruit was tested with a cylindrical flat plate (35 mm of diameter) with the probe centered over different locules at $90^{\circ}$ on the equator of the fruit. Force deformation curves were recorded using a TA.XT Plus Texture Analyzer (Stable Micro Systems) as follows: pre-test 
speed of $1.5 \mathrm{~mm} \mathrm{~s}^{-1}$, test speed of $1 \mathrm{~mm} \mathrm{~s}^{-1}$ and a compression distance of $3 \mathrm{~mm}$. Firmness was defined as the maximum at a constant deformation $(3 \mathrm{~mm})$.

Soluble sugars and starch quantification

Freeze-dried samples of leaves and fruits were ground in a ball mill (TE 350,Tecnal, Brazil). Ten milligrams of each sample was extracted five times with $1.5 \mathrm{ml}$ of $80 \%(\mathrm{v} / \mathrm{v})$ ethanol at $80{ }^{\circ} \mathrm{C}, 20 \mathrm{~min}$. The total extraction volume $(7.5 \mathrm{ml})$ was dried under vacuum and the samples were resuspended in $1 \mathrm{ml}$ of deionized water. To remove pigments, an extraction with $0.5 \mathrm{ml}$ of chloroform was performed. A 500 $\mu \mathrm{l}$ aliquot was used for sugar identification and quantification by High Performance Anion Exchange Chromatography with Pulsed Amperometric Detection (HPAEC/PAD) using Dionex-DX500 system (Dionex, CA, USA) and a CarboPac PA1 column using isocratic elution of $\mathrm{NaOH} 200 \mathrm{mM}$. A calibration curve was carried out using standard solutions of glucose, fructose, sucrose, and raffinose with a concentration range from $50 \mu \mathrm{M}$ to $200 \mu \mathrm{M}$ (de Souza et al., 2013). For starch quantification, the pellets obtained after ethanol extraction were washed with water, dried for $1 \mathrm{~h}$ at $60^{\circ} \mathrm{C}$ and incubated for 30 min at $75{ }^{\circ} \mathrm{C}$ with $0.5 \mathrm{ml}\left(120 \mathrm{U} \mathrm{ml}^{-1}\right.$ ) of thermo stable $\alpha$-amylase (EC 3.2.1.1) from Bacillus licheniformis (MEGAZYME, Bray Co. Wicklow, Ireland) in MOPS $10 \mathrm{mM} \mathrm{pH} \mathrm{6.5.} \mathrm{This} \mathrm{procedure} \mathrm{was} \mathrm{repeated} \mathrm{totalizing}$ $120 \mathrm{U}$ of $\alpha$-amylase. Samples were cooled to $50^{\circ} \mathrm{C}$ and then digested with $15 \mathrm{U}$ of amyloglucosidase (EC 3.2.1.3) from Aspergillus niger (MEGAZYME) in $100 \mathrm{mM} \mathrm{pH} 4.5 \mathrm{NaAcO}$ buffer for 30 min at $50{ }^{\circ} \mathrm{C}$ twice. Enzymatic reaction was stopped adding $100 \mu \mathrm{l}$ of percloric acid $0.8 \mathrm{M}$ for protein precipitation. After a centrifugation for $5 \mathrm{~min}$ at $10,000 \times \mathrm{g}$, an aliquot of $50 \mathrm{ul}$ was incubated with $250 \mathrm{ul}$ of Glucose PAP Liquiform (CENTERLAB, Brasil) containing glucose oxidase $\left(\sim 11,000 \mathrm{U} \mathrm{ml}^{-1}\right)$, peroxidase $\left(\sim 700 \mathrm{U} \mathrm{ml} \mathrm{l}^{-1}\right), 290$ $\mathrm{mmol} / / \mathrm{D}-4$-aminoantipirine, and $50 \mathrm{mM}$ of phenol $\mathrm{pH} 7.5$ were added. On this system glucose oxidase catalyzes glucose oxidation producing $\mathrm{H}_{2} \mathrm{O}_{2}$ that reacts with D-4-aminoantipirine and phenol under the action of peroxidase. These reactions produce a red antipirilquinonimine whose color intensity is proportional to glucose concentration. After $15 \mathrm{~min}$ at $30{ }^{\circ} \mathrm{C}$, absorbance was measured on spectrophotometer coupled to an ELISA reader at $490 \mathrm{~nm}$.

\section{Cell wall composition}

Freeze-dried samples of leaves and fruits $(250 \mathrm{mg})$ were milled for further extraction. After extraction with $80 \%(\mathrm{v} / \mathrm{v})$ ethanol at $80{ }^{\circ} \mathrm{C}$ for five times to remove soluble sugars, $20 \mathrm{ml}$ of DMSO $90 \%(\mathrm{v} / \mathrm{v})$ were added to the pellets, and the suspensions were stirred for $24 \mathrm{~h}$ to remove starch followed of 2 times 20 $\mathrm{ml}$ DMSO $90 \%(\mathrm{v} / \mathrm{v})$ stirred for $3 \mathrm{~h}$. Supernatants were discarded and the pellets were washed 6 times with distilled water, freeze-dried, and weighed. The remained cell wall material was called alcoholinsoluble residue (AIR). AIR was extracted 3 times in $20 \mathrm{ml}$ of aqueous $0.5 \%(\mathrm{~m} / \mathrm{v})$ ammonium oxalate $\mathrm{pH} 7$ at $80{ }^{\circ} \mathrm{C}$ for $1 \mathrm{~h}$ each with stirring. The supernatants (ammonium oxalate-soluble fraction) were combined and dialyzed (membrane cut off 12,400 ) for $12 \mathrm{~h}$ against running tap water and then dialyzed 
for $8 \mathrm{~h}$ with distilled water, freeze-dried and weighed. To the remaining cell wall material from leaves, $20 \mathrm{ml}$ of $0.1 \mathrm{M} \mathrm{NaOH}$ supplemented with $3 \mathrm{mg} \mathrm{ml}^{-1} \mathrm{NaBH}_{4}$ were added and the suspension was stirred for $1 \mathrm{~h}$. This procedure was repeated 2 times. The supernatants ( $\mathrm{NaOH}$-soluble fraction) were neutralized with glacial acetic acid and dialyzed for $12 \mathrm{~h}$ with running tap water followed by distilled water for $10 \mathrm{~h}$. The samples were freeze-dried and weighed. For both fractions, $2 \mathrm{mg}$ aliquots were hydrolyzed by adding $100 \mathrm{ul}$ of $72 \% \mathrm{H} 2 \mathrm{SO} 4$. After $30 \mathrm{~min}$ at $30{ }^{\circ} \mathrm{C}$, the solution was diluted to $3 \% \mathrm{H}_{2} \mathrm{SO}_{4}$ and autoclaved $1 \mathrm{~h}$ at $121{ }^{\circ} \mathrm{C}$ (Saeman et al., 1945). After deionization through cation and anion exchange columns (Dowex), the neutral monosaccharide composition was determined by HPAEC/ PAD in a Dionex DX-500 system using a CarboPac PA1 column. Monosaccharides were eluted in water using a post-column addition of $500 \mathrm{mM} \mathrm{NaOH}$ for sugar detection during $40 \mathrm{~min}$ and a flow rate of $1 \mathrm{ml} \mathrm{min}$.

Uronic acid determination

The uronic acid was quantified in the ammonium oxalate soluble fraction essentially as described in Filisetti-Cozzi and Carpita (1991). Five mg of the freeze-dried material was hydrolyzed with $1 \mathrm{ml}$ of $\mathrm{H}_{2} \mathrm{SO}_{4}$. After $5 \mathrm{~min}$ in an ice bath, the procedure was repeated totalizing $2 \mathrm{ml}$ acid. Subsequently, $0.5 \mathrm{ml}$ of water was added and after $5 \mathrm{~min}$ on ice, the the procedure was repeated. Finally, the mixture was diluted to $10 \mathrm{ml}$ with distilled water. In order to perform the colorimetric assay, $40 \mu \mathrm{l}$ of $4 \mathrm{M} \mathrm{K}$ sulphamic acid/potassium sulfamate $\mathrm{pH} 1.6$, and $2.4 \mathrm{ml} \mathrm{of} \mathrm{H}_{2} \mathrm{SO}_{4}$ containing borate were added to 400 $\mu \mathrm{L}$ of the diluted solution. The mixture was boiled for $20 \mathrm{~min}$. After the addition of $80 \mu \mathrm{l} \mathrm{of} \mathrm{m-}$ hydroxybiphenyl $0.15 \%(\mathrm{~m} / \mathrm{v})$ in $\mathrm{NaOH} 0.5 \%(\mathrm{~m} / \mathrm{v})$, absorbance was read at $525 \mathrm{~nm}$. For each sample measurements were done in duplicate.

Ascorbic acid

One hundred $\mathrm{mg}$ of fresh leaf or fruit tissue were extracted with $1 \mathrm{ml}$ of $3 \%(\mathrm{v} / \mathrm{v})$ TFA (trifluoracetic acid). Five hundred $\mu \mathrm{l}$ of the supernatant was applied to a Extract-clean $\mathrm{C} 18$ column $(500 \mathrm{mg} / 8.0 \mathrm{ml}, 50$ $\mu \mathrm{m}$ average particle size and $60 \AA$ pore size, Alltech Associates, Inc., USA) equilibrated with $100 \mathrm{mM}$ phosphate buffer $\mathrm{pH}$ 7, and then column was eluted with $1.5 \mathrm{ml}$ of $100 \mathrm{mM}$ phosphate buffer $\mathrm{pH}$ 7. To $500 \mu \mathrm{l}$ of the eluate, $500 \mu \mathrm{l}$ of $100 \mathrm{mM} \mathrm{K}_{2} \mathrm{HPO}_{4}$ buffer $\mathrm{pH} 8.5$ was added. To quantify total ascorbic acid, $15 \mu \mathrm{lDTT}(0.1 \mathrm{M})$ and $125 \mu \mathrm{l}$ of $3 \%(\mathrm{v} / \mathrm{v})$ TFA were added to $500 \mu \mathrm{l}$ of extraction mix. To measure reduced ascorbic acid, $15 \mu \mathrm{l}$ of $100 \mathrm{mM}$ buffer phosphate $\mathrm{pH} 7$ and $125 \mu \mathrm{l}$ of $3 \%(\mathrm{v} / \mathrm{v})$ TFA were added to $500 \mu \mathrm{l}$ of extraction mix. Both samples were incubated $3 \mathrm{~min}$ at room temperature. Ascorbic acid quantification was performed by HPAEC/PAD using a silica-based reversed-phase C18 column (particle size 5 pm, $150 \times 4.6 \mathrm{~mm}$, HL90-5s, Bio-Sil; Bio-Rad, Munich). The mobile phase consisted of a $\mathrm{KH}_{2} \mathrm{PO}_{4}$ buffer $(100 \mathrm{mM})$ at pH 3.0 (with phosphoric acid) and was delivered isocratically at a flow rate of 0.5 $\mathrm{ml} / \mathrm{min}$. Ascorbic acid resulted in a peak at $3.5 \mathrm{~min}$. Quantification was done based on a standard solutions of reduced and oxidized ascorbic acid. 


\section{Gas chromatography-mass spectrometry}

For metabolic profiling, frozen leaves ( $100 \mathrm{mg}$ ) were extracted in 1,400 $\mu \mathrm{l}$ of methanol, as described by Roessner et al. (2001) with the modifications proposed by Lisec et al. (2006); $60 \mu$ l of internal standard (0.2 $\mathrm{mg} \mathrm{ml}^{-1}$ ribitol) was added for quantification. In the case of ripe fruits ( $250 \mathrm{mg}$ ) the reagent volumes were adjusted using 2,000 $\mu \mathrm{l}$ of methanol and $120 \mu \mathrm{l}$ of ribitol as described in Osorio et al. (2012). In both cases, the mixture was extracted for 15 min at $70{ }^{\circ} \mathrm{C}$, mixed vigorously with 1 volume of water, centrifuged at $2,200 \times \mathrm{g}$, and subsequently reduced to dryness under vacuum. The residue was re-dissolved and derivatized for $120 \mathrm{~min}$ at $37^{\circ} \mathrm{C}$ (in $60 \mu \mathrm{l}$ of $30 \mathrm{mg} \mathrm{ml}^{-1}$ methoxyamine hydrochloride in pyridine) followed by a $30 \mathrm{~min}$ treatment at $37{ }^{\circ} \mathrm{C}$ with $120 \mu \mathrm{l}$ of $\mathrm{N}$-methyl- $N$-[trimethylsilyl] trifluoroacetamide. Sample volumes of $1 \mu \mathrm{l}$ were then injected in splitless and split modes, using a hot needle technique. The gas chromatography-mass spectrometry (GC-MS) system was composed of an AS 2000 autosampler, a GC 6890N gas chromatographer (Agilent Technologies, USA), and a Pegasus III time-of-flight mass spectrometer (LECO Instruments, USA). Chromatography was performed with a MDN-35 capillary column, $30 \mathrm{~m}$ length, $0.32 \mathrm{~mm}$ inner diameter and $0.25 \mu \mathrm{m}$ film thickness (MachereyNagel). Samples were injected at $230 \stackrel{\circ}{ } \mathrm{C}$ in splitless mode with helium carrier gas flow set at $2 \mathrm{ml} / \mathrm{min}$. The flow rate was kept constant with electronic pressure control enabled. The temperature program

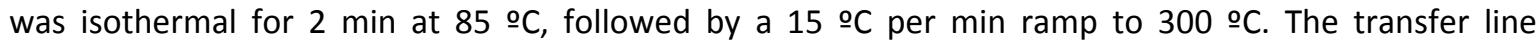

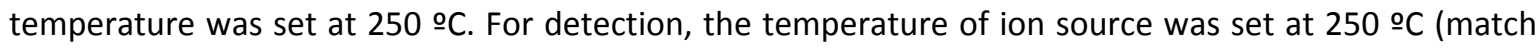
transfer line condition). Mass spectra were recorded at 20 scans per sec with a scanning range of 70 to $660 \mathrm{~m} / \mathrm{z}$. The remaining monitored chromatography time proceed with filament turned off. The filament bias current was $-70 \mathrm{~V}$ and detector voltage was 1,525 V. Both chromatograms and mass spectra were evaluated using ChromaTOF chromatography processing and mass spectral de-convolution software, version 3.00 (LECO Instruments, USA). Identification and quantification were performed with TagFinder 4.0 software and the mass spectra were cross-referenced with those in the Golm Metabolome Database (Schauer et al., 2005; Kopka et al., 2005). Three to six biological replicates were used for this analysis.

\section{Data analyses}

Differences in phenotypic parameters were analyzed by Infostat software (Di Rienzo et al., 2011). When the data set showed homoscedasticity, an ANOVA followed by a Tukey or Dunnett tests $(P<0.05)$ was used to compare transgenic lines against wild-type controls. Due to lack of homoscedasticity in some cases, a non-parametric comparison was also performed by applying the Kruskal-Wallis test $(P<0.05)$. 
RESULTS

GAUT gene family diversity in S. lycopersicum

On the basis of a metabolic QTL analysis performed in a S. pennellii introgression line collection (Schauer et al., 2006), we have previouly identified a putative GAUT encoding gene co-localizing with a QTL for fruit galacturonate content (Bermúdez et al., 2008). Since no GAUT genes have been described in tomato and they belong to a large gene family, we first performed a complete phylogenetic analysis. The recently published tomato genome (The Tomato Genome Consortium, 2012) was screened to identify all GAUT sequences using $A$. thaliana and $O$. sativa orthologous genes as baits (Caffall et al., 2009). This search retrieved 17 tomato genes. In order to predict the subcellular localization of the encoded tomato proteins, five different programs were tested using At3g61130 (AtGAUT1) and At2g38650 (AtGAUT7) as controls, which are experimentally demonstrated to localize in Golgi apparatus (Atmodjo et al., 2011). Interestingly, Sherloc, which predicts using sequence and text based features (Shatkay et al., 2007), and Multiloc, which is based on N-terminal targeting sequences (Hoeglund et al., 2006), were those that accurately predicted both proteins to be located within the Golgi. With the exception of SIGAUT2, for which both programs indicated mitochondrial localization, and SIGAUT7, which according to MultiLoc is targeted to endoplasmic reticulum, all tomato GAUTs seemed to be directed to the Golgi (Table 1).

For each A. thaliana GAUT gene, a corresponding tomato ortholog was identified, with the exception of the GAUT12 and GAUT13 clades which were rather represented by two paralogs in $S$. lycopersicum. The tree topology demonstrated that the GAUT identified by Bermúdez et al. (2008) is a GAUT4. The clades for GAUT3, 10, 11 and 15 revealed a single copy in the eudicot and monocot species analysed, and the topology was according to the phylogenetic relationships between them. GAUT1/2 and GAUT8/9 clades seem to have diverged following the mono/eudicot split undergoing duplication in the monocot lineage as evidenced by the presence of three rice paralogues. GAUT4 and GAUT7 clades displayed a single copy in eudicots whilst being represented by three and five paralogues in rice, respectively. Finally, clades GAUT5/6 and GAUT13/14 exhibited a similar pattern wherein, after the divergence of tomato and $A$. thaliana, gene duplication in the eudicots was followed by a subsequent gene divergence (Figure 1A). The 17 tomato GAUT genes were mapped onto the Tomato-EXPEN 2000 map housed at the SGN website (http://solgenomics.net/) and were found to be evenly distributed among chromosomes $1,2,3,4,6,7,10$, and 12, with no obvious association between genomic localization and phylogenetic distribution (Figure 1B).

In order to investigate organ expression specificity, a qPCR analysis was performed in leaves and ripe fruits. GAUTs 8, 12,13, 14 and 15 showed higher expression in vegetative tissue in comparison with ripe fruits, whereas the rest of the paralogs did not display differential expression between the tested tissues (Figure 2A). Further, a broader developmental expression profile was carried out for the GAUT4 
gene which showed to be ubiquitously expressed. However, increased levels of mRNA were detected in growing tissues such as sink leaves, mature green and green fruits, though in the latter the increase was not statistically significant (Figure 2B).

\section{GAUT4 structural characterization}

The identification of the genomic clone from S. lycopersicum, and its comparison to the corresponding mRNA sequence allowed the determination of GAUT4 gene structure. GAUT4 is composed of twelve exons with three of these being non-coding exons. The coding region spans 2,040 nt resulting in a protein of 679 amino acids (Figure 3A). The protein topology displayed both transmembrane and GT8 domains. Within the latter, the characteristic GT8 motif DxD was present. Moreover, the GAUT family specific motif previously described by Sterling et al. (2006) was also identified, albeit showing an amino acid substitution with respect to the arabidopsis/rice consensus sequences. In silico analysis of the protein primary structure suggested that GAUT4 is targeted to the Golgi (Table 1) and probably remains anchored to the membrane as evidenced by the presence of a transmembrane domain (Figure 3B). This result is in agreement with the localization of the GAUT4:GFP fusion protein for which the punctate fluorescence signal in the cytoplasm of mesophyll cells matches that which would be anticipated for proteins targeted to this subcellular compartment (Figure 3C).

\section{Generation and primary characterization of GAUT4 silenced plants}

With the aim of gaining further knowledge about GAUT4 specific function, S. lycopersicum transgenic lines expressing a GAUT4 hairpin construct were generated. The level of silencing was assessed by QPCR in source leaves and ripe fruits and three lines showing significantly reduced levels of GAUT4 mRNA (RNAi2, RNAi-40 and RNAi42), were propagated for further phenotypic characterization (Figure 4). Since functional redundancy has been hypothesized within the GT family (Mohnen et al., 2008), the expression levels of other four uncharacterized GAUT genes (GAUT3, GAUT7, GAUT10 and GAUT15) were investigated in leaves and fruits of the transgenic lines. These genes were chosen because they belong to different clades of GAUT phylogeny spanning all the gene family diversity. Neither co-silencing effects nor compensatory up-regulation were detected for any of the tested genes (data not shown).

Carbon assimilation and other photosynthetic parameters were evaluated at the vegetative stage of the plants and no significant differences were observed between silenced and control plants (Supplementary Table S2). Notwithstanding these results, GAUT4 silenced plants showed higher vegetative growth as revealed by the size of eight-week-old T1 plants (Figure 5A and Supplementary Figure S1). The biomass increment (Figure 5B) was mainly due to an increase in the leaf water content which raised approximately $4 \%$ in the silenced plants (Figure 5D). To gain insights about the origin of the biomass increment, morphometric analyses were performed from source leaf cross-sections of the 
T1 plants. The palisade parenchyma was larger in transgenic plants compared to wild type controls (Supplementary Figure S2A and S2B). Furthermore, the cell density was also higher in this tissue (Supplementary Figure S2C) in accordance with the differences in growth parameters.

On assessing fruit characterristics, whilst flowering time was unaltered, the number (Figure 5E) and weight (Figure 5F) of fruits, as well as the harvest index (Figure 5G) decreased significantly in the trangenic plants. However, transgenic ripe fruits were more resistant to pressure as demonstrated by the flat plate compression test (Figure $5 \mathrm{H}$ ). Due to the insufficient fruit production of GAUT4 silenced plants, further biochemical characterization was exclusively performed at the ripe stage, impeding an evaluation across fruit development.

\section{Biochemical characterization of the GAUT4-silenced plants}

Since GAUT4 was expected to be involved in pectin synthesis, a cell wall fractionation was performed in order to evaluate the impact of this gene silencing on the cell wall composition. From leaf tissue, two cell wall fractions were evaluated in which all pectic polysaccharides are supposed to be extracted: the chelator-soluble fraction, extracted with ammonium oxalate; and the alkali-soluble fraction, extracted with $0.1 \mathrm{~N} \mathrm{NaOH}$. In the latter, hemicellulose traces could also be present. After the ammonium oxalate extraction, an unworkable amount of material remained from fruit pericarp thus, only the chelator fraction was assessed for this tissue. In leaves of silenced plants, the cell wall was basically unaltered, both in amount (Figure 6) and composition (Table 2). By contrast, transgenic fruits contained less amount of ammonium oxalate-soluble pectin (Figure 6) with reduced content of rhamnose, arabinose and galactose (Table 2). For interpretation of the occurrence and properties of cell wall polysaccharides from sugar composition, three sugar ratios were analyzed which are the measure for the linearity of pectin, contribution of RG-I to the entire pectin population and the extent of branching of RG-I (Houben et al., 2011). The ratios suggest that GAUT4 silencing affects RG-I accumulation, specially based on Rha/Uronic acids ratio, with a clear stronger impact in fruits. Interestingly, in both analyzed organs RG-I branching in transgneic plants was increased by $26 \%$ (Table 3).

To identify whether the reduction in GAUT4 expression could be associated with a shift of plant metabolism in general, a detailed evaluation of primary metabolism was carried out by GC-MS and HPLC. The resultant metabolic profile showed that GAUT4 silencing did not produce massive biochemical changes but rather only specific alterations in a handful of metabolites (Supplementary Table S3). It is worth to note that free galacturonic acid was slightly increased in leaves, while the increment was more significant in fruits in agreement with the lower pectin amount observed in the latter organ (Figure 7A and B). Raffinose was the only altered soluble sugar displaying consistently decreased levels in the leaves of the transgenic plants (Figure 7C). 
Finally, aiming to better understand the relationship between the increase in vegetative biomass and the strong reduction in harvest index, the starch contents were enzymatically quantified. Whereas in leaves no significant changes were observed, in fruits the accumulation of this polymer was reduced, suggesting a shift in carbon partitioning between source and sink tissues (Figure 8). 


\section{DISCUSSION}

GAUT genes encode a set of enzymes belonging to the CAZy GT8 family of glycosyltransferases that are associated with pectin and hemicellulose biosynthesis (Cantarel et al., 2009). In the present study, we performed the genomic identification of the GAUT gene family in S. lycopersicum and the functional characterization of the GAUT4 member. After the identification of all gaut genes encoded in the tomato genome, the phylogenetic analysis revealed that the tomato genome harbors all the orthologous genes to those previously described for A. thaliana. Caffall et al. (2009) reported the existence of two copies of GAUT12 gene in poplar, while no orthologs were identified in rice. In tomato, our survey retrieved also two GAUT12 genes, reenforcing the hyphotesis that GAUT12 has a specialized role in the synthesis of secondary wall GX of dicot walls as proposed by Persson et al. (2007). The tree topology also suggested that GAUT12 constitutes a monophyletic group with GAUT13 and GAUT14. This finding is in discrepancy with the phylogeny proposed by Caffall et al. (2009), in which GAUT15 appeared more closely related to GAUT13/14 clade. Three pairs of recently duplicated genes originated after the split between $A$. thaliana and S. Iycopersicum were identified: SIGAUT5 and SIGAUT6, SIGAUT12-1 and SIGAUT12-2 as well as SIGAUT13-1, SIGAUT13-2 and SIGAUT14. The 17 tomato GAUTs were mapped and interestingly those pairs of genes that are closely linked according to the phylogenetic analysis are distantly located within the genome, suggesting that they have arisen from a segmental duplication followed by a genomic rearrangement of the tomato genome (Song et al., 2012). A similar observation has also been reported for tomato tocopherol biosynthetic genes (Almeida et al., 2010). Moreover, Kong et al. (2011) determined the relationship between GATL paralog genes based also on the segmental duplication history of the corresponding genomic regions in A. thaliana (Blanc and Wolfe, 2004).

All of the 17 GAUTs identified were revealed to be transcriptionally active in the fruits and/or leaves. Expression profiles suggested that, although cell wall biosynthesis/degradation is an ubiquitous metabolic process in plant cells, there is a certain degree of organ/tissue specificity in GAUT activity probably associated with differential pectin composition. Tissue specificity has previously been demonstrated for GAUT genes. In this sense, by using in situ PCR, Orfila et al. (2005) demonstrated that the GAUT8 from A. thaliana is expressed in discrete regions around the vascular bundles. Similarly, GAUT12 was also expressed in vascular tissues in A. thaliana, as revealed by promoter:gus fusion studies (Persson et al., 2007). In tomato, GAUT8 and GAUT12 are more highly expressed in leaves than in fruits. Since vascular tissue density is much more abundant in leaves than in the fruit pericarps, our results suggest a similar expression pattern to that shown for the $A$. thaliana orthologous loci. Interestingly, GAUT13, GAUT14 and GAUT15, which cluster together with GAUT12, have a similar expression pattern possibly indicating similar function as proposed by Caffall et al. (2009). In particular, GAUT4 was ubiquitously expressed, as was also observed in A. thaliana. However, higher expression levels were 
documented in growing stages, pinpointing its crucial role for normal development as indicated by the lack of ability to rescue the corresponding $A$. thaliana mutant (Caffall et al., 2009).

Pectic polysaccharides are synthesized in the Golgi apparatus of plant cells, sorted to vesicular compartments and subsequently secreted to the apoplastic space (Caffall and Mohnen, 2009). Phylogenetic analysis, structural characterization and subcellular localization experiments demonstrated that the gene under study is indeed the tomato GAUT4. Moreover, the results are in close agreement with the assumed model for biosynthesis of pectin/hemicellulose wall polymers in which enzyme active sites face the Golgi lumen being anchored, directly or indirectly, by transmembrane domains (Peña et al., 2007; Caffall and Mohnen, 2009; Atmodjo et al., 2011).

Pectin comprises as much as $30 \%$ of dicot cell walls (Ridley et al., 2001). Two-thirds of the worldwide tomato production concerns processing tomato with modifications in the structure and composition of pectin being directly related to alterations in juice texture and extractability (Sila et al., 2009). Moreover, intact fresh fruit texture is a quality index for consumption in natura (Barrett et al., 1998; Lahaye et al., 2012). To gain further insights about pectin metabolism and particularly the role of GAUT4 gene, tomato transgenic plants expressing a hairpin RNA construct were obtained. The ripe fruits of silenced lines displayed significantly lower levels of ammonium oxalate-soluble pectin and the pectin contained reduced contents of Rha, Gal and Ara. These data, together with the reduction of $70 \%$ in Rha/uronic acids ratio, suggest that GAUT4 plays a role in RG-I backbone synthesis. The absence of the observed effect in leaves could be explained by the compensation of other paralogs which are also expressed in leaves but not in fruits (i.e. GAUT2, GAUT5, GAUT13, GAUT14 or GAUT15). These other enzymes could be either playing similar biochemical function and/or balancing the lack of RG-I producing other polymer or altering branching pattern, leading to slight alterations in sugar ratios. In this sense, in both analyzed organs an increase level (26\%) of RG-I branching was observed. Transgenic potato plants with reduced proportion of RG-I displayed an increase in the uronic acids content exposing also pectin biosynthesis compensation (Oomen et al., 2002).

In contrast with previous reports on GAUT deficient plants which displayed dwarfism (Peña et al. 2007, Persson et al. 2007, Bouton et al. 2002), GAUT4 silencing resulted in taller plants with higher vegetative biomass. The morpho-anatomical analysis of the leaves enlightened about the increased water content and fresh mass observed in transgenic plants. The reduction in GAUT4 activity might be resulted in a looser cell wall, thus, in order to keep the pressure potential and consequently the water potential constant, the compact palisade parenchyma enlarged and increased cell density. This is in line with the evidences indicating that hydraulics plays an essential but passive role in controlling cell growth (Szymanski and Cosgrove, 2009; Alim et al., 2012).

Intriguingly, the silencing of GAUT4 resulted in a decreased provision of carbon to sink tissues. This was evidenced in the decreased harvest index mostly as a consequence of the reduction in total fruit weight and number associated with the lower fruit starch accumulation. Recently, Wormit et al. 
(2012) demonstrated that carbohydrate metabolism is responsive to changes in cellulose biosynthesis via an osmosensitive mechanism. All phenotypic data presented here including growth parameters, biochemical profile and histological analyses suggest that the pleiotropic effects caused by GAUT4 silencing are the consequence of the same metabolic crosstalk, and they allow extending the proposed mechanism to cell wall biosynthesis.

Regarding this unknown metabolic crosstalk, our data provide evidence supporting the hypothesis that raffinose represents an important carbon source during fruit set and early development (Patrick and Offler, 1996; Nguyen-Quoc and Foyer, 2001) since its level was reduced in source leaves of the transgenic plants. Raffinose is synthesized from UDP-GIc by subsequent reactions catalyzed by UDPglucose 4-epimerase [EC 5.1.3.2], galactinol synthase [EC 2.4.1.123] and raffinose synthase [EC:2.4.1.82]. The latter combines galactinol and sucrose to produce myo-Inositol and raffinose (Unda et al., 2012). On this regard, it has been demonstrated that, despite strong evidence for apoplastic unloading of sugars (Fridman et al., 2004; Hackel et al., 2006), a functional symplastic continuity of cell connections and numerous plasmodesmata between the phloem and storage parenchyma cells exist in young fruits. It is thus conceivable that carbon is partially unloaded via the symplast and, therefore, raffinose might represent an important carbon source. Virtually, all cell wall precursors are derived from UDP-D-glucose (UDP-GIc) and GDP-D-mannose (GDP-Man) nucleotide sugars via a series of mechanistically related reactions that are catayzed by 4-epimerases, 3,5-epimerases, 4-reductases, 4,6-dehydratases, dehydrogenases, and decarboxylases (Reiter, 2008). Thus, the reduction of GAUT4 activity could unbalance nucleotide sugar interconversion reactions leading to a raffinose content reduction in transgenic lines once it is synthesized from UDP-Glc (Caffall and Mohnen, 2009). Moreover, the sucrose reduction trend observed in leaves of silenced plants reenforces this hyphotesis.

Fruits of transgenic plants exhibited incresed firmness. During tomato ripening, a decrease in the hydrostatic pressure (turgor) within fruit cells has been well documented to contribute to softening (Shackel et al.,1991). Presumably, this is due to a combination of events that lead to a dilution of the cell content and/or the direct loss of water from the fruit. These events may include: redistribution of solutes or solute leakage from the cell, breakdown of cell wall structure and transpiration. The elevation in apoplastic solute concentrations may occur as a result of increasing membrane leakiness and/or breakdown of complex cell wall polysaccharides into smaller soluble components (Harker et al., 1997). Although membrane structure remains intact during fruit ripening, membrane conductivity (permeability) increases and thus, there is a tendency for solutes to leak into the extracellular fluid, for the cell wall to hydrate, and for intercellular spaces to become water-soaked (Harker et al., 1997). However, the possible influence of solutes derived from cell wall catabolism on the osmotic potential of the apoplast fluid has not been demonstrated. In this context, the higher firmness found in GAUT4 silenced fruits could be explained by the following hypotheses. First, as lower amount of ammonium oxalate-soluble pectin was observed, less intercellular solute accumulation might explain the higher cell 
turgor. Recently, Lunn et al. (2013) reported a similar phenotype where transgenic tomatoes with a blockage in pectin deposition showed reduced amount of pectin together with an increase in fruit firmness. Secondly, the reduction in carbon influx observed in transgenic fruits could alter the increase in membrane conductivity while the increment in free GalA contributes for water retention. Further experiments will be conducted to clarify the mechanisms underlying this phenomenon.

Our results additionally bring insights to explain the impossibility of identifying gaut4 mutants in A. thaliana described by Caffall et al. (2009). First, it has been reported that $A$. thaliana seed mucilage is primarily composed of RG-I (Arsovski et al., 2009) hence, a gaut4 mutation would compromise seed viability. Secondly, raffinose is an important source of carbon storage and desiccation tolerance in Arabidopsis seeds and consequently the alteration of nucleotide sugar interconvertion reactions would compromise UDP-Glc production and ultimately raffinose biosynthesis (Zhou et al., 2011).

Interestingly, GAUT4 silenced plants mimic the S. pennellii introgressed line 4-3-2 (IL4-3-2). This line exhibited lower amount of GAUT4 mRNA (Fei et al., 2011), showed a fruit free galacturonic acid QTL and exhibited dramatically reduced yield (Schauer et al., 2006). Likewise, the transgenic plants analysed here displayed less pectin and an increase in free galacturonic acid in the fruits as well as a reduction in the harvest index. Therefore, the results shown in this work suggest that the GAUT4 gene is one of, or the sole, genetic determinant(s) of the $S$. pennellii introgressed line phenotype as we previously suggested (Bermúdez et al. 2008). In the same genomic region of chromossome 4, Chaïb et al. (2006) mapped a QTL for fruit mealiness and instrumental firmness. Further, biochemical characterization revealed alterations in pectin composition as well as in cell size (Lahaye et al., 2012 and 2013) sustaining the results presented here.

Concluding, the results presented characterized GAUT gene family in tomato and showed that changes in the structure of cell wall polysaccharides correlate with their spatial and temporal locations in developing plant tissues. Moreover, silencing of GAUT4 gene altered pectin composition and affected plant growth and development. The observed phenotypes revealed physiological mechanisms, via cell wall polysaccharides and raffinose metabolisms, that modulate plant resource allocation resulting in an unprecedented shift in source-sink carbon partioning in tomato.

\section{SUPPLEMENTARY DATA}

Supplementary Table S1. Primers used in qRT-PCR.

Supplementary Table S2. Photosynthetic parameters measured by gas exchange in tomato GAUT4silenced lines.

Supplementary Table S3. Metabolite relative content in GAUT4-silenced lines.

Supplementary Figure S1. Heritability of silenced phenotype.

Supplementary Figure S2. Leaf structural analyses of GAUT4-silenced plants. 


\section{ACKNOWLEDGEMENT}

FG, LB, BSL, APS and JA were recipients of FAPESP fellowships. FC is member of CONICET. MR and MSB hold fellowships from CNPq. This work was partially supported with grants from FAPESP (Brazil), CNPq (Brazil), USP (Brazil), Instituto Nacional de Ciência e Tecnologia do Bioetanol (Brazil), Max Planck Society (Germany), INTA (Argentina), ANPCyT (Argentina), CONICET (Argentina) and under the auspices of the EU SOL Integrated Project FOOD-CT-2006-016214. 


\section{REFERENCES}

Alim K, Hamant O, Boudaoud A. 2012. Regulatory role of cell division rules on tissue growth heterogeneity. Front Plant Science 3, 174.

Almeida J, Quadrana L, Asís R, Setta N, de Godoy F, Bermúdez L, Otaiza SN, Corrêa da Silva JV, Fernie AR, Carrari F, et al. 2011. Genetic dissection of vitamin E biosynthesis in tomato. Journal of Experimental Botany 62, 3781-98.

Altschul SF, Gish W, Miller W, Myers EW, Lipman DJ. 1990. Basic local alignment search tool. Journal of Molecular Biology 215, 403-410.

Arsovski AA, Popma TM, Haughn GW, Carpita NC, McCann MC, Western TL. 2009. AtBXL1 encodes a bifunctional beta-D-xylosidase/alpha-L-arabinofuranosidase required for pectic arabinan modification in Arabidopsis mucilage secretory cells. Plant Physiology 150, 1219-34.

Atmodjo MA, Sakuragi Y, Zhu X, Burrell AJ, Mohanty SS, Atwood JA. 2011. Galacturonosyltransferase (GAUT)1 and GAUT7 are the core of a plant cell wall pectin biosynthetic homogalacturonan:galacturonosyltransferase complex. Proceedings of National Academy of Science 50, 20225-30.

Bannai H, Tamada Y, Maruyama O, Nakai K, Miyano S. 2002. Extensive feature detection of N-terminal protein sorting signals. Bioinformatics 18, 298-305.

Barrett DM, Garcia E, Wayne JE. 1998. Textural modification of processing tomatoes. Critical Reviews in Food Science and Nutrition 38, 173-258.

Bermúdez L, Urias U, Milstein D, Kamenetzky L, Asis R, Fernie AR, Van Sluys MA, Carrari F, Rossi M. 2008. A candidate gene survey of quantitative trait loci affecting chemical composition in tomato fruit. Journal of Experimental Botany 59, 2875-2890.

Blanc G, Wolfe KH. 2004. Functional divergence of duplicated genes formed by polyploidy during arabidopsis evolution. Plant Cell 16, 1679-1691.

Bombarely A, Menda N, Tecle IY, Buels RM, Strickler S, Fischer-York T, Pujar A, Leto J, Gosselin J, Mueller LA. 2011. The Sol Genomics Network (solgenomics.net): growing tomatoes using Perl. Nucleic Acids Research 39, D1149-55.

Bouton S, Leboeuf E, Mouille G, Leydecker MT, Talbotec J, Granier F, Lahaye M, Höfte H, Truong HN. 2002. QUASIMODO1 encodes a putative membrane-bound glycosyltransferase required for normal pectin synthesis and cell adhesion in Arabidopsis. Plant Cell 14, 2577-2590.

Brummell DA, Bird CR, Schuch W, Bennett AB. 1997. An endo-1,4- B-glucanase expressed at high levels in rapidly expanding tissues. Plant Molecular Biology 33, 87-95.

Brummell D, Harpster M, Civello P, Palys J, Bennett A, Dunsmuir P. 1999a. Modification of expansin protein abundance in tomato fruit alters softening and cell wall polymer metabolism during ripening. Plant Cell 11, 2203-16.

Brummell DA, Hall BD, Bennett AB. 1999b. Antisense suppression of tomato endo-1,4-beta-glucanase Cel2 mRNA accumulation increases the force required to break fruit abscission zones but does not affect fruit softening. Plant Molecular Biology 40, 615-22.

Caffall KH, Pattathil S, Phillips SE, Hahn MG, Mohnen D. 2009. Arabidopsis thaliana T-DNA mutants implicate GAUT genes in the biosynthesis of pectin and xylan in cell walls and seed testa. Molecular Plant 2,1000-14.

Caffall KH, Mohnen D. 2009. The structure, function, and biosynthesis of plant cell wall pectic polysaccharides. Carbohydrate Research 344, 1879-900.

Cantarel BL, Coutinho PM, Rancurel C, Bernard T, Lombard V, Henrissat B. 2009. The CarbohydrateActive EnZymes database (CAZy): an expert resource for glycogenomics. Nucleic Acids Research 37, D233-8.

Chapman NH, Bonnet J, Grivet L, Lynn J, Graham N, Smith R, Sun G, Walley PG, Poole M, Causse M, King GJ, Baxter C, Seymour GB. 2012. High-resolution mapping of a fruit firmness-related quantitative trait locus in tomato reveals epistatic interactions associated with a complex combinatorial locus. Plant Physiology 159, 1644-57.

Chou KC, Shen HB. 2010. Plant-mPLoc: a top-down strategy to augment the power for predicting plant protein subcellular localization. PLoS ONE 5, e11335. 
de Souza AP, Arundale RA, Dohleman FG, Long SP, Buckeridge M. 2013. Will the exceptional productivity of Miscanthus $\mathrm{x}$ giganteus increase further under rising atmospheric CO2? Agricultural and Forest Meteorology 171-172, 82-92.

Di Rienzo JA, Casanoves F, Balzarini MG, Gonzalez L, Tablada M, Robledo CW. 2011. InfoStat versión 2011. Grupo InfoStat, FCA, Universidad Nacional de Córdoba, Argentina. URL http://www.infostat.com.ar.

Di Rienzo JA. 2009. Statistical software for the analysis of experiments of functional genomics. RDNDA. Argentina. 756587.http://sites.google.com/site/fgStatistics/.

Emanuelsson O, Brunak S, von Heijne G, Nielsen H. 2007. Locating proteins in the cell using TargetP, SignalP, and related tools. Nature Protocols 2, 953-971.

Fei Z, Joung JG, Tang X, Zheng Y, Huang M, Lee JM, McQuinn R, Tieman DM, Alba R, Klee HJ, Giovannoni JJ. 2011. Tomato Functional Genomics Database: a comprehensive resource and analysis package for tomato functional genomics. Nucleic Acids Research 39, 1156-1163.

Filisetti-Cozzi TMCC, Carpita NC. 1991. Measurement of uronic acids without interference from neutral sugars. Analalytical Biochemstry 197, 157-162.

Fridman E, Carrari F, Liu Y, Fernie AR, Zamir D. 2004. Zooming in on a quantitative trait for tomato yield using interspecific introgressions. Science 305, 1786-1789.

Gerrits PO. 1991. The application of glycol methacrylate in histotechnology; some fundamental principles. Groningen, Department of Anatomy and Embryology, State University Groningen.

Giovannoni JJ, DellaPenna D, Bennett AB, Fischer RL. 1989. Expression of a chimeric polygalacturonase gene in transgenic rin (ripening inhibitor) tomato fruit results in polyuronide degradation but not fruit softening. Plant Cell 1, 53-63.

Hackel A, Schauer N, Carrari F, Fernie AR, Grimm B, Kühn C. 2006. Sucrose transporter LeSUT1 and LeSUT2 inhibition affects tomato fruit development in different ways. The Plant Journal 45, 18092.

Harholt J, Suttangkakul A, Vibe Scheller H. 2010. Biosynthesis of pectin. Plant Physiology 153, 384-95.

Harker FR, Redgwell RJ, Hallett IC, Murray SH, Carter G. 1997. Texture of Fresh Fruit. In: John Wiley and Sons, Inc. Horticultural Reviews,121-224.

Hoeglund A, Doennes P, Blum T, Adolph HW, Kohlbacher O. 2006. MultiLoc: prediction of protein subcellular localization using $\mathrm{N}$-terminal targeting sequences, sequence motifs, and amino acid composition. Bioinformatics 22, 1158-1165.

Houben K, Jolie RP, Fraeye I, Van Loey AM, Hendrickx ME. 2011. Comparative study of the cell wall composition of broccoli, carrot, and tomato: structural characterization of the extractable pectins and hemicelluloses. Carbohydrate Research 346, 1105-1111.

Jones DT, Taylor WR, Thornton JM. 1992. The rapid generation of mutation data matrices from protein sequences. Computational Applied Biosciences 8, 275-82.

Karimi M, Inzé D, Depicker A. 2002. GATEWAY vectors for Agrobacterium - mediated plant transformation. Trends in Plant Science 7, 193-195.

Kong Y, Zhou G, Yin Y, Xu Y, Pattathil S, Hahn MG. 2011. Molecular analysis of a family of Arabidopsis genes related to galacturonosyltransferases. Plant Physiology 155, 1791-805.

Kopka J, Schauer N, Krueger S, Birkemeyer C, Usadel B, Bergmüller E, Dormán P, Weckwerth W, Gibon Y, Stitt M, Willmitzer L, Fernie AR, Steinhauser D. 2005. GMD@CSB.DB: the GolmMetabolome Database. Bioinformatics 21, 1635-1638.

Lahaye M, Quemener B, Causse M, Seymour GB. 2012. Hemicellulose fine structure is affected differently during ripening of tomato lines with contrasted texture. International Journal Biological Macromoleculees 51, 462-70.

Lahaye M, Devaux MF, Poole M, Seymour GB, Causse M. 2013. Pericarp tissue microstructure and cell wall polysaccharide chemistry are differently affected in lines of tomato with contrasted firmness. Postharvest Biology and Technology 76, 83-90.

Leboeuf E, Guillon F, Thoiron S, Lahaye M. 2005. Biochemical and immunohistochemical analysis of pectic polysaccharides in the cell walls of Arabidopsis mutant QUASIMODO 1 suspensioncultured cells: implications for cell adhesion. Journal of Experimental Botany 56, 3171-3182.

Lillie RD. 1965. Histopathologic technic and practical histochemistry. 3rd ed., New York, McGraw-Hill. 
Lisec J, Schauer N, Kopka J, Willmitzer L, Fernie AR. 2006. Gas chromatography mass spectrometrybased metabolite profiling in plants. Nature Protocols 1, 387-396.

Lunn D, Phan TD, Tucker GA, Lycett GW. 2013. Cell wall composition of tomato fruit changes during development and inhibition of vesicle trafficking is associated with reduced pectin levels and reduced softening. Plant Physiology et Biochemistry doi:10.1016/j.plaphy.2013.02.005.

Maxwell K, Johnson GN. 2000. Chlorophyll fluorescence--a practical guide. Journal of Experimental Botany 51, 659-68.

Mohnen D. 2008. Pectin structure and biosynthesis. Current Opinion in Plant Biology 11, 266-77.

Nguyen-Quoc B, Foyer CH. 2001. A role for "futile cycles" involving invertase and sucrose synthase in sucrose metabolism of tomato fruit. Journal of Experimental Botany 52, 881-9.

Nunes-Nesi A, Carrari F, Lytovchenko A, Smith AMO, Loureiro ME, Ratcliffe RG, Sweetlove LJ, Fernie AR. 2005. Enhanced photosynthetic performance and growth as a consequence of decreasing mitochondrial malate dehydrogenase activity in trans- genic tomato plants. Plant Physiology 137, 611-622.

OBrien TP, Feder N, McCully ME. 1964. Polychromatic staining of plant cell walls by toluidine blue 0 . Protoplasma 59, 368-373.

Oms-Oliu G, Hertog MLATM, Van de Poel B, Ampofo-Asiama J, Geeraerd AH, Nicolaï BM. 2011. Metabolic characterization of tomato fruit during preharvest development, ripening, and postharvest shelf-life. Postharvest Biology and Technology 62, 7-16.

Oomen RJFJ, Doeswijk-Voragen CHL, Bush MS, Vincken JP, Borkhardt B, van den Broek LAM, Corsar J, Ulvskov P, Voragen AGJ, McCann MC, et al. 2002. In muro fragmentation of the rhamnogalacturonan I backbone in potato (Solanum tuberosum L.) results in a reduction and altered location of the galactan and arabinan side-chains and abnormal periderm development. The Plant Journal 30, 403-13.

Orfila C, Sørensen SO, Harholt J, Geshi N, Crombie H, Truong HN, Reid JSG, Knox JP, Scheller HV. 2005. QUASIMODO1 is expressed in vascular tissue of Arabidopsis thaliana inflorescence stems, and affects homogalacturonan and xylan biosynthesis. Planta 222, 613-22.

Osorio S, Alba R, Nikoloski Z, Kochevenko A, Fernie AR, Giovannoni JJ. 2012. Integrative comparative analyses of transcript and metabolite profiles from pepper and tomato ripening and development stages uncovers species-specific patterns of network regulatory behavior. Plant Physiology 159, 1713-29.

Patrick JW, Offler CE. 1996. Post-sieve element transport of photoassimilates in sink regions. Journal of Experimental Botany 47, 1165-1177.

Peña M J, Zhong R, Zhou G, Richardson EA, O'Neill MA, Darvill AG, York WS, Ye Z. 2007. Arabidopsis irregular xylem8 and irregular xylem 9 : implications for the complexity of glucuronoxylan biosynthesis. The Plant Cell 19, 549-563.

Persson S, Caffall KH, Freshour G, Hilley MT, Bauer S, Poindexter P, Hahn MG, Mohnen D, Somerville C. 2007. The Arabidopsis irregular xylem8 mutant is deficient in glucuronoxylan and homogalacturonan, which are essential for secondary cell wall integrity. The Plant Cell 19, 23755.

Rasband WS ImageJ, U. S. National Institutes of Health, Bethesda, Maryland, USA, http://imagej.nih.gov/ij/, 1997-2012.

Reiter WD. 2008. Biochemical genetics of nucleotide sugar interconversion reactions. Current Opinion in Plant Biology 11, 236-43.

Ridley BL, Neill MAO, Mohnen D. 2001. Pectins: structure, biosynthesis, and oligogalacturonide-related signaling. Phytochemistry 57, 929-967.

Roessner U, Willmitzer L, Fernie AR. 2001. High-Resolution Metabolic Phenotyping of Genetically and Environmentally Diverse Potato Tuber Systems. Identification of Phenocopies. Plant Physiology 127, 749-764.

Ruijter JM, Ramakers C, Hoogaars WMH, Karlen Y, Bakker O, van den Hoff MJB, Moorman AFM. 2009. Amplification efficiency: linking baseline and bias in the analysis of quantitative PCR data. Nucleic Acids Research 37, e45. 
Saeed Al, Sharov V, White J, Li J, Liang W, Bhagabati N, Braisted J, Klapa M, Currier T, Thiagarajan M, et al. 2003. TM4: a free, open-source system for microarray data management and analysis. Biotechniques 34, 374-8.

Saeman JF, Bulb JL, Harris EE. 1945. Quantitative saccharifi-cation of wood and cellulose. Industrial and Engeneering Chemistry 17, 35-37.

Saladié M, Matas AJ, Isaacson T, Jenks MA, Goodwin SM, Niklas KJ, Xiaolin R, Labavitch JM, Shackel KA, Fernie AR, et al. 2007. A reevaluation of the key factors that influence tomato fruit softening and integrity. Plant Physiology 144, 1012-1028.

Schauer N, Steinhauser D, Strelkov S, Schomburg D, Allison G, Moritz T, Lundgren K, Roessner-Tunali U, Forbes MG, Willmitzer L, Fernie AR, Kopka J. 2005. GC-MS libraries for the rapid identification of metabolites in complex biological samples. Federation of European Biochemical Societies Letters 579, 1332-1337.

Schauer N, Semel Y, Roessner U, Gur A, Balbo I, Carrari F, Pleban T, Perez-Melis A, Bruedigam C, Kopka J, et al. 2006. Comprehensive metabolic profiling and phenotyping of interspecific introgression lines for tomato improvement. Nature Biotechnology 24, 447-54.

Shackel KA, Greve C, Labavitch JM, Ahmadi H. 1991. Cell turgor changes associated with ripening in tomato pericarp tissue. Plant Physiology 97, 814-816.

Shatkay H, Höglund A, Brady S, Blum T, Dönnes P, Kohlbacher O. 2007. SherLoc: high-accuracy prediction of protein subcellular localization by integrating text and protein sequence data. Bioinformatics 23, 1410-1417.

Sienkiewicz-Porzucek A, Sulpice R, Osorio S, Krahnert I, Leisse A, Urbanczyk-Wochniak E, Hodges M, Fernie AR, Nunes-Nesi A. 2010. Mild reductions in mitochondrial NAD-dependent isocitrate dehydrogenase activity result in altered nitrate assimilation and pigmentation but do not impact growth. Molecular Plant 3, 156-73.

Sila DN, Buggenhout SV, Duvetter T, Fraeye I, Roeck AD, Loey AV, Hendrickx M. 2009. Pectins in processed fruits and vegetables : part II - structure - function relationships. Comprehensive Reviews in Food Science and Food Safety 8, 86-104.

Smith DL, Abbott JA, Gross KC. 2002. Down-Regulation of Tomato B-Galactosidase 4 Results in Decreased Fruit Softening. Plant Physiology 129, 1755-1762.

Song C, Guo J, Sun W, Wang Y. 2012. Whole genome duplication of intra-and inter-chromosomes in the tomato genome. Journal of Genetics and Genomics 39, 361-368.

Sterling JD, Atmodjo MA, Inwood SE, Kumar Kolli VS, Quigley HF, Hahn MG, Mohnen D. 2006. Functional identification of an Arabidopsis pectin biosynthetic homogalacturonan galacturonosyltransferase. Proceedings of National Academy of Science 103, 5236-5241.

Szymanski DB, Cosgrove DJ. 2009. Dynamic coordination of cytoskeletal and cell wall systems during plant cell morphogenesis. Current Biology 19, 800-811.

Tamura K, Peterson D, Peterson N, Stecher G, Nei M, Kumar S. 2011. MEGA5: molecular evolutionary genetics analysis using maximum likelihood, evolutionary distance, and maximum parsimony methods. Molecular Biology and Evolution 28, 2731-9.

The Tomato Genome Consortium. 2012. The tomato genome sequence provides insights into fleshy fruit evolution. Nature 485, 635-641.

Thompson JD, Higgins DG, Gibson TJ. 1997. The CLUSTAL_X windows interface: flexible strategies for multiple sequence alignment aided by quality analysis tools. Nucleic Acids Research 25, 48764882.

Tieman DM, Harriman RW, Ramamohan G, Handa AK. 1992. An antisense pectin methylesterase gene alters pectin chemistry and soluble solids in tomato fruit. The Plant Cell 4, 667-679.

Unda F, Canam T, Preston L, Mansfield SD. 2012. Isolation and characterization of galactinol synthases from hybrid poplar. Journal of Experimental Botany 63, 2059-69.

Vincken JP, Schols HA, Oomen RJFJ, McCann MC, Ulvskov P, Voragen AGJ, Visser RGF. 2003. If Homogalacturonan were a side chain of rhamnogalacturonan I. Implications for cell wall architecture. Plant Physiology 132, 1781-1789. 
Wormit A, Butt SM, Chairam I, McKenna JF, Nunes-Nesi A, Kjaer L, O'Donnelly K, Fernie AR, Woscholski R, Barter MC, Hamann T. 2012. Osmosensitive changes of carbohydrate metabolism in response to cellulose biosynthesis inhibition. Plant Physiology 159, 105-117.

Yin Y, Chen H, Hahn MG, Mohnen D, Xu Y. 2010. Evolution and function of the plant cell wall synthesisrelated glycosyltransferase family 8. Plant Physiology 153, 1729-46.

Zhou T, Zhang R, Guo S. 2011. Molecular cloning and characterization of GhGolS1, a novel gene encoding galactinol synthase from cotton (Gossypium hirsutum). Plant Molecular Biology Report 30, 699-709. 


\section{TABLES AND FIGURES}

Table 1. Identification of tomato genes encoding for galacturonosyltranferases.

\begin{tabular}{|c|c|c|c|c|c|c|c|c|}
\hline Enzyme $^{a}$ & $\begin{array}{l}\text { A. thaliana locus } \\
\text { (no. amino acids) }\end{array}$ & Tomato unigene $^{b}$ & $\begin{array}{r}\text { Subcc } \\
\text { TargetP }^{c}\end{array}$ & $\begin{array}{l}\text { ular loca } \\
\text { SherLoc }{ }^{d}\end{array}$ & $\begin{array}{l}\text { ation } \\
\text { Multiloc }\end{array}$ & Tomato locus $^{f}$ & Linked marker ${ }^{g}$ & $\begin{array}{l}\text { Chromosome } \\
\text { Position }^{h} \text { (cM) }\end{array}$ \\
\hline GAUT1 & At3g61130 (673) & SGN-U565384 & nd & G & G & Solyc01g093970 & P51 & $1(69 \mathrm{cM})$ \\
\hline GAUT2 & At2g46480 (528) & SGN-U598345 & nd & M & M & Solyc10g017600 & T1720 & $10(32.5 \mathrm{cM})$ \\
\hline GAUT3 & At4g38270 (680) & SGN-U567225 & SP & G & G & Solyc01g112210 & C2_At4g38240 & 1 (165cM) \\
\hline GAUT4 & At5g47780 (616) & SGN-U575018 & SP & G & G & Solyc04g015270 & T0891 & 4 (53cM) \\
\hline GAUT5 & At2g30575 (610) & SGN-U574664 & SP & G & G & Solyc07g005360 & T1112 & $7(0.4 \mathrm{cM})$ \\
\hline GAUT6 & At1g06780 (589) & SGN-U569431 & SP & G & G & Solyc12g010200 & CLET-8-K4 & 12 (41cM) \\
\hline GAUT7 & At2g38650 (619) & SGN-U574191 & nd & G & ER & Solyc10g074650 & T0283 & $10(36 \mathrm{cM})$ \\
\hline GAUT8 & At3g25140 (559) & SGN-U565194 & nd & G & G & Solyc06g083310 & U146140 & $6(97.2 \mathrm{cM})$ \\
\hline GAUT9 & At3g02350 (561) & SGN-U563256 & M & G & G & Solyc02g089440 & cLES-3-G11 & $2(111 \mathrm{cM})$ \\
\hline GAUT10 & At2g20810 (466) & SGN-U574750 & M & G & G & Solyc04g064490 & T0877 & 4 (67cM) \\
\hline GAUT11 & At1g18580 (332) & SGN-U565457 & M & G & G & Solyc03g114810 & cLED-19-N16 & 3 (107cM) \\
\hline \multirow{2}{*}{ GAUT12 } & \multirow{2}{*}{ At5g54690 (535) } & SGN-U601760 & nd & G & G & Solyc07g064050 & TG438 & 7 (73cM) \\
\hline & & SGN-U599179 & nd & G & G & Solyc10g006500 & T0418 & $10(1 \mathrm{cM})$ \\
\hline \multirow{2}{*}{ GAUT13 } & \multirow{2}{*}{ At3g01040 (532) } & SGN-U582378 & nd & G & G & Solyc02g067060 & T0869 & $2(21 \mathrm{cM})$ \\
\hline & & SGN-U563601 & nd & G & G & Solyc03g013630 & C2_At3g01060 & $3(72.7)$ \\
\hline GAUT14 & At5g15470 (432) & SGN-U573429 & nd & G & G & Solyc02g088630 & T1480 & $2(106 \mathrm{cM})$ \\
\hline GAUT15 & At3g58790 (540) & SGN-U573007 & nd & G & G & Solyc07g055930 & C2_At3g58790 & $7(44.6 \mathrm{cM})$ \\
\hline
\end{tabular}

${ }^{a}$ Enzyme name abbreviation.

${ }^{b}$ Tomato unigene number according to SGN (http://solgenomics.net/).

${ }^{c}$ Subcellular localization prediction according to TargetP 1.1 software (www.cbs.dtu.dk/services/TargetP/) (Emanuelsson et al., 2007). SP: secretory pathway. M: mitochondrion. nd: not determined because output score was below the requested cutoff for localization prediction.

${ }^{d}$ Subcellular localization prediction according to SherLoc (Shatkay et al., 2007). G: Golgi, M: mitochondria

${ }^{e}$ Subcellular localization prediction according to MultiLoc (MultiLoc et al., 2006). G: Golgi, M: mitochondria, ER: endoplasmic reticulum.

${ }^{f}$ S. lycopersicum locus according to SGN (http://solgenomics.net/).

${ }^{g}$ Closest mapped markers.

${ }^{h}$ Chromosome and genetic position in Tomato-EXPEN 2000 v52. 
Table 2. Sugar composition of the cell wall fractions of transgenic lines.

\begin{tabular}{|c|c|c|c|c|c|c|c|c|c|c|c|c|}
\hline & & \multicolumn{6}{|c|}{ Sugar content in ammonium oxalate-soluble fraction ( $\mu \mathrm{g} / \mathrm{g}$ AIR) } & \multicolumn{5}{|c|}{ Sugar content in $\mathrm{NaOH}$-soluble fraction ( $\mu \mathrm{g} / \mathrm{g}$ AIR) } \\
\hline & & fucose $^{a}$ & rhamnose $^{a}$ & arabinose $^{a}$ & galactose $^{a}$ & xylose $^{a}$ & uronic acids $^{b}$ & fucose $^{a}$ & rhamnose $^{a}$ & arabinose $^{a}$ & galactose $^{a}$ & xylose $^{a}$ \\
\hline \multirow{4}{*}{ Leaves } & RNAi2 & $23.4 \pm 1.3$ & $274.4 \pm 65.9$ & $403.8 \pm 54.7$ & $326.9 \pm 115.1$ & $36.6 \pm 3.1$ & $102,153.9 \pm 10,424.2$ & $5.1 \pm 0.4$ & $24.6 \pm 6.5$ & $209.3 \pm 8.9$ & $136.1 \pm 24.8$ & $44.2 \pm 15.5$ \\
\hline & RNAi40 & $22.0 \pm 6.8$ & $288.7 \pm 81.9$ & $493.0 \pm 178.8$ & $399.2 \pm 144.8$ & $27.8 \pm 6.6$ & $107,127.6 \pm 8,695.0$ & $5.5 \pm 0.5$ & $32.9 \pm 6.1$ & $211.0 \pm 14.7$ & $310.0 \pm 25.6$ & $38.0 \pm 2.6$ \\
\hline & RNAi42 & $22.3 \pm 1.3$ & $237.3 \pm 40.6$ & $460.4 \pm 21.3$ & $372.8 \pm 17.2$ & $31.0 \pm 6.8$ & $104,676.3 \pm 16,229.8$ & $4.4 \pm 0.6$ & $35.2 \pm 15.6$ & $220.9 \pm 54.9$ & $282.4 \pm 107.5$ & $26.6 \pm 3.4$ \\
\hline & WT & $24.1 \pm 4.1$ & $314.6 \pm 55.3$ & $397.4 \pm 52.3$ & $321.8 \pm 42.4$ & $41.8 \pm 3.1$ & $100,326.8 \pm 8,536.2$ & $4.7 \pm 0.7$ & $27.6 \pm 6.4$ & $182.4 \pm 29.9$ & $135.6 \pm 16.3$ & $33.3 \pm 5.8$ \\
\hline \multirow{4}{*}{ Fruits } & RNAi2 & $79.2 \pm 18.9$ & $100.7 \pm 13.5$ & $609.8 \pm 73.0$ & $1,618.5 \pm 168.4$ & $237.7 \pm 48.8$ & $140,641.2 \pm 4,141.9$ & & & & & \\
\hline & RNAi40 & $114.2 \pm 24.6$ & $73.7 \pm 16.7$ & $436.4 \pm 81.6$ & $983.1 \pm 196.0$ & $196.2 \pm 53.2$ & $168,608.4 \pm 34,643.9$ & & & & & \\
\hline & RNAi42 & $88.1 \pm 24.6$ & $152.4 \pm 20.9$ & $669.7 \pm 36.9$ & $1527.1 \pm 163.2$ & $196.6 \pm 12.0$ & $201,196.4 \pm 11,135.3$ & & & & & \\
\hline & WT & $171.7 \pm 35.3$ & $353.5 \pm 81.6$ & $1,417.5 \pm 141.2$ & $3424.6 \pm 135.5$ & $739.5 \pm 29.1$ & $192,813.6 \pm 564.6$ & & & & & \\
\hline
\end{tabular}

Monosacharaides were measured by HPAEC/ PAD in ammonium oxalate and NaOH-soluble fractions.

${ }^{b}$ Uronic acids were quantified spectophotometrically in ammonium oxalate-soluble fraction.

Data indicate means from at least three biological replicates. Significant statistic differences from wild type (WT) are indicated in bold ( $p<0.05)$ 
Table 3. Sugar ratios for the different polysaccharide fractions of transgenic lines.

\begin{tabular}{ccccc}
\hline & & $\begin{array}{c}\text { Linearity of pectin } \\
\text { Uronic acids/(Xyl+Gal+Rha+Ara+Fuc) }\end{array}$ & $\begin{array}{c}\text { Contribution of RG-I to pectin population } \\
\text { Rha/Uronic acids }\end{array}$ & $\begin{array}{c}\text { Branching of RG-I } \\
\text { (Ara+Gal)/Rha }\end{array}$ \\
\multirow{2}{*}{ Leaves } & RNAi plants & 91.2 & 0.0026 & 3.1 \\
\multirow{2}{*}{ Fruits } & WT plants & 91.2 & 0.0031 & 2.3 \\
& RNAi plants & 74.3 & 0.0006 & 18.6 \\
& WT plants & 28.5 & 0.0020 & 13.7 \\
\hline
\end{tabular}

Ratios were calculated based on Table 2 data. 

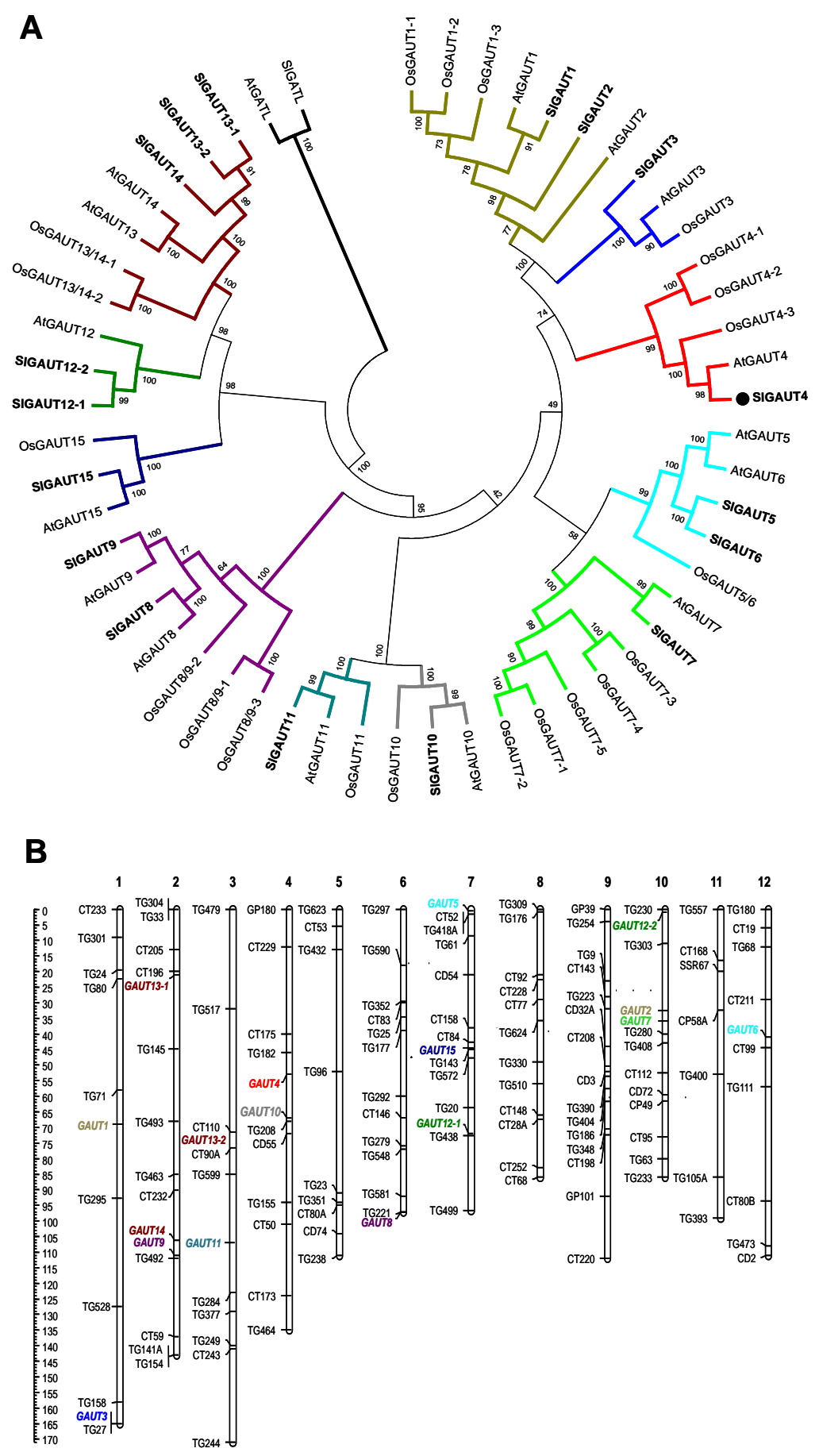

Figure 1. The GAUT protein family and the genomic localization of GAUT genes in tomato.

(A) Phylogenetic analysis of the GAUT family in Arabidopsis thaliana (At), Oryza sativa (Os) and Solanum lycopersicum (SI). A. thaliana and $O$. sativa sequences were obtained from Caffall et al. (2009). The tomato orthologues were identified in this work. The tree was rooted with AtGATL and SIGATL which are galacturonosyltransferase-like proteins from $A$. thaliana and $S$. lycopersicum, respectively. Bootstrap values greater than $50 \%$ are indicated on the branches. The black dot identifies the gene described by Bermúdez et al. (2008). (B) The 17 identified genes were localized in the Tomato-EXPEN 2000 genetic map available at the Solanaceae Genomics Network (http://solgenomics.net/index.pl). Markers and GAUT genes, are indicated on the left side of the chromosomes. GAUT genes are highlighted in the same color pattern as their branches on the phylogenetic tree. Genetic distances are indicated on the left border. 
A
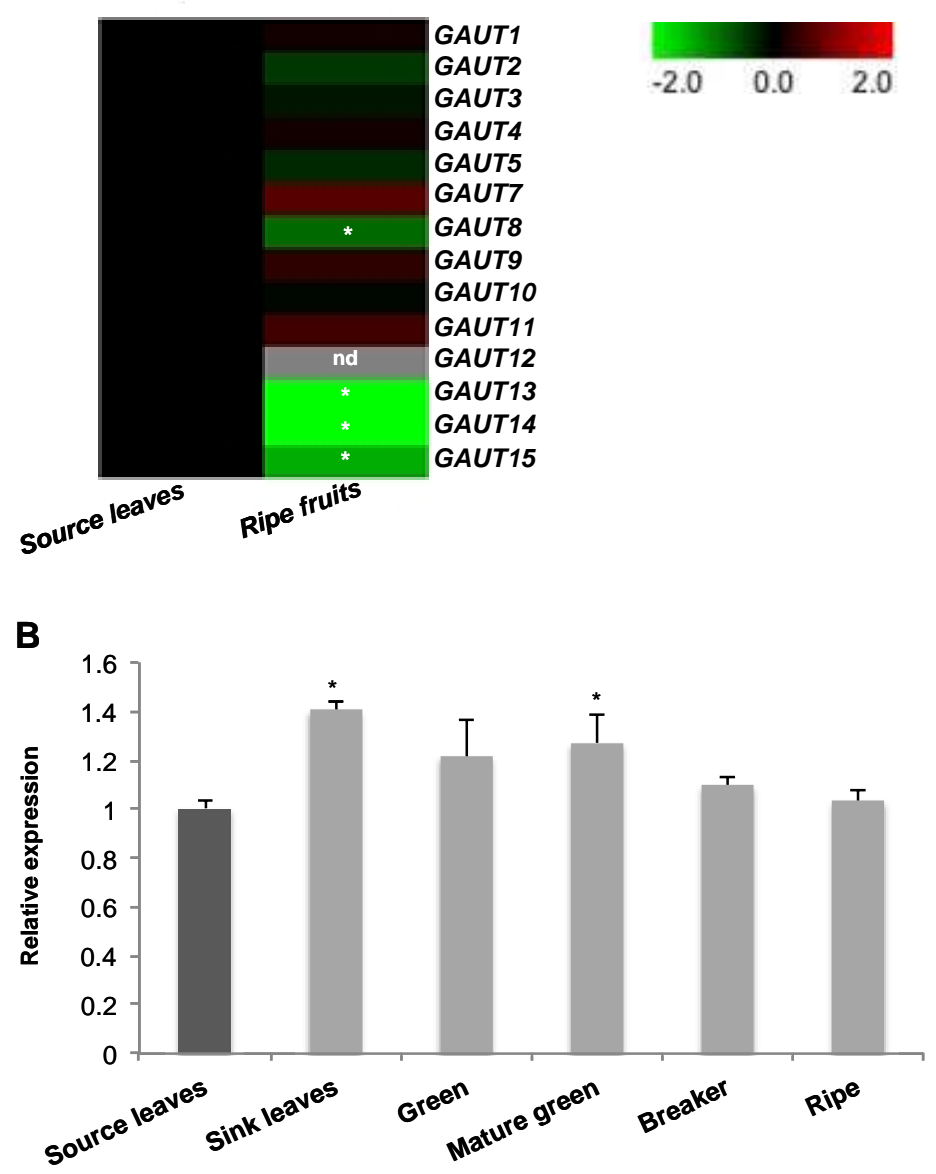

Figure 2. Expression profile of GAUT genes in tomato.

(A) Gene expression profiles of fourteen members of the gaut gene family were measured by qPCR in samples from source leaves and ripe fruits $(n=3)$. Relative gene expression levels $(\log 2)$ are shown in a color scale where green and red indicate decreased and increased transcript levels in ripe fruits with respect to source leaves (black boxes), respectively. Gray box indicates not detected (nd). The heat map was constructed using MeV software (Saeed et al., 2003). GAUT12 and GAUT13 represent the expression of both paralog pairs, GAUT12-1 and GAUT12-2, and GAUT13-1 and GAUT13-2. (B) GAUT4 gene expression profile in source and sink leaves, and green, mature green, breaker and ripe fruits. Data indicate relative expression normalized to source leaf value (black bar). All data are means from at least three biological replicates. Significant statistic differences from source leaves are indicated with asterisk $(P<0.05)$. 
A

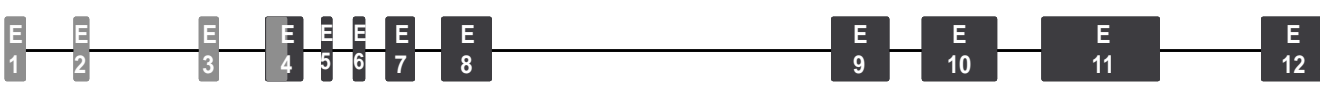

$274 \mathrm{bp}$

GT8 family motif

B

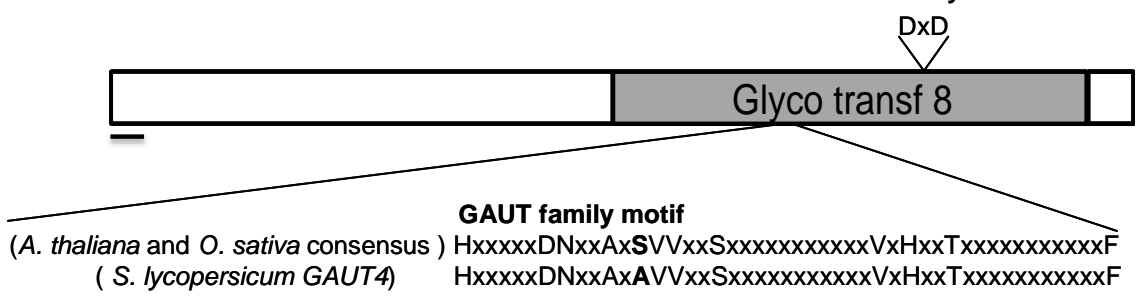

C

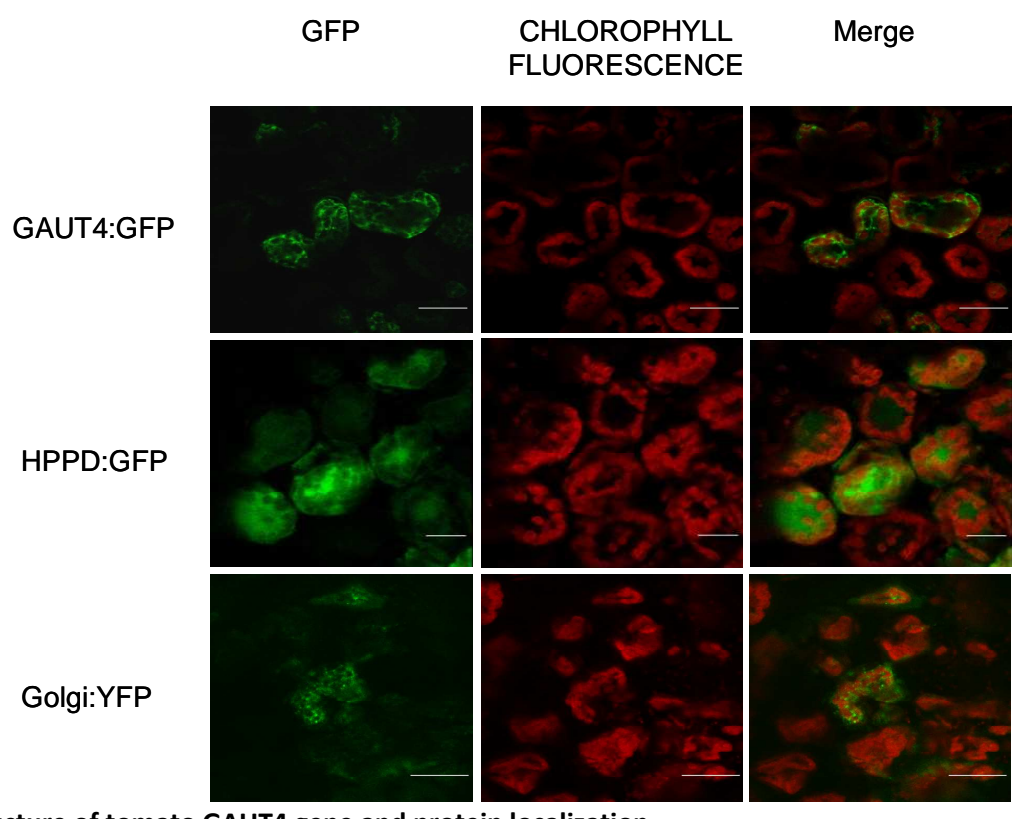

Figure 3. Structure of tomato GAUT4 gene and protein localization.

(A) Exons are indicated as E. Coding and non-coding exons are in black and grey, respectively. The lines represent the introns. (B) Schematic representation of GAUT4 protein structure exhibiting the GT8 domain (Glyco_transf 8) as a grey box with the family characteristic motifs, GT8 and GAUT. The dark line indicates the position of the transmembrane domain. (C) Confocal imaging of $N$. benthamiana mesophyll cells expressing GAUT4:GFP, HPPD:GFP (a cytosolic control) and Golgi:YFP (a Golgi complex control) fusion proteins. GFP, chlorophyll fluorescence and merged signals are indicated above the panels. The scale bar represents $25 \mu \mathrm{m}$ for GAUT4:GFP and HPPD:GFP fusions, and $50 \mu \mathrm{m}$ for Golgi:YFP control. 

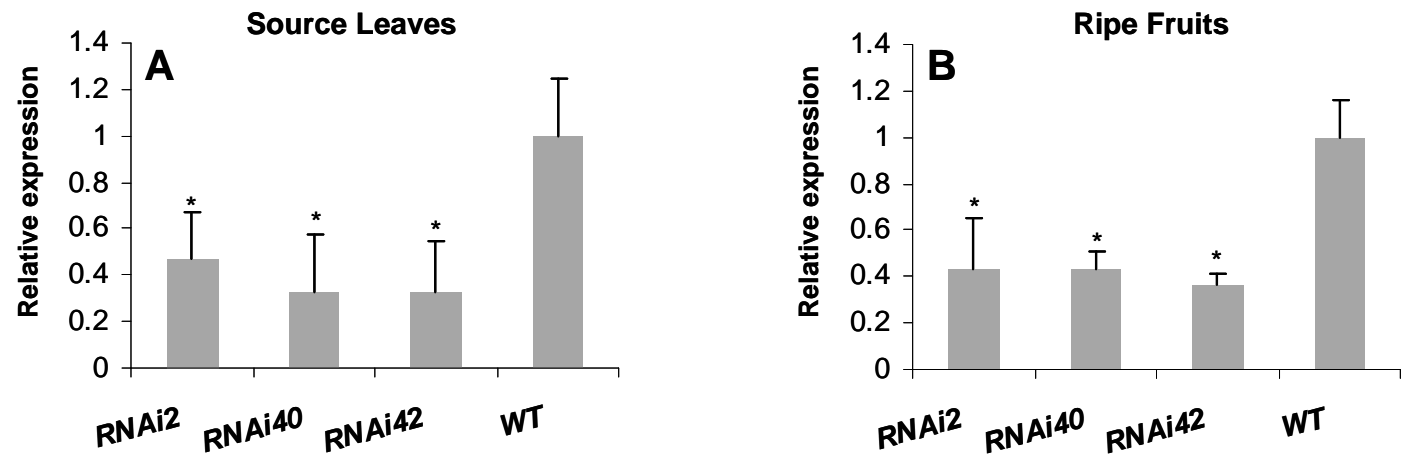

Figure 4. GAUT4 expression level in silenced transgenic plants.

GAUT4 expression was measured by qPCR in samples from source leaves (A) and ripe fruits (B). Data indicate relative expression means from at least three biological replicates normalized to wild type value. Significant statistic differences from wild type (WT) are indicated with asterisk $(P<0.05)$. 

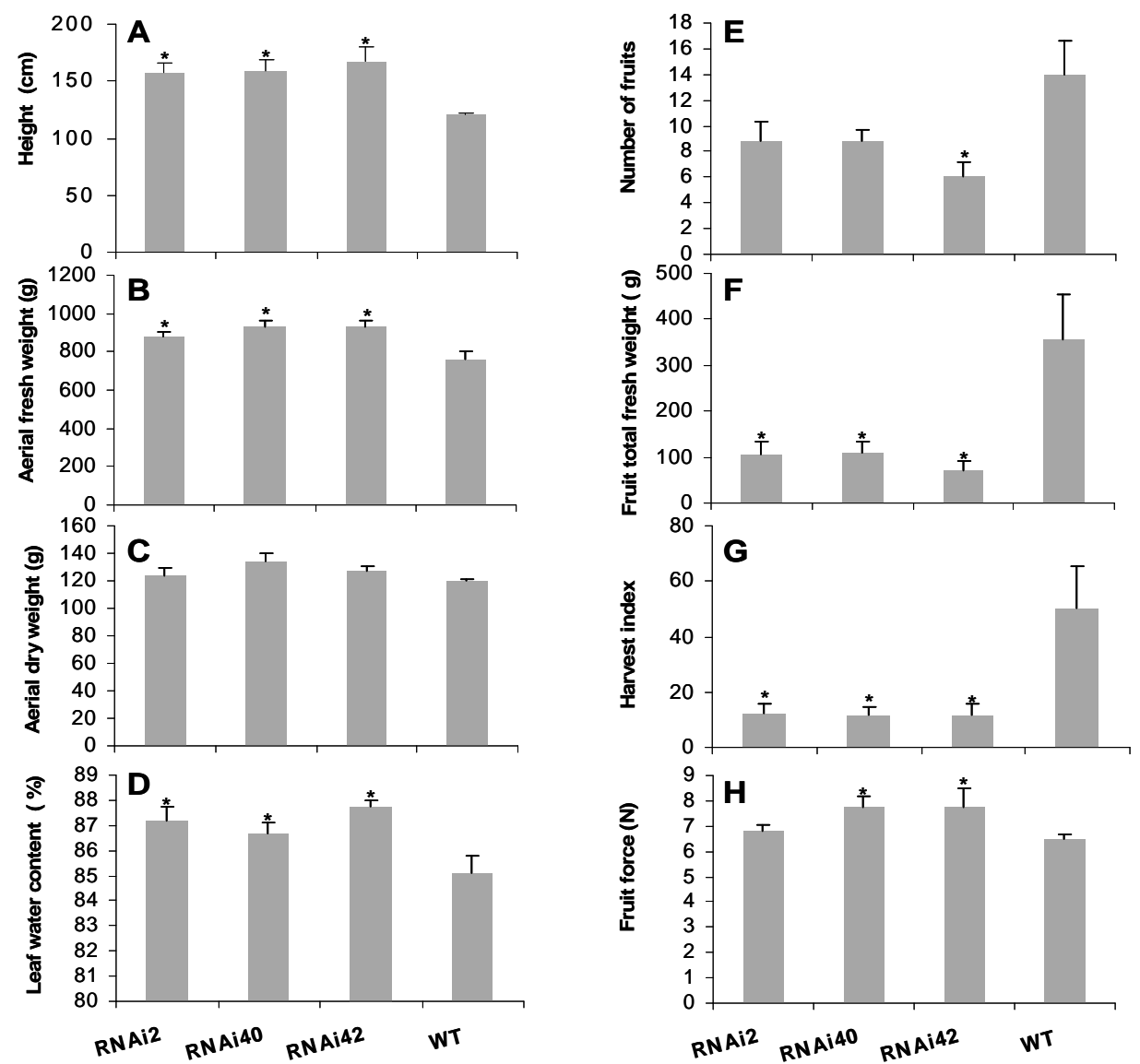

Figure 5. Phenotypic characterization of the GAUT4-silenced plants.

Height of wild type and T1 silenced plants with eight-week-old from base to apex (A). Six-month-old T0 plants were harvested and fresh (B) and dry (C) aerial biomass, and leaf water content (D) were calculated. Regarding fruits, the total number of fruits $(E)$ and total fruit weight $(F)$ at harvest time were measured, and harvest index (G) was calculated. Firmness was measured on intact fruits at ripe stage $(H)$. Values are means from at least three biological replicates for $A, B, C, D, E, F$ and $G$, and from at least 5 fruits per line for $\mathrm{H}$. Significant statistic differences from wild type (WT) are indicated with asterisk $(P<0.05)$. 
Source Leaves
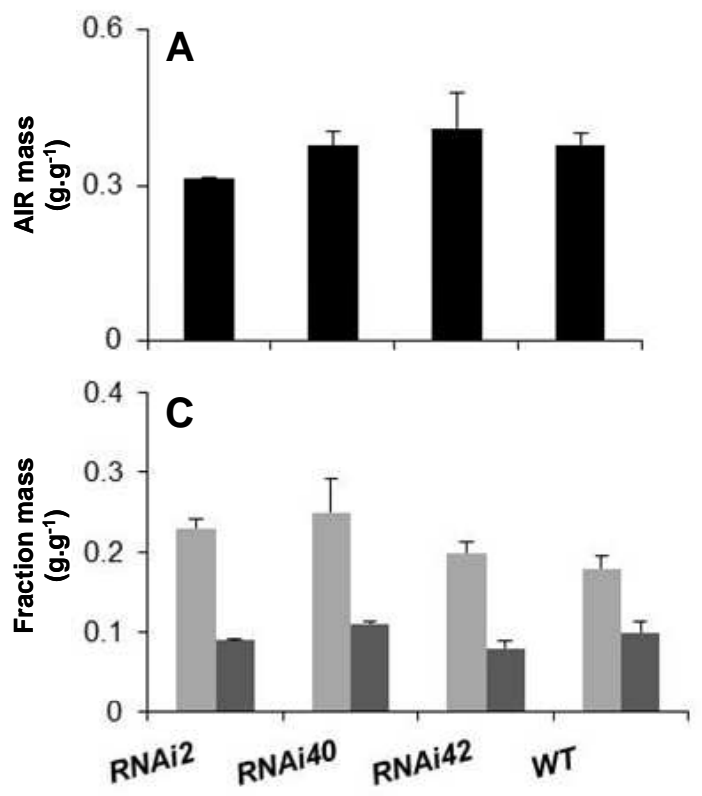

ammonium oxalate-soluble fraction
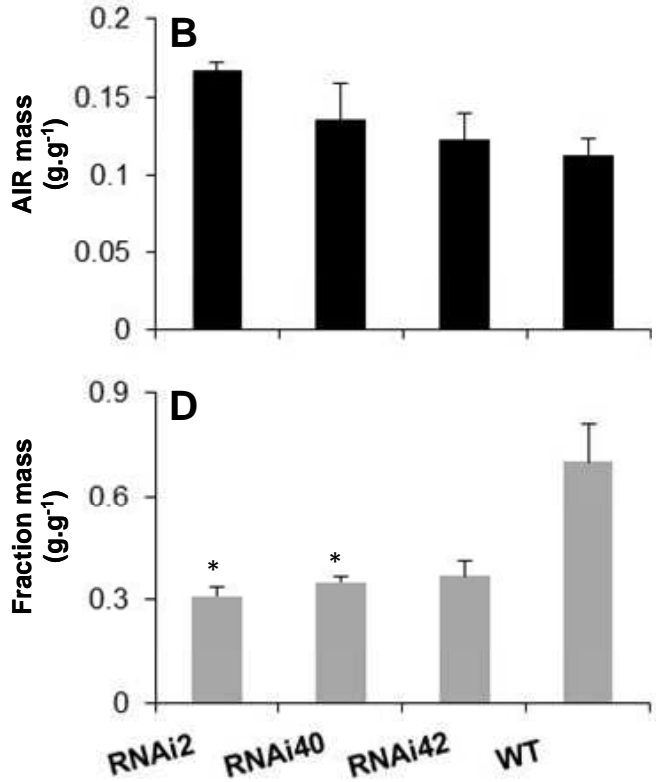

- $\mathrm{NaOH}$-soluble fraction

Figure 6. Cell wall polysaccharides content in GAUT4-silenced plants.

The alcohol-insoluble fraction (AIR) containing the cell wall was extracted from leaves (A) and fruits (B) and expressed relative to dry material. AIR was fractioned by subsequent extractions with ammonium oxalate and $\mathrm{NaOH}$ from source leaves (C) and only with ammonium oxalate from ripe fruits (D). The mass for each fraction was expressed relative to AIR. Significant statistic differences from wild type (WT) for any given fraction are indicated with asterisk $(P<0.05)$. 
Source Leaves
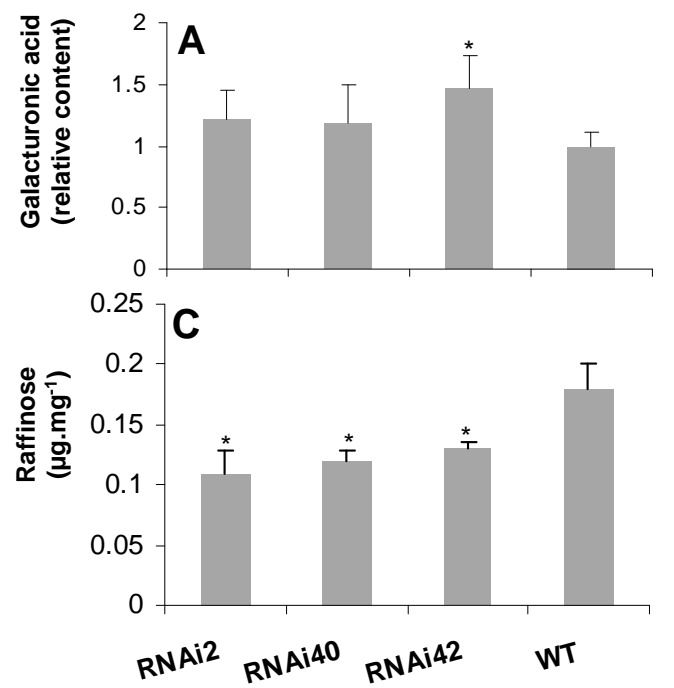

Ripe Fruits

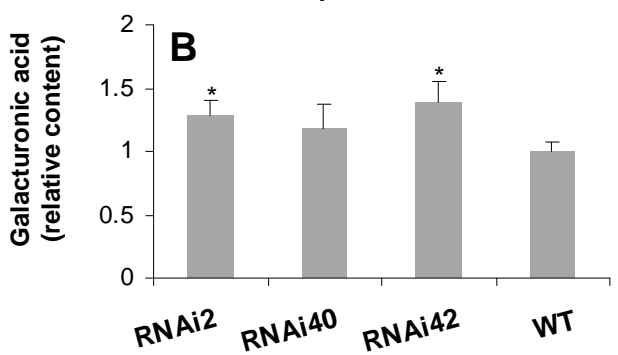

Figure 7. Soluble metabolites content in GAUT4-silenced plants.

Galacturonic acid was quantified by GC-MS from source leaves (A) and ripe fruits (B) and data were normalized to wild type genotype and expressed as relative content. Free raffinose content in source leaves (C) was measured by HPLC and expressed relative to dry weight. This monosaccharide was not detected in ripe fruits in agreement with the decrease across fruit development reported by Oms-Oliu et al. (2011). All values indicate means from at least three biological replicates and significant statistic differences from wild type (WT) are indicated with asterisk $(P<0.05)$. 
Source Leaves

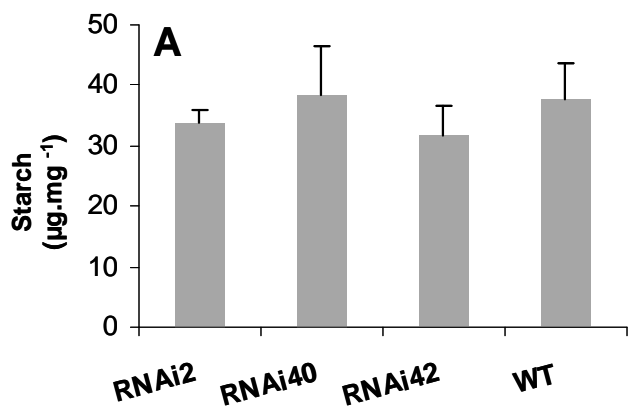

Ripe Fruits

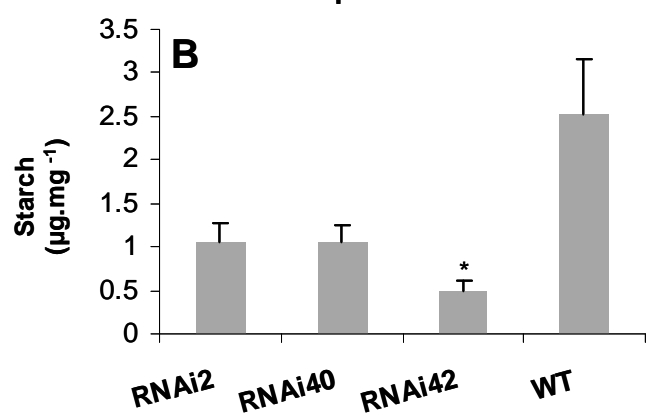

Figure 8. Starch content in GAUT4-silenced plants.

Starch was quantified enzymatically in source leaves (A) and ripe fruits (B). Values are expressed relative to dry weight. Data indicate means from at least three biological replicates. Significant statistic differences from wild type (WT) are indicated with asterisk $(\mathrm{P}<0.05)$. 
Supplementary Table S1. Primers sed in qRT-PCR.

\begin{tabular}{|c|c|c|c|}
\hline Gene & Forward & Reverse & $\begin{array}{c}\text { Annealing } \\
\text { temperature }\left({ }^{0} \mathrm{C}\right)\end{array}$ \\
\hline GAUT-1 & GTCCCCTTGGCGCAAATG & CTGAGCATTAGCTCCAAAACACAG & 55 \\
\hline GAUT-2 & CGCATAGTCACGTTTCCATGATC & GGCAGCAGATATCAGAATCGAAC & 55 \\
\hline GAUT-3 & TGCTGAAGAAAAGGAGTGCATTC & GATCTTCAAGCTTTTCCTTGTTTG & 55 \\
\hline GAUT-4 & CGAGCAGCAGTCATACACTAC & GTGCAGAGAACACTTCATGAACCAC & 55 \\
\hline GAUT-5 & CCTGCACTTCACGGGTACACACG & GTCTTCTAGGTCAAACGGAATCG & 55 \\
\hline GAUT-7 & GCACAGCACAGGTGTTGGTGAC & GCGACGCCATAAACAGTAGCTCCC & 55 \\
\hline GAUT-8 & GCAGCTAATGAAGGCGAAGAAG & GGAGTAGGCTTCCCATCATCTG & 55 \\
\hline GAUT-9 & CGAGGAAGCTGAAGTTGGAAATTG & CAAACTGTTTCAAGGAGTCGTCATC & 55 \\
\hline GAUT-10 & CAAGACTCTGACACCCAGAACTACTAC & GAAACACAACCTTCTTAAGTGCAGG & 55 \\
\hline GAUT-11 & GAATGAGCAGGTTGTGCATGAG & CTCCCATGCAAGATGAAGATTG & 55 \\
\hline GAUT12 & GGCATGTTACTGTTCTGCCTGC & CTAAGGTCGAACATTTTCGTTCTCC & 55 \\
\hline GAUT-12-1 & CCTTATATCGCCGAGTTTGAGGC & CTAGCGTGGAACATTTTCGTTCTCC & 55 \\
\hline GAUT-13-1 & GCTGCAAGGACAATACGCAG & GAGTCAAAGTAGCACACATCCC & 55 \\
\hline GAUT-14 & GGGGTTTGGGGGATTTTGATTTG & CACCGAATCCCAATCCCAATTC & 55 \\
\hline GAUT-15 & CATTGCCTATCCCTCAAGTTAGC & CAACAGACGCAGCAAGCACATTG & 55 \\
\hline GAUT4RNAitrans ${ }^{a}$ & GTATCTGGAGAGACAGCAAGGG & GCGAAGTTCTCTAATGAAGTGGGG & 55 \\
\hline EXPRESSED & TGGGTGTGCCTTTCTGAATG & GCTAAGAACGCTGGACCTAATG & 60 \\
\hline TIP4 & GCTGCGTTTCTGGCTTAGG & ATGGAGTTTTTGAGTCTTCTGC & 60 \\
\hline$E F 1-\alpha$ & ATTGGAAACGGATATGCTCCA & TCCTTACCTGAACGCCTGTCA & 55 \\
\hline
\end{tabular}

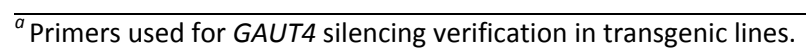


Supplementary Table S2. Photosynthetic parameters measured by gas exchange in tomato GAUT4-silenced lines.

\begin{tabular}{|c|c|c|c|c|c|c|c|c|c|}
\hline \multirow[t]{3}{*}{ Lines } & \multicolumn{4}{|c|}{ Assimilation rate } & $\mathrm{ETR}^{b}$ & $\begin{array}{l}\text { photochemical } \\
\text { quenching }\end{array}$ & $\begin{array}{c}\text { non-photochemical } \\
\text { quenching }\end{array}$ & $1-p Q^{c}$ & PSII eficiency \\
\hline & \multicolumn{4}{|c|}{$\operatorname{PFD}\left(\mu \mathrm{mol} \mathrm{m}{ }^{-2} \mathrm{~s}^{-2}\right)^{a}$} & & & & & \\
\hline & 200 & 400 & 800 & 1200 & & & & & \\
\hline RNAi2 & $5.42( \pm 1.6)$ & $9.26( \pm 1.1)$ & $12.108( \pm 1.0)$ & $12.688( \pm 1.8)$ & $121.93 \pm 18.38$ & $0.42 \pm 0.07$ & $1.38 \pm 0.10$ & $0.58 \pm 0.07$ & $0.23 \pm 0.04$ \\
\hline RNAi40 & $3.4578( \pm 1.7)$ & $6.218( \pm 2.4)$ & $6.972( \pm 2.0)$ & $7.362( \pm 2.6)$ & $108.06 \pm 19.50$ & $0.41 \pm 0.07$ & $1.67 \pm 0.17$ & $0.59 \pm 0.07$ & $0.21 \pm 0.04$ \\
\hline RNAi42 & $4.626( \pm 1.1)$ & $8.724( \pm 3.3)$ & $10.34( \pm 3.0)$ & $12.37( \pm 3.9)$ & $130.51 \pm 18.65$ & $0.46 \pm 0.04$ & $1.75 \pm 0.46$ & $0.54 \pm 0.04$ & $0.26 \pm 0.04$ \\
\hline WT & $4.556( \pm 2.5)$ & $7.528( \pm 2.0)$ & $9.722( \pm 2.0)$ & $12.68( \pm 2.0)$ & $113.38 \pm 20.33$ & $0.4 \pm 0.07$ & $1.49 \pm 0.30$ & $0.61 \pm 0.07$ & $0.22 \pm 0.04$ \\
\hline
\end{tabular}

Photon flux density.

${ }^{b}$ Electron transport rate.

${ }^{c}$ Reduced plastoquinone accumulation. 
Supplementary Table S3. Metabolite relative content in GAUT4-silenced lines.

\begin{tabular}{|c|c|c|c|c|c|c|c|c|c|c|c|c|c|c|c|c|c|c|c|c|c|c|c|c|c|}
\hline & & \multicolumn{12}{|c|}{ Leaves } & \multicolumn{12}{|c|}{ Fruit } \\
\hline & \multirow{2}{*}{$\begin{array}{c}\text { Metabolite } \\
\text { 4-amino butyric acid }\end{array}$} & \multicolumn{3}{|c|}{ RNAi2 } & \multicolumn{3}{|c|}{ RNAi40 } & \multicolumn{3}{|c|}{ RNAi42 } & \multicolumn{3}{|c|}{ WT } & \multicolumn{3}{|c|}{ RNAi2 } & \multicolumn{3}{|c|}{ RNAi40 } & \multicolumn{3}{|c|}{ RNAi42 } & \multicolumn{3}{|c|}{ WT } \\
\hline \multirow{21}{*}{ 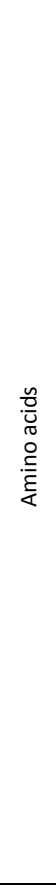 } & & 0.71 & \pm & 0.04 & 0.80 & \pm & 0.15 & 0.91 & \pm & 0.11 & 1.00 & \pm & 0.09 & 1.18 & \pm & 0.10 & 1.26 & \pm & 0.22 & 0.81 & \pm & 0.08 & 1.00 & \pm & 0.16 \\
\hline & 4-hydroxy-prolina & 1.58 & \pm & 0.39 & 1.29 & \pm & 0.22 & 0.83 & \pm & 0.10 & 1.00 & \pm & 0.06 & 1.20 & \pm & 0.20 & 1.40 & \pm & 0.20 & 0.80 & \pm & 0.10 & 1.00 & \pm & 0.10 \\
\hline & Alanine & 0.85 & \pm & 0.02 & 1.26 & \pm & 0.05 & 1.05 & \pm & 0.08 & 1.00 & \pm & 0.05 & 0.93 & \pm & 0.07 & 0.92 & \pm & 0.12 & 0.83 & \pm & 0.11 & 1.00 & \pm & 0.19 \\
\hline & Arginine & 0.84 & \pm & 0.05 & 1.15 & \pm & 0.02 & 1.11 & \pm & 0.18 & 1.00 & \pm & 0.11 & ND & \pm & ND & ND & \pm & ND & ND & \pm & ND & ND & \pm & ND \\
\hline & Asparagine & 0.92 & \pm & 0.20 & 0.74 & \pm & 0.17 & 0.54 & \pm & 0.05 & 1.00 & \pm & 0.26 & ND & \pm & ND & ND & \pm & ND & ND & \pm & ND & ND & \pm & ND \\
\hline & Asparagine & ND & \pm & ND & ND & \pm & ND & ND & \pm & ND & ND & \pm & ND & 1.55 & \pm & 0.23 & 1.34 & \pm & 0.24 & 1.42 & \pm & 0.02 & 1.00 & \pm & 0.17 \\
\hline & Glutamine & ND & \pm & ND & ND & \pm & ND & ND & \pm & ND & ND & \pm & ND & 1.25 & \pm & 0.34 & 1.18 & \pm & 0.15 & 1.34 & \pm & 0.35 & 1.00 & \pm & 0.09 \\
\hline & Glycine & 0.84 & \pm & 0.05 & 1.56 & \pm & 0.45 & 0.86 & \pm & 0.23 & 1.00 & \pm & 0.15 & 0.89 & \pm & 0.20 & 1.14 & \pm & 0.29 & 0.84 & \pm & 0.16 & 1.00 & \pm & 0.06 \\
\hline & Homoserine & 0.84 & \pm & 0.04 & 1.09 & \pm & 0.21 & 0.69 & \pm & 0.11 & 1.00 & \pm & 0.03 & ND & \pm & ND & ND & \pm & ND & ND & \pm & ND & ND & \pm & ND \\
\hline & Isoleucine & 0.78 & \pm & 0.05 & 0.91 & \pm & 0.03 & 0.69 & \pm & 0.08 & 1.00 & \pm & 0.07 & 1.17 & \pm & 0.17 & 1.27 & \pm & 0.31 & 0.94 & \pm & 0.10 & 1.00 & \pm & 0.11 \\
\hline & Leucine & ND & \pm & ND & ND & \pm & ND & ND & \pm & ND & ND & \pm & ND & 0.94 & \pm & 0.08 & 0.89 & \pm & 0.05 & 0.73 & \pm & 0.03 & 1.00 & \pm & 0.13 \\
\hline & Lysine & 0.80 & \pm & 0.02 & 0.97 & \pm & 0.07 & 0.59 & \pm & 0.06 & 1.00 & \pm & 0.03 & ND & \pm & ND & ND & \pm & ND & ND & \pm & ND & ND & \pm & ND \\
\hline & Methionine & 0.64 & \pm & 0.04 & 0.88 & \pm & 0.07 & 0.66 & \pm & 0.11 & 1.00 & \pm & 0.10 & 1.25 & \pm & 0.19 & 1.34 & \pm & 0.23 & 1.53 & \pm & 0.32 & 1.00 & \pm & 0.16 \\
\hline & Phenylalanine & 0.65 & \pm & 0.02 & 1.10 & \pm & 0.09 & 1.06 & \pm & 0.14 & 1.00 & \pm & 0.16 & ND & \pm & ND & ND & \pm & ND & ND & \pm & ND & ND & \pm & ND \\
\hline & Proline & 4.55 & \pm & 0.93 & 3.59 & \pm & 1.88 & 0.81 & \pm & 0.29 & 1.00 & \pm & 0.17 & 1.16 & \pm & 0.12 & 1.58 & \pm & 0.63 & 0.86 & \pm & 0.20 & 1.00 & \pm & 0.12 \\
\hline & Serine & 0.63 & \pm & 0.08 & 0.74 & \pm & 0.06 & 0.53 & \pm & 0.08 & 1.00 & \pm & 0.13 & 0.94 & \pm & 0.21 & 1.04 & \pm & 0.25 & 0.64 & \pm & 0.01 & 1.00 & \pm & 0.06 \\
\hline & Threonine & 0.91 & \pm & 0.07 & 1.00 & \pm & 0.03 & 0.71 & \pm & 0.06 & 1.00 & \pm & 0.09 & 1.18 & \pm & 0.21 & 1.33 & \pm & 0.29 & 0.82 & \pm & 0.04 & 1.00 & \pm & 0.05 \\
\hline & Tryptophan & ND & \pm & ND & ND & \pm & ND & ND & \pm & ND & ND & \pm & ND & 1.25 & \pm & 0.26 & 1.85 & \pm & 0.46 & 1.21 & \pm & 0.25 & 1.00 & \pm & 0.19 \\
\hline & Tyrosine & ND & \pm & ND & ND & \pm & ND & ND & \pm & ND & ND & \pm & ND & 0.90 & \pm & 0.21 & 1.20 & \pm & 0.26 & 0.88 & \pm & 0.18 & 1.00 & \pm & 0.15 \\
\hline & Valine & 0.75 & \pm & 0.05 & 1.07 & \pm & 0.03 & 0.96 & \pm & 0.08 & 1.00 & \pm & 0.07 & 0.90 & \pm & 0.17 & 1.31 & \pm & 0.20 & 0.90 & \pm & 0.15 & 1.00 & \pm & 0.17 \\
\hline & $\beta$-Alanine & 0.65 & \pm & 0.06 & 0.59 & \pm & 0.03 & 0.56 & \pm & 0.01 & 1.00 & \pm & 0.04 & 0.66 & \pm & 0.16 & 2.14 & \pm & 0.20 & 0.95 & \pm & 0.31 & 1.00 & \pm & 0.20 \\
\hline \multirow{10}{*}{$\begin{array}{l}\frac{\tilde{\omega}}{\sigma} \\
\stackrel{0}{n}\end{array}$} & Fructose* & 0.97 & \pm & 0.10 & 0.96 & \pm & 0.10 & 0.97 & \pm & 0.04 & 1.00 & \pm & 0.13 & 0.89 & \pm & 0.10 & 0.75 & \pm & 0.13 & 0.97 & \pm & 0.09 & 1.00 & \pm & 0.08 \\
\hline & $\begin{array}{l}\text { Arabinose } \\
\text { Fructose-6- }\end{array}$ & 1.28 & \pm & 0.01 & 1.05 & \pm & 0.05 & 0.89 & \pm & 0.07 & 1.00 & \pm & 0.07 & 1.19 & \pm & 0.19 & 0.81 & \pm & 0.01 & 1.02 & \pm & 0.05 & 1.00 & \pm & 0.02 \\
\hline & phosphate & ND & \pm & ND & ND & \pm & ND & ND & \pm & ND & ND & \pm & ND & 1.10 & \pm & 0.10 & 1.00 & \pm & 0.10 & 0.90 & \pm & 0.13 & 1.00 & \pm & 0.09 \\
\hline & Fucose & 1.33 & \pm & 0.11 & 1.13 & \pm & 0.08 & 1.80 & \pm & 0.43 & 1.00 & \pm & 0.07 & ND & \pm & ND & ND & \pm & ND & ND & \pm & ND & ND & \pm & ND \\
\hline & Galactose & 1.10 & \pm & 0.08 & 0.96 & \pm & 0.02 & 0.92 & \pm & 0.08 & 1.00 & \pm & 0.08 & 1.03 & \pm & 0.11 & 0.99 & \pm & 0.02 & 0.89 & \pm & 0.09 & 1.00 & \pm & 0.04 \\
\hline & $\begin{array}{c}\text { Glucose* } \\
\text { Glucose-6- }\end{array}$ & 1.12 & \pm & 0.11 & 1.18 & \pm & 0.11 & 1.04 & \pm & 0.04 & 1.00 & \pm & 0.08 & 0.93 & \pm & 0.14 & 0.76 & \pm & 0.12 & 0.99 & \pm & 0.12 & 1.00 & \pm & 0.08 \\
\hline & phosphate & 1.00 & \pm & 0.11 & 1.40 & \pm & 0.33 & 1.20 & \pm & 0.08 & 1.00 & \pm & 0.22 & 1.00 & \pm & 0.08 & 1.00 & \pm & 0.03 & 0.83 & \pm & 0.02 & 1.00 & \pm & 0.02 \\
\hline & Maltose & 0.63 & \pm & 0.05 & 0.78 & \pm & 0.04 & 0.95 & \pm & 0.09 & 1.00 & \pm & 0.04 & 0.50 & \pm & 0.11 & 0.70 & \pm & 0.17 & 0.22 & \pm & 0.03 & 1.00 & \pm & 0.35 \\
\hline & Mannose & 1.10 & \pm & 0.08 & 0.96 & \pm & 0.02 & 0.92 & \pm & 0.08 & 1.00 & \pm & 0.08 & 1.03 & \pm & 0.11 & 0.99 & \pm & 0.02 & 0.90 & \pm & 0.09 & 1.00 & \pm & 0.04 \\
\hline & Raffinose* & 0.61 & \pm & 0.10 & 0.66 & \pm & 0.04 & 0.72 & \pm & 0.03 & 1.00 & \pm & 0.09 & ND & \pm & ND & ND & \pm & ND & ND & \pm & ND & ND & \pm & ND \\
\hline
\end{tabular}




\begin{tabular}{|c|c|c|c|c|c|c|c|c|c|c|c|c|c|c|c|c|c|c|c|c|c|c|c|c|c|}
\hline & Rhamnose & 0.95 & \pm & 0.05 & 1.19 & \pm & 0.06 & 1.24 & \pm & 0.13 & 1.00 & \pm & 0.05 & 1.00 & \pm & 0.05 & 0.99 & \pm & 0.08 & 0.917 & \pm & 0.07 & 1.00 & \pm & 0.04 \\
\hline & Sucrose* & 0.70 & \pm & 0.02 & 0.83 & \pm & 0.04 & 1.00 & \pm & 0.03 & 1.00 & \pm & 0.08 & ND & \pm & ND & ND & \pm & ND & ND & \pm & ND & ND & \pm & ND \\
\hline & $\begin{array}{l}\text { Irenalose, } \\
\text { alpha,alpha }\end{array}$ & 0.81 & \pm & 0.03 & 0.88 & \pm & 0.03 & 1.38 & \pm & 0.08 & 1.00 & \pm & 0.05 & 0.92 & \pm & 0.08 & 0.83 & \pm & 0.14 & 0.83 & \pm & 0.15 & 1.00 & \pm & 0.08 \\
\hline & Xylose & 1.29 & \pm & 0.01 & 1.00 & \pm & 0.00 & 0.81 & \pm & 0.07 & 1.00 & \pm & 0.04 & 1.30 & \pm & 0.21 & 0.89 & \pm & 0.02 & 0.90 & \pm & 0.06 & 1.00 & \pm & 0.12 \\
\hline \multirow{23}{*}{ 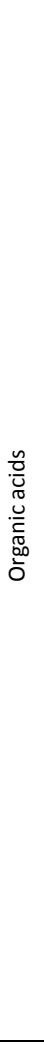 } & Aspartic acid & 1.11 & \pm & 0.11 & 1.05 & \pm & 0.07 & 0.92 & \pm & 0.12 & 1.00 & \pm & 0.09 & 1.41 & \pm & 0.10 & 1.36 & \pm & 0.03 & 1.14 & \pm & 0.08 & 1.00 & \pm & 0.02 \\
\hline & $\begin{array}{l}\text { Citric acid } \\
\text { Ascorbic acid }\end{array}$ & 1.02 & \pm & 0.17 & 1.30 & \pm & 0.18 & 1.56 & \pm & 0.23 & 1.00 & \pm & 0.14 & 1.12 & \pm & 0.12 & 1.02 & \pm & 0.01 & 1.00 & \pm & 0.02 & 1.00 & \pm & 0.03 \\
\hline & (Total)* & 1.53 & \pm & 0.16 & 1.41 & \pm & 0.19 & 1.00 & \pm & 0.10 & 1.00 & \pm & 0.16 & 1.04 & \pm & 0.07 & 1.01 & \pm & 0.10 & 0.98 & \pm & 0.03 & 1.00 & \pm & 0.02 \\
\hline & (Reduced)* & 1.52 & \pm & 0.22 & 1.49 & \pm & 0.23 & 1.06 & \pm & 0.15 & 1.00 & \pm & 0.22 & 1.28 & \pm & 0.16 & 1.18 & \pm & 0.06 & 1.17 & \pm & 0.07 & 1.00 & \pm & 0.08 \\
\hline & Fumaric acid & 1.15 & \pm & 0.05 & 1.24 & \pm & $\begin{array}{c}0.19 \\
0.105\end{array}$ & 1.14 & \pm & 0.13 & 1.00 & \pm & 0.02 & 1.00 & \pm & 0.13 & 1.00 & \pm & $\begin{array}{c}0.13 \\
\mathbf{0 . 0 7 9}\end{array}$ & 0.87 & \pm & 0.10 & 1.00 & \pm & $\begin{array}{l}0.08 \\
0.05\end{array}$ \\
\hline & $\begin{array}{l}\text { Galactinol } \\
\text { Galactonic acid-1,4- }\end{array}$ & 0.80 & \pm & 0.0649 & 1.06 & \pm & 3 & 0.87 & \pm & 0.092 & 1.00 & \pm & 0.0619 & 0.75 & \pm & 0.0685 & 0.64 & \pm & 2 & 0.77 & \pm & 0.1046 & 1.00 & \pm & 24 \\
\hline & lactone & 0.99 & \pm & 0.12 & 1.32 & \pm & 0.25 & 0.93 & \pm & 0.16 & 1.00 & \pm & 0.25 & 0.80 & \pm & 0.00 & 0.75 & \pm & 0.06 & 0.75 & \pm & 0.09 & 1.00 & \pm & 0.15 \\
\hline & $\begin{array}{l}\text { Galacturonic acid } \\
\text { Gluconic acid-1,5- }\end{array}$ & 1.22 & \pm & 0.24 & 1.19 & \pm & 0.31 & 1.47 & \pm & 0.26 & 1.00 & \pm & 0.12 & 1.29 & \pm & 0.11 & 1.18 & \pm & 0.20 & 1.39 & \pm & 0.16 & 1.00 & \pm & 0.08 \\
\hline & lactone & ND & \pm & ND & ND & \pm & ND & ND & \pm & ND & ND & \pm & ND & 1.11 & \pm & 0.11 & 0.67 & \pm & 0.13 & 0.89 & \pm & 0.15 & 1.00 & \pm & 0.15 \\
\hline & Glutamic acid & 0.83 & \pm & 0.02 & 0.85 & \pm & 0.02 & 0.83 & \pm & 0.12 & 1.00 & \pm & 0.10 & 1.17 & \pm & 0.10 & 1.14 & \pm & 0.07 & 0.97 & \pm & 0.11 & 1.00 & \pm & 0.05 \\
\hline & Glutaric acid, 2-oxo- & 0.75 & \pm & 0.11 & 1.11 & \pm & 0.16 & 0.56 & \pm & 0.08 & 1.00 & \pm & 0.22 & ND & \pm & ND & ND & \pm & ND & ND & \pm & ND & ND & \pm & ND \\
\hline & Glyceric acid & 1.48 & \pm & 0.26 & 1.38 & \pm & 0.11 & 1.66 & \pm & 0.04 & 1.00 & \pm & 0.12 & 1.08 & \pm & 0.14 & 1.08 & \pm & 0.18 & 0.80 & \pm & 0.02 & 1.00 & \pm & 0.09 \\
\hline & Isocitric acid & ND & \pm & ND & ND & \pm & ND & ND & \pm & ND & ND & \pm & ND & 1.18 & \pm & 0.18 & 1.07 & \pm & 0.07 & 1.16 & \pm & 0.09 & 1.00 & \pm & 0.08 \\
\hline & Malic acid & ND & \pm & ND & ND & \pm & ND & ND & \pm & ND & ND & \pm & ND & 1.18 & \pm & 0.08 & 0.85 & \pm & 0.13 & 0.86 & \pm & 0.08 & 1.00 & \pm & 0.15 \\
\hline & Nicotinic acid & 0.91 & \pm & 0.15 & 0.99 & \pm & 0.07 & 1.23 & \pm & 0.16 & 1.00 & \pm & 0.05 & 0.83 & \pm & 0.04 & 0.90 & \pm & 0.09 & 1.03 & \pm & 0.25 & 1.00 & \pm & 0.15 \\
\hline & Octadecanoic acid & 0.91 & \pm & 0.11 & 0.89 & \pm & 0.04 & 1.14 & \pm & 0.19 & 1.00 & \pm & 0.18 & 1.16 & \pm & 0.12 & 0.89 & \pm & 0.04 & 0.95 & \pm & 0.10 & 1.00 & \pm & 0.09 \\
\hline & Phosphoric acid & 1.94 & \pm & 0.58 & 1.93 & \pm & 0.13 & 1.41 & \pm & 0.31 & 1.00 & \pm & 0.14 & 1.22 & \pm & 0.11 & 0.91 & \pm & 0.11 & 0.93 & \pm & 0.02 & 1.00 & \pm & 0.04 \\
\hline & Pyroglutamic acid & 0.99 & \pm & 0.07 & 1.25 & \pm & 0.14 & 0.98 & \pm & 0.14 & 1.00 & \pm & 0.11 & 1.31 & \pm & 0.20 & 1.21 & \pm & 0.12 & 1.07 & \pm & 0.04 & 1.00 & \pm & 0.06 \\
\hline & Pyruvic acid & 1.24 & \pm & 0.25 & 1.00 & \pm & 0.11 & 0.89 & \pm & 0.10 & 1.00 & \pm & 0.15 & ND & \pm & ND & ND & \pm & ND & ND & \pm & ND & ND & \pm & ND \\
\hline & Quinic acid & 0.92 & \pm & 0.09 & 1.21 & \pm & 0.22 & 1.18 & \pm & 0.18 & 1.00 & \pm & 0.16 & 1.08 & \pm & 0.10 & 0.96 & \pm & 0.02 & 0.88 & \pm & 0.10 & 1.00 & \pm & 0.05 \\
\hline & Saccharic acid & 1.19 & \pm & 0.12 & 1.24 & \pm & 0.21 & 1.41 & \pm & 0.34 & 1.00 & \pm & 0.21 & 1.67 & \pm & 0.17 & 1.17 & \pm & 0.10 & 1.69 & \pm & 0.18 & 1.00 & \pm & 0.08 \\
\hline & Shikimic acid & 1.13 & \pm & 0.11 & 1.25 & \pm & 0.06 & 1.36 & \pm & 0.15 & 1.00 & \pm & 0.12 & ND & \pm & ND & ND & \pm & ND & ND & \pm & ND & ND & \pm & ND \\
\hline & Succinic acid & 1.04 & \pm & 0.07 & 0.83 & \pm & 0.01 & 0.82 & \pm & 0.06 & 1.00 & \pm & 0.11 & 1.35 & \pm & 0.15 & 0.91 & \pm & 0.07 & 1.18 & \pm & 0.09 & 1.00 & \pm & 0.22 \\
\hline \multirow{5}{*}{ 疍 } & Calystegine A3 & ND & \pm & ND & ND & \pm & ND & ND & \pm & ND & ND & \pm & ND & 0.72 & \pm & 0.09 & 0.89 & \pm & 0.23 & 0.60 & \pm & 0.20 & 1.00 & \pm & 0.29 \\
\hline & Calystegine B2 & 0.58 & \pm & 0.12 & 0.97 & \pm & 0.36 & 0.48 & \pm & 0.15 & 1.00 & \pm & 0.33 & ND & \pm & ND & ND & \pm & ND & ND & \pm & ND & ND & \pm & ND \\
\hline & Erythritol & ND & \pm & ND & ND & \pm & ND & ND & \pm & ND & ND & \pm & ND & 0.92 & \pm & 0.75 & 1.00 & \pm & 1.06 & 0.92 & \pm & 1.30 & 1.00 & \pm & 0.83 \\
\hline & Glycerol & 1.46 & \pm & 0.28 & 1.29 & \pm & 0.23 & 1.57 & \pm & 0.17 & 1.00 & \pm & 0.04 & 0.98 & \pm & 0.20 & 0.99 & \pm & 0.13 & 0.91 & \pm & 0.11 & 1.00 & \pm & 0.06 \\
\hline & myo-Inositol & 1.11 & \pm & 0.08 & 1.11 & \pm & 0.06 & 1.33 & \pm & 0.07 & 1.00 & \pm & 0.04 & 0.87 & \pm & 0.17 & 1.18 & \pm & 0.17 & 0.59 & \pm & 0.06 & 1.00 & \pm & 0.11 \\
\hline
\end{tabular}




\begin{tabular}{|c|c|c|c|c|c|c|c|c|c|c|c|c|c|c|c|c|c|c|c|c|c|c|c|c|}
\hline $\begin{array}{l}\text { myo-Inositol-1- } \\
\text { phosphate }\end{array}$ & ND & \pm & ND & ND & \pm & ND & ND & \pm & ND & ND & \pm & ND & 1.13 & \pm & 0.03 & 0.93 & \pm & 0.10 & 1.13 & \pm & 0.09 & 1.00 & \pm & 0.09 \\
\hline Phenethylamine & ND & \pm & ND & ND & \pm & ND & ND & \pm & ND & ND & \pm & ND & 1.29 & \pm & 0.08 & 1.29 & \pm & 0.25 & 1.07 & \pm & 0.22 & 1.00 & \pm & 0.12 \\
\hline Putrescine & 0.82 & \pm & 0.16 & 0.78 & \pm & 0.13 & 0.54 & \pm & 0.09 & 1.00 & \pm & 0.17 & 1.20 & \pm & 0.25 & 0.63 & \pm & 0.06 & 0.65 & \pm & 0.06 & 1.00 & \pm & 0.04 \\
\hline Squalene, all-trans- & 1.00 & \pm & 0.08 & 1.86 & \pm & 0.16 & 3.00 & \pm & 0.82 & 1.00 & \pm & 0.26 & 0.79 & \pm & 0.05 & 1.05 & \pm & 0.18 & 1.47 & \pm & 0.50 & 1.00 & \pm & 0.12 \\
\hline Uracil & ND & \pm & ND & ND & \pm & ND & ND & \pm & ND & ND & \pm & ND & 0.88 & \pm & 0.06 & 1.13 & \pm & 0.13 & 1.00 & \pm & 0.11 & 1.00 & \pm & 0.11 \\
\hline Urea & ND & \pm & ND & ND & \pm & ND & ND & \pm & ND & ND & \pm & ND & 0.91 & \pm & 0.13 & 0.73 & \pm & 0.03 & 0.92 & \pm & 0.20 & 1.00 & \pm & 0.11 \\
\hline
\end{tabular}

$\mathrm{ND}=$ Not detected

Numbers in bold means statistically different from WT plants $p<0,05$.

* Analysis by liquid chromatography. 
A

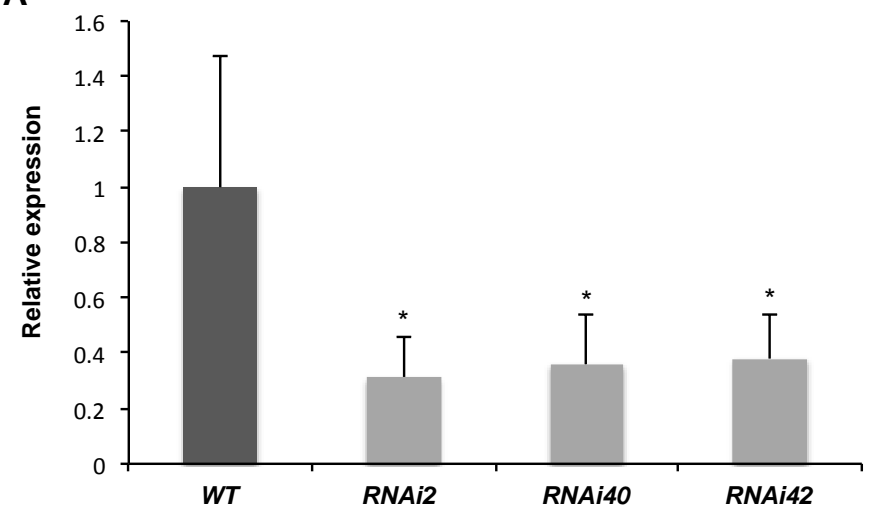

B

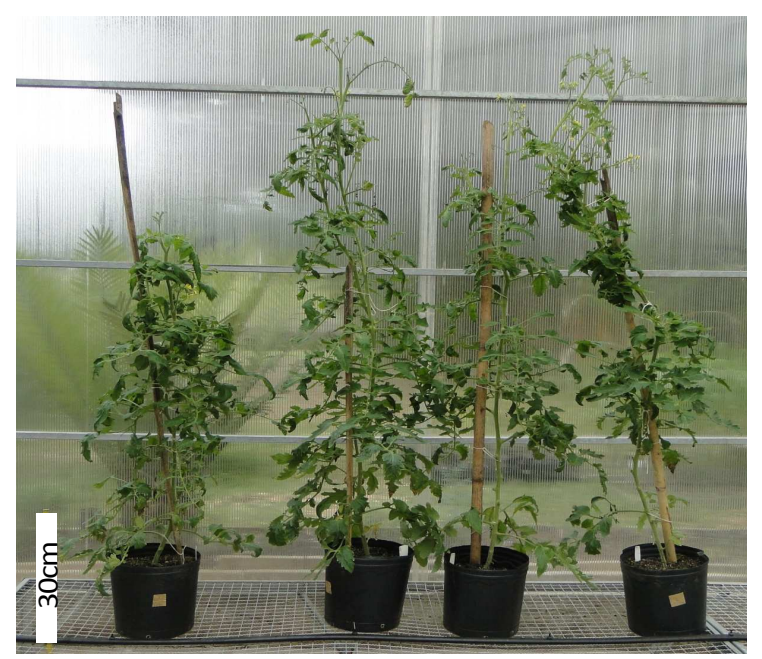

Supplementary Figure $\mathbf{S 1}$. Heritability of silenced phenotype.

(A) GAUT4 expression was measured by qPCR in leaves of eight-weekold T1 transgenic plants. Data indicate relative expression means from at least three biological replicates and significant statistic differences from wild type (WT) are indicated with asterisk $(P<0.05)$. (B) Appearance of WT (first left) and GAUT4-silenced T1 (right) plants. 
A

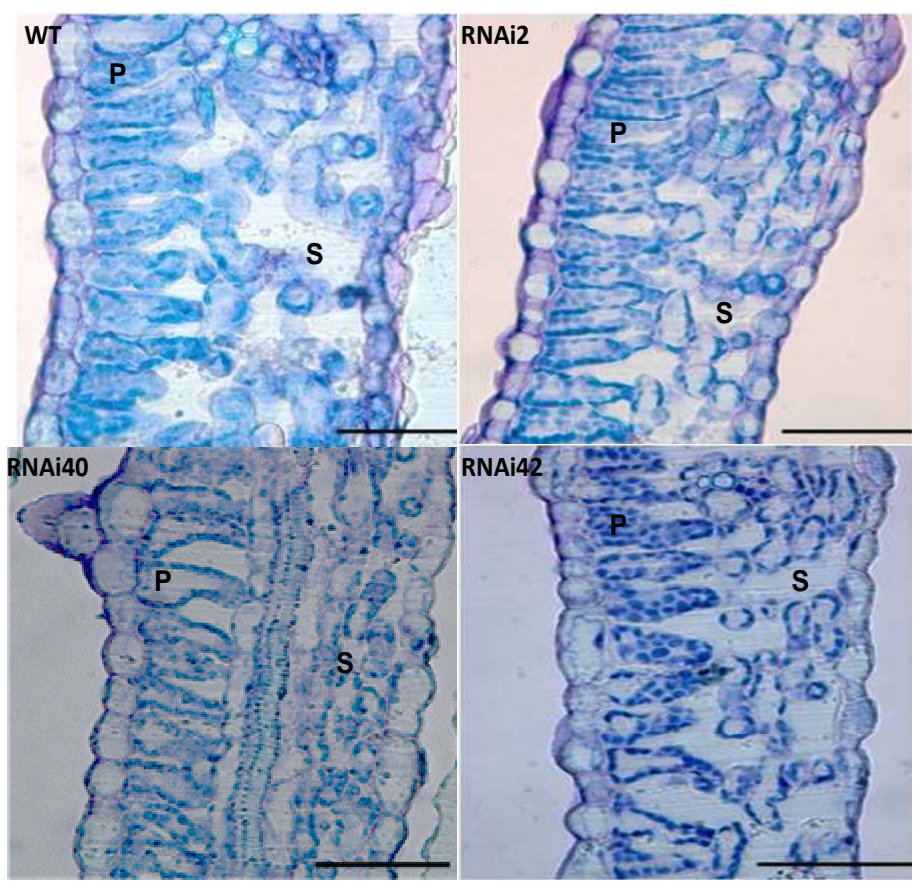

B

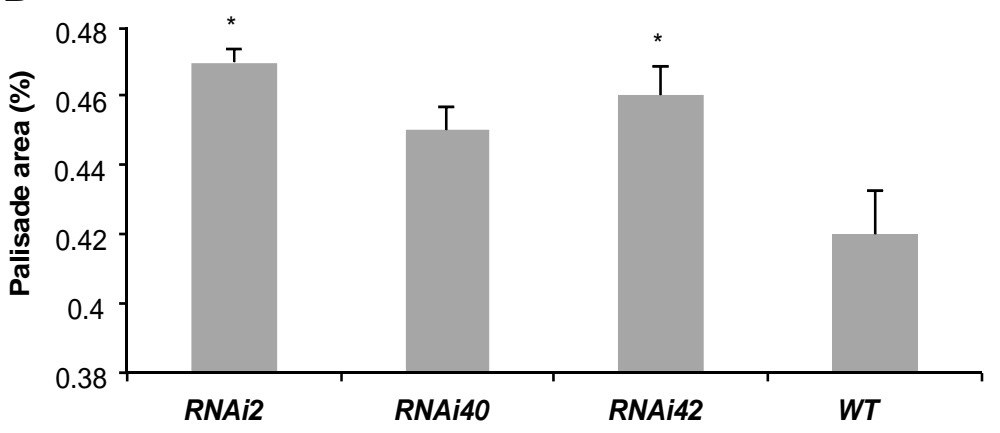

C

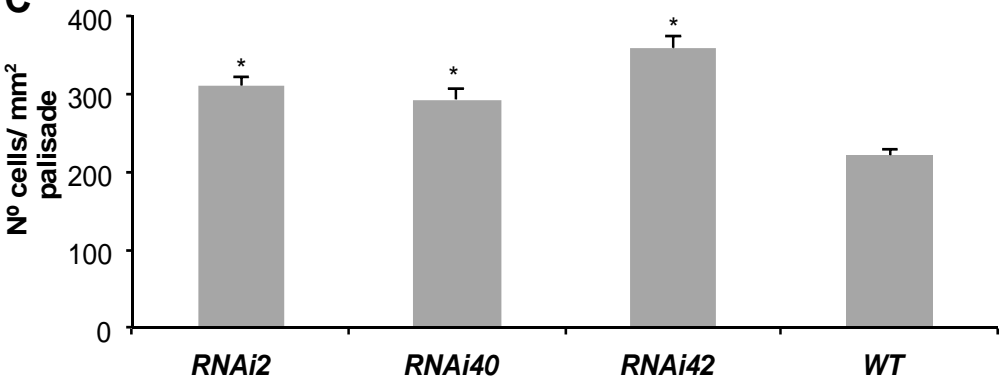

Supplementary Figure S2. Leaf structural analyses of GAUT4-silenced plants.

Source leaves of T1 plants were fixed, dehydrated and embedded in plastic resin. Cross-sections (10 $\mu \mathrm{m})$ were cut and stained with toluidine blue (A). P and S indicate palisade and sponge parenchyma, respectively. The relative area of palisade parenchyma (B) and the number of cell per area of palisade parenchyma (C) were calculated using ImageJ software (Rasband, http://imagej.nih.gov/ij/). The scale bar represents $50 \mu \mathrm{m}$. Data indicate means from at least six biological replicate per transgenic line. Significant statistic differences from wild type (WT) are indicated with asterisk $(\mathrm{P}<0.05)$. 


\section{CONCLUSÕES}

Foi caracterizada a família multigênica das GAUTs de tomateiro e realizado um estudo funcional do gene GAUT4, o qual foi identificado por Bermúdez et al. (2008) como um possível candidato associado a um QTL para ácido galacturônico livre em frutos maduros. A caracterização dessa família multigênica demonstrou que S. lycopersicum possui 17 GAUTS e que as diferenças no padrão de expressão espacial e temporal das mesmas poderiam explicar as alterações na estrutura dos polissacarídeos de parede nos diferentes tecidos e fases de desenvolvimento. O silenciamento gênico mediado por RNAi do gene da GAUT4 levou a alterações na composição da pectina, gerando efeitos pleiotrópicos no crescimento e no desenvolvimento da planta. O fenótipo obtido revelou mecanismos fisiológicos através do metabolismo dos polissacarídeos e de rafinose que modulam a alocação de recursos na planta, afetando a relação fonte-dreno em tomateiro. 


\section{CONSIDERAÇÕES FINAIS}


O trabalho apresentado visou à caracterização de regiões genômicas envolvidas no metabolismo de aminoácidos e na determinação da estrutura da parede celular. As abordagens aplicadas de genômicas e genética reversa permitiram atingir os objetivos propostos por meio da analise integrada do sistema biológico.

Dessa maneira, o estudo de microsintenia apresentado no Capítulo I permitiu datar a divergência entre S. lycopersicum e a espécie selvagem S. pennellii em 2,7 MYA. Ainda, demonstrou que ambos os genomas são altamente colineares, apresentando apenas polimorfismos pontuais sobre as regiões codificantes e variações mais significativas nas regiões regulatórias dos genes. Finalmente, foi identificado um novo gene candidato possivelmente envolvido nas alterações do conteúdo de aminoácidos descritas por Bermúdez et al. (2008). Os resultados apresentados nos Capítulos II e III permitiram caracterizar funcionalmente dois novos genes de tomateiro. O gene LFP demonstrou estar envolvido no metabolismo de poliaminas e participar do controle do crescimento do corpo vegetativo. Por outro lado, foram identificados e caracterizados transcricionalmente os 17 membros da família multigênica das galacturonosiltransferases (GAUTs) de tomateiro. O estudo funcional da GAUT4 mostrou que esta proteína é fundamental para a manutenção da quantidade e composição das pectinas no fruto. Adicionalmente, o silenciamento deste gene expôs um mecanismo de comunicação entre o metabolismo de pectinas e a regulação da relação fonte-dreno provavelmente mediado pela rafinose e açúcares nucleotídeos.

A escolha da estratégia de RNAi foi eficiente para revelar o efeito da queda dos produtos proteicos dos genes sob estudo para a manutenção do fenótipo selvagem de $S$. lycopersicum. Pelo contrario, a utilização de mutantes poderia ter resultado infrutífera no caso de genes com funções vitais no metabolismo e desenvolvimento da planta, como demonstrado pela impossibilidade de obter mutantes gaut4 de $A$. thaliana.

Sendo assim, os resultados obtidos não só aportaram evidencias que permitiram gerar hipóteses sobre a função das proteínas, mas também, revelar as conexões entre os diversos módulos funcionais do organismo. Desta forma a biologia de sistemas se apresenta como uma abordagem fundamental para a compreensão dos processos bioquímicos e fisiológicos e suas inter-relações, principalmente visando aplicações biotecnológicas. 
Artigos Publicados 
- Kamenetzky L, Asís R, Bassi S, de Godoy F, Bermúdez L, Fernie AR, Van Sluys MA, Vrebalov J, Giovannoni J, Rossi M, Carrari F (2010) Genomic analysis of wild tomato (Solanum pennellii) introgressions determining metabolic- and yield-associated traits. Plant Physiology 152:17721786. (Capítulo I)

-Almeida J, Quadrana L, Asís R, Setta N, de Godoy F, Bermúdez L, Otaiza SN, Corrêa da Silva JV, Fernie AR, Carrari F, Rossi M (2011) Genetic dissection of vitamin E biosynthesis in tomato. Journal of Experimental Botany 62: 3781-3798.

- Kajihara D, de Godoy F, Hamaji TH, Blanco SR, Van Sluys MA, Rossi M (2012) Functional characterization of sugarcane Mustang domesticated transposases and comparative diversity in sugarcane, rice, maize and sorghum. Genetics and Molecular Biology 35 (3): 632-639.

- Quadrana L, Almeida J, Otaiza SN, Duffy T, Corrêa da Silva JV, de Godoy F, Asís R, Bermúdez L, Fernie AR, Carrari F, Rossi M. (2013) Transcriptional regulation of tocopherol biosynthesis in tomato. Plant Mol Biol 81:309-325.

- de Godoy F, Bermúdez L, Silvestre LB, de Souza AP, Elbl P, Demarco D, Alseekh S, Insani M, Buckeridge M, Almeida J, Grigioni G, Fernie AR, Carrari F, Rossi M. Galacturonosyltransferase 4 silencing alters pectin composition and carbon partitioning in tomato (Journal of Experimental Botany, no prelo, Capítulo III)

- Bermúdez, de Godoy F, Demarco D, Osorio S, Almeida J, Corrêa da Silva JV, Blanco SR, Asis R, Fernie AR, Rossi $M$ and Carrari F. A small plastidial protein, sugar partitioning affecting, mediates the source-sink relationship in tomato plants (em revisão para resubmissão a Plant Journal). 
Anexo 1 


\title{
Genomic Analysis of Wild Tomato Introgressions Determining Metabolism- and Yield-Associated Traits ${ }^{1[\mathrm{C}][\mathrm{W}]}$
}

\author{
Laura Kamenetzky², Ramón Asís ${ }^{2,3}$, Sebastián Bassi, Fabiana de Godoy, Luisa Bermúdez, Alisdair R. Fernie, \\ Marie-Anne Van Sluys, Julia Vrebalov, James J. Giovannoni, Magdalena Rossi, and Fernando Carrari* \\ Instituto de Biotecnología, Instituto Nacional de Tecnología Agropecuaría, and Consejo Nacional de \\ Investigaciones Científicas y Técnicas, B1712WAA Castelar, Argentina (L.K., R.A., S.B., F.C.); Departamento \\ de Botânica, Instituto de Biociências, Universidade de São Paulo, Sao Paulo 05508-900, Brazil (F.d.G., L.B., \\ M.-A.V.S., M.R.); Max Planck Institute for Molecular Plant Physiology, D-14 476 Potsdam-Golm, Germany \\ (A.R.F.); and Boyce Thompson Institute for Plant Research and United States Department of Agriculture- \\ Agricultural Research Service, Cornell University, Ithaca, New York 14853 (J.V., J.J.G.)
}

With the aim of determining the genetic basis of metabolic regulation in tomato fruit, we constructed a detailed physical map of genomic regions spanning previously described metabolic quantitative trait loci of a Solanum pennellii introgression line population. Two genomic libraries from S. pennellii were screened with 104 colocated markers from five selected genomic regions, and a total of 614 bacterial artificial chromosome (BAC)/cosmids were identified as seed clones. Integration of sequence data with the genetic and physical maps of Solanum lycopersicum facilitated the anchoring of 374 of these BAC/ cosmid clones. The analysis of this information resulted in a genome-wide map of a nondomesticated plant species and covers $10 \%$ of the physical distance of the selected regions corresponding to approximately $1 \%$ of the wild tomato genome. Comparative analyses revealed that S. pennellii and domesticated tomato genomes can be considered as largely colinear. A total of 1,238,705 bp from both BAC/cosmid ends and nine large insert clones were sequenced, annotated, and functionally categorized. The sequence data allowed the evaluation of the level of polymorphism between the wild and cultivated tomato species. An exhaustive microsynteny analysis allowed us to estimate the divergence date of S. pennellii and S. lycopersicum at 2.7 million years ago. The combined results serve as a reference for comparative studies both at the macrosyntenic and microsyntenic levels. They also provide a valuable tool for fine-mapping of quantitative trait loci in tomato. Furthermore, they will contribute to a deeper understanding of the regulatory factors underpinning metabolism and hence defining crop chemical composition.

Tomato (Solanum species) fruits constitute one of the most important sources of minerals, vitamins, fibers, and antioxidants in the human diet. Genomic approaches focused on determining the genetic basis of pathway regulation underlying quantitative variation in the production of these nutrients will likely provide information to facilitate the identification of cardinal

\footnotetext{
${ }^{1}$ This work was supported by the Instituto Nacional de Tecnología Agropecuaría and the Agencia Nacional de Promoción Científica y Tecnológica (Argentina), the Fundação de Amparo à Pesquisa do estado de São Paulo and the Conselho Nacional de Desenvolvimento Científico e Tecnológico (Brazil), the Max Planck Society (Germany), the European Solanaceae Integrated Project FOOD-CT2006-016214, and the National Science Foundation Plant Genome Program (grant no. 05-01778).

2 These authors contributed equally to the article.

${ }^{3}$ Present address: Centro de Investigaciones en Bioquímica Clínica e Inmunología, Facultad de Ciencias Químicas, Universidad Nacional de Córdoba, CC 5000 Córdoba, Argentina.

* Corresponding author; e-mail fcarrari@cnia.inta.gov.ar.

The authors responsible for distribution of materials integral to the findings presented in this article in accordance with the policy described in the Instructions for Authors (www.plantphysiol.org) are: Fernando Carrari (fcarrari@cnia.inta.gov.ar) and Magdalena Rossi (mmrossi@usp.br).

${ }^{[C]}$ Some figures in this article are displayed in color online but in black and white in the print edition.

${ }^{[\mathrm{W}]}$ The online version of this article contains Web-only data.

www.plantphysiol.org/cgi/doi/10.1104/pp.109.150532
}

genes. The cumulative body of data concerning developmental and metabolic shifts coupled with those recently acquired using postgenomic tools has prompted the adoption of this species as a model system for plants bearing fleshy fruits (Mueller et al., 2005). Such a model is required, because although many of these processes might be shared by many different plant species, this should not be straightly assumed, since remarkable metabolic differences have been observed even between closely related species (Fernie and Willmitzer, 2001).

The facts that the domesticated species Solanum lycopersicum can be crossed with a number of its wild relatives and that these species have shown tremendous variation in metabolite content both in leaves and fruits (Schauer et al., 2006) render wild germplasm as an important source for metabolic gene discovery (Zamir, 2001). For this reason, extensive germplasm collections, including numerous natural and induced mutants and interspecific populations, have been made publicly available by the Tomato Genetics Resource Center (http:/ / tgrc.ucdavis.edu/). An example of this is the collection of 76 introgression lines (ILs; Eshed and Zamir, 1995) comprising single overlapping introgressions of the Solanum pennellii (accession no. LA716) genome within the $S$. lycopersicum genome (cv M82). These lines are an excellent source of the stable genetic variation used worldwide by different re- 
searchers to map 2,795 quantitative trait loci (QTLs) to date, including those affecting plant biomass, yield, drought tolerance, morphology, gene expression, and metabolism (Lippman et al., 2007). The success of the S. pennellii ILs in establishing new principles for plant breeding and for resolving the molecular basis of complex traits has been demonstrated by the cloning of the first QTLs in this species: FW2.2 (a fruit size gene; Frary et al., 2000) and Brix9-2-5 (a sugar yield gene; Fridman et al., 2000, 2004). The broad phenotypic diversity inherent in this population alongside its simple mapping framework has also led to the identification of heterotic QTLs for biomass production, a major step toward isolating heterosis genes (Lippman et al., 2007). A clone-based physical map of S. pennellii, however, is necessary to fully exploit this population and to produce a unique resource for Solanaceae genomics. Such a map would also provide previous information for comparative analyses, mapbased cloning, and validation of the sequence assemblies of the tomato whole genome (Solanaceae Genome Network [SGN]; www.sgn.cornell.edu).

The aim of our current research was to perform a large-scale comparative genome analysis of the $S$. pennellii wild tomato and S. lycopersicum. Five genomic regions (BINs) comprising more than 100 recently identified QTLs associated with fruit carbon primary metabolism (Schauer et al., 2006, 2008) were chosen. These QTLs include fruit color (Liu et al., 2003), volatile content (Tieman et al., 2006), and yield traits linked to metabolite variations found in the fruits (Eshed and Zamir, 1995; Schauer et al., 2006; Semel et al., 2006). The physical map, built by anchoring 374 clones from bacterial artificial chromosome (BAC) and cosmid S. pennellii genomic libraries to the tomato genetic map, revealed a consistent pattern of coaligning regions, thus suggesting that the two genomes can largely be considered as colinear. Targeted sequencing of 1,238,705 bp allowed the annotation of 407 genes and uncovered a high degree of microsynteny between the two species. To a lesser extent, microsynteny was also observed with the Arabidopsis genome. However, this colinearity was somewhat perturbed by differential transposable element (TE) insertion patterns, different intergenic region lengths, and extensive single nucleotide polymorphism (SNP) and insertion-deletion (InDel) polymorphism. The time of divergence between species was estimated to be 2.7 million years ago (MYA). Furthermore, the large data set presented here would constitute a useful tool for QTL fine-mapping and relatively easy screening of target clones in map-based cloning approaches.

\section{RESULTS}

Integration of Genetic and Physical Maps of S. pennellii and S. lycopersicum Genomic Regions Spanning QTLs

The S. pennellii IL population has allowed the association of more than 2,700 QTLs (for review, see
Lippman et al., 2007), including many related to fruit compositional quality (Schauer et al., 2006, 2008). Based on this data set repository and with the intention of resolving the genetic determinants responsible for the observed phenotypic variations, five genomic regions were selected: BINs $1 \mathrm{C}, 2 \mathrm{~B}, 4 \mathrm{I}, 7 \mathrm{H}$, and $11 \mathrm{C}$. These regions are associated with a total of 104 QTLs comprising traits related to fruit primary metabolite content, yield, and fruit volatile content (Eshed and Zamir, 1995; Schauer et al., 2006; Tieman et al., 2006; Table I). In order to reach the goal proposed above, an integration of the genetic and physical maps of $S$. pennellii and S. lycopersicum was performed. By screening two S. pennellii genomic libraries, 614 seed clones were identified using pooled overgo probes for the five selected BINs. Over $70 \%$ of the overgo probes hit at least one BAC or cosmid clone, and no major differences were observed between libraries (Supplemental Table S1). Two-dimensional pooling hybridization allowed the anchoring of 374 clones to their corresponding map positions (Table I). In addition, the map positions of $24 \%$ of these clones were confirmed by independent hybridizations to closely linked or cosegregating markers (Supplemental Table S2A).

The average insert size of anchored clones, as estimated by pulsed-field gel electrophoresis, was 108.3 $\mathrm{kb}$ (125.8 and $90.8 \mathrm{~kb}$ for BAC and cosmid, respectively). Since the $S$. pennellii genome has been estimated to be approximately 1.2 Gb (Arumuganathan and Earle, 1991) and considering the total number of clones of each library (see "Materials and Methods"), we estimate that genome coverage is 5.5 and 3.8 for the BAC and cosmid libraries, respectively, with an average of $4.7 \times$. Thus, the anchored $374 \mathrm{BAC} /$ cosmid clones represent around $1 \%$ of the wild tomato genome and approximately $10 \%$ of the physical distance of the selected regions. However, these values should be taken with caution, since they rely on a genetic map constructed with less than 100 individuals (TomatoEXPEN 2000, S. lycopersicum LA925 $\times$ S. pennellii LA716; http:/ /www.sgn.cornell.edu/).

To support the integration of the wild species clones with both the S. lycopersicum genomic sequence and the available genetic map, the 374 anchored BAC and cosmid clones were end sequenced. Both end sequences were obtained for 233 clones, only one end sequence reached a suitable quality criteria in 53 of the clones, and no high-quality sequence was produced for 88 clones. Thus, after quality and vector trimming, a total of 519 end sequences, representing $76 \%$ of all anchored clones, were obtained and subjected to further analyses. After masking repetitive elements, the sequences from clones anchored with the same marker were assembled into 54 contigs (Table I; Supplemental Table S2B). These analyses rendered a total of 436 nonredundant end sequences (312,095 bp).

To support the above analysis, $S$. pennellii clones were selected for full-length sequencing using the following criteria: (1) PCR confirmation for the presence of candidate genes previously identified by our 
Table I. S. pennellii BAC and cosmid clones anchored onto five genomic regions spanning fruit quantitative metabolic loci (QML) and yield-associated loci (YAL)

Metabolite QTLs and YALs listed here were previously reported by Eshed and Zamir (1995), Liu et al. (2003), Schauer et al. (2006), Semel et al. (2006), and Tieman et al. (2006).

\begin{tabular}{|c|c|c|c|c|c|c|c|c|}
\hline $\begin{array}{c}\text { Genomic } \\
\text { Region } \\
(\mathrm{BIN})\end{array}$ & $\begin{array}{l}\text { No. of } \\
\text { Markers }\end{array}$ & Seed Clones & $\begin{array}{cc}\text { Clones } & \text { Average } \\
\text { Anchored } & \text { Clone } \\
\text { by Individual } & \text { No. per } \\
\text { Hybridization } & \text { Marker }\end{array}$ & $\begin{array}{c}\text { Average } \\
\text { Clone No. } \\
\text { per cM }\end{array}$ & $\begin{array}{l}\text { No. of End No. of } \\
\text { Sequences Contigs }\end{array}$ & $\begin{array}{l}\text { Total Length of } \\
\text { Nonredundant } \\
\text { End Sequences }\end{array}$ & $\begin{array}{l}\text { Clones with } \\
\text { Confirmed } \\
\text { Position } \\
\text { by End } \\
\text { Sequencing }\end{array}$ & $\begin{array}{cc}\text { Clones } & \\
\text { with Single } & \text { Associated } \\
\text { Map } & \text { QML/YAL } \\
\text { Positions } & \end{array}$ \\
\hline
\end{tabular}

\begin{tabular}{|c|c|c|c|c|c|c|c|c|c|c|c|}
\hline & & & & \multicolumn{8}{|c|}{$b p$} \\
\hline $1 \mathrm{C}(19.4 \mathrm{cM})$ & 19 & 323 (for $1 \mathrm{C}$ and $2 \mathrm{~B}$ ) & 49 & 2.6 & 2.5 & 78 & 7 & 51,372 & 19 & 8 & $13^{\mathrm{a}}$ \\
\hline 2B (13.0 cM) & 25 & & 132 & 5.3 & 10.1 & 173 & 21 & 91,196 & 51 & 23 & $10^{\mathrm{b}} / 5^{\mathrm{c}}$ \\
\hline $4 \mathrm{I}(11.7 \mathrm{cM})$ & 19 & 81 & 55 & 2.8 & 4.7 & 71 & 6 & 43,361 & 31 & 21 & $37^{\mathrm{d}} / 10^{\mathrm{e}}$ \\
\hline 가 (36.0 сM) & 18 & 100 & 68 & 3.8 & 1.8 & 105 & 13 & 65,200 & 41 & 31 & $7^{f} / 2^{g}$ \\
\hline $11 \mathrm{C}(19.0 \mathrm{cM})$ & 23 & 110 & 70 & 3.0 & 3.7 & 92 & 7 & 60,966 & 19 & 17 & $12^{\mathrm{h}} / 8^{\mathrm{i}}$ \\
\hline Total & 104 & 614 & 374 & & & 519 & 54 & 312,095 & 161 & 100 & 104 \\
\hline Average & & & & 3.5 & 4.6 & & & & & & \\
\hline
\end{tabular}

${ }^{\mathrm{a}} \mathrm{Ala}$, Asp, Cys, Met, oxoproline-5, S-methyl-Cys, isomaltose, phosphate, Glc-6-P, sorbitol, quinate, succinate, threonate. ${ }^{\mathrm{b}}$ Glu, $S$-methyl-Cys, Fru, Gal, Glc, Man, glycerol-3-phosphate, dehydroascorbate, gluconate, isocitrate. ${ }^{\mathrm{C}}$ Flowers per plant, pericarp, seed number per fruit, seed number per plant, leaf morphology. ${ }^{\mathrm{d}}$ Asn, Asp, $\beta$-Ala, $\gamma$-aminobutyric acid, Glu, Gln, Ile, Leu, Lys, Met, Pro, Fru, Fuc, Glc, Suc, phosphate, Fru-6-P, Glc-6-P, glycerol-3-phosphate, inositol-1-phosphate, stearate, palmitate, citrate, dehydroascorbate, gluconate, glycerate, isocitrate, 3-methylbutanal, 3-methylbutanol, 2-methylbutanal, 2-methylbutanol, isovaleronitrile, isobutyl acetate, pentanal, trans-2-pentenal, 1-penten-3one, cis-2-penten-1-ol. eplant weight, Brix, fruit color, fruit length per width, fruit width, harvest index, pericarp, seed width, style length, green fruit at harvest time. $\quad{ }^{\mathrm{f}} \gamma$-Aminobutyric acid, homoserine, Ile, Leu, Met, Ser, Glc-6-P. $\quad{ }^{\mathrm{g}}$ Fruit length, fruit weight. $\quad{ }^{\mathrm{h}}$ Asp, $\gamma$-aminobutyric acid, Leu, Glc, dehydroascorbate, fumarate, pentanal, 3-methylbutanal, 3-methylbutanol, 2-methylbutanal, 2-methylbutanol, isovaleronitrile. ${ }^{\text {i Anther }}$ length, Brix yield, flowers per plant, fruit number, inflorescence number, pericarp per width, seed number per plant, seed weight per plant.

group (Bermúdez et al., 2008); (2) confirmation of physical map position by end sequence anchoring; and (3) availability of information from orthologous $S$. lycopersicum genomic regions. On the basis of these criteria, nine clones were sequenced: one clone anchored to BIN 1C, two to BIN 2B, one to BIN 4I, four to BIN $7 \mathrm{H}$, and one to BIN 11C. Insert lengths ranged from 50,564 to $148,978 \mathrm{bp}$. Map positions and clone identifiers are available in Supplemental Table S2A.

The full-length sequencing of these clones resulted in a total of $926,691 \mathrm{bp}$ of sequence, which, together with the end sequences described above, encompasses a total of 1,238,786 bp. This sequence volume represents $1.5 \%$ of the five genomic regions under study and about $0.1 \%$ of the entire S. pennellii genome. The complete data set, including hybridization anchored clones, masked nonredundant end sequences, and large insert clone sequences, was used to build a physical map. Figure 1 shows a graphical representation of the relationships found between the S. lycopersicum genetic map and the anchored clones of the wild species. The identity of $S$. pennellii sequences to mapped markers (blue lines) and to S. lycopersicum genomic sequence (red lines) allowed the determination of orthologous regions between the two species for $43 \%$ of the anchored clones.

At first glance, the topology of the maps of these five genomic regions showed that the $S$. pennellii genome can be considered colinear with that of the domesticated tomato. This can clearly be observed in Figure 1 by the density of the lines linking S. pennellii with $S$. lycopersicum clones and their positions on the map. However, it is possible to identify a few regions where red lines connect distant $S$. pennellii clones to a single $S$. lycopersicum one and vice versa (i.e. the interval 93-108 centimorgan [cM] in BIN 7H; Fig. 1D). These features suggest the occurrence of rearrangements such as chromosomal inversions and/or InDels. Another interesting feature of the map topology is apparent in the junction of the red lines linking several distant $S$. pennellii clones to narrower intervals within the $S$. lycopersicum genome. The $S$. pennellii clones anchored to a 10.7-cM interval (T1606-TG498 markers) on BIN 4I matched S. lycopersicum BACs $(\mathrm{A}-\mathrm{H})$ that were anchored with markers covering 5.5 cM (C2_At2g45730cLPT-2-K6) according to the Tomato-EXPEN 2000 map (Fig. 1C). Similarly, on BIN 11C, several S. pennellii BAC clones anchored within an interval of $3.0 \mathrm{cM}$ (SSR76-C2_At1g44790) matched a single S. lycopersicum BAC (A) anchored with the T1161 marker at 38.0 $\mathrm{cM}$ (Fig. 1E). Although this result is suggestive of a genome expansion event in S. pennellii, as reflected by the relative genome sizes of these species, it is not possible to formally exclude that this colinearity break reflects the low resolution of the map and/or the current relative paucity of information concerning the S. lycopersicum genomic clones in the regions studied here.

The number of anchored clones per marker (3.5; Table I) is in general agreement with the libraries' redundancy $(4.7 \times)$. However, the cLER-14H18 marker anchored 76 S. pennellii clones (BIN 2B; Fig. 1B), while only eight $S$. lycopersicum clones were identified (Supplemental Table S1). End sequence analyses and contig assemblies of $S$. pennellii clones revealed that most of them span the anchoring marker or a cosegregating one, thus confirming their map positions. Furthermore, 
A
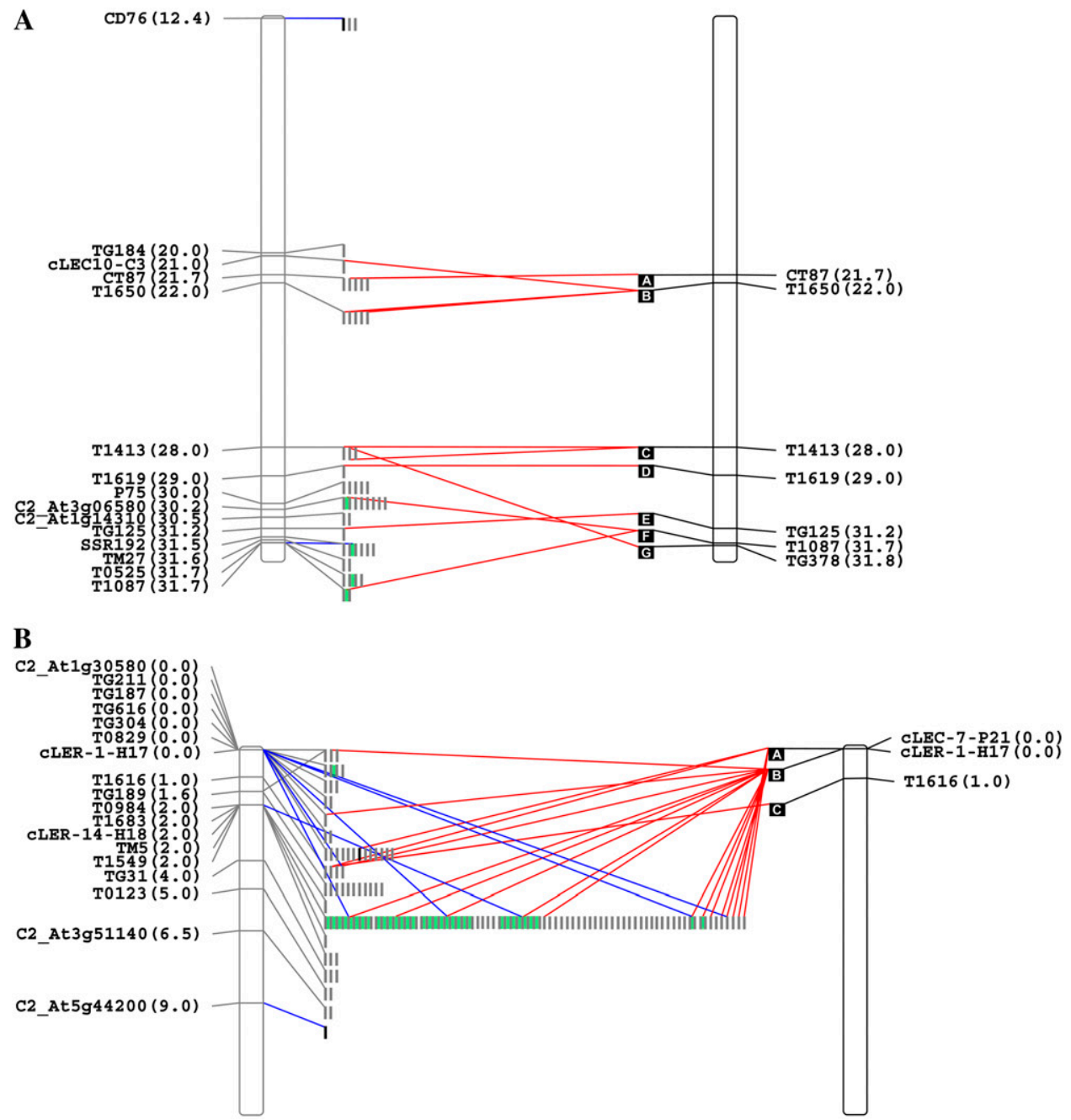

Figure 1. Integrated genetic and physical maps of selected genomic regions of S. pennellii and S. Iycopersicum. Genetic markers and their corresponding map positions (according to the Tomato-EXPEN 2000 map) are shown on the left and right sides of the $S$. pennellii and $S$. lycopersicum chromosome fragment representations, respectively. S. pennellii anchored BAC/ cosmid clones are represented by gray bars. Clones belonging to the same contig are grouped into green boxes. Full-length sequenced clones are represented by black bars. S. lycopersicum clones are represented as black squares ordered alphabetically. Gray lines link $S$. pennellii BAC/cosmid clones with their corresponding hybridizing genetic markers. Blue lines indicate the $S$. pennellii $\mathrm{BAC} / \mathrm{cosmid}$ end sequences containing the corresponding marker sequences. Red lines link $S$. pennellii BAC/cosmid end sequences matching $S$. lycopersicum BAC clone sequences. Black lines link S. Iycopersicum BAC clones to their corresponding markers. The entire data set is available at the SGN Web site in the Tomato Physical Map interface (http://www.sgn. cornell.edu/cview/). A, BIN 1C. B, BIN 2B. C, BIN 4I. D, BIN 7H. E, BIN 11C. [See online article for color version of this figure.]

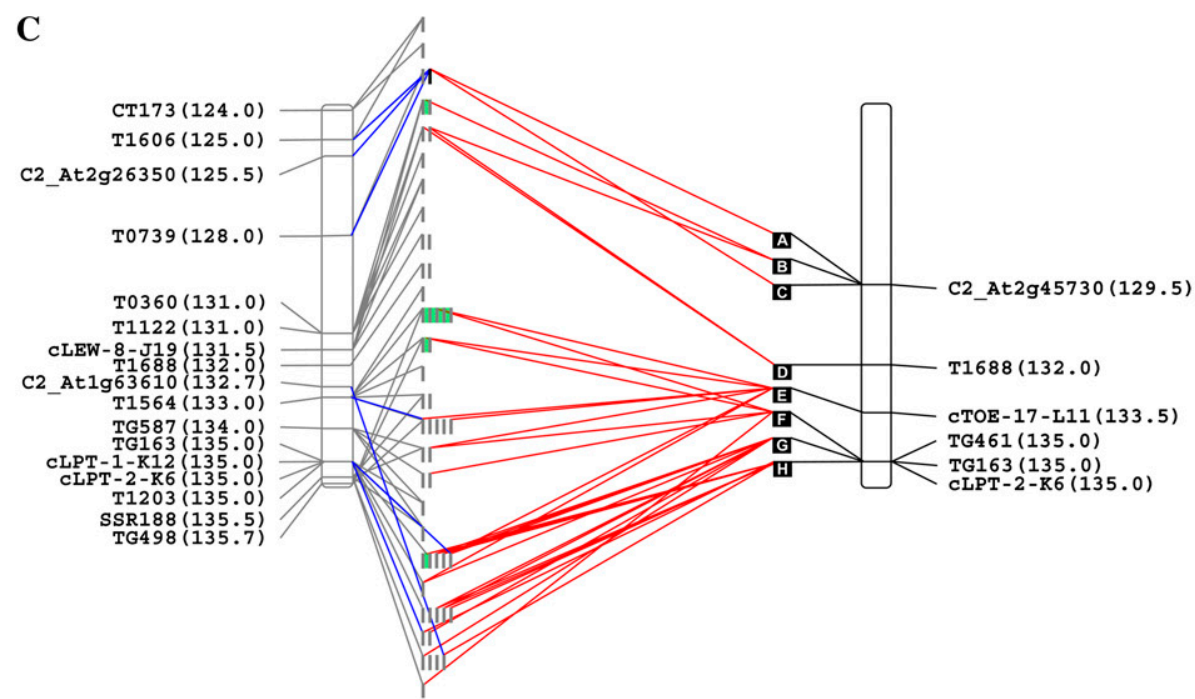

these clones hit only two contiguous S. lycopersicum BACs and harbor ribosomal genes and TEs. Taken together, these results suggest that a local amplification may well have occurred in the S. pennellii genome.

\section{Annotation and Functional Categorization of S. pennellii Coding Sequences}

The significant number of sequences generated, together with the fact that they are linked to physio- 

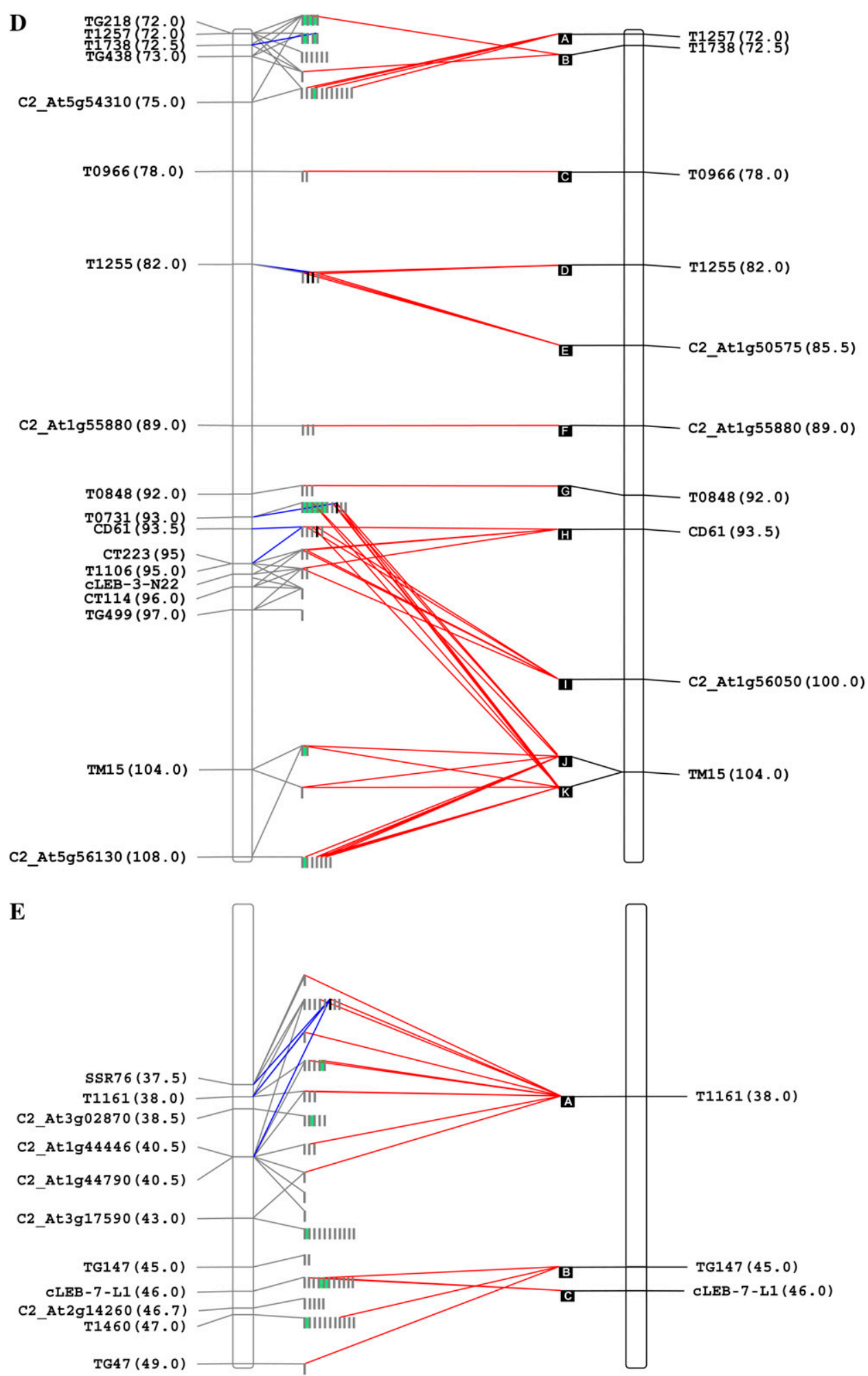

Figure 1. (Continued.)

logically relevant QTLs, renders this information an untapped resource for exposing known and novel genes that could be involved in controlling these traits. For this reason, an exhaustive annotation was attempted for the 436 nonredundant end sequences and the nine BAC/cosmid clones. From the nonredundant end sequences, a total of 298 putative genes were identified and assigned to functional categories (Supplemental 
Table S3). From the fully sequenced BAC/cosmid clones, 109 complete open reading frames were identified by two approaches: (1) utilizing the FGENESH (Salamov and Solovyev, 2000) and Augustus (Stanke et al., 2004) prediction softwares, and (2) manual confirmation by the cross-match interface of the phrap program and BLAST comparison (Supplemental Table S4). A detailed analysis of the large-insert sequence annotation revealed comparable gene density values of 0.1 genes $\mathrm{kb}^{-1}$ in BINs $1 \mathrm{C}, 2 \mathrm{~B}, 7 \mathrm{H}$, and $11 \mathrm{C}$. However, BIN 4I displayed 0.2 genes $\mathrm{kb}^{-1}$ and the lowest density of TEs (Supplemental Tables S4 and S5). The annotated sequences are representative of unigenes derived from cDNA libraries from a broad spectrum of tomato tissues and physiological conditions. Moreover, 103 of the 109 predicted open reading frames through the five genomic regions matched Arabidopsis genes, revealing a high degree of conservation in the gene repertories of the two species. Furthermore, with the exception of the BAC analyzed from chromosome 1, in all other clones, 13 microsyntenic segments were identified between the wild tomato species and Arabidopsis (Arabidopsis thaliana), which are highlighted in color in Supplemental Table S4. These regions encompass 54 genes that span 218,060 nucleotides representing about $25 \%$ of the annotated large-insert clone sequences.

The 407 annotated genes were further subjected to functional categorization using the MapMan ontology adapted for solanaceous species by UrbanczykWochniak et al. (2006). These genes fell into 23 of the 35 gene categories, and their distribution along the five genomic regions is shown in Figure 2. Total sequence percentage per BIN that fell into any functional category varied between $51 \%$ and $84 \%$ for BINs $11 \mathrm{C}$ and $4 \mathrm{I}$, respectively. The number of gene classes per BIN ranged from nine in BIN 11C to 19 in BIN 7H, revealing differences in gene diversity among BINs (Fig. 2). With the exception of region B on chromosome 2, "unknown function" (category 35) was the most represented category for all BINs. The second two most abundant categories, "DNA modifiers" (category 28) and "protein modification" (category 29), are those comprising ribosomal proteins and TEs, respectively. In all the BINs analyzed, a significant percentage of predicted coding regions fell into the "RNA regulation" category (category 27), which includes regulatory proteins such as MYB, WRKY, and zinc finger transcription factors. Several MapMan functional classes were found exclusively in certain genomic regions. For example, genes falling into the "major carbohydrates" category (category 2) were found only in regions of chromosomes 2 and 4. "TCA [tricarboxylic acid] cycle/organic acid transformations" and "cofactor and vitamin synthesis" categories (categories 8 and 18) were found only in BIN 1C, while "redox regulation" (category 21) was found exclusively in BINs $4 \mathrm{I}$ and $7 \mathrm{H}$. Genes related to "transport" (category 34) were found only in BINs 4I, $7 \mathrm{H}$, and $11 \mathrm{C}$. The same was found for genes related to "lipid metabolism" (category 11) and "tetrapyrrole synthesis" (category 19), which were present only in BIN $7 \mathrm{H}$ and $11 \mathrm{C}$, respectively.

\section{SNP and InDel Discovery}

Due to the importance of SNP and InDel discovery in genetic mapping, the number and density of these differences were evaluated within the 436 nonredundant end sequences and their corresponding S. lycopersicum orthologous regions (Supplemental Table

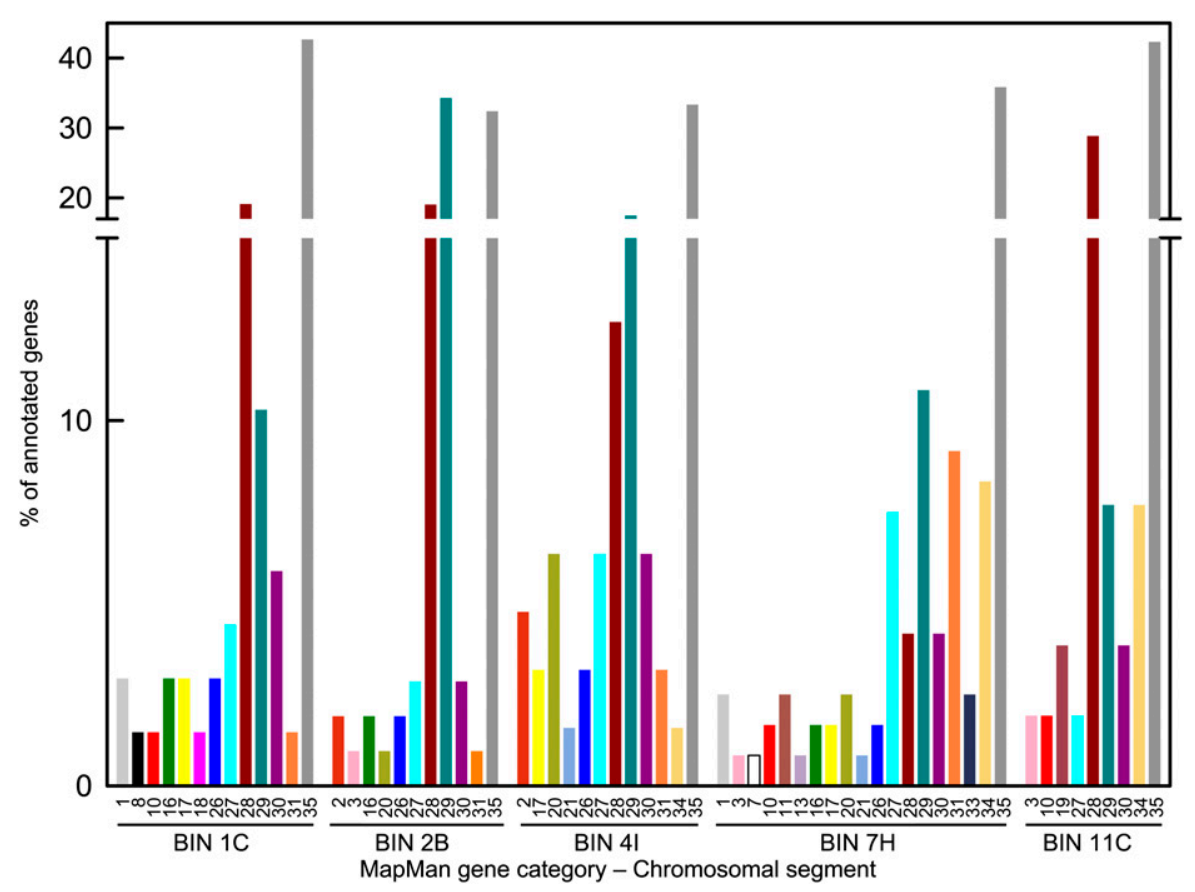

Figure 2. Functional categorization of S. pennellii genomic sequences. BAC/ cosmid end (singletons and contigs) and full-length sequences were categorized according to MapMan software (http:// mapman.mpimp-golm.mpg.de). Categories are as follows: 1, photosynthesis; 2, major carbohydrates; 3, minor carbohydrates; 7, oxidative pentose phosphate pathway; 8, tricarboxylic acid cycle/organic acid transformations; 10, cell wall; 11, lipid metabolism; 13, amino acid metabolism; 16 , secondary metabolism; 17 , hormones; 18, cofactor and vitamin synthesis; 19 , tetrapyrrole synthesis; 20, stress; 21 , redox regulation; 26, miscellaneous enzyme families; 27, RNA regulation; 28, DNA modifiers; 29, protein modifications; 30, signaling; 31, cell; 33, development; 34, transport; 35, unknown function. [See online article for color version of this figure.] 
A

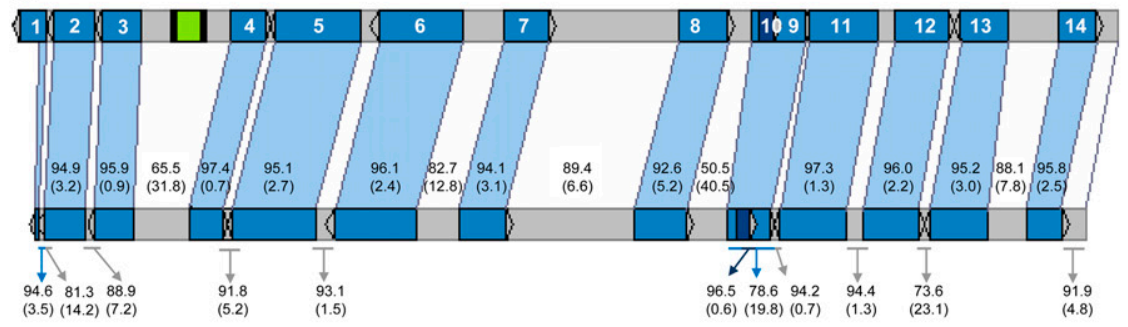

S. pennellii clone C04SpBP093E005.P4C04

S. Iycopersicum clone C04HBa0331L22

B

S. pennellii clone C07SpCP066B007.P5C04

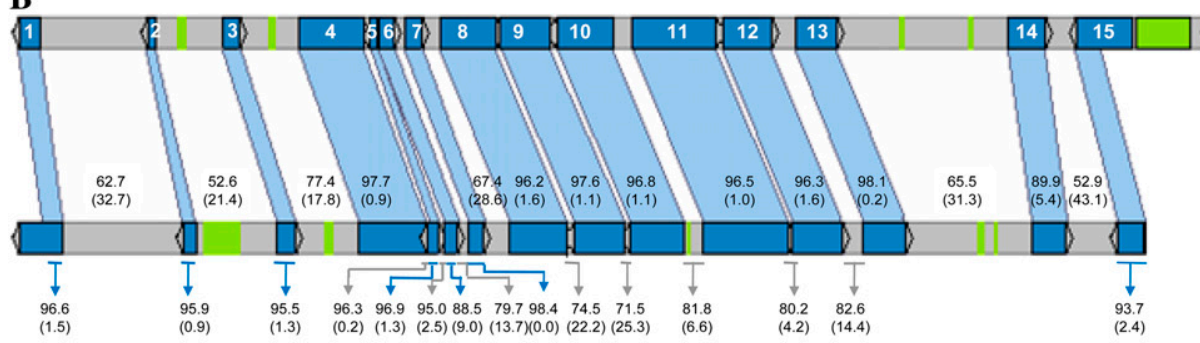

\begin{tabular}{ll|l|l|l|l|l|l|l|l|}
116 & 17 & 18 & 19 & 20 & 21 \\
\hline
\end{tabular}

C

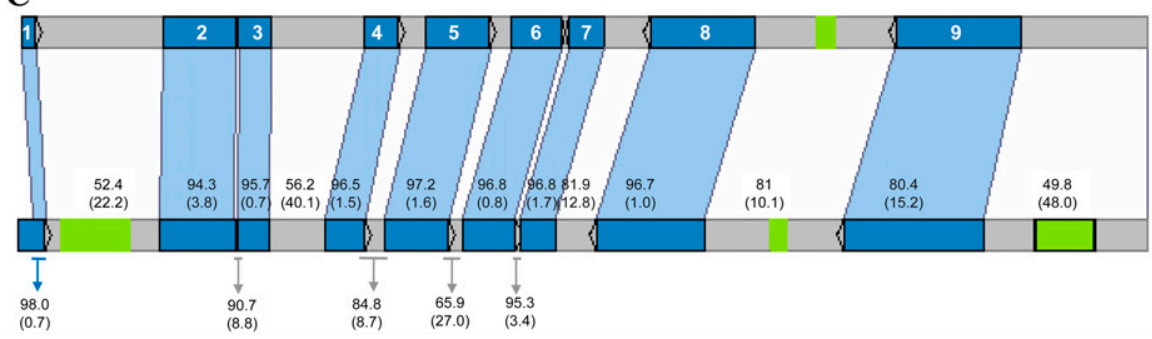

S. pennellii clone C11SpBP029K005.P4E08

S. Iycopersicum clone C11HBa0062I24 $5 \mathrm{~Kb}$

Figure 3. Comparative analysis between S. lycopersicum and S. pennellii orthologous genomic regions. Genes are indicated as blue arrows and coded according to Table II. Green blocks depict transposable elements. Green blocks squared in black correspond to retrotransposons, and their LTRs are indicated as black bars at the ends of the elements. The percentage identity and InDels (in parentheses) between genotypes along genic (including untranslated regions) and intergenic regions are indicated. Compared orthologous genomic regions of $\mathrm{BIN} 4 \mathrm{I}(\mathrm{A}), 7 \mathrm{H}(\mathrm{B})$, and 11C (C) are presented. [See online article for color version of this figure.]

S2C). Polymorphisms along each identified alignment were analyzed following stringent criteria: (1) nucleotide variations were regarded as reliable SNPs only if the quality of the base call achieved a quality value $(\mathrm{Qv}) \geq 20$; and (2) end sequences with only one $S$. lycopersicum matching region were used. This allowed the comparison of $59,510 \mathrm{bp}$ between both species. SNPs varied among genomic regions, ranging from 2.1 per $100 \mathrm{bp}$ in BIN I of chromosome 4 to 9.7 per $100 \mathrm{bp}$ in BIN B of chromosome 2, with an average of 4.3 (Supplemental Table S2C), according to the values expected for these plant species (L. Mueller, personal communication). In the same regions, the distribution of InDels also varied between 0.37 per $100 \mathrm{bp}$ in BIN 4I and 0.5 per $100 \mathrm{bp}$ in BIN 1C. A graphical overview of SNP and InDel mapping revealed that there were no particular patterns of polymorphism within the analyzed chromosomal regions (Supplemental Fig. S1). A high proportion of the SNPs and InDels identified were detected within predicted coding regions (Supplemental Table S3). In the case of the analyzed region of chromosome 2 (which showed the highest percent- age of polymorphisms), all the SNPs and InDels detected fell within three gene categories: 29 (protein modification), 35 (unknown function), and 28 (DNA modifiers).

Microsynteny and Evolutionary Analyses of S. pennellii and S. lycopersicum Orthologous Regions

Large-insert clones from S. pennellii were compared with the corresponding conserved syntenic segments of S. lycopersicum in order to explore both the differences in genome structure and the sequence divergence between these closely related species. Although this work embraces the study of five genomic regions, the following analyses were focused solely on BINs 4I, $7 \mathrm{H}$, and $11 \mathrm{C}$ because they are the only ones that do not span repetitive sequences and for which unambiguous orthologous sequences from S. lycopersicum were available.

We observed that the syntenic regions contain 38 distinct genes showing conserved genomic ordering, orientation, and gene structure (exon/intron) between 
Table II. Comparative analysis between S. lycopersicum and S. pennellii orthologous genomic regions

SI, S. Iycopersicum; Sp, S. pennellii; At, Arabidopsis; CB, total of compared bases; ND, not determined; UD, undetermined because $d n=0$.

\begin{tabular}{|c|c|c|c|c|c|c|c|c|c|c|}
\hline \multirow[t]{2}{*}{$\mathrm{BIN}$} & \multirow[t]{2}{*}{$I D^{\mathrm{a}}$} & \multirow[t]{2}{*}{ Name $^{b}$} & \multicolumn{2}{|c|}{$\begin{array}{l}\text { Identity (InDels) } \\
\text { CB: XXX }\end{array}$} & \multirow[t]{2}{*}{ Exons $^{d}$} & \multirow{2}{*}{$\begin{array}{l}\text { Length }^{\mathrm{e}} \\
\text { (Amino } \\
\text { Acids) }\end{array}$} & \multirow{2}{*}{$\begin{array}{l}\text { Amino Acid } \\
\text { Polymorphisms }\end{array}$} & \multicolumn{3}{|c|}{$d s / d n^{g}$} \\
\hline & & & Exons & Introns & & & & $S I-S p$ & $S I-A t$ & $S p-A t$ \\
\hline \multirow[t]{14}{*}{41} & Sp04gBP4C04.1 & Diphthine synthase & $\begin{array}{c}99(0) \\
\text { CB: } 100\end{array}$ & & $1^{\mathrm{h}}$ & $33^{i}$ & 0 & & & \\
\hline & Sp04gBP4C04.2 & $\begin{array}{l}\text { Putative chaperone protein } \\
\text { DNAJ-related }\end{array}$ & $\begin{array}{c}99(0) \\
\text { CB: } 480\end{array}$ & $\begin{array}{l}95.3(2.7) \\
\text { CB: } 2,224\end{array}$ & 5 & 159 & 2 & 5.3 & $7.2^{\mathrm{j}}$ & $7.5^{\mathrm{j}}$ \\
\hline & Sp04gBP4C04.3 & Expressed gene 1 & $\begin{array}{l}98.6(0) \\
\text { CB: } 633\end{array}$ & $\begin{array}{l}94.9(1.1) \\
\text { CB: } 2,077\end{array}$ & 7 & 179 & 4 & & & \\
\hline & Sp04gBP4C04.4 & $\begin{array}{l}\text { Abscisic acid-responsive } \\
\text { HVA22 family protein }\end{array}$ & $\begin{array}{l}98.4(0.0) \\
\text { CB: } 966\end{array}$ & $\begin{array}{l}96.0(1.5) \\
\text { CB: } 1,202\end{array}$ & 6 & 321 & 9 & 1.83 & $2.23^{\mathrm{j}}$ & $2.15^{\mathrm{j}}$ \\
\hline & Sp04gBP4C04.5 & E2F transcription factor & $\begin{array}{l}98.8(0) \\
\text { CB: } 996\end{array}$ & $\begin{array}{l}94.3(3.3) \\
\text { CB: } 5,294\end{array}$ & 10 & 331 & 8 & & & \\
\hline & Sp04gBP4C04.6 & $\begin{array}{l}\text { Putative eukaryotic initiation } \\
\text { factor } 3 \gamma \text {-subunit } \\
\text { family protein }\end{array}$ & $\begin{array}{c}98.7(0) \\
\text { CB: } 1,341\end{array}$ & $\begin{array}{l}95.3(3.1) \\
\text { CB: } 4,320\end{array}$ & 13 & 446 & 7 & 3.0 & $3.12^{\mathrm{j}}$ & $3.11^{\mathrm{j}}$ \\
\hline & Sp04gBP4C04.7 & $\begin{array}{l}\text { Putative zinc finger } \\
\text { (C2 } 2 \text { type) } \\
\text { family protein }\end{array}$ & $\begin{array}{l}97.6(0.4) \\
\text { CB: } 1,359\end{array}$ & $\begin{array}{l}91.4(5.0) \\
\text { CB: } 1,865\end{array}$ & 4 & 451 & 13 & $3.8^{\mathrm{j}}$ & $3.9^{j}$ & $3.9^{j}$ \\
\hline & Sp04gBP4C04.8 & Plastidic hexokinase & $\begin{array}{l}99.2(0) \\
\text { CB: } 1,500\end{array}$ & $\begin{array}{l}88.8(8.1) \\
\text { CB: } 2,111\end{array}$ & 9 & 499 & 2 & $11^{\mathrm{j}}$ & $4.6^{j}$ & $4.6^{j}$ \\
\hline & Sp04gBP4C04.9 & $\begin{array}{l}\text { Putative clathrin assembly } \\
\text { protein AP17-like protein }\end{array}$ & $\begin{array}{l}100(0) \\
\text { CB: } 429\end{array}$ & $\begin{array}{l}73.1(25.2) \\
\text { CB: } 3,113\end{array}$ & 6 & 142 & 0 & UD & $17.8^{j}$ & $17.8^{\mathrm{j}}$ \\
\hline & Sp04gBP4C04.10 & Expressed gene 2 & $\begin{array}{l}96.5(0.6) \\
\text { CB: } 909\end{array}$ & & 1 & ND & ND & & & \\
\hline & Sp04gBP4C04.11 & Expressed gene 3 & $\begin{array}{l}98.3(0.3) \\
\text { CB: } 1,851\end{array}$ & $\begin{array}{l}96.7(1.6) \\
\text { CB: } 1,684\end{array}$ & 10 & 608 & 9 & & & \\
\hline & Sp04gBP4C04.12 & $\begin{array}{l}\text { Putative transcription } \\
\text { coactivator-like protein }\end{array}$ & $\begin{array}{l}99.4(0) \\
\text { CB: } 507\end{array}$ & $\begin{array}{l}96.2(2.2) \\
\text { CB: } 1,604\end{array}$ & 5 & 168 & 0 & UD & $8.7^{\mathrm{j}}$ & $8.7^{\mathrm{j}}$ \\
\hline & Sp04gBP4C04.13 & $\beta$-Fructofuranosidase & $\begin{array}{c}99.2(0) \\
\text { CB: } 1,713\end{array}$ & $\begin{array}{l}91.2(6.1) \\
\text { CB: } 2,008\end{array}$ & 4 & 570 & 1 & $26^{\mathrm{j}}$ & $8.0^{\mathrm{j}}$ & $7.7^{\mathrm{j}}$ \\
\hline & Sp04gBP4C04.14 & Putative cytomatrix protein & $\begin{array}{c}99(0) \\
\text { CB: } 1,062\end{array}$ & $\begin{array}{c}94(3.8) \\
\text { CB: } 1,796\end{array}$ & 4 & 353 & 8 & 1.1 & 1.3 & 1.3 \\
\hline \multirow[t]{12}{*}{$7 \mathrm{H}$} & Sp07gCP5C04.1 & $\begin{array}{l}\text { Glycerophosphoryl diester } \\
\text { phosphodiesterase } \\
\text { family protein }\end{array}$ & $\begin{array}{c}98.8(0.0) \\
\text { CB: } 162\end{array}$ & $\begin{array}{l}95.9(1.9) \\
\text { CB: } 1,025\end{array}$ & $2^{\mathrm{h}}$ & $54^{i}$ & 2 & & & \\
\hline & Sp07gCP5C04.2 & $\begin{array}{l}\text { Protease inhibitor/seed } \\
\text { storage/lipid } \\
\text { transfer protein } \\
\text { family protein }\end{array}$ & $\begin{array}{c}97.8(0.0) \\
\text { CB: } 315\end{array}$ & & 1 & 104 & 5 & 1.04 & $1.99^{\mathrm{j}}$ & $1.95^{\mathrm{j}}$ \\
\hline & Sp07gCP5C04.3 & $\begin{array}{l}\text { Polygalacturonase-inhibiting } \\
\text { protein } 1 \text { (PGIP1) }\end{array}$ & $\begin{array}{l}97.7(0.0) \\
\text { CB: } 984\end{array}$ & & 1 & 327 & 6 & $5.8^{\mathrm{j}}$ & $4.1^{\mathrm{j}}$ & $3.6^{\mathrm{j}}$ \\
\hline & Sp07gCP5C04.4 & Similar to fimbrin-like protein & $\begin{array}{l}98.8(0.0) \\
\text { CB: } 2,571\end{array}$ & $97.0(1.5)$ & 12 & 856 & 0 & UD & $7.3^{\mathrm{j}}$ & $7.4^{\mathrm{j}}$ \\
\hline & Sp07gCP5C04.5 & Expressed gene 1 & $\begin{array}{l}96.9(1.3) \\
\text { CB: } 669\end{array}$ & & 1 & ND & ND & & & \\
\hline & Sp07gCP5C04.6 & Wax synthase isoform 3 & $\begin{array}{l}86.8(11.1) \\
\text { CB: } 1,053\end{array}$ & & 1 & 350 & 53 & 2 & $2.07^{\mathrm{j}}$ & $2.06^{\mathrm{j}}$ \\
\hline & Sp07gCP5C04.7 & Wax synthase isoform 3 & $\begin{array}{l}98.4(0.0) \\
\text { CB: } 1,035\end{array}$ & & 1 & 344 & 10 & 1.9 & $2.1^{\mathrm{j}}$ & $2.0^{\mathrm{i}}$ \\
\hline & Sp07gCP5C04.8 & Cell division protein FtsZ & $\begin{array}{l}99.0(0.0) \\
\text { CB: } 1,254\end{array}$ & $\begin{array}{l}95.1(2.2) \\
\text { CB: } 3,438\end{array}$ & 6 & 417 & 1 & $15.5^{\mathrm{j}}$ & $6.0^{\mathrm{j}}$ & $6.3^{j}$ \\
\hline & Sp07gCP5C04.9 & $\begin{array}{l}\text { TATA-binding protein-associated } \\
\text { factor }\end{array}$ & $\begin{array}{l}99.3(0.0) \\
\text { CB: } 1,734\end{array}$ & $\begin{array}{l}96.5(1.8) \\
\text { CB: } 2,580\end{array}$ & 12 & 577 & 9 & 0.87 & $2.9^{j}$ & $2.9^{j}$ \\
\hline & Sp07gCP5C04.10 & Similar to syntaxin 52 (SYP52) & $\begin{array}{l}94.8(4.8) \\
\text { CB: } 735\end{array}$ & $\begin{array}{c}94.9(2.8) \\
\text { CB: } 2,427\end{array}$ & 5 & 243 & 11 & & & \\
\hline & Sp07gCP5C04.11 & Ser/Thr protein phosphatase & $\begin{array}{l}99.5(0.0) \\
\text { CB: } 918\end{array}$ & $\begin{array}{l}96.1(1.1) \\
\text { CB: } 5,494\end{array}$ & 8 & 305 & 1 & 8.0 & $29.8^{j}$ & $32.6^{\mathrm{j}}$ \\
\hline & & & & & & & (Table conti & Ies on $f_{c}$ & ollowing & page.) \\
\hline
\end{tabular}




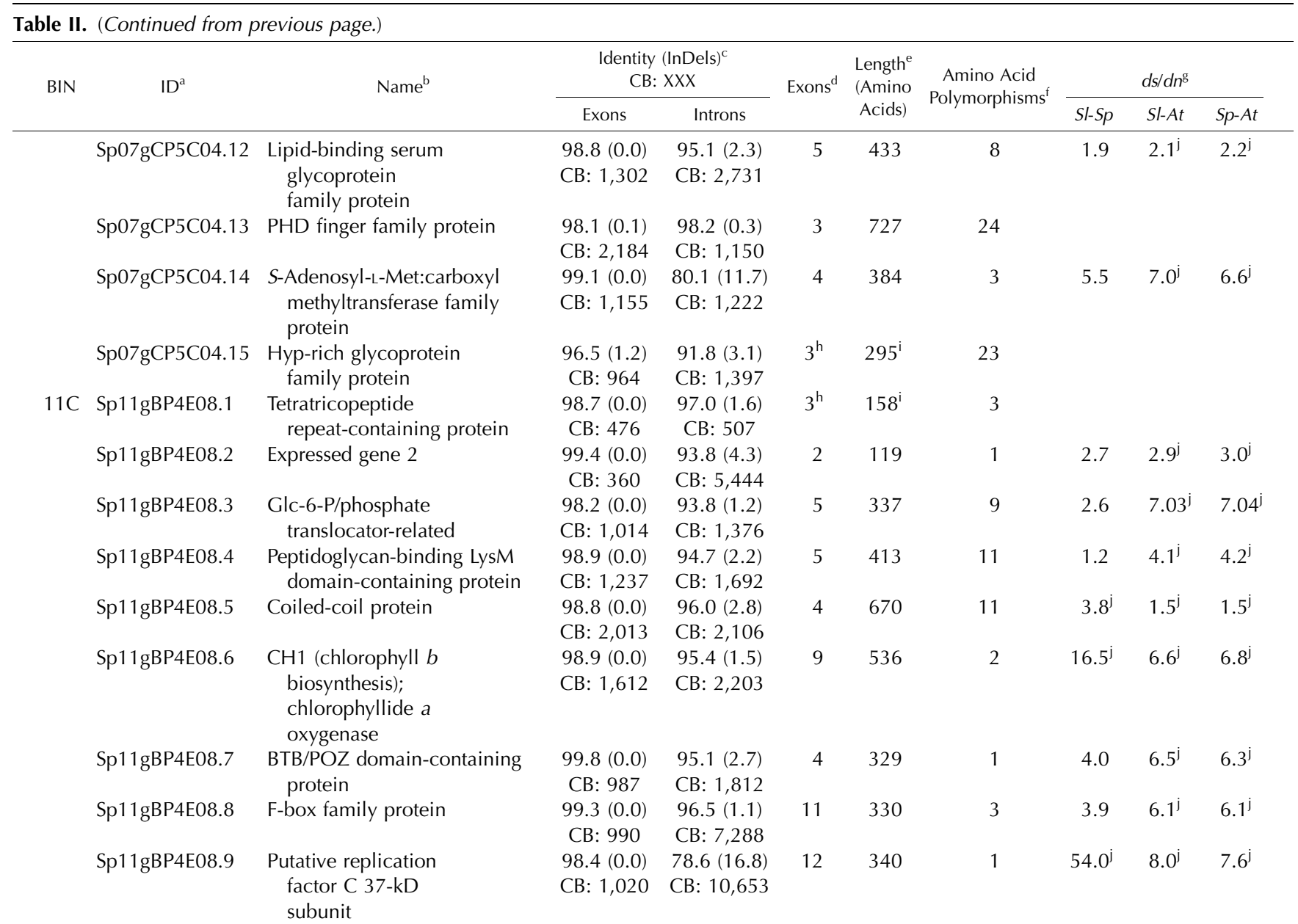

\footnotetext{
${ }^{\mathrm{a}}$ Gene identification. $\quad{ }^{\mathrm{b}}$ Gene functional identity. $\quad{ }^{\mathrm{c}}$ Percentage of identity and InDels between the $S$. lycopersicum and $S$. pennellii regions analyzed. $\quad{ }^{\mathrm{d}}$ Number of exons compared between both genotypes. ${ }^{\mathrm{e}}$ Number of amino acids compared between both genotypes. ${ }^{\mathrm{f}}$ Polymorphic amino acids on the predicted protein sequence. $\quad{ }^{\mathrm{g}}$ Synonymous distance/nonsynonymous distance. hexons not included in the comparative evolutionary analysis of $S$. pennellii and $S$. lycopersicum orthologous regions. i Only partial sequences were compared because genes were located at the end of the clones for any of the genotypes. $\quad$ 'Statistically significant purifying selection $(P<0.05)$.
}

both species and that this nearly perfect colinearity is slightly altered by intergenic regions of variable size and a differential pattern of TE insertions (Fig. 3; Supplemental Table S5). An analysis of the distribution of polymorphisms revealed, as expected, a higher percentage of InDels in intergenic regions than in genic ones (Fig. 3) and in introns as opposed to exons (Table II). The degree of conservation for each gene was evaluated by estimating the rate of synonymous and nonsynonymous substitution distances $(d s / d n)$. This analysis was carried out for all genes that fulfilled the following criteria: (1) they displayed full-length coding sequences (thus, uncompleted genes located on the BAC/cosmid ends were excluded); (2) they exhibited no frameshifts or stop codons (gene Sp07gCP5C04.8 was excluded); (3) they had Arabidopsis orthologs; and (4) they showed homogeneous relative substitution rates between S. pennellii and S. lycopersicum, considering Arabidopsis as an outgroup. For all 27 analyzed genes, the ratio $d s / d n$ was greater than 1 , thus indicating the absence of positive selection (Table II). A test of selection was performed in order to assess whether genes were undergoing neutral $(d s=d n)$ or purifying $(d s>d n)$ selection, revealing that both cases were present. Interestingly, all the genes that displayed nonstatistically significant purifying selection between $S$. pennellii and S. lycopersicum also displayed amino acid polymorphisms. It is important to note that the $d s / d n$ ratio may be subject to misinterpretation if the codon usage is restricted; however, for the data set used in this work, no codon bias was observed for any gene in all three species analyzed.

Since in this work, 27 loci belonging to three different chromosomes of $S$. pennellii were sequenced and the corresponding orthologs from $S$. lycopersicum were identified, these data represent a unique source to investigate the divergence time between these closely related tomato species. Using the fossil record estimation of 120 MYA for the divergence between Arabidopsis and Solanaceae 
(Bell et al., 2005; Magallon and Sanderson, 2005) and the $d s$ of the concatenated coding sequences, the genomic region-specific substitution rates and the species divergence time were estimated. Analysis of the substitution rate revealed no significant differences between BINs, suggesting that the three regions analyzed may code for important conserved proteins (Table III). When all three regions are considered together, the species divergence time was estimated at 2.7 MYA (Fig. 4).

Two Copia-like long terminal repeat (LTR) retrotransposons with perfect tandem duplication sites were found among the genomic regions analyzed in this work. A SHACOP_I_MT in BIN 4I was present only in S. pennellii (Supplemental Table S5), and a TOPSCOTCH LP_I in BIN 11C was found only in S. lycopersicum. Based on the molecular clock, their insertion times were estimated and, as expected, both elements appeared after the species split (Fig. 4), in agreement with the species divergence time estimated above.

\section{DISCUSSION}

In the study described herein, we performed a largescale analysis of the S. pennellii genome and compared it with that of its cultivated tomato counterpart $S$. lycopersicum. To achieve this goal, different approaches were taken: (1) a macrosynteny analysis via the construction of a physical map; (2) sequencing, annotation, and functional categorization of a portion of the wild tomato genome; (3) polymorphism evaluation between these species; and (4) a microsynteny analysis aimed at exposing the variation that has driven the evolutionary change between these two species. Data compilation was focused on five genomic regions: BINs 1C, 2B, 4I, 7H, and 11C, spanning 104 QTLs associated with fruit carbon primary metabolism (Schauer et al., 2006, 2008), fruit color (Liu et al., 2003), volatile content (Tieman et al., 2006), and yield traits linked to metabolite variations found in the fruits (Eshed and Zamir, 1995; Schauer et al., 2006; Semel et al., 2006). Although the high number of QTLs in the studied regions may merely reflect the effect of a few QTLs on several related traits, rather than the existence of multiple independent QTLs, the analyses of the generated data set will serve as a bridge for linking the genome to phenotypes for basic and applied studies.

\section{Comparative Physical Map between S. pennellii and S. lycopersicum}

Due to its versatility and low cost, physical mapping has become a natural component of large genomesequencing endeavors (Gregory et al., 2002; Wallis et al., 2004). In fact, this strategy was originally adopted for the tomato genome-sequencing project (Mueller et al., 2009). Here, a comparative physical map was built anchoring 374 S. pennellii BAC/cosmid clones, which resulted in approximately $10 \%$ of the physical distance coverage of the five selected regions and $1 \%$ of the total wild tomato genome. Across the five regions studied, $58 \mathrm{~S}$. lycopersicum BAC clones were fully sequenced and available on the SGN Web site. The physical map presented here anchored 31 of these clones to $S$. pennellii sequences, representing reliable coverage of $53 \%$ of the sequence information available for the reference genome.

Overall, the topology of the physical map built here reveals a high level of colinearity between $S$. pennelli and the cultivated tomato genomes. However, this colinearity is based on the quality of the S. lycopersicum physical map and on the genetic distances between the markers of the $S$. lycopersicum $\times S$. pennellii reference map, which are far from perfect, especially considering that the latter was constructed with fewer than 100 individuals. However, two independent results support the accuracy of the S. pennelli physical map. First, $24 \%$ of the initially anchored clones were further localized at the same position by hybridization with another closely linked or cosegregating marker. Second, the positions of $43 \%$ of the anchored clones were confirmed by sequence identity to both mapped markers and to $S$. lycopersicum genomic sequences.

The hypothesis of Solanaceae genome colinearity has been proposed several times based on comparative genetic mapping experiments, which yielded evidence for the conservation of gene repertoire and colinear chromosome segments for related species (Wang et al., 2008). Particular features of the physical map presented here suggest the presence of local breaks in the colinearity of the regions analyzed. For example, the instances wherein S. pennelli and $S$. lycopersicum clones are distant from each other are suggestive of chromosomal inversion and/or InDels. Moreover, some S. pennellii genomic intervals seem to

Table III. Estimation of divergence time between S. lycopersicum and S. pennellii

\begin{tabular}{lllrr}
\hline \multicolumn{1}{c}{ BIN } & \multicolumn{1}{c}{ S. lycopersicum BAC } & \multicolumn{1}{c}{ S. pennellii BAC/Cosmid $^{\mathrm{b}}$} & Substitution Rate $^{\mathrm{c}}$ & Divergence Time $^{\mathrm{d}}$ \\
\hline $4 \mathrm{I}^{\mathrm{e}}$ & C04HBa0331L22 & C04SpBP093E005.P4C04 & $4.26 \times 10^{-09}$ & $2,936,857( \pm 690,736)$ \\
$7 \mathrm{H}^{\mathrm{f}}$ & C07HBa0061J13 & C07SpCP066B007.P5C04 & $4.44 \times 10^{-09}$ & $2,700,421( \pm 661,591)$ \\
$11 \mathrm{C}^{\mathrm{g}}$ & C1HBa0062I24 & C11SpBP029K005.P4E08 & $4.40 \times 10^{-09}$ & $2,838, .221( \pm 667,537)$ \\
$4 \mathrm{I} / 7 \mathrm{H} / 11 \mathrm{C}$ & All S lycopersicum genes & All S. pennellii genes & $4.37 \times 10^{-09}$ & $2,744,163( \pm 448,205)$ \\
\hline
\end{tabular}

${ }^{a} S$. lycopersicum concatenated coding regions. $\quad{ }^{\mathrm{b}} S$. pennellii concatenated coding regions. $\quad{ }^{\mathrm{c}}$ Region-specific substitution rate (substitutions per site per year) calculated according to the fossil record estimation of 120 MYA for the divergence between Arabidopsis and Solanaceae (Bell et al., 2005; Magallon and Sanderson, 2005). $\quad{ }^{\mathrm{d} S p e c i e s ~ d i v e r g e n c e ~ t i m e ~ i n ~ M Y A ~( \pm c o n f i d e n c e ~ i n t e r v a l) . ~} \quad{ }^{\mathrm{e}}$ Concatenated coding regions of genes $2,4,6,7,8,9,12,13$, and $14 . \quad{ }^{f}$ Concatenated coding regions of genes $2,3,4,6,7,8,9,11,12$, and 14 . ${ }^{\mathrm{g}}$ Concatenated coding regions of genes 2 to 9 . 


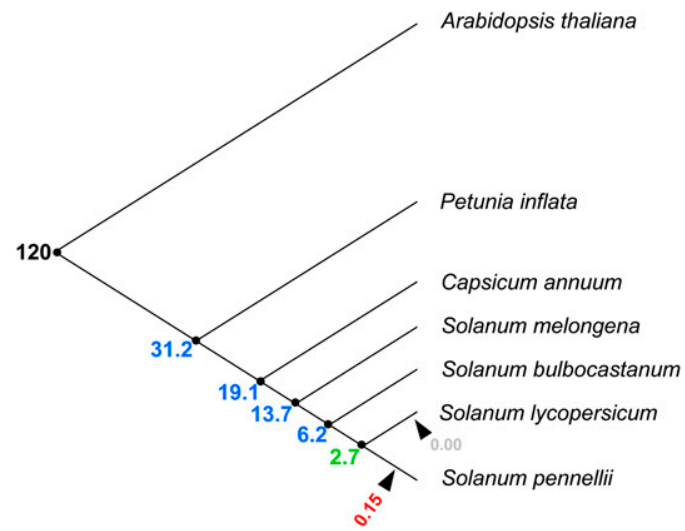

Figure 4. Species divergence time in MYA according to Bell et al. (2005; black), Magallon and Sanderson (2005; black), and Wang et al. (2008; blue). S. pennellii and S. lycopersicum divergence (green) was estimated using a molecular clock. SHACOP_I_MT (red) and TOPSCOTCH_LP_I (gray) retrotransposon insertions are indicated by arrows. [See online article for color version of this figure.]

be compressed in S. lycopersicum, hinting at the expansion of specific S. pennellii regions, which is in agreement with the larger genome size estimation for this species (Arumuganathan and Earle, 1991). The results of microsynteny analysis, which revealed larger intergenic regions in $S$. pennellii than in $S$. lycopersicum, reinforce this statement. These rearranged regions, together with the screening for SNPs and InDels, will likely facilitate the identification of polymorphic markers.

As reported by Zhao et al. (2002), the sequence of 114 BAC clones from the taxonomically related rice subspecies Oryza sativa indica 'Guangluai 4' was particularly useful for gap closing of sequence gaps of rice chromosome 4. Although a significant number of InDels were detected between the two tomato species, the $S$. pennellii BAC/cosmid clones anchored in this work allowed the detection of 64 extension clones (those matching the S. lycopersicum genome at only one end) and another 21 clones filling in gaps between two S. lycopersicum clones (those matching two nonoverlapping S. lycopersicum clones of the same region). Together with the information obtained from the anchoring results described above, all these sequences provide useful tools for comparative genome analyses, map-based cloning, validation of genome sequence assemblies, and an easier access to the regulatory sequences surrounding important genes.

\section{Annotation of S. pennellii Coding Sequences}

After annotation of the 436 nonredundant end sequences and the nine BAC/cosmid clones, 407 genes were identified. In agreement with all large-scale plant genome analyses, our results for large-insert sequences display an inverse distribution between genes and TE-containing regions (Arabidopsis Genome Initiative, 2000; Paterson et al., 2009). In particular, the gene density along BIN $4 \mathrm{I}\left(0.2\right.$ genes $\left.\mathrm{kb}^{-1}\right)$ doubles that of the rest of the genomic regions analyzed ( 0.1 genes $\mathrm{kb}^{-1}$ ), while it displays the lowest density of TEs. Gene identification by end sequence data analysis also revealed BINs $4 \mathrm{I}$ and $7 \mathrm{H}$ as the most gene-enriched regions. These gene density values are higher than those previously estimated for S. lycopersicum heterochromatin (Van der Hoeven et al., 2002; Wang et al., 2008; Mueller et al., 2009), although it should be noted that they may reflect a bias considering the high abundance of QTLs in these genomic regions.

Focusing on a region of tomato chromosome 7 of about $57 \mathrm{~kb}$, Rossberg et al. (2001) found the same arrangement of five predicted genes as that found in a region of Arabidopsis chromosome 1. This kind of colinearity with Arabidopsis has also been reported for a region of tomato chromosome 2 harboring the major fruit-shape locus ovate with Arabidopsis chromosome 4 (Ku et al., 2001) and between a tomato centromeric BAC of chromosome 6 harboring the FER locus and three distinct regions on Arabidopsis chromosomes 2, 3, and 5 (Guyot et al., 2005). With the exception of the case of BIN 1C, our results from BAC/ cosmid full-length sequencing revealed several examples of microsynteny between the S. pennellii and Arabidopsis genomes. These results, together with those recently published from genome-wide approaches in Arabidopsis detecting a few genetic "hot spots" exhibiting major effects on hundreds of QTLs (Lisec et al., 2008; Fu et al., 2009), open new routes to explore further relations between common pathways regulating metabolism in these two species.

Concerning gene categorization, the number of gene classes per BIN ranges between nine for BIN 11C and 19 for BIN 7H, suggesting a functional compartmentalization of the genome, at least for the analyzed regions. Among all the identified genes, several plausible candidates that could directly underlie previously reported metabolic QTLs can be identified. However, the analyzed sequences represent only $10 \%$ of these regions, and the participation of these genes defining the metabolic QTLs remain to be functionally proven. A combination of the generation of recombinant lines harboring smaller introgressions of the $S$. pennellii genome and reverse genetic approaches is under way at present to assess the candidature of these genes.

\section{Microsynteny and Evolutionary Analysis of Orthologous Regions}

Domestication of crops is arguably the most dramatic recent event in plant evolution. Evidence indicates that most of the anatomical changes selected during domestication are determined by the modification of gene expression patterns of a few regulatory loci (Doebley et al., 1997). This is the case, for example, of the fw2.2 locus, responsible for the fruit weight variation between wild and cultivated tomato (Frary et al., 2000). Moreover, the large- and small-fruit alleles 
do not differ in protein sequence but in transcription levels due to promoter polymorphisms (Nesbitt and Tanksley, 2002). With the putative fruit-related loci analyzed in this work, a slightly different panorama is observed when comparing S. pennellii and S. lycopersicum. A total of 277,534 bases were compared between both species. A total of 32 out of the 38 completed genes identified displayed amino acid polymorphisms, and 16 out of the 27 genes with estimated $d s / d n$ displayed neutral selection. Even the eight genes with significant purifying selection showed amino acid polymorphisms. These results indicate that coding regions have accumulated polymorphisms since both species diverged. With the exception of a cytomatrix-encoding protein (Sp04gBP4C04.14), all the coding regions displayed significant purifying selection between tomato and Arabidopsis, thus indicating that the analyzed genes have a conserved function.

Using an estimated substitution rate of $6.03 \times 10^{-9}$ and four loci, Nesbitt and Tanksley (2002) reported that S. pennellii and S. lycopersicum diverged 7.0 MYA. More recently, Wang et al. (2008) reported the analysis of sequences for an unduplicated conserved syntenic segment in the genomes of five Solanaceae species (petunia [Petunia hybrida], pepper [Capsicum annuum], eggplant [Solanum melongena], potato [Solanum tuberosum], and tomato). The results indicated that the last common ancestor of these species lived approximately 31.2 MYA and that the divergence of tomato and potato had occurred approximately 6.2 MYA. In this study, a more precise calculation using specific substitution rates and genetic distances of 27 different loci along three different chromosomes allows us to estimate the divergence between $S$. pennellii and S. lycopersicum at 2.7 MYA. Since $S$. pennellii is one of $S$. lycopersicum's most distantly related wild species, our results indicate that the lycopersicum species of the genus Solanum began its radiation more recently than previously estimated. Two different Copia-like LTR retrotransposons were found through the analyzed regions. Their corresponding insertion dates were estimated, and they were shown to have occurred after both tomato species diverged. Recently, several reports have demonstrated the impact of TEs on important agronomical traits. As illustrative examples, we can mention the effects of the insertion of retrotransposons in $\beta$-carotene accumulation in cauliflower (Brassica oleracea) plastids (Lu et al., 2006) and in gene duplication causing morphological variations of tomato fruit (Xiao et al., 2008). In this direction, work is in progress to further investigate whether the recently inserted retrotransposons identified here could be involved in differential gene expression patterns between S. pennellii and S. lycopersicum.

\section{CONCLUSION}

In this work, we integrated physical and genetic maps of selected regions of two tomato species, $S$. lycopersicum and S. pennellii. Together with BAC/ cosmid end sequencing, we detected a number of putative SNPs and InDels that could be particularly useful as a screening tool in fine-mapping approaches and that, following experimental validation, could be of considerable practical relevance in breeding programs. Moreover, they will aid in filling marker-poor segments of the genome and in understanding the relationship between levels of crossing over per physical distance and levels of polymorphism in Solanaceae species. Targeted sequencing of BAC/cosmid clones, gene annotation, and comparative analyses suggest that changes in both coding and noncoding sequences could be implicated in the phenotypic diversity within the genus. In addition, a precise estimation of S. pennellii and S. lycopersicum divergence time indicates that tomato radiation occurred 2.7 MYA.

The framework of the physical map, sequence assembly, and novel candidate genes presented here provides a considerable collection of resources for tomato research, especially considering the 104 QTLs that have previously been mapped to the genomic regions analyzed. Together with previous genomic sequences of $S$. pennellii candidate genes (Bermúdez et al., 2008), these resources constitute a valuable data set repository of genomic information for this Solanaceae species. Work is in progress to further characterize the functions of several of the novel candidate genes described here.

\section{Note}

While this paper was under revision, a draft of the tomato genome sequence was released (December 1, 2009, International Tomato Genome Sequencing Consortium; http://solgenomics.net/tomato/). Thus, the analyses performed in this work were rerun and 82 further S. pennellii $\mathrm{BAC} /$ cosmid clones were putatively anchored to $S$. lycopersicum scaffolds. However, it is important to point out that these scaffolds are not yet physically ordered and, consequently, the expected map positions of these $S$. pennellii sequences are not confirmed. Although the $S$. pennellii sequences reported here were compared with a considerable number of BAC sequences and with a draft version of the cultivated tomato genome, $35 \%$ of the S. pennellii BAC/cosmid clones remained unanchored. This could be indicative of either a discontinued synteny between the species and/or a lack of corresponding S. lycopersicum genomic sequence information and thus requires further analyses.

\section{MATERIALS AND METHODS}

\section{Screening and Anchoring of Solanum pennellii Genomic Clones}

The five genomic regions selected for analysis were BINs 1C, 2B, 4I, 7H, and $11 \mathrm{C}$, which were determined by the overlapping of Solanum pennelli IL introgressed fragments according to the Tomato-EXPEN 1992 map (Solanum 
lycopersicum LA925 × S. pennellii LA716; http://www.sgn.cornell.edu/; Eshed and Zamir, 1995). In order to select markers spanning the regions of interest, Southern-blot hybridizations were performed using the BIN flanking markers as probes (Sambrook et al., 1989). This analysis allowed us to delimit the five selected BINs between markers TG24 and TG80, TG31 and CT106, CT173 and TG464, TG199 and TG499, and TG523 and TG384 for the 1C, 2B, 4I, 7H, and $11 \mathrm{C}$ chromosomal segments, respectively (data not shown). The selected regions carry a total of 277 molecular markers mapped on the publicly available Tomato-EXPEN 2000 and Tomato-EXPEN 1992 maps spanning 99.1 cM (BIN 1C, 19.4 cM; BIN 2B, 13.0 cM; BIN 4I, 11.7 cM; BIN 7H, 36.0 cM; BIN $11 \mathrm{C}, 19.0 \mathrm{cM}$ ). A total of 104 markers that map to single loci in S. lycopersicum were used for library screening (Table I). Ninety overgo-derived markers were selected from the collection available at the SGN site. The other 14 were inhouse designed with the OligoSpawn software (Zheng et al., 2006). The complete list of the 104 overgoes used in this study is given in Supplemental Table S1.

The S. pennellii (accession LA716, the donor parent of the IL population) genomic libraries were built in pBeloBACII (52,992 clones) and pCLD04541 (50,304 clones) vectors for BAC and cosmid, respectively (Chen et al., 2007). Both libraries were the result of genomic DNA partially digested with HindIII endonuclease. High-density membranes were screened with 15 to 20 pooled overgo probes (first hybridization). A two-dimensional pooling strategy was performed in order to anchor each clone to its corresponding hybridizing marker (second hybridization). Hybridizations were performed according to Sambrook et al. (1989) with minor modifications. BAC/cosmid filters were prehybridized in a solution containing $2 \times$ SSC, $0.1 \%$ SDS, and $10 \mathrm{mg} \mathrm{mL}^{-1}$ salmon sperm DNA for $3 \mathrm{~h}$ at $65^{\circ} \mathrm{C}$. Probes were denatured with $0.4 \mathrm{~N} \mathrm{NaOH}$ added to each hybridization recipient and hybridized at $65^{\circ} \mathrm{C}$ overnight. Filters were washed in $2 \times$ SSC and $0.1 \%$ SDS at $65^{\circ} \mathrm{C}$ for $5 \mathrm{~min}$ and then in $1.0 \times$ SSC and $0.1 \%$ SDS at $65^{\circ} \mathrm{C}$ for $30 \mathrm{~min}$.

\section{BAC/Cosmid Clone Insert Size Estimation and Sequencing}

DNA was purified using the R.E.A.L Prep 96 Plasmid Kit (Qiagen). Clone insert sizes were estimated by pulsed-field gel electrophoresis by digesting 0.5 to $2 \mu \mathrm{g}$ of purified DNA with NotI endonuclease in order to release the insert. Insert size was calculated with ImageQuant TL 7.0 software (G\&E).

For BAC/cosmid end sequencing, 0.2 to $0.5 \mu \mathrm{g}$ of purified DNA was used, and sequencing reactions were performed with ABI Big Dye Terminator version 3.1. Samples were read in an ABI 3730 sequencer. Vector and lowquality sequences $(\mathrm{Qv}<20)$ were trimmed out, and only reads above 300 nucleotides were considered.

$\mathrm{BAC} /$ cosmid full-length sequencing was performed either by shotgun (Macrogen) or pyrosequencing (454 Life Sciences, through a partnership with Roche). Reads were assembled using the Phred+Phrap+Consed software package (Ewing and Green, 1998; Gordon et al., 1998).

\section{Map Building}

All the generated sequences were masked using the Repeat Masker program (http://www.repeatmasker.org) before analysis in order to avoid further associations with nonorthologous regions. End reads from BAC/ cosmid clones, anchored to the same marker, were subjected to contig assembly with the DNA Baser version 2.60 .90 software with default parameters. A Python script (Chapman and Chang, 2000) was used to analyze the nonrepetitive sequences, either from contigs or singletons by BLASTN (Altschul et al., 1990). The databases used were (1) all currently available $S$. lycopersicum genomic clone sequences and (2) the marker sequence database. Both databases are accessible at the ftp site of http://www.sgn.cornell.edu/. For comparison against $S$. lycopersicum BAC sequences (version 441, October 5 , 2009, containing 1,188 sequences and encompassing $127,592,092 \mathrm{bp}$ ), a hit criterion of above $80 \%$ identity was considered. For comparison against marker sequences (database containing 9,625 sequences and encompassing $3,947,844 \mathrm{bp}$ ), only hits with at least $96 \%$ identity across more than $150 \mathrm{bp}$ were considered. Furthermore, the associations between S. lycopersicum genomic clone sequences and marker sequences were identified using the Marker search feature from the SGN Web site with the parameters mentioned above. The complete set of established relationships is presented in Supplemental Table S2A. Anchored clones and end sequences are available at the SGN Web site in the Tomato Physical Map interface (http://www.sgn.cornell. edu/cview/).

\section{Annotation of BAC/Cosmid End Sequences and Polymorphism Analyses}

Nonrepetitive singletons and contigs were annotated by comparison against the following databases: nonredundant proteins at the National Center for Biotechnology Information (November 2008 version, 9,487,554 sequences and 3,243,454,420 bp), the unigenes database at SGN (February 2009 version, 123,550 sequences and 92,327,235 bp), and the Arabidopsis (Arabidopsis thaliana) protein database (The Arabidopsis Information Resource $8,38,963$ sequences and 85,192,362 bp) using BLASTN and BLASTX with e-values $\leq 10^{-6}$, above $80 \%$ identity along $\geq 300 \mathrm{bp}$. Repetitive sequences were annotated by comparison against The Institute for Genomic Research (TIGR) plant repeat databases (ftp://ftp.tigr. org/pub/data/TIGR_Plant_Repeats/) using BLASTN with e-values $\leq 10^{-5}$ (Altschul et al., 1990). All annotated sequences (including large-insert sequences; see below) were organized in functional classes according to the MapMan ontology software (http:// mapman.mpimp-golm.mpg.de).

SNP and InDel analyses were performed with the SeqScape version 2.5 software using a base call value of 20 or greater as true nucleotides, removing bases from the ends until fewer than four bases out of 20 had Qv $<20$ and filtering settings by default. Graphical output was performed by a bespoke Python script, which parses the formatted SeqScape output and reads both the position and the kind of polymorphism (SNP or InDel). An arbitrary value of 1 was used for SNPs, while InDels could take a value of 2 or 3 depending of the InDel size. Positive values were used for SNPs and insertions and negative values were used for deletions.

\section{Large-Insert Sequence Annotation}

S. pennellii BAC/cosmid full-length sequences as well as three S. lycopersicum BAC clones, C04HBa0331L22, C07HBa0061J13, and C11HBa0062I24, were annotated using two different gene prediction programs: FGENESH (www. softberry.com; Salamov and Solovyev, 2000) and Augustus (http://augustus. gobics.de; Stanke et al., 2004). Each BAC/cosmid was screened independently against the SGN unigene database (http:/ / www.sgn.cornell.edu/; September 2009 version, 123,550 sequences and 92,327,235 bp) using the sequence comparison programs cross-match (www.phrap.org). Predicted genes were hand curated by comparison with the corresponding identified unigene by BLAST (Altschul et al., 1990). When no unigene hit was found at the SGN database, TIGR Plant Transcript Assemblies database was used (http:// plantta.tigr.org/). Only genes predicted both by gene prediction programs and matching an mRNA sequence were annotated. The criteria for gene annotation were (1) at least $95 \%$ identity and above $90 \%$ coverage of the unigene length or (2) at least $70 \%$ identity over $85 \%$ of sequence length when only Arabidopsis mRNAs were found.

Repetitive sequences were identified using RepeatMasker (http://www. repeatmasker.org) software, and only elements covering at least $70 \%$ of the matching repeat sequence were considered. LTR retrotransposons were also identified using LTR finder (http://tlife.fudan.edu.cn/ltr_finder/). Element class and family name, as well as the matching repeat sequence available at Repbase (www.girinst.org), are indicated in Supplemental Table S5.

A new nomenclature to name $S$. pennellii genes is proposed: $\mathrm{SpXXgB(or} \mathrm{C)}$ XXXXX.\#, where Sp stands for $S$. pennellii, the two digits indicate the chromosome number, $g$ represents the genomic sequence, B stands for BAC or $C$ for cosmid vectors, the five digits address library coordinates, and \# stands for consecutive numbers indicating gene order within the clone.

For comparative analysis between S. lycopersicum and S. pennellii orthologous genomic regions, the S. lycopersicum BAC clone sequence that better spanned the $S$. pennellii sequence was selected. Sequence comparisons between genotypes for InDel and SNP identification were calculated using the Needleman-Wunsch global alignment algorithm available at http:/ / www.ebi. ac.uk/Tools/emboss/align/.

\section{Evolutionary Analyses}

Alignments of coding regions were performed with ClustalW multiple alignment software (version 1.5; Thompson et al., 1994) and hand curated with reference to amino acid alignment. Synonymous $(d s)$ and nonsynonymous $(d n)$ distances and their SE values were estimated with MEGA 3.1 (Kumar et al., 2004) using the corrected Nei-Gojobori method (JukesCantor). Codon bias was determined by the effective number of codons value computed using DNAsp version 4.10.9 (Rozas et al., 2003). Test of 
selection was also performed with MEGA 3.1 (Kumar et al., 2004) using the corrected Nei-Gojobori method. To reject the null hypothesis of neutral selection $(d s=d n), P<0.05$ was considered in the $Z$ test. Relative rate tests were performed utilizing HYPHY (http://www.hyphy.org) using the codon model proposed by Muse and Gaut (1994). To reject the homogeneity null hypothesis, $P<0.05$ was considered in the $\chi^{2}$ test. Genomic region-specific substitution rates $(K)$ and species divergence time were estimated using $K=d s / 2 T$, where $d s$ is the estimated number of synonymous substitutions per site between homologous sequences (synonymous distance) and $T$ is the divergence time. $K$ was estimated using the fossilsupported Arabidopsis/Solanaceae divergence time (120 MYA; Bell et al., 2005; Magallon and Sanderson, 2005), and $d s$ was estimated based on concatenated coding regions per chromosome.

For retrotransposon dating, both LTRs of copies with target site duplications were aligned using the ClustalW multiple alignment software (version 1.5; Thompson et al., 1994). The distance $(D)$ between LTRs and its SE were estimated with MEGA 3.1 (Kumar et al., 2004) using Kimura 2-parameter, which corrects for homoplasy and differences in the rates of transition and transversion. The retrotransposon insertion date was estimated using $T=D / 2 K$, where $K$ represents the $1.3 \times 10^{-8}$ substitutions per site per year as proposed by Ma and Bennetzen (2004). Confidence intervals were calculated using the SE of the mean distance $(D)$ as estimated with MEGA 3.1.

Sequence data from this article have been deposited within the GenBank data libraries under accession numbers FI277973 to FI278499, FJ809740 to FJ809747, and FJ812349.

\section{Supplemental Data}

The following materials are available in the online version of this article.

Supplemental Figure S1. SNP and InDel mapping.

Supplemental Table S1. Markers used for S. pennellii BAC/cosmid genomic library screening.

Supplemental Table S2. S. pennellii physical map data, S. pennellii contig sequences, and SNPs and InDels between $S$. pennellii end sequences and S. lycopersicum BAC clones.

Supplemental Table S3. BAC/cosmid end sequence annotation.

Supplemental Table S4. Annotation of $S$. pennellii fully sequenced BAC/ cosmid clones from BINs 1C, 2B, 4I, 7H, and 11C.

Supplemental Table S5. S. pennellii transposable elements identified in full-length sequenced clones.

\section{ACKNOWLEDGMENTS}

We thank Mariana Conte for technical assistance and Agustín Montenegro and Ignacio Tevez for taking care of the tomato plants. L.K., R.A., and F.C. are members of Consejo Nacional de Investigaciones Científicas y Técnicas.

Received November 6, 2009; accepted January 26, 2010; published January 29, 2010.

\section{LITERATURE CITED}

Altschul SF, Gish W, Miller W, Myers EW, Lipman DJ (1990) Basic local alignment search tool. J Mol Biol 215: 403-410

Arabidopsis Genome Initiative (2000) Analysis of the genome sequence of the flowering plant Arabidopsis thaliana. Nature 408: 796-815

Arumuganathan K, Earle E (1991) Estimation of nuclear DNA content of plants by flow cytometry. Plant Mol Biol Rep 9: 208-218

Bell CD, Soltis DE, Soltis PE (2005) The age of the angiosperms: a molecular timescale without a clock. Evolution 59: 1245-1258

Bermúdez L, Urias U, Milstein D, Kamenetzky L, Asis R, Fernie AR, Van Sluys MA, Carrari F, Rossi M (2008) A candidate gene survey of quantitative trait loci affecting chemical composition in tomato fruit. J Exp Bot 59: 2875-2890
Chapman BA, Chang JT (2000) Biopython: Python tools for computational biology. ACM SIGBIO Newsletter 20: 15-19

Chen KY, Cong B, Wing R, Vrebalov J, Tanksley SD (2007) Changes in regulation of a transcription factor lead to autogamy in cultivated tomatoes. Science 318: 643-645

Doebley J, Stec A, Hubbard L (1997) The evolution of apical dominance in maize. Nature 386: 485-488

Eshed Y, Zamir D (1995) An introgression line population of Lycopersicon pennellii in the cultivated tomato enables the identification and fine mapping of yield-associated QTL. Genetics 141: 1147-1162

Ewing B, Green P (1998) Basecalling of automated sequencer traces using phred II: error probabilities. Genome Res 8: 186-194

Fernie AR, Willmitzer L (2001) Molecular and biochemical triggers of potato tuber development. Plant Physiol 127: 1459-1465

Frary A, Nesbitt TC, Grandillo S, Knaap E, Cong B, Liu J, Meller J, Elber R, Alpert KB, Tanksley SD (2000) fw2.2: a quantitative trait locus key to the evolution of tomato fruit size. Science 289: 85-88

Fridman E, Carrari F, Liu YS, Fernie A, Zamir D (2004) Zooming in on a quantitative trait for tomato yield using interspecific introgressions. Science 305: 1786-1789

Fridman E, Pleban T, Zamir D (2000) A recombination hotspot delimits a wild-species quantitative trait locus for tomato sugar content to $484 \mathrm{bp}$ within an invertase gene. Proc Natl Acad Sci USA 97: 4718-4723

Fu J, Keurentjes JJB, Bouwmeester H, America R, Verstappen FWA, Ward JL, Beale MH, de Vos RCH, Dijkstra M, Scheltema RA, et al (2009) System-wide molecular evidence for phenotypic buffering in Arabidopsis. Nat Genet 41: 166-167

Gordon D, Abajian C, Green P (1998) Consed: a graphical tool for sequence finishing. Genome Res 8: 195-202

Gregory SG, Sekhon M, Schein J, Zhao S, Osoegawa K, Scott CE, Evans RS, Burridge PW, Cox TV, Fox CA, et al (2002) A physical map of the mouse genome. Nature 418: 743-750

Guyot R, Cheng X, Su Y, Cheng Z, Schlagenhauf E, Keller B, Ling HQ (2005) Complex organization and evolution of the tomato pericentromeric region at the FER gene locus. Plant Physiol 138: 1205-1215

Ku HM, Liu J, Doganlar S, Tanksley SD (2001) Exploitation of Arabidopsistomato synteny to construct a high-resolution map of the ovate-containing region in tomato chromosome 2. Genome 44: 470-475

Kumar S, Tamura K, Nei M (2004) MEGA3: integrated software for molecular evolutionary genetics analysis and sequence alignment. Brief Bioinform 5: 150-163

Lippman ZB, Semel Y, Zamir D (2007) An integrated view of quantitative trait variation using tomato interspecific introgression lines. Curr Opin Genet Dev 17: 545-552

Lisec J, Meyer RC, Steinfath M, Redestig H, Becher M, Witucka-Wall H, Fiehn O, Törjék O, Selbig J, Altmann T, et al (2008) Identification of metabolic and biomass QTL in Arabidopsis thaliana in a parallel analysis of RIL and IL populations. Plant J 53: 960-972

Liu YS, Gur A, Ronen G, Causse M, Damidaux R, Buret M, Hirschberg J, Zamir D (2003) There is more to tomato fruit colour than candidate carotenoid genes. Plant Biotechnol J 1: 195-207

Lu S, Van Eck J, Zhou X, Lopez AB, O'Halloran DM, Cosman KM, Conlin BJ, Paolillo DJ, Garvin DF, Vrebalov J, et al (2006) The cauliflower Or gene encodes a DnaJ cysteine-rich domain-containing protein that mediates high levels of $\beta$-carotene accumulation. Plant Cell 18: 3594-3605

Ma J, Bennetzen JL (2004) Rapid recent growth and divergence of rice nuclear genomes. Proc Natl Acad Sci USA 101: 12404-12410

Magallon SA, Sanderson MJ (2005) Angiosperm divergence times: the effect of genes, codon positions, and time constraints. Evolution 59: 1653-1670

Mueller L, Tanksley S, Giovannoni JJ, Vaneck J, Stack S, Buels R (2009) A snapshot of the emerging tomato genome sequence. Plant Genome 2: 78-92

Mueller LA, Solow TH, Taylor N, Skwarecki B, Buels R, Binns J, Lin C, Wright MH, Ahrens R, Wang Y, et al (2005) The SOL Genomics Network: a comparative resource for Solanaceae biology and beyond. Plant Physiol 138: 1310-1317

Muse SV, Gaut BS (1994) A likelihood approach for comparing synonymous and nonsynonymous nucleotide substitution rates, with application to the chloroplast genome. Mol Biol Evol 11: 715-724

Nesbitt TC, Tanksley SD (2002) Comparative sequencing in the genus Lycopersicon: implications for the evolution of fruit size in the domestication of cultivated tomatoes. Genetics 162: 365-379

Paterson AH, Bowers JE, Bruggmann R, Dubchak I, Grimwood J, 
Gundlach H, Haberer G, Hellsten U, Mitros T, Poliakov A, et al (2009) The Sorghum bicolor genome and the diversification of grasses. Nature 457: 551-556

Rossberg M, Theres K, Acarkan A, Herrero R, Schmitt T, Schumacher K, Schmitz G, Schmidt R (2001) Comparative sequence analysis reveals extensive microcolinearity in the lateral suppressor regions of the tomato, Arabidopsis, and Capsella genomes. Plant Cell 13: 979-988

Rozas J, Sánchez-DelBarrio JC, Messeguer X, Rozas R (2003) DnaSP, DNA polymorphism analyses by the coalescent and other methods. Bioinformatics 19: 2496-2497

Salamov AA, Solovyev VV (2000) Ab initio gene finding in Drosophila genomic DNA. Genome Res 10: 516-522

Sambrook J, Fritsch T, Maniatis T (1989) Molecular Cloning: A Laboratory Manual. Cold Spring Harbor Laboratory Press, Cold Spring Harbor, NY

Schauer N, Semel Y, Balbo I, Steinfath M, Repsilber D, Selbig J, Pleban T, Zamir D, Fernie AR (2008) Mode of inheritance of primary metabolic traits in tomato. Plant Cell 20: 509-523

Schauer N, Semel Y, Roessner U, Gur A, Balbo I, Carrari F, Pleban T, Perez-Melis A, Bruedigam C, Kopka J, et al (2006) Comprehensive metabolic profiling and phenotyping of interspecific introgression lines for tomato improvement. Nat Biotechnol 24: 447-454

Semel Y, Nissenbaum J, Menda N, Zinder M, Krieger U, Issman N, Pleban T, Lippman Z, Gur A, Zamir D (2006) Overdominant quantitative trait loci for yield and fitness in tomato. Proc Natl Acad Sci USA 103: $12981-12986$

Stanke M, Steinkamp R, Waack S, Morgenstern B (2004) AUGUSTUS: a Web server for gene finding in eukaryotes. Nucleic Acids Res 32: 309-312

Thompson J, Higgins D, Gibson T (1994) CLUSTAL W: improving the sensitivity of progressive multiple sequence alignment through sequence weighting, position-specific gap penalties and weight matrix choice. Nucleic Acids Res 22: 4673-4680
Tieman DM, Zeigler M, Schmelz EA, Taylor MG, Bliss P, Kirst M, Klee HJ (2006) Identification of loci affecting flavour volatile emissions in tomato fruits. J Exp Bot 57: 887-896

Urbanczyk-Wochniak E, Usadel B, Thimm O, Nunes-Nesi A, Carrari F, Davy M, Bläsing O, Kowalczyk M, Weicht D, Polinceusz A, et al (2006) Conversion of MapMan to allow the analysis of transcript data from solanaceous species: effects of genetic and environmental alterations in energy metabolism in the leaf. Plant Mol Biol 60: 773-792

Van der Hoeven R, Ronning C, Giovannoni J, Martin G, Tanksley S (2002) Deductions about the number, organization, and evolution of genes in the tomato genome based on analysis of a large expressed sequence tag collection and selective genomic sequencing. Plant Cell 14: 1441-1456

Wallis JW, Aerts J, Groenen MA, Crooijmans RP, Layman D, Graves TA, Scheer DE, Kremitzki C, Fedele MJ, Mudd NK, et al (2004) A physical map of the chicken genome. Nature 432: 761-764

Wang Y, Diehl A, Wu F, Vrebalov J, Giovannoni J, Siepel A, Tanksley SD (2008) Sequencing and comparative analysis of a conserved syntenic segment in the Solanaceae. Genetics 180: 391-408

Xiao H, Jiang N, Schaffner E, Stockinger EJ, Van der Knaap E (2008) A retrotransposon-mediated gene duplication underlies morphological variation of tomato fruit. Science 319: 1527-1530

Zamir D (2001) Improving plant breeding with exotic genetic libraries. Nat Rev Genet 2: 983-990

Zhao Q, Zhang Y, Cheng Z, Chen M, Wang S, Feng Q, Huang Y, Li Y, Tang Y, Zhou B, et al (2002) A fine physical map of the rice chromosome 4. Genome Res 12: 817-823

Zheng J, Svensson JT, Madishetty K, Close TJ, Jiang T, Lonardi S (2006) OligoSpawn: a software tool for the design of overgo probes from large unigene datasets. BMC Bioinformatics 7: 7 


\section{FIGURE S1A}

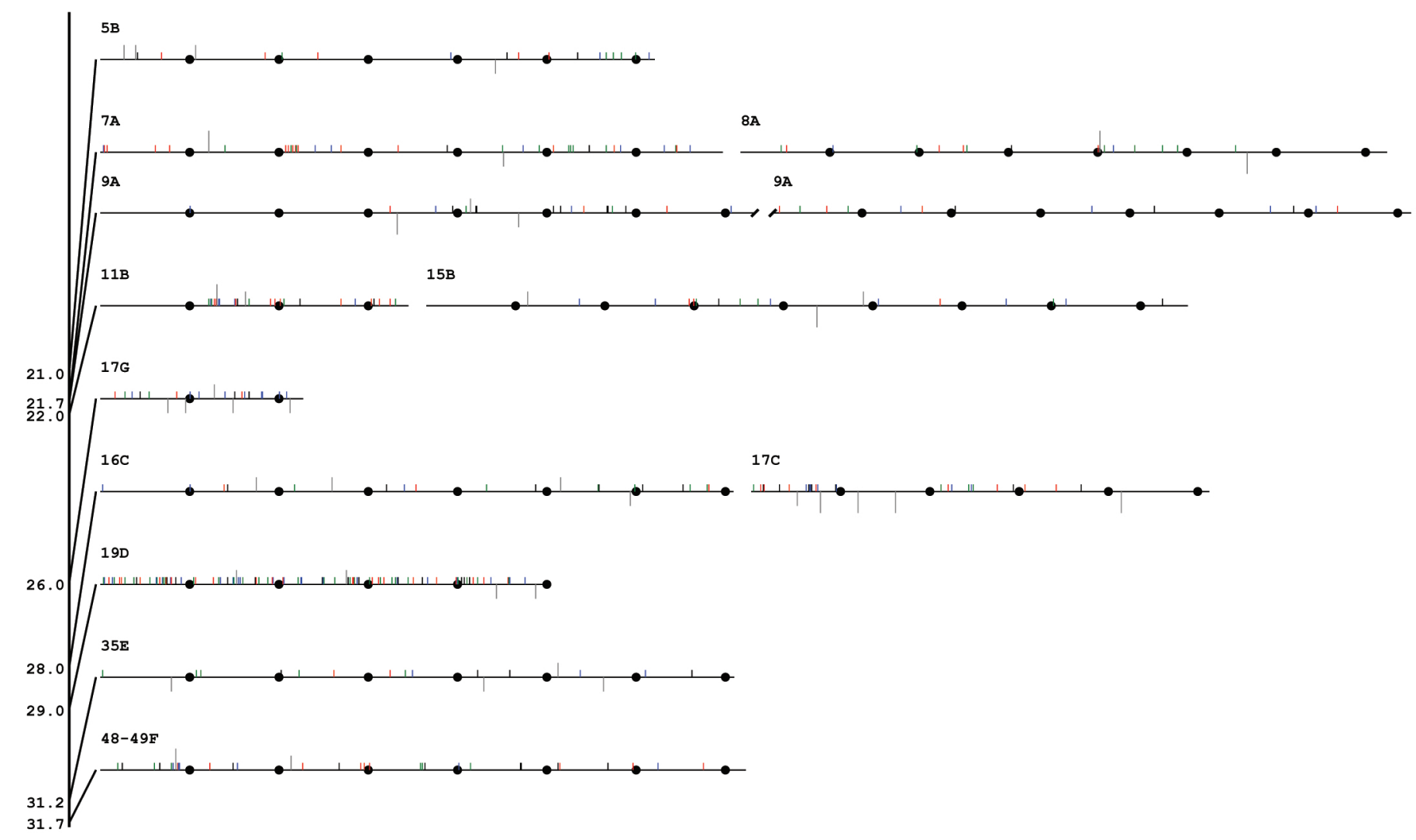




\section{FIGURE S1B}

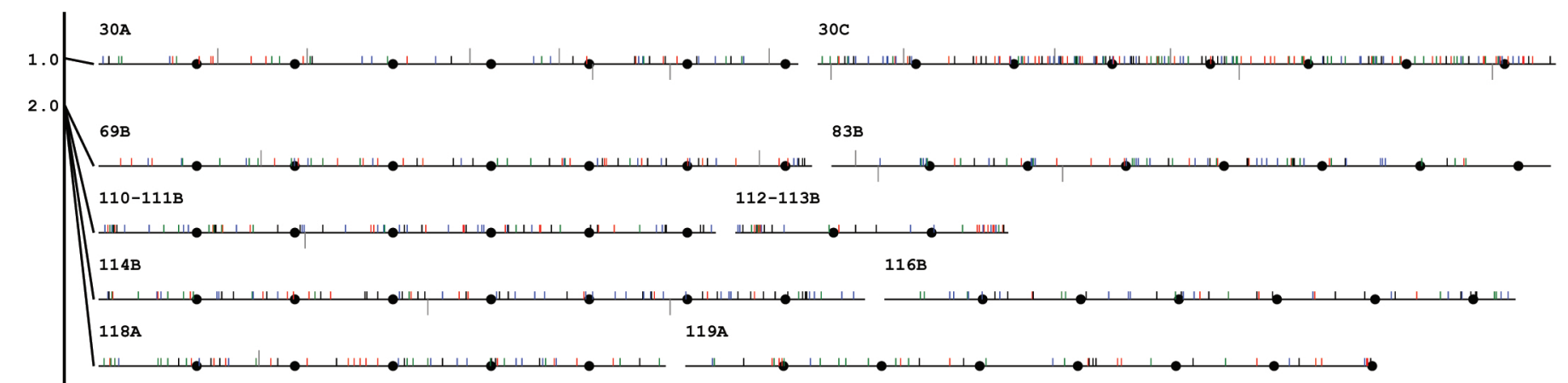




\section{FIGURE S1C}

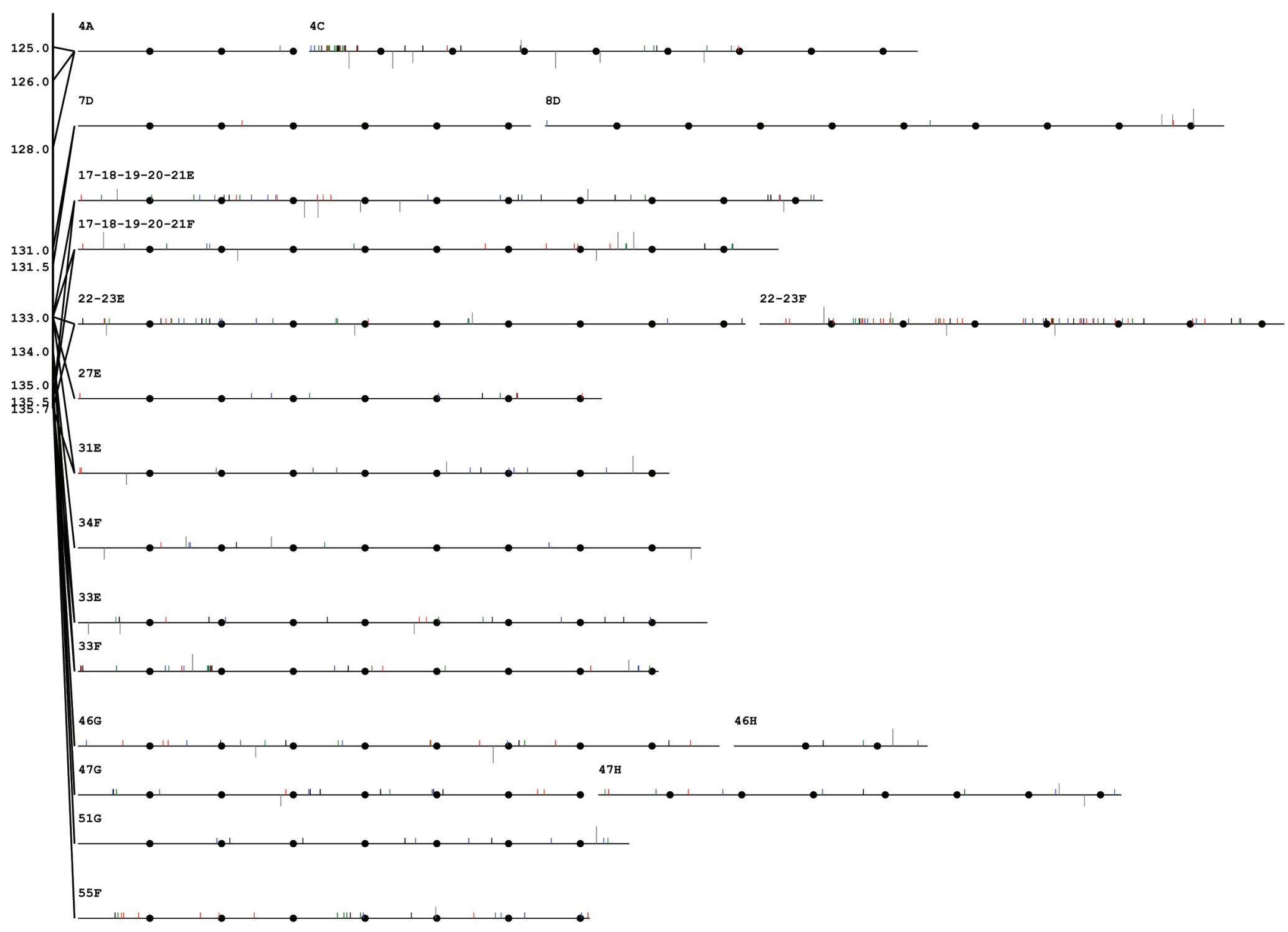


FIGURE S1D

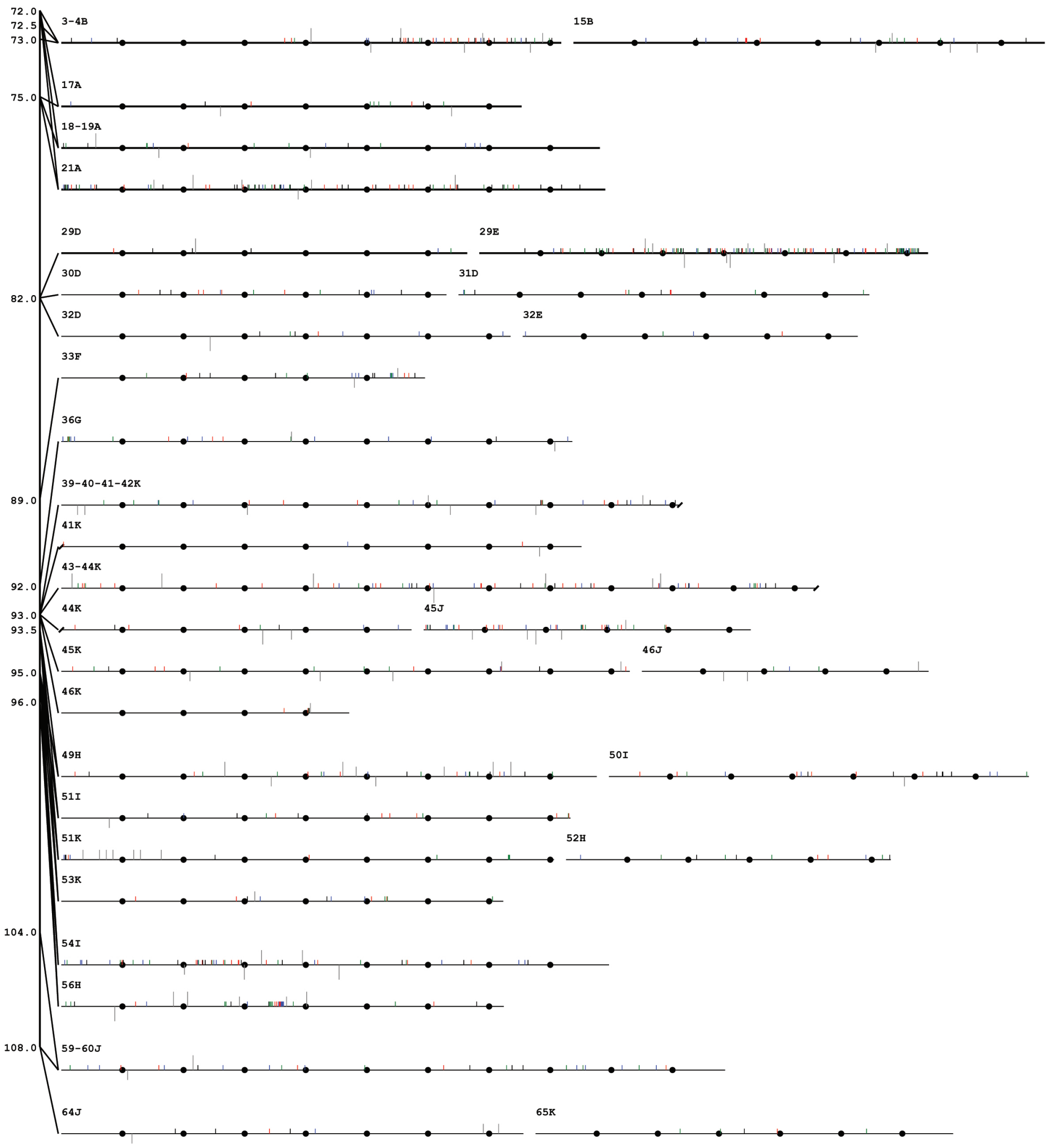


